University of San Diego

Digital USD

1986

\title{
Understanding Individual Political Behaviors in Organizations: Instrument Development and Validation
}

Gloria E. Bader EdD

University of San Diego

Follow this and additional works at: https://digital.sandiego.edu/dissertations

Part of the Leadership Studies Commons

\section{Digital USD Citation}

Bader, Gloria E. EdD, "Understanding Individual Political Behaviors in Organizations: Instrument Development and Validation" (1986). Dissertations. 494.

https://digital.sandiego.edu/dissertations/494

This Dissertation: Open Access is brought to you for free and open access by the Theses and Dissertations at Digital USD. It has been accepted for inclusion in Dissertations by an authorized administrator of Digital USD. For more information, please contact digital@sandiego.edu. 
UNDERSTANDING INDIVIDUAL POLITICAL

BEHAVIORS IN ORGANIZATIONS:

INSTRUMENT DEVELOPMENT AND VALIDATION

\author{
by \\ Gloria E. Bader \\ A dissertation submitted in partial fulfillment \\ of the requirements for the degree of \\ Doctor of Education \\ University of San Diego \\ 1986
}

Dissertation Committee

Joseph C. Rost, Ph.D., Director

William P. Foster, Ed.D.

Trudy J. Sopp, Ph.D. 
(C) Copyright by Gloria E. Bader 1986

A1.1 Rights Reserved

Reproduced with permission of the copyright owner. Further reproduction prohibited without permission. 
UNDERSTANDING INDIVIDUAL POLITICAL BEHAVIOR

IN ORGANIZATIONS: INSTRUMENT DEVELOPMENT AND VALIDATION

BADER, GLORIA E., Ed.D. University of San Diego, 1986. 297 pp.

Director: Joseph C. Rost, Ph.D.

Organizational politics impacts decision making, leadership, policy implementation, change, and individual effectiveness. Although generally acknowleciged as a reality of organizational life, political behavior is misunderstood, certainly a highly sensitive topic and furthermore, scholarly literature decries the paucity of empirical research on the topic.

Consequently, the purpose of this research was to design and validate an instrument, in the in-basket simulation format, that measures an individual's political effectiveness. The instrument's proposed purpose was the exploration of an individual's political behavior for two reasons: (1) as a new research tool to facilitate quantitative and qualitative research; and (2) as a developmental activity for the participants.

Using critical incidents about political behavior and merger case studies, an in-basket simulation was constructed upon the following elements: a composite definition of political behavior; a typology of political behavior; and the body of social exchange theory which includes power considerations. Content validity was established through the verification of the in-basket instrument's three hypotheses: (1) that various political behaviors can be presented by the in-basket respondents, (2) that these behaviors will range from ineffective to effective solutions to organizational situations, and (3) that the 
political behaviors expressed will vary with the type of problem presented.

The instrument was administered to two volunteer pilot groups of 33 managers from various organizations. The managers' responses to the in-basket items were evaluated by a panel of judges who then organized a behaviorally anchored scoring key and scoring procedures. Two pairs of independent scorers marked the in-basket responses for each pilot group and the interrater reliability calculations were statistically significant. Trained assessors conducted post in-basket interviews which explored the respondents' motives for acting or not acting in a political manner. The in-basket instructions, scoring, and administration procedures were standardized. In summary, a valid and reliable instrument for measuring and interpreting individual political behavior was developed. 


\section{DEDICATION \\ In memory of my father, \\ Danie1 S. Bader, II \\ $1906-1972$}




\section{Acknowledgements}

No dissertation in the social sciences can be written without enormous help from others. My dissertation committee gave me scholarly advice, excellent critiques, and enduring encouragement. My indebtedness to Drs. Joseph Rost, William P. Foster, and Trudy Sopp is great. Academic leaders in the field of organizational behavior and psychology who supported my initial design and gave me confidence were Drs. Daniel Farre11, Western Michigan University; Peter J. Frost, University of British Columbia; William Graham, San Diego State University; Johanna and Milton Lessner, Oak Knoll Family Therapy Center; Lyman Porter and Newt on Margulies from the University of California, Irvine; and Eugene Raudsepp, Princeton Creative Research. The faculty of the School of Education at the University of San Diego, especially Drs. Edward Kujawa and Susan Zgliczynski, offered guidance and their friendly interest in my research.

Research in the social sciences is very dependent on the cooperation of volunteers. Although their names must remain anonymous, I am indebted to the 33 managers who participated in the study. My colleagues in various organizations invited these managers to participate in the research project and I extend appreciation to these professional associates: Marty Anaya, Dick Daleke, Terry Dearstone, Wendy Doty, Terry Hayes, Cathy Herbert, Sue Marsha11, Karen Morse, Mike Pittinger, Michele Tamayo, Ed Titus, Judy Underhill, Wini Van Huizen, Gail Walraven, and Gail Westmoreland.

The panel of judges, Betty Fortier, Bruce Griffiths and $\mathrm{Dr}$. William Shine, deserve special acknowledgement and my sincere appreciation for their commitment to the research project. Each judge 
also contacted associates to be in the sample group. There is no doubt that the judges contributed to the quality of the research, especially the scoring key.

During busy semesters, many uriversity students gave their time, talent, and enthusiasm as assessors and scorers. Other than the meager deli lunches and pizza that I provided them, there is no way to thank each student enough for their involvement in the project. They were: Sheryl Lynn Bogard, Sherry Boyette, Tom Diamond, Susan Flock, Miriam Fultz, Karen Hampton, Mark Hoffman, Lorama Malone, Bonnie Montoya, Linda Pierson, Ann Rybowiak, Mindy Schwartz-Katz, Julie Smith, and Leslie Solomon.

My entire doctoral program was made possible through the sponsorship of my employer, Cubic Corporation. Through each course, exam, and chapter over the past five years, I received steadfast support from $\mathrm{Dr}$. Gary J. Frost, the Corporate Director of Employee Relations. My fellow colleagues at Cubic kindly assisted me by bringing realism into the research simulation and by offering friendly encouragement. They wrote memos in longhand, tested items, and volunteered for audio and video taping. To Mark Chaffee, Edward Chomas, Jeanne Davis, Gidget Gould, Vikki Kimberlin, Patricia Mitche11, George Murphy, Bernie Piotrowski, Gary Shrock, Mark Taylor, and Patricia Yates-List, I offer sincere gratitude.

Three other Cubic Corporation colleagues deserve hearty accolades. Tony Ciavarelli patiently critiqued my statistics and instrument development procedures and Melissa Pregill provided invaluable editorial suggestions and continual support. Louise Truman, as my loyal typist, was prompt and cheerful. 
Scott Meyers of Studio West donated his time and sound engineering talents to the taping of the telephone messages. Steve Williams of San Diego State University was extremely helpful as my statistics and computer assistant.

For the past few years, I have been an active member of the San Diego, Organization Development Network. My many friends and colleagues in this organization who encouraged me throughout my years of study deserve recognition, particularly Barbara Donohue, Bruce Griffiths, and Linda Shoob.

My School of Education, University of San Diego friends have offered research guidance, humor, and perspective. They are kevin Freiberg, Dr. Rosemary Goodyear, Rita King, and Tony Smith. Dr. William Shine, who was also a judge, certainly fits into this group. My thanks are presented also to Bill Kieckhaefer for his critique of my proposal and to Ed Quiroga for helping with the Performance Reviews. Fina and Rita are due cheers for watching me write for a year.

Finally, J. David Archibald provoked lively discussions on scientific methodology, made me laugh, and helped with countless details such as writing 50 post-it notes and delivering pizza. I love him for that and much, much more. 


\section{Table of Contents}

Dedication.....................................

Acknowledgements...................................

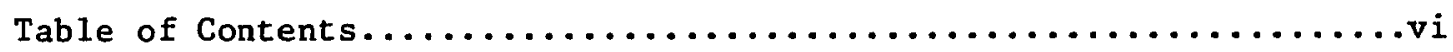

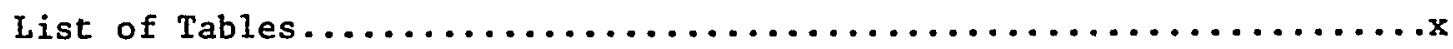

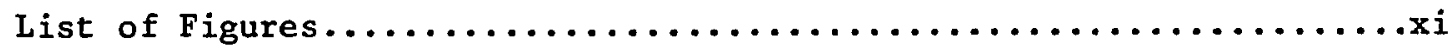

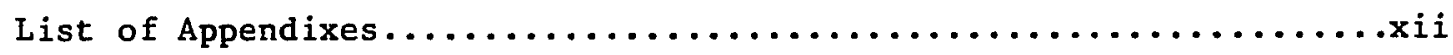

CHAPTER ONE - The Need for Instrumentation..................

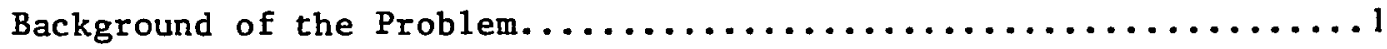

Objective of the Research $\ldots \ldots \ldots \ldots \ldots \ldots \ldots \ldots \ldots \ldots \ldots \ldots \ldots \ldots$

Research Design and Methodology $\ldots \ldots \ldots \ldots \ldots \ldots \ldots \ldots \ldots \ldots$

Pilot Groups, Expert Judges and Scoring Key.............

Assessor Training and Feedback of Results................

Validity....................................

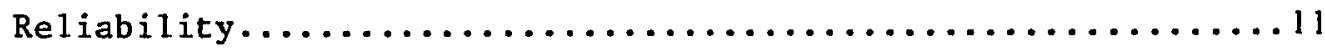

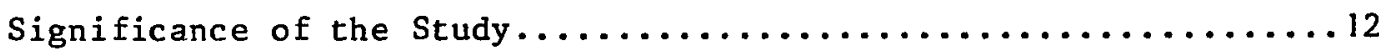

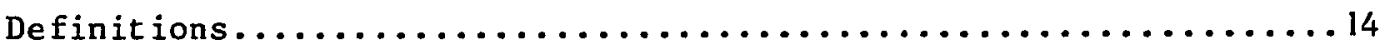

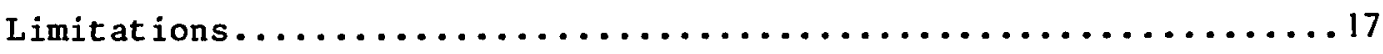

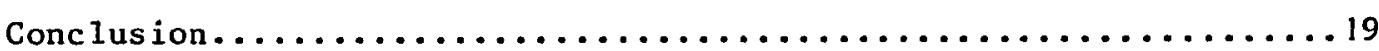

CHAPTER TWO - Review of the Literature...................... 1

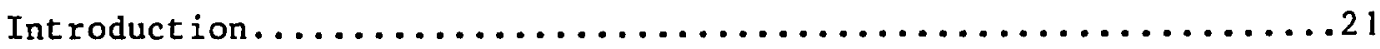

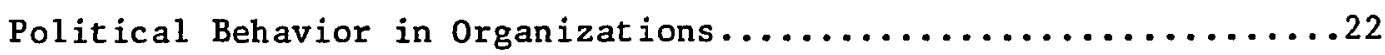

Models and Classifications of Political Behavior...........26

Summaries of Six of the Most Timely and Relevant Studies......30

Analysis of the Politicai Actor.......................... 35

Various Approaches to Power............................ 35

vi 
Social Exchange Theory............................ 44

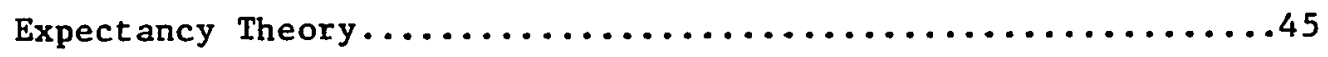

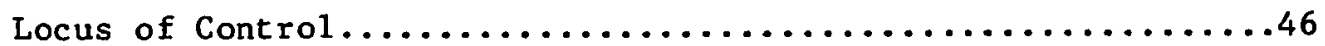

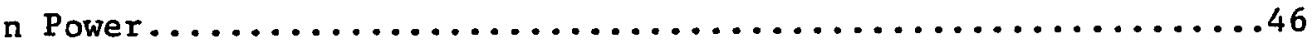

Attribution Theory..............................

Discussion................................... 48

The In-Basket Test............................... 50

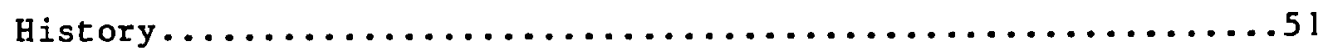

Assessment centers..............................

Design and Evaluation of the In-Basket.................. 58

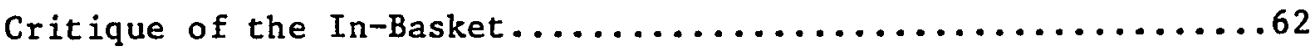

CHAPTER THREE - The Meret In-Basket Experiment.................65

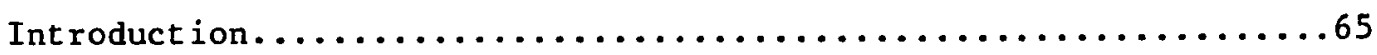

The In-Basket Instrument: Historical Contributions..........65

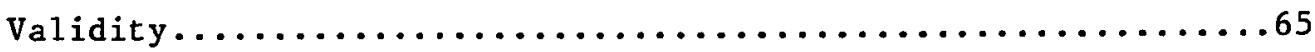

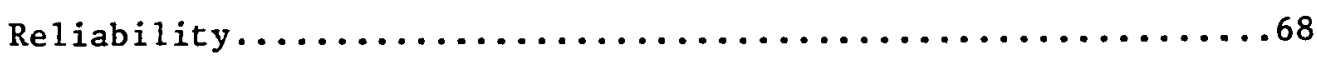

The Procedures and Design Facets of the Meret

In-Basket Development...........................

The Dimensions..............................

The Choice of the Situation.......................

A Synopsis of the Meret Simulation, Instructions for the

Participants and Administration Procedures............... 73

Synopsis...............................

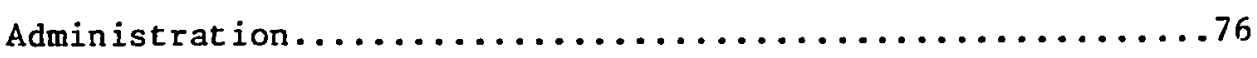

The Interview and the Action Report Form...............78

Tryout $\ldots \ldots \ldots \ldots \ldots \ldots \ldots \ldots \ldots \ldots \ldots \ldots \ldots \ldots \ldots \ldots \ldots \ldots$

vii 
Judging and Scoring Key Development.................. 80

Assessor Training.............................

Feedback of Results to Participants.....................83

Pilot Groups and Panel of Judges.....................83

CHAPTER FOUR - Results of the Experiment $\ldots \ldots \ldots \ldots \ldots \ldots \ldots \ldots \ldots$

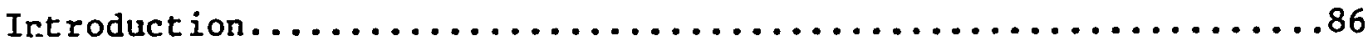

Hypothesis 1: Various Political Behaviors Can Be

Presented by the In-Basket Respondents...................86

Hypothesis 2: The Behaviors Will Range from Ineffective to

Effective Solutions to Organizational Situations.............87

Hypothesis 3: The Political Behaviors Expressed Will

Vary With the Type of Problem Presented..................93

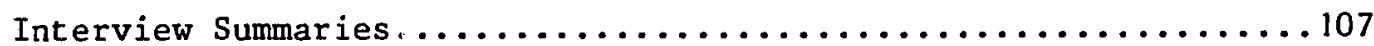

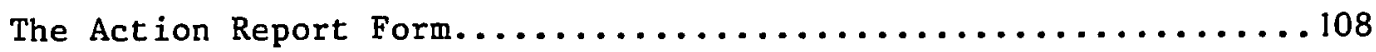

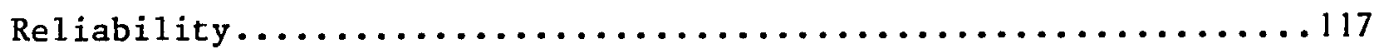

CHAPTER FIVE - Understanding Individual Political Behavior........127

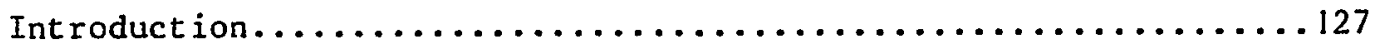

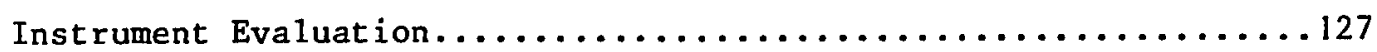

A Measure of an Individual's Political Behavior...........127

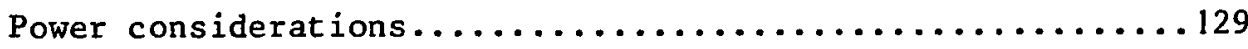

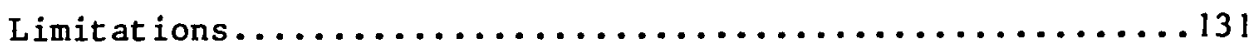

The Purpose of the Test: Research and Development.........136

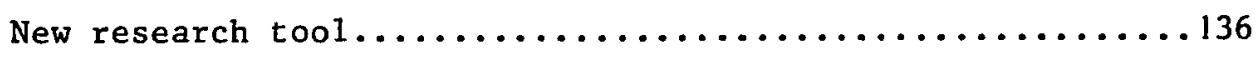

A developmental activity......................... 142

A Framework for Understanding Political

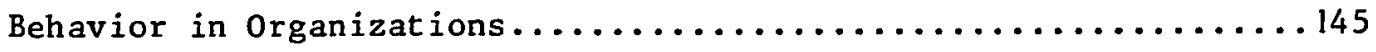

viii 
Environmental Conditions............................ 149

Significance of the Research..........................

Leadership Studies............................... 151

Observations of the Researcher........................

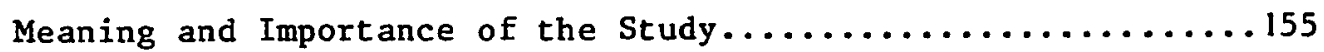

References......................................... 160

Appendixes...................................... 174 


\section{List of Tables}

Table 1. Scores of 33 Respondents on Effectiveness Range

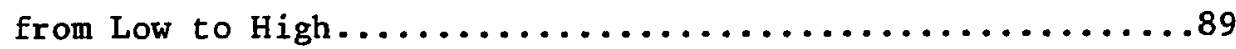

Table 2. Frequency and Distribution of 33 Cases...............91

Table 3. Participants' Ranks for the In-Basket Items...........110

Table 4. Judges' Ranks for the In-Basket Items after

the First Pilot Group........................

Table 5. Judges' Weights for the In-Basket Items after

the First Pilot Group..........................

Table 6. Judges' Consensus of Ranks and Weights for the

In-Basket Items and Ranks of the Pilot Groups..........115

Table 7.- Scoring Conversion from the Raw Score

to the Adjusted Score.......................... 20

Table 8. Interrater Reliability Scores of First Pilot Group,

Means, Standard Deviations, Pearson " $r$ " Coefficients

Between Two Scorers' Independent Ratings of the Seven

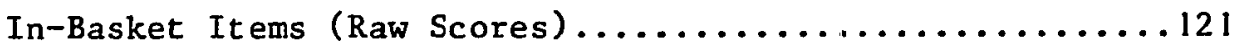

Table 9. Interrater Reliability Scores of Second Pilot Group, Means, Standard Deviations, Pearson " $r$ " Coefficients Between Two Scorers' Independent Ratings of the Seven

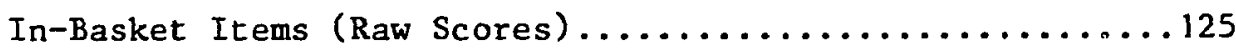




\section{List of Figures}

Figure 1. Typology of Political Behavior in Organizations.........31

Figure 2. Waller Message: Political Behaviors Exhibited.........95

Figure 3. Administration Outline: Political Behaviors Exhibited...97

Figure 4. Letter of Resignation: Political Behaviors Exhibited....98

Figure 5. Computer Memo: Political Behaviors Exhibited...........99

Figure 6. Farley Message: Political Behaviors Exhibited.........101

Figure 7. Ramirez Message: Political Behaviors Exhibited........ 102

Figure 8. Performance Reviews: Political Behaviors Exhibited.....103

Figure 9. Frequency of Behaviors Over A11 Items.............. 104

Figure 10. Totals of Political Activities for Items.............. 105

Figure 11. Comparison of Studies of Political Behavior (PB) in

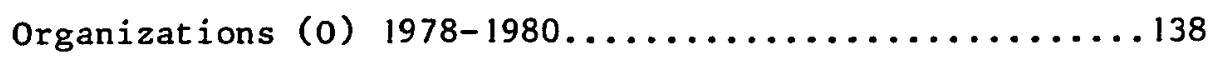

Figure 12. Framework for Understanding Political Behavior in

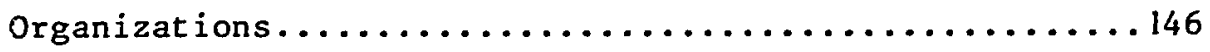

Figure 13. Environmental Conditions...................... 50

Figure 14. Leader, Power-Wielder, and Levels of Political Activity.......................... 157 


\section{List of Appendixes}

* A. Background Information......................... 174

* B. Organization Chart.............................. 175

* C. Newspaper Article............................... 176

* D. Video (Teleconference) Script of Bryan Emerson.............177

* E. Large envelope that contained F, G, H, I, J, K, N, O, P, Q...178

* F. Final Instructions............................. 179

* G. Waller Message............................... 180

* H. Envelope from Muse International.................... 181

* I. Administration Outline (with in Appendix H)............. 82

* J. Letter of Resignation......................... 184

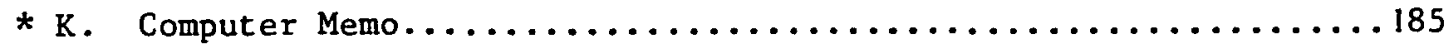

* L. Farley Message (transcription) $\ldots \ldots \ldots \ldots \ldots \ldots \ldots \ldots \ldots \ldots$

* M. Ramirez Message (transcription) $\ldots \ldots \ldots \ldots \ldots \ldots \ldots \ldots \ldots . \ldots \ldots$

* N. Envelope - Sealed with three performance reviews inside,

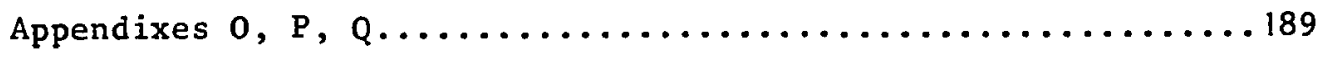

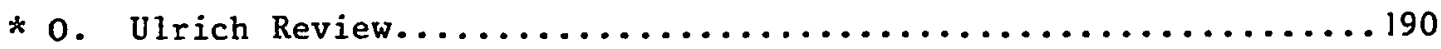

* P. Ramirez Review.............................. 192

* Q. Wallace Review..................................... 194

R. Materials for Meret In-Basket (summary of items)...........196

S. Administration Directions for Pilot Groups................. 197

T. Administration Directions for Meret In-Basket............. 199

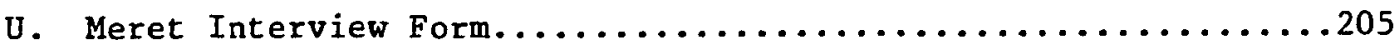

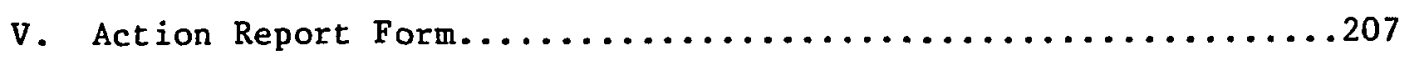

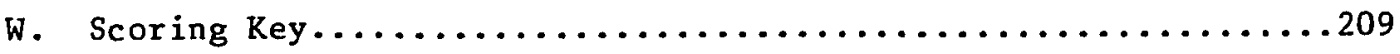

x. Dimensions.................................... 18

xii 


\section{List of Appendixes (Cont inued)}

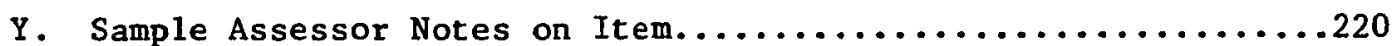

2. Sample Assessor Notes on Item...........................

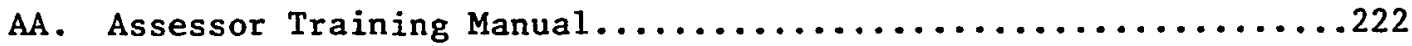

BB. Assessor Correspondence: Explanation of Research.........247

CC. Assessor Correspondence and Materials..................250

DD. Assessor Correspondence: Appreciation................257

EE. Scorers' Training Out 1 ine and Materials.................. 259

FF. Scorers' Training Outline and Materials (revised)..........260

GG. Feedback Letter to Participants...................... 261

HH. Sample Dimension Sheet (with assessor's comments)..........268

II. Sample Scoring Key: Waller Message.................. 270

JJ. Outline of Open Discussion Session..................272

KK. Letters to Contacts....................................

LL. Letters to Participants: Explanation of Research..........275

MM. Consent Forms...................................

NN. Acknowledgement Letters to Participants.................278

00. Training Agenda for Panel of Judges and Correspondence.......281

PP. Variety and Ranges of Political Behavior Presented by the

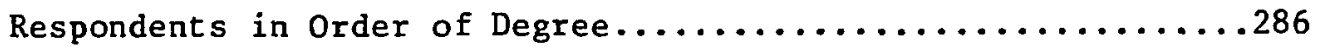

QQ. Matrix of Types of Problem and Political

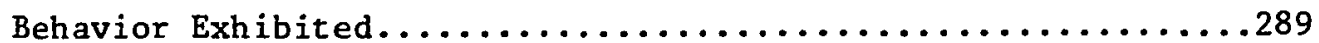

RR. Addenda to Assessor Training........................... 290

SS. Scoring Sheet for Each Participant...................29l

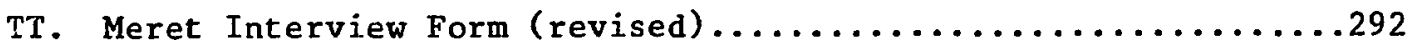

UU. Scoring Practice for In-Basket Raters.................. 294 


\section{List of Appendixes (Cont inued)}

VV. Sample Comments for Participants........................ 295

WW. Letter from Student Assessor............................

$\mathrm{Xx}$. Letter from Participant in the Pilot Group................297

* Items A through $Q$ comprise the in-basket instructions and materials 
CHAPTER ONE

The Need for Instrumentation

Background of the Problem

Organizational politics impacts decision making, leadership, policy implementation, change, and individual effectiveness. Although generally acknowledged as a reality of organizational life, politica1 behavior is misunderstood and is certainly a highly sensitive topic among organizational actors (Porter, Allen, \& Angle, 1981). Scholarly literature decries the paucity of empirical research in organizational politics (Cobb, 1986; Farrel1 \& Peterson, 1982; Frost \& Hayes, 1979; Madison, Allen, Porter, Renwick, \& Mayes, 1980; Porter et al., 1981).

A strong theoretical and empirical base is required from nontraditional approaches to organizations such as the political one which can explain and assist organizations in ways the dominant rational approach cannot. The traditional rational model emphasizes logic, order, and goal-directed behavior that is predictable. Since its explication by Weber, Taylor, and Fayol in the early 1900s, this approach to organizational life has been so pervasive that other models need the sling and courage of a David to defeat the Goliath. But actually, defeat is not the purpose; complementarity is.

For the past 20 years, the idea that politics occurs within organizations has been p:asented in organizational theory writing without empirical support for however a political model might appear. Only recently have research efforts attempted to explore this phenomena (Cobb, 1986; Porter, et al,, 1981). Perhaps the most significant reason for 
this slow explication of organizational politics has been the even slower paradigm shift from the scientific or rational model to the political one. Bacharach and Lawler stated, "While the rational managerial proponents err in failing to consider the internal dynamics of organizations, the adherents of the individualistic approach fail to consider the political and structural contexts that impinge on an individual's cognitions and actions" (1981, p. 212). Another major cause for the scarcity of studies has been the taboo related to the very word political in organizations. This is a sensitive area. That the concept is interdisciplinary--touching political science, organization theory, psychology, and sociology--makes the task no less difficult. Finally, as Gandz and Murray wrote, "The methodological problems in studying such a subject empirically are profound. Only rarely will protagonists in political events reveal their innermost thoughts to unknown researchers" (1980, p. 453). Few methodological tools exist to assist the researcher. The shelf is bare.

\section{Objective of the Research}

Consequently, the objective of this research is to design and validate an instrument that could explore and measure an individual's political behavior. This new instrument has been developed, validated, pilot tested, and examined for reliability. As an exploratory research effort, the instrument should contribute to the very scarce, if not empty, pool of organization political behavior assessments and facilitate quantitative and qualitative research.

An unstructured situational test in the in-basket format was constructed to simulate a dilemma that would evoke political behavior from 
the examinees. The test's purpose was to quantify, describe and understand individuals' political behavior in organizations. As a simulation, it assessed the participant's ability to engage in political activity because, as Frederiksen stated, the in-basket "provides an opportunity for the examinee to display spontaneously certain response tendencies which comprise a part of his 'personality'" (1966, p. 107). The in-basket format served all the requirements of this research, particularly the importance of projection versus self-report for this subject area.

\section{Research Design and Methodology}

The long and detailed history of in-basket development presented a clear format for the researcher. The many design phases, each with their own vigor and complexity, included dimension choice, participant's instruction writing, administrator's manual preparation, interview planning, tryout, judging, scoring key development, assessor training, and feedback of results. Followed carefully, these phases facilitate successful instrument construction whatever the theme of the in-basket .

Important for construct validity, a definition of political behavior was utilized throughout the research. Drawn from the work of Porter et al. (1981) which synthesized existing definitions of politics from theoretical writings, the definition features several elements. Organizational political behavior is defined as "Social influence attempts which can be obligations and resource exchange; that are discretionary (i. e., that are outside the behavioral zones prescribed or prohibited by the formal organization); that are intended (designed) to 
promote or protect the self-interests of individuals or groups (units); and that threaten the self-interests of others (individuals, units)" (Porter et al., 1981).

This definition does not address the differences between negative political behaviors or behaviors attributed to be negative by others and the more positive political behaviors. For many, most if not all political behavior is deemed negative. As this definition includes the elements of self-interest and threatening the self-interests of others, it does not alleviate the problem of the perjorative nature of the word political. The more positive political tactics such as alliance building, gaining support from a higher level, and sense of the organization are lost in the words self-interest and threaten.

Because one of the contributions of this research aspires to join leadership with political skills, the problems with this definition are apparent. It must be made explicit that many political tactics are constructive, effective and positive. In fact, the best solutions to the in-basket simulation of this research are just that, rather than negative behaviors.

The final judgment as to the positive or negative label on political behavior is the satisfaction. of the greater good. But the difficulty of the give and take of politics is that someone or some group may lose. The manner in which one acts politically may make the difference.

Self-interests may reflect a common good or the greater good of an organization. Competition and conflict is extremely healthy for individuals and groups. If the Porter et a1. (1981) definition is subsumed 
under the purposefulness of leadership, then the tide can be turned and political behavior can be seen as more positive than negative. Selfinterests for purely selfish reasons and threats to others for only win/lose outcomes are Machiavellian behaviors rather than leadership ones.

From the general domain of political behavior, 10 dimensions or types of political behavior were examined: (1) Self-interest/Power, (2) Coalition Building, (3) Neutralizing Opposition, (4) Gaining Support, (5) Use of Information, (6) Using Resources, (7) Exchanging Favors, (8) Outside Activity, (9) Bargaining and Compromising, and (10) Sense of the Organization.

Consequently, an initial task of the research was answering the question, "What items and situations will evoke political behaviors?" A special scenario, woven from case studies of mergers, was created so a variety of political behaviors might be evoked. Critical incidents about mergers, power, and politics from the literature featured themes that have been included in the simulation, such as reorganization, resignations, ambiguity, and competition.

The scenario centers on the merger of two fictitious publishing companies--one, Meret Publishing Company of Ramona, California and the other, Muse International of St. Louis, Missouri. The merger focuses on the reorganization of Meret's administrative department because of its acquisition by the larger St. Louis firm.

The key position of the in-basket centers on Chris Wallace, a middle manager, two levels from the president of Meret Publishing Company, Coventry Meret. Chris's role description as the manager of human 
resources and Meret's organization chart appears in the instructions. These instructions set the stage for the simulation. The preliminary instructions also describe both organizations, their norms and culture, in a mock newspaper article on the acquisition of Meret by Muse International. Most importantly, the instructions include the playing of a video recording of a senior vice-president at Muse, Bryan Emerson, who spoke to Chris and his or her two peer level managers at Meret in a teleconference type of setting. Emerson's message contains the paramount instructions for Chris in the in-basket. Its placement at the beginning is strategic because it is important to involve the participants as quickly and fully as possible (P. J. Frost, personal communication, August 14, 1984; Lopez, 1966).

The next step in the instrument design proceeded with the writing of the scenario materials in the form of incidents, anecdotes, reports, letters, conversations and records (Lopez, 1966). Since political behavior is often induced from interpersonal contacts in addition to written items, two taped telephone conversations are utilized to add face validity to the instrument. Each interrelating, the seven different written materials or items are sufficiently ambiguous to evoke a wide range of responses and solutions from the participants. (To preview all the in-basket materials in the order they appeared to the pilot groups, see Appendixes A through Q.)

After the materials for the in-basket were produced (Appendix R), special directions for administering the simulation were formulated (Appendix S). These directions provided for the in-basket's timing, the introduction of the audio/visual items, and various announcements. 
Later, a final set of directions was organized for the future use of the instrument (Appendix T).

Another important design step was to plan the interview with the participant. The interview was scheduled to take place immediately after he/she had completed the in-basket exercise. Frequently, these interviews posed such open-ended questions as "What did you think of company $\mathrm{X}$ ?" "What did you think of person $\mathrm{X}, \mathrm{Y}, \mathrm{Z}$ ?" "What did you do for such and such an item?" Contemporary in-basket developers use post-test questions that are more structured, even comprising multiplechoice responses. Thornton and Byham reported: "New procedures for in-basket evaluation using highly structured patterned interviews appear to offer great hope for cutting down the amount of assessor time required and for increasing the reliability of the measurement" (1982, p. 186). The purpose of the interview is to offer the participant the opportunity to explain decisions more completely and to establish the degree of the participant's understanding of the characters and the problems in the exercise (Griffiths, 1979). The content of these interviews attest to the motives of the political or nonpolitical actor. In some instances, ethical dilemmas surface and reasoning processes emerge.

For reliability purposes, the interview for this research (Appendix U) was combined with a written form (Appendix V) in what Kesselman et a1. (1982) called an action report form. The results from the Action Report Form, plus the colorful reflections of the more open interview, complement each other. Together with the in-basket, the Meret 
Interview Form and Action Report Form provided three data points for the triangulation of the information.

Pilot Groups, Expert Judges and Scoring Key

The literature does not define organization political behavior by industry or setting. All organizations, whether public or private, large or small, technical or service-related, are political (March, 1962). Therefore, the pilot groups and judges panel were heterogeneous among a variety of organizations. Since the middle manager level is neglected in research and bereft of legitimate feedback and development opportunities, the pilot groups were drawn from the middle management ranks.

Professional colleagues of the researcher were approached and requested to solicit volunteers from their particular organizations. From these volunteers, two pilot groups, for a total of 33 people, were randomly formed to represent a variety of organizational types: public sector, education, finance, industry, military, health, and sales fields. A panel of three expert judges was chosen from these organizational types as well. The Madison et al. (1980) study verified the political astuteness of most senior level executives; therefore, the judges came from senior levels and demonstrated political knowledge by reason of their position and experience.

As in the Frederiksen Air Force prototype of the in-basket (Frederiksen, 1962), tryouts of the instrument were conducted with the pilot groups. The individual's answers (from the first pilot group) to the Meret in-basket formed a large pool of responses--the basis for the 
scoring key that needed to be established. The judges sorted the responses along a continuum of political effectiveness for the Meret situation and also generated a list of considerations and relationships for each in-basket item. After the first pilot group trial run, the entire administration and scoring key work was repeated for the second pilot group to refine the instructions, the items, and the scoring key which resulted in a precise, comprehensive, and reliable scoring key (Appendix W).

Assessor Training and Feedback of Results

Assessor training and feedback of results were the final design imperatives. Assessors is the term used for the interviewers of the examinees. Volunteers were selected from classes in psychology, business and public administration at local universities to act as assessors. The volunteers were trained to analyze the in-baskets and conduct the interviews. The American Psychological Association, the American Educational Research Association, and the National Council on Measurement in Education (1978) highlight important standards and ethical considerations for assessor training in the assessment center process. These standards were applied to the in-basket assessors as well. The assessors learned how to classify and how to analyze the elicited behaviors to minimize bias and distortion (Gill, 1979). When and what kind of feedback to be given was determined in the design phase. The attention to these and other phases of the in-basket design certainly contributed to the validity and reliability aspects of the instrument which will be highlighted next. 
$\underline{\text { Validity }}$

As in any instrument development, attention to validity and reliability is critical. Keil, in an excellent discussion of assessment center validity, states: "Validity is not a thing, it is sometimes not a property of a thing. Validity is a concept that takes on meaning only in relation to specific events and processes" (1981, p. 79). Rather than a statistical correlation for Keil, validity emerged from every developmental step and process. The processes, of course, were the many important phases of the in-basket design that directly impact internal validity.

To ascertain validity, three hypotheses based in the purpose of the in-basket instrument were examined. From the instrument's purpose--to explore and measure political behavior--followed these three hypotheses: (1) various political behaviors can be presented by the in-basket respondents, (2) these behaviors will range from ineffective to effective solutions to organizational situations, and (3) the political behaviors expressed will vary with the type of problem presented. The second hypothesis presupposes that the best solutions to the Meret in-basket are political ones. This presupposition is based on the nature of the merger simulation and its highly political environment.

The underlying theoretical constructs of the simulation were confirmed from the participants' behavioral responses in the in-basket and the follow-up interviews. Three elements formed the theoretical bases of the in-basket: the definition of political behavior, the body of social exchange theory with its attention to power, and the typology of political behavior of Farrell and Peterson (1982). These three 
elements attend to the causes, the motives, and the ranges of behavior defined as political. Content validity was built upon careful construction of incidents, background information, materials, and the scoring key. Predictive and concurrent validity can only be achieved through time and simultaneous testing respectively, and the fact that these two types of validity were not addressed was an inherent limitation of the instrument development at its origins.

For more than 30 years, in-basket research and application has earned unusually high marks in every validity area, particularly face validity (Meyer, 1970). Realism has been heightened in this in-basket simulation by using colored letterheads, varieties of paper and size, actual handwritten notes, and the taped audio and video materials.

Reliability

Reliability has been directly attributed to the training of the assessors (Gill, 1982) and to the quality of the scoring key. Because the Educational Testing Service (ETS) originated the in-basket, there have been great contributions to the psychometric knowledge of inbasket scoring. Using both interrater correlations and split half scores (correlations between odd and even test items), Frederiksen, Saunders and Ward (1957) attested to high degrees of scoring reliability for in-baskets that ETS developed. This interrater reliability was noteworthy of in-basket simulations (Mackinnon, 1975). The continual effort of in-basket researchers to design structured interviews and action report forms has also benefited reliability.

Therefore, following general in-basket design recommendations from the literature, several endeavors were made to ensure the stability of 
the in-basket over time, which is the actual meaning of reliability (Borg \& Gall, 1983).

1. The scoring key included both behavioral anchors, weights for the items, and considerations for the assessors. It was refined and improved after giving the in-basket to the second pilot group.

2. Training of the assessors was conducted, evaluated and recorded for consistency.

3. Scoring reliability was measured by comparing the in-basket scores assigned by one assessor with scores assigned by a second assessor. A product-moment correlation coefficient between the scores assigned by the two assessors was computed (Frederiksen, 1962). This is known as interrater reliability (Bourgeois \& Slivinski, 1974).

4. The panel of judges reached a consensus on the scoring key, as well as the weights and ranks of the items.

5. The reliability of the interview summaries was derived from using two interviewers and their consensus for each participant (Guba . \& Lincoln, 1982).

6. Using an action report form together with the interview summaries and the actual scoring results of the in-baskets offered a strong and valuable triangulation of data (Guba \& Lincoln, 1982).

7. The directions for administering the in-basket were recorded and used consistently for each sample group.

\section{Significance of the Study}

In 1981 , Porter et a1. remarked that the study of organizational politics was in its infancy and he called attention to the political actor. of the several factors that comprise the activity of 
organizational politics, the belief system, motives, and personal characteristics of the political actor are indeed critical. The questions arise: Who is the political actor? Who has the propensity to engage in political behavior? When? Why? Are some factors more important than others? Not only are the answers to these questions underpinnings to research on political behavior in organizations, but also, the answers may serve as a hueristic device aiding the understanding of political leadership and the political education of organizational members. The post in-basket interviews of the participants yielded rich qualitative data addressing these questions.

The entire process of the development and validation of the inbasket was rich in support of the theory of political behavior in organizations. The assessors improved their understanding of the issue through the training, interviewing, and the scoring of materials. The subjects themselves heightened their level of political awareness and, in turn, expanded their repertoire of political tactics. All of these secondary outcomes of the instrument development are reported in the findings of the research.

The research effort should contribute to the development of future leaders, to the future of research on political activity in organizations, to the history and study of the in-basket as an instrument of great potential and adaptability, and to individual political assessment on many levels. These four contributions are timely and significant for several reasons. Leaders must recognize and understand the levels and complexities of political behavior and, in today's global society, the cross-cultural nature of political behavior (Dexter, 1976; 
Frost \& Hayes, 1979). Also, new leadership theories demand political skills of leaders (Burns, 1978; Hickman \& Silva, 1984; Lindblom, 1968), and holistic views of policymaking and implementation give significant weight to political behavior (A11ison, 197l). Tushman offered, "As organizations become more complex internally and as the change rate of technical and economic environments increases, the internal dynamics of organizations must be understood. The importance of a political perspective is then accentuated" (1977, p. 214). The requirement for political savvy is stronger than ever before.

\section{Definitions}

Action report form: a multiple-choice questionnaire based on the in-basket items which quantifies the decision making processes of the individual (Kesselman, Lopez, \& Lopez, 1982).

Assessment centers: a laboratory type program, usually two or three days long, consisting of a series of simulations, written exercises, and interviews designed to predict future success in management. Behavior: words, gestures, and all outward activity conducted by an individual and observed by others.

Behaviorally anchored rating scale (BARS): a scale from low to high or poor to good consisting of specific behaviors that are anchored or placed on a continuum.

Coalition: an interacting group of individuals formed independent of the formal structure to take action about an issue (Stevenson, Pearce, \& Porter, 1985).

Concern: any matter of interest to one or more parties about which they feel threatened, that they think will lead to an undesirable 
consequence, or that they are anxious to substantitate (a claim requiring empirical validation).

Exchange of favors: actions or chits often saved up and later cashed in for favors; sometimes called one's stock exchange.

Gatekeepers: the individuals within the stakeholding groups who have the power to facilitate or prevent access to the change agent.

In-basket: a simulation requiring written responses and various actions that measures a person's potential on several dimensions such as decision making, judgment, and control.

Issue: a statement, proposition, or focus that allows for different, often conflicting, points of view.

Leadership: the relationship of a leader and followers that moves toward the accomplishment of a common purpose through competition, conflict, and political activity.

Machiavellianism: an interpersonal style characterized by cunning, duplicity, or bad faith; named from the works of Machiavelli who viewed politics as amoral and that any means, however unscrupulous, can justifiably be used in achieving political power.

Organization: an institution or unified group of people using structures and policies to reach specific goals.

Organization development (OD): the planned intervention into organizationa1 systems that promotes change and productivity on various level.s.

Political actor: the individual who engages in political behavior. 
Political behavior: "Social influence attempts which can be obligations and resource exchange; that are discretionary (i.e., that are outside the behavioral zones prescribed or prohibited by the formal organization); that are intended (designed) to promote or protect the self-interests of individuals or groups (units); and that threaten the self-interests of others (individuals, units)" (Porter et al., 1981). Examples of political behavior are coalition-building, bargaining, negotiating, whistleblowing, insurgency and withholding information.

Power: a person's potential at a given point in time to influence the attitude or behavior of one or more persons.

Rational mode1: a goal directed, analytical, and hierarchical system of reference for organization decision making.

Reliability: stability of measurement over time based on internal consistency of items and consistency of test administration over repeated applications.

Sanction: punishments or threats of punishments.

Simulation: an exercise or activity close to real-life situations that is designed to predict a person's future success in that situation.

Situational tests: standardized tests, such as the in-basket, designed to elicit lifelike behavior and approach realism.

Stakeholders: groups having some common characteristics (e. g., supervisors, quality control inspectors, long-term employees, data processing department) that have some stake or interest in the change issue. Some groups might be very vocal, others silent. Usually, a unique language and culture exists among stakeholding audiences. 
Triangulation: the verification of a proposition from data of different sources and methodologies to strengthen the validity of a research project.

Validity: four interdependent validity concepts:

1. Criterion-related validities are predictive and concurrent. Predictive validity indicates the extent to which an individual's future level on a criterion can be predicted.

2. Concurrent validity indicates present association of the test scores with a particular criterion.

3. Content validity is the estimate of how an individual performs within a given domain.

4. Construct validity indicates the relation between a hypothesized trait and high or low scores on a test.

\section{Limitations}

There needs to be a method of analysis for the mysteries of political behavior. Although that statement seems contradictory and although the complexities of human behavior are difficult to comprehend, the effort of this research is to offer an instrument to understand political behavior in organizations. The advantages of experimenting with the in-basket and the very need for a research tool far outweigh the limitations of the study (L. W. Porter, personal communication, November 5, 1984).

One limitation challenges the choice of the in-basket instrument itself. The in-basket has been researched and used successfully for many years in the planning, organizing, and controlling areas of management. Would a shift to political behavior change the nature of the 
instrument itself, or would the in-basket prove to be adaptable? Indeed, political behaviors are usually manifest in the patterns of daily activity, conversations, and meetings rather than in written materials of a typical in-basket. A person's political response can be in a letter or a report, but often it is through interpersonal contact of some kind. Political behaviors are frequently subtle and sometimes manipulative. The term political is often used pejoratively. Such problems have discouraged research in political behaviors (Porter et al., 1981). The originator of the in-basket, Frederiksen (1957), strongly believed it to be an instrument of unlimited potential and, therefore, it should prove to be a productive vehicle for future research .

Another concern is the choice of expert judges. Are there objective criteria that mark a person as politically astute? Gandz and Murray (1980) suggested that executive success was related to political astuteness because an organization's climate was most political at senior management levels. It is from these levels that the judges were chosen. Although the judges worked using a given definition of political behavior and achieved a consensus, this limitation was not alleviated.

A final limitation examined the background of the person acting politically, for part of political theory presumes a person's possessing a stock exchange of favors and compromises with others (Burns, 1961). Although the participant's instructions and the inbasket items themselves refer to various favors and alliances, a strong prehistory of social exchange was not established. Relationships 
within the simulation only were surmised and therefore tested superficially.

\section{Conclusion}

Bacharach and Lawler recommended bringing action to the forefront of organizational analysis. They wrote:

An action perspective is concerned with discovering how people act in and on a given social setting. We need not begin by making any assumptions about the consensual nature of organizations but, rather, concern ourselves with deciphering the patterned relationships between actors' definitions of the situation and their consequent behavior. The action perspective may give rise to a phenomenological perspective on organizations. We, however, contend that an action perspective can serve another purpose: It provides a means of arraying the various concepts and themes from previous social psychological research that are germane to the development of a political theory of organizations. Taking an action perspective, social psychologists who are concerned with politics stress such issues as actors' definitions of the power situation and the tactical actions they undertake to bring about desired outcomes. For social psychologists, politics is a series of competitive tactical encounters. These encounters entail an assessment of the situation (that is, an evaluation of one's power vis-a-vis that of significant competitors), and a selection of countertactics by which to thwart the competitors' tactics. Parallel encounters occur in organizational settings. (1981, p. 7) 
Bacharach and Lawler saw the need to specify the viable units of political action. The instrument of the research is very much an action based experiment complete with units of analysis--the 10 dimensions of political behavior.

The political astuteness of educational leaders in a complex world must increase. The Meret in-basket provides a vehicle for future research, a diagnostic and personal development tool (Morrison, McCa11, \& DeVries, 1978) and a responsible discussion point for leaders and organization theorists.

The following chapter lays the groundwork for the instrument's theoretical and practical foundation. In it, the literature is reviewed in three parts: (1) the concept of political behavior, (2) the political actor, and (3) the in-basket instrument itself. 
CHAPTER TWO

Review of the Literature

Introduction

The slow explication of organizational politics in scholarly literature stems from various reasons. The sensitivity of the area, the pejorative nature of the word politica1, its interdisciplinary aspects, the dominance of the rational model, and the lack of methodological tools are all significant obstacles to building a theory of organizational politics through empirical research. What literature does exist on organizational politics has failed, according to Farrell and Peterson (1982), to distinguish (a) prescribed job behavior from discretionary political behavior, (b) calculated from accidental political behavior, and (c) macro from micro levels of analysis. Consequently, the conceptual writings about political behavior and the methodologies embraced to study the phenomena reflect these obstacles.

The first part of this chapter examines the historical and theoretical underpinnings of the study of organizational political behavior. Exploratory models and categories of political behavior that eventually emerged from the theoretical sources are reported and synthesized into a typology of political behavior. Enriching this typology is an analysis of several contemporary studies aimed directly at political behavior. Part one forms a major portion of the underlying theoretical construct used to develop the in-basket instrument.

Another portion of the instrument's underlying construct is the body of social exchange theory, with its emphasis on power which is 
reviewed in part two through an analysis of the political actor. The third and final part of the literature review examines the in-basket instrument, its history, and its major characteristics.

\section{Political Behavior in Organizations}

In one of the earliest discussions of individual political activity in organizations, Burns drew conclusions from studies of political conflict in British electronics firms. He offered the definition: "Behavior is identified as political when others are made use of as resources in competitive situations" (1961, p. 257). For Burns, political action always involved the advancement of self-interest and the notion of exchange or contracts. "Politics, then," he wrote, "involves obligations, which are the exchange of currency of resources" (1961, p. 279). The exploitation of human, physical, or even symbolic resources for the achievement of more control over others was emphasized by Burns. Zaleznik (1970) called Burns's stock exchange or obligations idea the banking system in power transactions and Allison (1971) referred to the pulling and hauling over resources. Self-interest may be individual or collective, but it always makes a claim, as Pettigrew stated, "against the resource sharing system of the organization" (1975, p. 192).

Looking at the organization as a whole, March presented a prescient and innovative paper to the American Political Sciences Association in 1962. For the first time, attention was called to the political realities of businesses. March stated, "A business firm is a political coalition and the executive in the firm a political broker. 
The composition of the firm is not given; it is negotiated. The goals of the firm are not given; they are bargained" (1962, p. 672).

After Burns's and March's significant contributions, definitions of organizational political behavior appeared sporadically in the literature. Because what one individual may term political may not be viewed so by another, an agreement on a definition must be reached to understand better the political processes in organizations. Mayes and Allen substantiated the importance of influence and behaviors nonsanctioned by the organizations. Their definition read: "Organizational politics is the management of influence to obtain ends not sanctioned by the organization or to obtain sanctioned ends through nonsanctioned influence means" (1977, p. 675).

Porter et al. presented another definition in their summative paper on upward influence in organizations. It was a synthesis of the preceeding definitions, where organizational political behavior was defined as:

Social influence attempts that are discretionary (i. e., that are outside the behavioral zones prescribed or prohibited by the formal organization), and that are intended (designed) to promote or protect the self-interests of individuals or groups (units). These self-interests threaten the self-interests of others (individuals, units). (1981, p. 112)

Adding the classic resource sharing element referred to by Burns (1961) would amplify this definition.

Many writers have urged a political framework for the study of organizations (Benson, 1983; Dyson, 1976; Frost, 1980; Scho11, 1981; and 
Tushman, 1977). The conventional view of organizations has been rational. Its positivist methodology often became an end in itself, and the nonquantifiable factors such as culture, environment, causal elements, power, and politics were only occasionally considered, let alone researched.

The historical antecedents to the political aspects of organizations challenged the orthodox schools. For example, Meyers (1978) saw the traditional research as a celebration of the myths of rationality. Pfeffer, concentrating on the micropolitics of organizations, stated: "Organizations are not rational decision mechanisms, but rather arenas in which persons and groups participate" (1978, p. 37). Looking for answers to the nonrational linkages in organizations, Weick (1976) stepped into the unchartered waters with his loose-coupling concept. Who had dared question ambiguities in organizations before Cohen and March (1974)?

Benson (1983) called these writers the demythologizers. His attention to the importance of the dialectical nature of organizations emphasized the nonrational change processes in organizations (Bader, 1982).

The political model is still not fully developed and certainly not established. It begins to account for what the rational model cannot explicate, but it needs maturing. Ironically, maturity builds on the nature and amount of empirical studies. Over 20 years ago, March (1962) stated that the political theory was neither well defined nor possessing a particularly strong language. "The research is the micropolitics of organizations is in its infancy," wrote Porter et al. 
(1981, p. 144). Recently, a few steps have been taken, and these instances will be addressed shortly.

The topics of power and politics are problematic in nature (Pfeffer, 1981). Difficult to define and measure, they are troublesome concepts to practicing managers because of their implications and connotations. After all, managers are heavily socialized to the rational imperatives. Zaleznik wrote: "Executives are reluctant to acknowledge the place of power both in individual motivation and in organizational relationships. Somehow, power and politics are dirty words" (1970, p. 48). In fact, organizations and individuals tend to deny political behavior they may be part of, particularly related to decision making (Porter et al., 1981). It is a topic usually hidden from public view-the dark side of organizational behavior. "For these reasons and more," wrote Porter et al., "any direct attempts to study the politics of upward influence in a field setting are virtually doomed from the start" (1981, p. 134).

As much as a clear political model of organization theory is needed to understand and to analyze organizational behavior, it will be a long way in coming. A strong mode1, Nadler (1980) observed, must be explicit, theory based, operationally defined, empirically validated, valid (face validity), and general. The crisis, declared Benson (1983), is the fact that political actors and forces may lie outside the scheme of analysis. Herein is the weakness of traditional organizational theory because it has failed to reflect upon its own praxis.

The earliest studies of political behavior have been observational ones by practitioners in the field (Burns, 1961; Pettigrew, 1975; 
Zaleznik, 1970). The trend to study resource allocation has been consistent, and as early as 1962, March noted, "Problems in politics have been studied from the point of view of concepts developed for economic systems" (p. 665). Pfeffer and Moore (1980) have specialized in budget and power analyses in university settings.

For the most part, three variables foster political activity: uncertainty, the importance of the activity to the larger organization, and the salience of the issue to the individual. Uncertainty includes reorganizational changes and personnel changes. When uncertainty combines with personal stakes, the individual will most likely consider political actions (Porter et al., 1981). A final condition for political activity reiterates the resource scarcity discussion of Burns (1961). What, then, are these political activities?

\section{Models and Classifications of Political Behavior}

A variety of listings of political behavior exist in several academic disciplines. A few of the lists are operationally defined and none are empirically validated. Certain writers have amplified one or more special political behaviors. For example, Dyson (1976) 1isted withholding information and exploiting the incompetence of others as gamelike qualities in organizations. Recent efforts have been made to extend Allison's famous Model III as a basis for empirical research (Murray, 1979). Model III attributes international policymaking to the complexities of political behavior. The model complements the rational (I) and organizational process (II) ones, and indeed, it brings the political actor into focus. Allison summarized: "What moves the chess pieces is not simply the reasons that support a course 
of action (I), or the routines of organizations (II) that enact an alternative, but the power and skill of proponents and opponents of the action in question" (1971, p. 145). For Allison, the actions and decisions of national governments should be seen as collages of political behavior, such as coalitions, bargains, compromises, games, and action channels. Other examples of political behavior from the political science discipline are presented by Lindblom (1980), who uses the word play instead of the words interaction or behavior and refers to persuasion, threats, exchanges, mutual adjustment, and control.

Many additional examples of political behavior are described by professionals in the organizational development (OD) discipline. Recognizing the fact that oD consultants enter into political arenas, they have delineated strategic behavior for them. For example, Schein (1977) indicated several methods: research, trade-offs, aligning with a powerful other, using a neutral cover, and withholding information as choices of political behaviors. Bateman (1980) reiterated the model of political influencing behaviors of Mayes and Allen (1977). He recommended oD consultants follow that framework of behaviors: considerations of political goals, power analyses, identification and commitment of political targets, implementation of power tactics, and constant monitoring of the process. Although these elements are described sequentially, they actually overlap and intertwine.

The OD literature has continued to assist the understanding of political realities in organizations. Originally, Bennis had strong words to say. "There seems to be a fundamental deficiency in models of change associated with organizational development. It systematically 
avoids the problem of power, or the politics of change" (1969, p. 78). Pettigrew (1975) was one of the first oD professionals to address the political context of the oD interventionist's work. He cited five power resources necessary for the consultant: expertise, control over information, political access and sensitivity, assessed stature, and group support. For Pettigrew, a consultant's ineffectiveness results from reacting to rather than anticipating political events. Bennis would agree.

"Understanding and skillful use of an organization's political dynamics are essential for successful oD interventions," wrote Margulies and Raia (1984, p. 20). Their model recommended the need to identify and use available sources of power, the need to develop political skills, and the need to expand perspectives of the consulting role. For them, political behavior included such skills for the change agent as expansion of one's power base, the development of support networks, and the management of one's image.

Most recent ly, Cobb (1986) organized a theoretical model to assist OD consultants in the political diagnosis of the client system. Recognizing the micro, intermediate, and macro levels of a client system, he presented a dispositional, or stage setting approach, to political situations that included forms of stakeholder analysis, coalitions, and network linkages. His purpose was to develop an initial "map" of this political territory for the oD consultant. For Cobb, individuals and groups are the main sources of information.

The Porter et al. study (1981) addresses the complexities of political behavior including norms, situational factors, actor 
characteristics, target selection, and methods. The authors use a classification system summarized from Mowday that is insufficient for the present research. The five behaviors (tactics) of the classification do not include the influence methods highlighted in the Allen, Madison, Porter, Renwick and Mayes study (1980). Despite the weaknesses of the classification model, this conceptual paper explores salient hypotheses regarding organizational politics.

In contrast to most of these classifications of political behavior which are on the microlevel, Zald and Berger (1978) transferred three phenomena of social movements to organizations. Rarely has organizational politics taken note of political processes in nations and communities, and Zald and Berger explored just that. With specific organization cases to substantiate their points, the authors described coup d'etat, bureaucratic insurgency and mass movements as unconventional political activities.

The model of Farrell and Peterson (1982) subsumed many of the above behaviors in an explicit framework. In fact, their effort to develop the typology was from the neglect of distinguishing the various types of organizational behavior. For them, political behavior was either legitimate or illegitimate. Their term illegitimate is important to define. It is extreme political behavior that violates the "rules of the game" of the organization. It is action too dangerous or threatening to the organization for the organization to allow. It is usually undertaken by alienated members and by those who feel they have little to lose. Often this form of political behavior risks loss of membership or extreme sanctions on the part of the political actor. 
Within these two categories, behavior can also be placed into a quadrant: internal/vertical, internal/lateral, external/vertical, and external/lateral. The internal/external range allows for the open systems reality of organizations today. The more familiar vertical/lateral behaviors are exemplified by apple-polishing and exchange of favors.

Insert Figure 1 about here

Summaries of Six of the Most Timely and Relevant Studies

Actual studies of political behavior in organizations have been quite rare, the exception being Pfeffer's study of the budgetary process in a university setting (1980). The following six summaries are significant transitions from the earlier conceptual writings and, as such, contribute to the construct validity of the proposed instrument.

Allen et al. (1980) offered an unusual inquiry into organizational politics through a study of managerial personnel in 30 electronics organizations. The researchers used open-ended questions in semistructured interviews such as "What are the tactics of organizational politics of which you are aware?" and "What are the personal characteristics of those people you feel are more effective in the use of organizational politics?" (1979, p. 77). The answers to these questions resulted in tables of political tactics and personal characteristics of effective political actors. The managers in the study were able and willing to identify the behaviors, and the researchers stated that the managers cited three tactics: attacking or blaming others, use of 


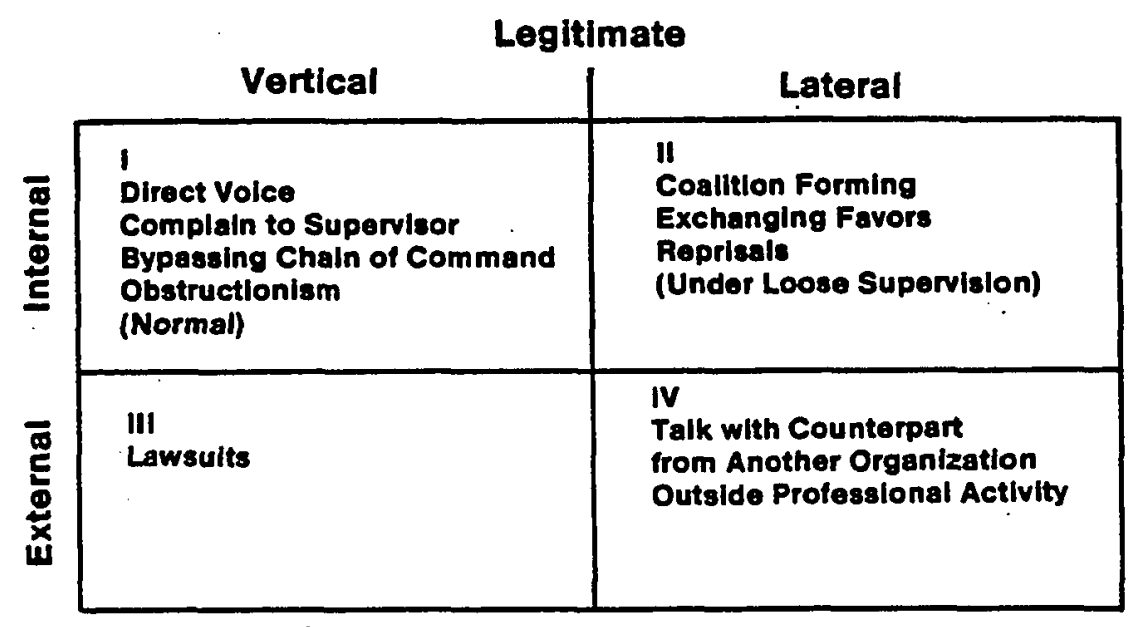

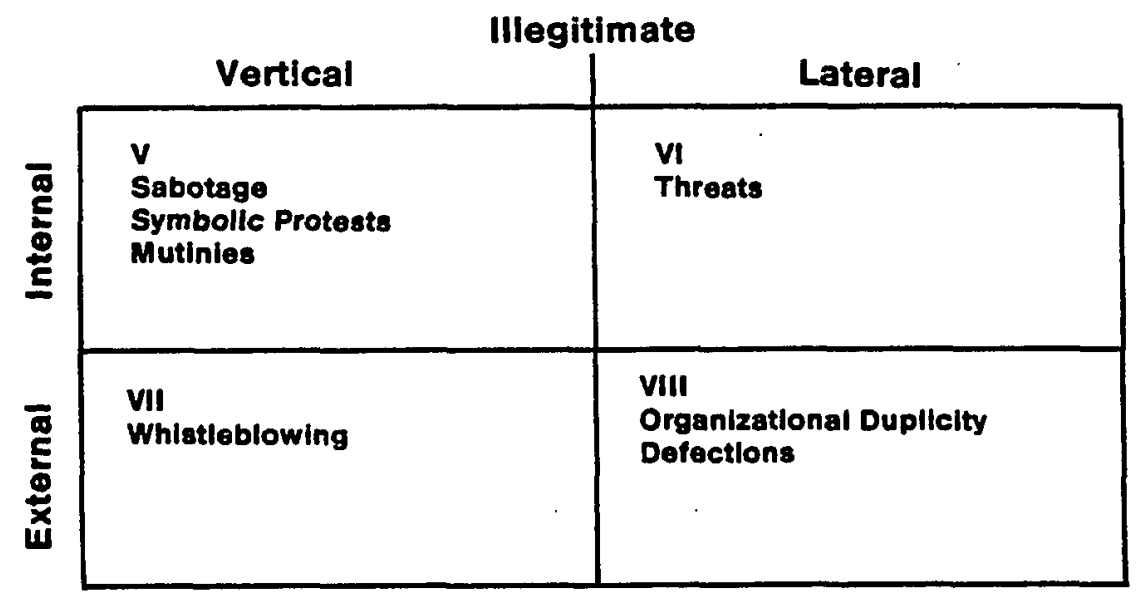

Figure 1. A Typology of Political Behavior in Organizations

From "Patterns of Political Behavior In Organizations" by D. Farrell and J. Peterson, 1982. Academy of Management Review, 7,p.407. 
information, and impression management. The sample of managers did not reach a consensus on personal characteristics, but the characteristics most cited (articulateness; sensitivity to other individuals, situations, and opportunities; and competence) have also been evident on lists of traits of effective leaders (Stodgi11, 1974).

Frost and Hayes (1979) viewed the negotiating phase of a social exchange process as the arena of organizational politics. They solicited actual examples of behavior from two vocational institutions, one Canadian and the other Australian. A group of judges then reviewed the examples and placed them into the three categories of administrative, discretionary, and political behavior. The nature of the data and small sample size make generalizations inappropriate, but the study's exploratory nature can be supported.

The study affirmed the hypothesis that negotiations phase behaviors would be judged political. The authors plan to construct a different data gathering methodology which will attempt to gather patterns through clustering or factoring techniques, but this has not been accomplished yet (P. J. Frost, personal communication, August 14, 1984).

Managers' perceptions of organizational politics were investigated by Madison et a1. (1980). For the first time, researchers asked organizational actors about their perceptions of the incidents and characteristics of organizational politics. Through interviews with three managers on three levels in 30 electronics organizations, the researchers concluded:

1. Organizational politics was a frequent activity. 
2. Ninety percent of the managers agreed that organizational politics occurred more frequently at middle and upper levels of management, and $60 \%$ agreed that political behavior was more prevalent at staff levels, for example, marketing rather than line positions.

3. Particular situations, such as reorganization changes, personnel changes, and budget allocations produced increased political activity .

4. Organizational politics caused both positive and negative outcomes for individual and organizational goals.

How people use power to influence their colleagues or superiors was the concern of the Kipnis, Schmidt and Wilkinson study which consisted of two parts. Using content analysis of written descriptions by managers of their attempts to influence their bosses, coworkers, or subordinates, a wide range of tactics emerged. Many of the tactics reported by the sample do not appear in the literature (e.g., use of deceit, clandestine actions), nor do they fit into the existing typologies of power and influence. Respondents ( $N=165)$ were graduate business students enrolled in evening classes. It was unclear whether the respondents were all managers at a specific level or otherwise. "The findings of the study," stated the authors, "suggest that in organizational settings the choice of influence tactics is associated with what the respondents are trying to get from the target person, the amount of resistance shown, and the power of the target person" (1981, p. 109).

A complementary study of Kipnis et al. to the previously mentioned study sought to identify through factor analysis the dimensions of 
influence underlying the specific behaviors of the first study. The instructions to the three questionnaires used were unusual:

This questionnaire is a way of obtaining information about how you go about changing your boss's (or co-worker's or subordinate's) mind so that he or she agrees with you. Below are described various ways of doing this. Please do not answer in terms of what you would like to do. (1981, p. 110)

The results of the study yielded eight dimensions of influence related to the target person's status. Assertiveness, sanctions, ingratiation, and rationality were associated with influencing either superiors or subordinates. The tactics of exchange of benefits, blocking, and upward appeal affected the influence of bosses. Coalitions appeared when the influence of subordinates was occurring. The authors recognized that self-report measures were insufficient and encouraged replication using different methodologies. The scales developed could certainly be utilized to measure influence in future research.

The sixth study, based on a self-administered questionnaire to MBA students, was an attempt to develop an understanding of the meaning of workplace politics to those who work in a variety of organizations (Gandz \& Murray). The findings are clear, wrote the authors: "Talk about politics is common in the workplace; respondents see politics as deviations from techno-economic rationality, as pervading discretionary more than other types of organizational processes, and as more prevalent among higher and middle managerial levels than among lower and nonmanageria1 levels" (1980, p. 450). Organization politics was seen as a subjective state rather than one of conflict, power, and influence 
as is usually presented in the literature. Therefore, the authors suggest a phenomenological approach to research on the subject.

\section{Analysis of the Political Actor}

of the several factors that affect organizational politics, the belief systems, motives, and personal characteristics of the political actor are indeed critical. The questions arise: Who is the political actor? Who has the propensity to engage in political behavior? When? Why? Are some factors more important than others? Not only are the answers to these questions underpinnings to the present research, but also, the answers may serve as a heuristic device aiding the understanding of political leadership and the political education of organizationa1 members.

After the relationship between power and politics is explored, this part of the literature review highlights the various theories, models, methodologies, and questions about the political actor. For example, one theory from the psychology discipline, the power motive, will complement the social psychologists' perspectives, specifically, Machiavellianism. In addition, an emphasis from behaviorial science, that of attributed characteristics of political actors, is discussed. Various Approaches to Power

Power and political behavior have always been theoretically and empirically linked. Pfeffer, in his comprehensive synthesis of the subject of power, integrated the two concepts:

If the power is a force, a store of potential influence through which events can be affected, politics involves those activities or behaviors through which power is developed and used in 
organizational settings. Power is a property of the system at rest; politios is the study of power in action. An individual, subunit or department may have power within an organizational context at some period of time; politics involves the exercise of power to get something accomplished, as well as those activities which are undertaken to expand the power already possessed or the scope over which it can be exercised. (1981, p. 7)

The traditional literature and research spoke of power as the larger phenomenon, rarely using the term political. The differences in the definitions of power have been remarkably diverse, which is not surprising considering the many disciplines that addressed it. The common elements about power that have emerged are reflected in Pfeffer's (1981) description. Power is relational, potential or active, goal directed, adaptive, multileveled, contextual, and dynamic. The contributions of the many disciplines to the understanding of power and political behavior originated from their respective views of reality or background assumptions whether implicit or explicit. Sometimes theorizing developed and expanded upon unchallenged grounds (Morgan, 1980). It is important to recognize this and to consider the value of a sharper analysis of power that would result from examining and rethinking power from alternative paradigms. Morgan described the functionalist paradigm from which social systems and behaviorism stem, and indeed the very questions of this research.

The functionalist paradigm is based upon the assumption that society has a concrete, real existence, and a systemic character oriented to produce an ordered and regulated state of affairs. It 
encourages an approach to social theory that focuses upon understanding the role of human beings in society. Behavior is always seen as being contextually bound in a real world of concrete and tangible social relationships. The ontological assumptions encourage a belief in the possibility of an objective and value-free social science in which the scientist is distanced from the scene which he or she is analyzing through the rigor and technique of the scientific method. The functionalist perspective is primarily regulative and pragmatic in its basic orientation, concerned with understanding society in a way which generates useful empirical knowledge. (1980, p. 608)

Opposing paradigms should offer other ways of looking at the political actor.

Before psychologists and sociologists lectured and hypothesized about power, philosophers and thinkers such as Plato, Machiavelli, Hobbes, Nietzsche, Adler, and Freud wrote about man's aggressive instincts and strivings for power (Kipnis, 1981; Winter, 1073). In the 1950 s, the power motive as a focus of study became a special domain for certain psychoanalytical writers. Their concerns, summarized Tannebaum (1966), related to one's feelings about controlling and being controlled by others, feelings of superiority and inferiority, dominance and submission, independence and dependence, conformity or reactions to authority. Often power was associated with manliness and virility.

From this group, the most significant work related to the understanding of the power motive and its thought processes was presented by Veroff (1957), Uleman (1972), and Winter (1973). Each used the 
Thematic Apperception Test (TAT) because of its presumed ability to detect and assess even unconscious strivings for power (Lips, 1981). Veroff (1957) initially devised a scoring system on $n$ Power based on groups' responses to five pictures. He related the high $n$ Power to Political and Economic values in the Allport-Vernon Scale of Values. Building on the TAT scoring, Uleman (1972) matched $n$ Power TAT scores with personality theories, specifically Adler's premise that power was related to an inferiority complex and striving for superiority or social attention. Winter (1973) further utilized the TAT and the $n$ Power scoring key. He believed that the power motive was the one key variable for the understanding of power behavior. The other variables which have been empirically measured included locus of control, personal causation, Machiavellianism, and attribution by others. But these variables were different from the power motive, believed Winter. This motive was a way of determining those changes in behavior that could not be readily explained by external forces alone.

The TAT was employed by Winter with male college undergraduates at Wesleyan and Harvard in aroused and neutral groups. The aroused group, student leaders waiting for the results of an election, were expected to portray more power images in their TAT stores. Using the carefully constructed $\mathrm{n}$ Power scoring system, scores were derived and correlated with other behaviors. High power scores on the TAT predicted such actions as drinking, gambling, watching sports, and precocious sexuality. In recognition of these studies, McClelland (1984), in collaboration with Winter, later developed his theory of the two faces of power-unsocialized and socialized. 
The power imagery of TAT respondents revealed five categories of power behaviors:

1. Actions (assaults, attacks, chasing, exploitation).

2. Giving help, assistance, advice or support.

3. Trying to control another person through regulating his/her behavior or the conditions of his/her life.

4. Trying to influence, persuade, convince, bribe, make a point, argue.

5. Trying to impress some other person or the world at large. In summary, Winter maintained that the situation, individual factors and motives affected a person's power inclination. This combination was paramount. Unfortunately, the TAT was rarely expanded to wider and more varied sample groups.

The same complaint, that of samples of convenience from college undergraduates, has been true of the series of studies on the Machiavellianism personality conducted by Christie and Geis (1970). Named for the 16th-century author whose name has become synonymous with the use of guile, deceit, and opportunism in interpersonal relations, the "Machiavellian" was one who viewed and manipulated others for his or her own purposes. Using ideas from The Prince and The Discourses of Machiavelli, Christie and Geis developed a hypothetical construct and, in turn, a scale to measure related personal characteristics such as:

1. A lack of affect in interpersonal relations.

2. A lack of concern with conventional morality; a utilitarian rather than moral view of interactions with others.

3. A lack of gross psychopathology. 
4. A low ideological commitment, a focus on getting things done rather than a focus upon long range ideological goals.

From ancient and modern power theorists, Christie and Geis saw the common assumptions that people were basically weak, fallible, gullible and, therefore, that a rational person should take advantage of the situation to maximize his or her own gains. Evolving five different scales and scoring procedures on the Mach scale, the researchers and their assistants carried out numerous laboratory type studies. No significant correlations between Mach scores and I.Q. or years of education were found. Nor were authoritarianism, racial attitudes, political ideology, and demographic variables correlated.

When bargaining conditions were ambiguous in the lab setting, success in interpersonal bargaining was doubled for the high Machs. They were more opportunistic, favored face-to-face interaction, remained detached from ego-involving elements in bargaining and resisted social influence. Wrote Christie and Geis, "They win by political strategies without manipulating obviously when success depends upon the cooperation or recognition of others" (1970, p. 309). They cooly use others. "They," continued Christie and Geis, "manipulate more, win more, are persuaded less, [and] persuade others more." (1970, p. 312). Cobb (1986) saw the diagnosis/analysis of basic political styles attempted by Christie and Geis as important and relevant to organizational development (OD) concerns.

The organizational psychologists' study of power and political behavior has evolved from trait and situational approaches to management and leadership. Yuk1 lists over a dozen studies directed at the 
effects of applying French and Raven's five power bases: legitimate, reward, coercive, expert, and referent. He also lists 11 forms of influence and related studies, yet concluded that all these efforts are insufficient when he wrote, "Much remains to be learned about the dynamics of reciprocal influence processes and the consequences of having and using different forms of power" (1981, p. 280).

Another trend in power studies has been the zero versus non-zero sum attitudes which Bacharach and Lawler synthesized:

The major difference between zero-sum and variable-sum approaches is that a zero-sum approach assumes a fixed level of total power and a perfectly negative relationship between the power of each individual party, where a variable sum approach assumes that the total power in the relationship can change (from environmental changes, tactical action, and so forth) and that it is inappropriate to assume a priori a particular relationship between the power of each party. (1981, p. 67)

Tannebaum (1966) studied numerous organizations and concluded that power is not a zero-sum commodity. When subordinates have more power, it does not follow that managers have less. In organizations where there is a greater amount of power at all levels, the organization is likely to be more effective and individual members more satisfied. Bacharach and Lawler (1981) would concur that power is multidirectional and that this side of power should be a central concern of a political model of organizations. To acknowledge this multidimensional aspect of power, Salancik and Pfeffer had a cross section of organizational members rate themselves and their peers on a scale of influence or power. 
The agreement as to who had influence was remarkably high. Their conclusions were innovative: "Power facilitates the organization's adaptation to its environment or its problems. Power helps organizations become aligned with their realities (1981, p. 54). Similarly, Kantes (1977) defined a powerful individual as one who has the ability to get things done and this ability comes from knowing the environment.

These emphases came closer to the heart of organizational politics and the political actor. The political actor uses influence rather than direct authority to achieve his or her goals. There is, as has been said before, little systematic information on how people use power to influence multidimensional relationships (Kipnis et a1., 1981). Two extremely useful studies by Kipnis et al. (1981) contribute to our understanding of the political actor.

Another concern of organizational psychologists has been the nurturing and developing of the instincts needed to effectively acquire and use power (Dubrin, 1978; Kotter, 1983). Kotter reported that managers who are successful at acquiring considerable power tend to share these common characteristics:

1. Sensitivity to what others consider legitimate acquisition and use of power, including recognition of the "obligations" involved in using power.

2. Possession of a good intuitive understanding of the various types of power and methods of influence--when, where, and with whom to use them.

3. Development of all types of power, and ability to use them. 
4. Establishment of career goals with ambitions toward managerial positions that allow successful development and use of power.

5. Use of all resources, including formal authority and power to develop still more power.

6. Recognition and acceptance of the exercise of power as legitimate, that in using power-oriented behavior they clearly influence other people's behavior and lives.

Significantly, there are strains of social exchange theory, locus of control, and attribution theory in these six characteristics.

Before attempting an integrated model of analysis of the political actor, it may be helpful to consider the sociological perspective on power. 0lsen (1970) observed two sets of literature from the bifurcation of focus social psychologists and sociologists had of power. On the one hand, interpersonal power relations are studied, and on the other, interorganizational ones. Gamson (1968) stated that the sociologists' attention is the actor in a system. Reflecting social exchange theory, Hawley wrote, "Every social act is an exercise of power, every social relationship is a power equation, and every social group or system is an organization of power" (1970, p. 10). For sociologists, actors may be small groups, organizations, total societies, as well as individuals (01sen, 1970). Their concerns are social influence, e. g., voting behavior; social perception; the nature, distribution and use of power in societies. Exchange theory, ecological perspectives, elitism, Marxism, and normative ethics are typical themes. 0lsen offered a formula for the political person: "In general, the amount of power an actor exercises in a particular 
relationship is a resultant of the extent and adequacy of his committed resources, multiplied by his skill in converting resources into pressures, minus the degree of resistance encountered" (1970, p. 4).

Social psychologists have studied the political actor more from the relational aspect than the personality focus of the clinical psychologists. Several sociopsychological theories are summarized because they contribute to the understanding of the multidimensional and complex power dynamic: social exchange theory, expectancy theory, locus of control, the need for power ( $n$ Power), and attribution theory. Social Exchange Theory

This theory underlies relations between groups, as well as those between individuals. It includes conflicts between opposing forces as well as cooperation; both intimate attachments and connections between distant members of a community. It is oriented toward ends that can only be achieved through interaction or any behavior involved in socially mediated goals. The exchange entails unspecified obligations and tends to engender feelings of personal obligation, gratitude and trust (Blau, 1964). In this approach to social relationships, power is central, especially the dependence aspect of power. Bacharach and Lawler (1981) presented two assumptions of the exchange theory: (1) dependence is inherent in social life and therefore, (2) exchanges are intrinsic aspects of any social relationship. The power of an actor is a function of the other person's dependence on the actor. Consequently, power must be studied in terms of a network of relationships, whereas most theories and research on power emphasize the coercive aspects of power relations and neglect the underlying stakes actors have 
in existing relationships (Bacharach \& Lawler, 1981). In an exchange, one person will be successful if they negotiate the outcomes or payoffs for the other (Lips, 1981). The outcome is determined by the principle of least interest. The actors will attach values or priorities to the various outcomes obtained from a given relationship. Power, summarized Bacharach and Lawler, is not an attribute--it is embedded in social relationships. "Social exchange theory is an at tempt to explain how the reciprocal process of influence...occurs over time," wrote Yukl (1981).

Expectancy Theory

A further extension of the action-outcome concerns of social exchange theory is the expectancy theory of Vroom and its twin subjective expected utility (SEU) of Edwards (Porter et a1., 1981). Individuals are believed to behave in a manner that maximizes their expected net value. Porter et al, wrote:

This, in turn, suggests that organization members undertake a series of subjective cost-benefit analyses, using salient available information. Some of the more explicit information available is the political actor's knowledge of the results of past attempts at social influence. Thus, the individual's "expectancy set" regarding the efficacy of engaging in upward political influence will be at least in part determined by what has gone before. (p. 21)

Expectancy theory is a rational choice process of weighing the desired outcomes versus the undesired ones. The higher a positive SEU is, the more likely a political influence attempt (Yukl, 1981). 
Locus of Control

Lips (1981) reviewed Rotter's work about internal or external control and the extent to which people believe they are in control of their lives. These beliefs are"reflected in one's behavior. On a scale Rotter developed, an individual may score high on internal control, if he or she feels they are captain of their own ship or in control of their life. The higher internal score could predict other factors, such as propensity to seek and use information relevant to personal decisions; changing other people's attitudes; belief in their own skill rather than luck; and social independence. "One's locus of control," wrote Lips, "may relate to how powerful one feels and the ways in which one uses power" (1981, p. 69). The underlying problem of this theory is the dilemma of one's espoused locus versus the real behaviors. Porter et al. (1981) speculated that internals faced with a problem in which political influence is possible might arrive at a more positive SEU computation than an externally centered person. Internals might, therefore, favor political activism.

n Power

The earlier discussion of the TAT's n Power studies must be complemented by attention to McClelland's (1984) work in this area. As a behavioral scientist, McClelland began studying the power motive in managers. This $n$ Power in managers differs from the $n$ Achievement he observed in business entrepreneurs. What aroused thoughts of being powerful? He confronted the negative tone associated with the research on power with its pejorative synonyms for power: Machiavellianism, zero sum, and authoritarianism. Furthermore, he discovered that 
individuals disliked being told they have a high need for power. McClelland extended the work of Winter (1973) to the actions of the high $n$ Power individuals and categorized two faces of power (Thompson \& Luthans, 1981). The two faces are opposites. The negative and more primitive personal power face is a win-lose coercive type, and the positive social power face is concerned with group goals or with finding goals that will move men (McClelland, 1984).

McClelland observed specific behaviors in high $\mathrm{n}$ Power individuals which will assist us in answering some of the questions about the political actor. The individual with a high $n$ Power seeks positions of leadership; influences others to task performance; collects prestige objects; mentors, trains and/or instructs others; is active in organizational politics; seeks, withholds, uses information to control others; drinks when feeling powerless.

Attribution Theory

This theory centers on the relation between a person's perception and the interpersonal event. The individual makes certain ascriptions about behavior of others and interprets that behavior (Luthans, 1977). The importance of this concept appeared in several discussions of political behavior. For example, Porter et al. wrote:

Attributions of intention often vary widely between those who are the source of the behavior and those who are observing or labeling the behavior. It is our contention that if the behavior is seen by organizational participants as intended to promote or protect self-interests then (meeting the other criteria) the label "political" is appropriate. (1981, p. 112). 
The theories overviewed are certainly not integrated into one framework for the understanding of the political actor. The power relationship is the context for political action and encompasses the most basic issues underlying organizational politics (Bacharach \& Lawler, 1981). The body of literature on power is disjointed. The theorists, claimed Bacharach and Lawler, "fail to integrate the insights of the other theorists systematically. This produces the impression that various theorists hold conflicting notions of power rather than that they emphasize different and complementary dimensions of power" (p. 11).

\section{Discussion}

If all social interaction based on the give and take of social exchange theory is therefore political, what can we learn about the political actor in this broad picture? In other words, are there social exchanges that are not politica1? Expectancy theory hypothesized about the complex thought processes leading to a decision--equations, weighing, and so forth--yet have they ever approached the theory from the viewpoint of the participant? Could a phenomenological approach offer alternative insights? "What motivated you to perform this particular political activity?" might be a valuable question to ask and interpret. The locus of control issue loses its impact on the power dynamic as a contending variable particularly because the opposite has never been challenged. Do externals (as discussed in the section on locus of control) never act politically? If they do, when? And, why?

The power motive and $n$ Power speculations offer more potential for the understanding of the political actor. These probings into consciousness are worthwhile endeavors. Socialization affects one's $n$ 
Power and sheds light on how people form political norms and ethics. Without some recognition of the organization's political norms and without some internalization of these norms, political behavior would not ensue no matter how strong the self-interest at stake is. These variables at the heart of political behavior could be examined in the instrument of this research.

As initially posited, looking at power and political behavior from alternative paradigms may prove useful. Other questions are raised. The subjective interpretive paradigm which centers on individual consciousness has influenced the power motive, $n$ Power, and the studies of Kipnis et al. (1981) and Allen et al. (1979) to a certain degree. Phenomenological studies and longitudinal endeavors would tremendously enrich the picture. Bacharach and Lawler challenged, "Ask not what is power, but to what phenomena does the notion of $n$ power sensitize us?" (1981, p. 12).

A paradigm which moves into the change arena, the radical humanist one, seeks to explain how individuals link thought and action. Burrell and Morgan (1979) described this view of reality as one which emphasizes the importance of overthrowing the limitations of existing social arrangements, the constraints of the status quo. This could be enriching for the study of the political actor, especially the personality of the artistic or intuitive individual in the Jungian personality typology. Change is always part of political activity, and this paradigm offers critical elements that have been neglected. Similarly, the radical structuralist paradigm attends to change. The focus of this perspective is on anti-organizational behaviors, especially in the 
Marxist sense. Many political behaviors, such as organizational coups, whistleblowing, and insurgency fall into this frame, yet the political act or remains unexamined here.

\section{The In-Basket Test}

The in-basket test is a simulation exercise requiring the performance of a managerial position by dealing with the mail and related items which have presumably accumulated in the in-basket of the manager. Each subject is confronted with a standard set of problems in the form of letters, memos, report, and related materials. The exercise provides an excellent training tool for prospective managers, and it is widely used for this purpose in industry. In addition, several methods of scoring performance on these materials have been worked out so that the in-basket is frequently used as a selection aid. (Meyer, 1970, p. 297)

There are some variations on Meyer's (1970) definition of the inbasket that include the concept of game (Lopez, 1966) or test (Frederiksen, 1962). Confusion arises when the words game, simulation, exercise, or test are used interchangeably in the literature, yet actually the in-basket is all of these and more. In its fullest application, the in-basket is an extensively experiential learning device for the subject, a research instrument, and a selection aid.

Analyzing the definitions and these multi-purposes of the inbasket throughout its 30 year history will be the initial emphasis of literature reviewed in this section. Four other aspects of the inbasket will be discussed: assessment centers, the design and 
evaluation of the in-basket, validity and reliability, and a critique of the in-basket.

\section{History}

The original conception of the in-basket by its inventor, Norman Frederiksen, was that of a situational test. Frederiksen and his colleagues from the Educational Testing Service (ETS) were asked to study the desired outcomes of the Air Force's Command and Staff School. Their task was to evaluate the effectiveness of the curriculum and instruction for the school, but Frederiksen was immediately responsive to the potential application of his prototype in-basket method for individual performance and even personality study (Frederiksen, 1957, 1962, 1966). He attempted to devise, as he wrote in 1957, "a sensitive measure which may at the same time be objectively and reliably scored" ( $p$. 2). The original purpose of the in-basket, which was curriculum and instruction evaluation, received little further attention in practice or theory. Frederiksen's serendipitous discovery of other uses of the test was critical to the history of the instrument, for he and his ETS colleagues then provided a rich literature base to the lineage of the in-basket.

In designing this first in-basket for the Air Force, Frederiksen thoroughly analyzed the curriculum and objectives of the Command and Staff School. The major purpose of the course was to increase the administrative proficiency of the students. From the analysis, over 500 behavioral descriptions of the desired outcomes of the course were classified into categories which would delineate psychologically meaningful functions. For example, demonstrating flexibility, 
adaptability, and willingness to introduce change were included in this statement: "Can comprehend the effect on Air Force activities of possible political-economic events such as the closing of highways and railways into Berlin" (Frederiksen, 1957, p. 3). Another example of the flexibility function was this: "Readily plans for and makes changes in procedures which are consequences of the introduction of new research developments" (p. 3).

The next step for the ETS staff was to prepare materials that would evoke the range of the desired behaviors and skills. These materials consisted of written memoranda, messages, reports, and documents. The students were to react and respond to the items as if they were the actual decision maker. After a tryout of the test, precise preliminary student instructions for the instrument were completed. A scoring procedure was then developed from the responses of a Sample Group I. For each of the various problems, between 5 and 15 types of responses were identified. Further refinements were made on the incorporated Sample Group II's responses, then the responses were submitted to two panels of senior officers in the Air Force. The judges were asked to rank and place a value on the problems in the in-basket in order to develop a scoring key (Frederiksen, 1957).

"The in-basket materials were tried out in July 1953 by administering them to the entire Class 53-B of the Command and Staff School," wrote Frederiksen (1957, p. 10). The purpose of this tryout was to provide data for operational, statistical and scoring concerns. Several conclusions were drawn from the tryout. 
1. The detailed analysis of performance on the test provided maximum guidance to the instructors on the quality of their teaching, thus accomplishing the major purpose of the test.

2. The test could be used as a baseline measurement.

3. The breadth of information obtained from the test called for improved evaluation procedures. For example, the test might evaluate chacteristics not originally intended to be measured. Cooperativeness and sympathy or harshness in dealing with subordinates were evidenced in the tryout. "The in-basket," commented Frederiksen, "may be thought of as a projective test which reveals a great deal more about the personality of the writer than is revealed by the objective scoring method" (1957, p. 22).

4. To improve the content reliability of the test, more effort must be made in the selection and revision of items. Homogeneous subtests must be more explicit.

5. The test could be scored with a reasonably high degree of reliability.

6. No criterion of validity was available from this first form.

No other researcher or industrial psychologist has contributed as much inventiveness, foresight, and statistical attention to the inbasket instrument as Frederiksen. He continually marveled at the potential uses of the in-basket. He wrote, "It is also possible to consider the in-basket test as a rather elaborate performance test in the area of personality" (1962, p. 1). Later in 1966 he added, "Perhaps the principal virtue of an unstructured situational test such as an inbasket is that it provides an opportunity for the examinee to display 
spontaneously certain response tendencies which comprise a part of his personality" (p. 107).

The next major use of the in-basket was quite different. The American Telephone and Telegraph Company's (AT\&T) Management Progress Study was initiated in 1956 as a long range research study of the psychological development of adulthood (Bray, 1964). "It was a study of both individual characteristics of young managers and characteristics of their organizational settings," wrote Thornton and Byham (1982, p. 55). As a longitudinal study, all data were separated from any operational decision making in the company and from career decision making about the participants. In their recent definitive work on the history of assessment centers, Thornton and Byham wrote, "Seldom is such a 'pure' study conducted in industry" (1982, p. 59). Bray conceived and led the study. The assessment center process, amplified with an inbasket exercise developed with the assistance of the ETS, was used as a baseline measurement for the 422 men in the study. Here the history of the in-basket joins that of the assessment centers.

Assessment centers. The origins and evolution of the assessment center method are important to the study of the in-basket, for this exercise became one of the major components of centers--indeed, Gill (1982) called it the most popular single assessment method. Many of the validity and reliability concerns of the in-basket are embedded in assessment center research. The Management Progress Study incorporated the in-basket into its $2 \frac{1}{2}$ days of pretesting in the assessment center context. With this unbiased study began the long and healthy research 
base on assessment centers and, directly and indirectly, on the inbasket.

"An assessment center is a procedure (not a location)," wrote Thornton and Byham, "that uses multiple assessment techniques to evaluate employees for a variety of manpower purposes and decisions" (1982, p. 13). The first assessment centers used multiple simulations and initiative tests to evaluate candidates for "James Bond" type work in irregular warfare during WW II. The office of Strategic Services (OSS) designed complex exercises with several purposes in mind for its candidates. One interest was to study highly effective individuals and to delineate these persons as a whole, a goal similar to that of the Management Progress Study. Another aspect was the concern for an individual's favorable qualities and one's potential for effective functioning. Lastly, the OSS favored the predictive validity of its simulations and exercises (Mackinnon, 1975). When the Management Progress Study adopted this method, the assessment center began its business life. Shortly afterwards, the Michigan Bell Telephone system initiated assessment centers--the first operational use for management selection (Mackinnon, 1975). Today, 300 to 1,000 centers exist. The social and environmental influences of the 1970s added significantly to this rise of assessment centers since 1956. Mackinnon (1975) highlighted some reasons for this.

1. There was a need for more effective managers, particularly because it was costly to hire managers who failed.

2. Psychologists and their specialized testing were not effective in business environments. 
3. Assessment centers used more than one observer. The centers had high face validity.

4. The Civil Rights Act encouraged the selection and development of women and minorities and the assessment center passed the legal hurdles regarding job-relatedness, objectivity, and fairness towards these groups. For example, Moses and Boehm (1975) studied the predictive validity of the AT\&T centers from 1963 through 1971 for 4,846 women and found the methods valid for women as well as for men. In fact, they concluded, "An individual rated 'more than acceptable' was 10 times more likely to have received two or more promotions than one rated 'not acceptable'" (p. 529).

5. The American Management Association (AMA) and Development Dimensions, Inc. (DDI) began developing and specializing in assessment center technology, including in-basket construction.

U1schak (1983) added that the participants saw the assessment centers as extremely fair and accurate representations of their behavior. All these factors strengthened the growth and diversification of assessment centers in the United States and abroad. Centers became a high-powered tool presenting specific, reliable, and valid information about a manager's strong and weak points (Ulschak, 1983). For Fletcher (1982), assessment centers were the Rolls-Royce of psychological assessment.

Assessment centers in business, then, were originally used for research and shortly afterwards for selection. Because an incredible amount of personal behavioral data were obtained from an assessment center, many corporations began using such centers for management 
training purposes. In addition, the assessment centers facilitated career decision making through specific feedback on one's performance during the simulation (Keil, 1981).

Again, it is important to state that the in-basket is a major assessment center exercise, so the history and strength of centers parallel that of the in-basket. Just as the assessment centers have had a variety of purposes from research, evaluation, and selection to training, needs analysis, and career decision-making aspects, so too has the in-basket. The in-basket has served these myriad of purposes as an instrument itself. However, assessment centers have rarely excluded the in-basket from its repertoire of exercises so valuable is the in-basket to typical assessment centers.

The history of the in-basket continues. In fact, there is a renewed interest in using job simulations (Kesselman et a1., 1982). Frederiksen's (1966) construct validity studies supported the use of situational tests for providing dependent variables in socialpsychological experiments. In the past few years, the in-basket has been used for a variety of research studies, for example: occupational sex discrimination (Terborg \& Ilgen, 1975); bias towards physical attractiveness in rating performance (Robins, 1983); interrater reliability regarding sexually and racially mixed groups (Schmitt \& Hill, 1977); the influence of sex-role stereotypes in promotion, development, and supervision (Rosen \& Jerdee, 1974); differences in behavior shown to different subordinates (Kim \& Organ, 1983); and training for management (Gi11, 1982). Through the in-basket, Shapira and Dunbar (1980) 
investigated Mintzberg's managerial roles. This study will be addressed shortly in the leadership discussion.

Design and Evaluation of the In-Basket

Each of the design phases of the in-basket has its own vigor and complexity. The many phases include: job analysis, dimension choice, student instruction writing, material selection, interview planning, tryout, judging, scoring key development, assessor training and feedback of results. The designer eventually asks, "What items will evoke the behaviors which typify the characteristics I am looking for?" This key question flows from the purpose of the in-basket.

Every instrument must have a purpose (Benson 1982), and Keil (1981) recommends that careful attention be paid to this principle in the design of simulations. The most stringent design requirements are for selection purposes which are legally and ethically apparent. As a training tool, the instrument may allow for more breadth and depth in the design phases. In short, the specific purposes of the in-basket must be stated and understood by all involved in its design and evaluation.

Truskie (1981) suggested involving managers and supervisors in the design and delivery of training programs, and the designing of an inbasket calls for just that type of cooperation. Job analysis must be conducted first to determine the contents of the position to be simu1ated. Several levels of job performance must be noted: the functiona1, the interpersonal, and the cognitive. Categories and dimensions of behavior then emerge, again depending on the purpose of the instrument. Some of the dimensions of the Management Progress Study 
were human relations, personal impact, perception of threshold social cues, behavior flexibility, and tolerance of uncertainty (Mackinnon, 1975). In all, 25 variables were listed for that study (Bray, Campbel1, \& Grant, 1974). Dimensions of Frederiksen's original Air Force evaluative in-basket included individual and interactive behaviors, such as the flexibility behavior and interaction with others. Gi11 (1982) enumerated some of the behaviors that can be assessed via the in-basket: recall, insight, analytical and critical thinking, logical reasoning and problem solving, creativity, judgment, sensitivity to social subtleties, ability and willingness to make decisions, establishment of priorities, delegation, written communications, coping with stress, and management control. From this list, it can be seen that the in-basket measures what other instruments cannot.

Lopez (1966), who extensively designed in-baskets for the American Management Association (AMA) and New York Port Authority, wrote of the design schedule:

After training or selection objectives have been established, a position has been identified, the general outline of the situation determined, the emphasis selected, and the level of decision making defined, the next step in the actual construction process begins with the collection of a large supply of content material in the form of incidents, anecdotes, reports, case studies, and problems, drawn either from a real job (the ideal solution) or from indirect sources such as textbooks and magazine articles on management. (1966, pp. 35-36) 
From the raw materials compiled, problems appropriate to the objectives are selected.

A critical part of the in-basket is the set of preliminary respondent instructions. It is important to motivate the participant to enter fully into the situation so that he or she may ease into the assigned role. The situation must be plausible and even complicated with time pressures. Background information, organization charts, and position descriptions are necessary (Lopez, 1966).

The set of problems in the in-basket should call for personal judgments. They should be sufficiently ambiguous to evoke a wide range of possible solutions (Lopez, 1966). Some items should have high impact on the organizations; others might require immediate attention. Certain problems may demand more information or may affect others significantly. Lopez suggested including overview problems, tensionreducing problems, and even telephone taped interruptions. The number of problems usually ranges from 10 to 25 , though the General Electric Plan Manager in-basket contained 38 items (Crooks, 1968).

The next design step was to plan the interview to be given to the participant immediately after he or she had completed the exercise. Originally, these interview questions asked such open-ended questions as "What did you think of company $\mathrm{X}$ ?" "What did you think of person $\mathrm{X}$, Y, Z?" "What did you do for each item?" Now the post questions are more structured, even comprised of multiple choice responses in what Kesselman et al. (1982) called an Action Report Form. Thornton and Byham reported: "New procedures for in-basket evaluation using highly structured patterned interviews appear to offer great hope for cutting 
down the amount of assessor time required and for increasing the reliability of measurement" (1982, p. 186). The purpose of the post inbasket interview is to offer the participant the opportunity to explain his/her decisions more fully and to establish the degree of the participants' understanding of the characters and the problems in the exercise (Griffiths, 1979).

As in the Frederiksen Air Force prototype, a tryout of the instrument occurs next. The pilot group's responses form a pool of responses--the basis for the scoring key that will be developed. Hundreds of possible responses for the items are frequently generated. Griffiths (1979) recommended transcribing all the responses to $3 \times 5$ cards for the purpose of easier sorting and weighting of the items by the judges. The judges weight the items by priority and usually an $80 \%$ agreement is required for final inclusion in the scoring key. Judges sort the responses into degrees of effectiveness and also generate a list of considerations and the interrelatedness for each item. A precise, comprehensive, and reliable scoring key is finally formed.

Assessor training and feedback of results are the final design imperatives. The American Psychological Association, the American Educational Research Association and the National Council on Measurement in Education (1978) highlighted important standards and ethical considerations for assessor training. These standards are applicable to inbasket assessors as well. The assessors must know how to classify and analyze the elicited behaviors to minimize bias and distortion (Gill, 1979). When and what kind of feedback to be given must be determined in the design phase. The attention given to all the phases of the in- 
basket design strengthens the validity and reliability of the instrument .

Critique of the In-Basket

There have been several major criticisms of the in-basket that deserve attention. The time and effort required to design the exercise and the time demanded to score and report on the student's performance are formidable. AMA and DDI have constructed many off-the-shelf inbaskets to alleviate the design time demands, but of course, these are not as robust or valid as custom-made exercises.

Another charge leveled at the in-basket is that the in-basket is static in nature (Gill, 1982). As originally conceived, it did not allow for interruptions or time pressures. Gibson (1961) designed an in-basket for Harvard Business School students that successfully used a motion picture integrated with printed case material to make the simulation as realistic as possible. Although not empirically measured, Gibson learned that people usually do not observe or hear accurately; that in spontaneous decisions one usually reacts emotionally first; that pressures do make a difference; and that involving film and printed material produced a high degree of personal involvement. Such realism encouraged the respondent to display dominant aspects of his or her personality and to behave naturally, which Lopez (1966) and many other experts favor in the in-basket.

Another objection to the in-basket has been the inadequate quality of feedback to the participants. Except in pure research such as the Management Progress Study, feedback is usually given orally. It summarizes the content and style description of the candidate's 
performances, his or her strengths and weaknesses. Often an outlined plan for future development is discussed. More research needs to be done on the optimal timing of feedback (Mackinnon, 1975) and the reliability of feedback presented from the assessor point of view. APA (1978) guidelines require a training of assessors in thorough understanding of feedback procedures.

Each of these three major criticisms of the in-basket regarding time, its static nature, and feedback quality is outweighed by its effective characteristics which can be highlighted:

1. Empirical evidence of internal validity.

2. Objective and reliable scoring methods.

3. Qualitative data leading to personal insight (Wadde11, 1982) and the in-basket's value to management education.

4. Measurement of behaviors other instruments cannot (Gill, 1979).

5. Assessor training as a valuable experience in and of itself (Mackinnon, 1975).

6. Improvement in scoring methods.

7. Appreciable amount of data produced.

8. Wide acceptance by participants.

9. A research base of 30 years.

10. The multiple purpose to which it can be put: research, selection, training, and personal as well as career development.

These characteristics of the in-basket substantiate its choice as the instrument of this research. Producing quantitative data as well as qualitative material, the in-basket simulation is the next best 
thing to the observation of real life behavior because it is capable of raising complex behavior and reasoning, precisely the reality of political behavior. 


\section{CHAPTER THREE}

The Meret In-Basket Experiment

\section{Introduction}

The purpose of this research is to design an instrument, in the simulation format, which would measure the amount, type, and occasion of an individual's political behavior. The procedures that were followed to design and validate this instrument are based on the 30year history of the in-basket and particularly, the contributions of Frederickson et al. (1962, 1966, 1957, 1972) and Lopez (1966). These contributions are summarized in the first section of this chapter. The procedures used to design the Meret in-basket are explained in this chapter's second section. These design facets contribute to the instrument's validity and reliability. The third and final section describes the pilot groups and panel of judges. Generally, this chapter is a chronology of the instrument's design supplemented by the Meret in-basket items and training materials in the appendixes.

\section{The In-Basket Instrument: Historica1 Contributions}

\section{Validity}

Keil (1981), in an excellent discussion of assessment center validity, stated: "Validity is not a thing, it is sometimes not a property of a thing. Validity is a concept that takes on meaning only in relation to specific events and processes" (p. 79). The processes, of course, are the many important phases or procedures of the in-basket's design that directly impact its internal validity. For content validity, the processes of dimension selection, material selection, scoring 
key development, and so forth must be close to a 1:1 ratio between the targeted job level and the exercises as possible. Moving farther from that ratio, say a 1:5 or 1:10 concept, requires that the in-basket designer cope with construct validity and guard against inference when scoring. Accurate coding of the examinee's behavior in the scoring key development phase protects against inference and thus guards construct validity.

Keil's point is important because the term validity is confusing and no longer useful (Fitzpatrick, 1983). Some test developers say the scores themselves are the validity measure in contrast to Keil's belief that validity results from the process of the instrument's development. Indeed, the test scores must represent the hypothesized traits, but the test's foundations are even more critical.

Many of the early validity studies focused on the scores themselves to ascertain concurrent, predictive, construct validity. Using the Plant Manager's in-basket that was developed by the ETS, Meyer (1970) conducted a study with 81 General Electric unit managers to examine internal validity issues. Scores on the test related significantiy to job performance ratings of managers, attesting to concurrent validity. Meyer showed that the test did not only measured managerial experience, but it also provided a measure of managerial ability or aptitude. Other internal validity issues for assessment centers have been clearly established in numerous studies (Thornton \& Byham, 1982).

Frederiksen (1962) conducted several factor analytic studies of the content and style of in-basket responses that demonstrated patterns 
of performance. For example, work performance variance fell into three factors: preparing for action, amount of work, and seeking guidance. Frederiksen, long attracted to the personality assessment potential of the in-basket, also performed several construct validity studies (1966). Relating in-basket performance to psychological test scores, Frederiksen observed such personality and interest correlations as: imaginative courses of action and high vocabulary; writing volume and high active scores on the Thrustone Temperament Schedule; procrastination and low educational level; and others. He summarized his construct validity studies: "It would therefore seem reasonable to consider using scores on situational tests like the in-basket as dependent variables in social-psychological experiments, or as provisional criteria for validating tests which approach the problem of measuring personality less directly" (p. 87).

Predictive validity of the in-basket has been demonstrated in several studies such as the AT\&T study described in chapter two, and the works of Lopez (1966) and Meyer (1970). Lopez (1966) described the Sears \& Roebuck study that utilized the in-basket to predict effectiveness in an executive role. "They found," wrote Lopez, "that performance on the in-basket test was a reasonably good predictor of executive, managerial, and decision-making performance" (p. 103).

After more than 30 years of research and application, the inbasket has earned unusually high marks in every validity area, particularly face validity (Meyer, 1970). Some in-basket designers go to great length to produce letters and reports on colored letterhead, various sizes of paper and type size. The items are not copied. 
Consequently, realism is heightened (Crooks, 1968; Thornton \& Byham, 1982) and the in-basket's validity for all of its purposes seems obvious and acceptable to participants.

For the Meret in-basket, two types of validity were established and integrated--content and construct. Content validity, with its subset of face validity, was built upon an actual merger situation, which gave realism to the items and the entire political environment or domain of the simulation. Construct validity was built upon several theoretical principles. The first is a definition of political behavior as: "Social influence attempts that are discretionary (i.e., that are outside the behavioral zones prescribed or prohibited by the formal organization), and that are intended (designed) to promote or protect the self-interests of individuals or groups (units). These selfinterests threaten the self-interests of others (individuals, units)" (Porter, et al., 1981, p. 112). The second is the body of power literature from various disciplines summarized in chapter two, and the third is the typology of political behavior depicted in Figure 1. Validity was tested through the three hypotheses of the instrument: (1) various political behaviors can be presented by the in-basket respondents, (2) these behaviors will range from ineffective to effective solutions to organizational situations, and (3) the political behaviors expressed will vary with the type of problem presented.

$\underline{\text { Reliability }}$

Reliability, which is stability of measurement over time, has been directly attributed to the training of the assessors (Gill, 1982) and to the quality of the scoring key. The ETS origins of the in-basket 
have contributed greatly to the psychometric knowledge of scoring reliability. Using the results of two scorers of the in-baskets and split half scores which are correlations between odd and even test item scores, Frederiksen (1957) attested to high degrees of reliability in the scoring of in-baskets. This interrater reliability has been a hallmark of in-basket simulations (Mackinnon, 1975). The continual effort to design structured interviews and action plan reports has also improved reliability.

No single research project on the in-basket has been comprehensive enough to answer all the validity and reliability issues at once. As Lopez summarized, "the procedure has been that each succeeding investigator has stood on the shoulders of his predecessors to gain a longer and wider view of the problem" (p. 86). To summarize, the major studies and their researchers have been the following:

1. The Air Force - Norman Frederiksen

2. Management Progress Study - Douglas Bray

3. Be11 System - Joel Moses

4. Bureau of Business - Norman Frederiksen

5. School Administration Study - John Hemphi11

6. Harvard Business School - Lewis Ward

7. IBM - Walter McNamara and William Dodd

8. General Electric - Herbert Meyer

9. Port Authority - Felix M. Lopez

10. Sears \& Roebuck - V. Jon Benz

Part two of this chapter explains the procedures or processes that were followed in the Meret in-basket development. 


\section{The Procedure and Design Facets of}

the Meret In-Basket Development

\section{The Dimensions}

All in-basket instruments focus on particular dimensions of behavior, sometimes called competencies, thus the Meret in-basket focuses on a variety of political behaviors drawn from the literature. As first constructed, the Meret in-basket had 11 behavioral dimensions. After the first tryout, the dimension concerning use of deceit was merged with the information dimension. The former was seen as an illegitimate behavior and the researcher did not want to focus on a negative political tactic. If use of deceit appeared in the responses of the examinees, it could be noted in the information dimension. The final $10 \mathrm{di-}$ mensions are listed in an abbreviated format in Appendix $\mathrm{X}$.

The body of power literature discussed in chapter two emphasizes the importance of one's need for power, therefore, the first dimension addresses this construct. Dimensions two through nine are derived chiefly from Farrell and Peterson's (1982) typology of political behavior (Figure 1). The merger simulation could have evoked behaviors such as lawsuits and threats, but this was not likely so these dimensions were not examined. The 10th dimension, the Sense of the Organization, is a traditional in-basket consideration. It is often termed differently as extraorganizational sensitivity, sensitivity to social subtleties, stakeholder sense, and appreciating existing organizational values and customs. One of the expert judges for the research project who has extensive assessment center experience strongly recommended this 10th dimension's inclusion though it does not clearly appear in 
the literature as a specific political competency (B. E. Griffiths, personal communication, January 10, 1986). The 10 dimensions are as follows:

1. Self-interest, Power: ambition and desire for influence, wanting power ( $\mathrm{n}$ power), the power motive, independence, dominance, and superiority.

2. Coalition Building: alliances and coalition building with other individuals and units, developing and maintaining a power base. (Independent of the formal structure, coalitions are explicitly created by their members for a specific purpose. Coalitions must act as a group, e.g., joint 1 y signing a memorandum.)

3. Neutralizing Opposition: neutralizing or destroying stakeholders, e.g., firing, ignoring, reprisals, blocking, attacking or blaming others. (Scapegoating and blaming are usually reactive. Proactive attacking is more personal and is usually geared toward reducing competition with a rival.)

4. Gaining Support: gaining support from higher levels, aligning with powerful others, clearing the investment with the immediate boss, ingratiating oneself with one in authority, praising, establishing good rapport, and touching bases.

5. Use of Information: using information as a political tool, e.g., withholding, distorting, using information to overwhelm others, outright lying or falsifying in some instances, using selective disclosures or innuendoes, whistleblowing, and overwhelming the target with data to obscure a piece of information. 
6. Using Resources: using material and physical resources, accessing information, securing personnel assignments, equipment, or space as political tools. Also, collecting data, garnering real or symbolic resources to support one's position.

7. Exchanging Favors: exchanging favors, horse trading, deve1oping quid pro quo deals, making payoffs in exchange for support, and performing services or favors to create obligations.

8. Outside Activity: talking with a counterpart from another organization or engaging in outside professional activity.

9. Bargaining, Compromising: bargaining, negotiating, compromising, usually with regard to issues and policies.

10. Sense of the Organization: stakeholder sense/analysis, understanding organizational dynamics and the macroview, and knowing the gatekeepers and power centers.

The Choice of the Situation

The Madison et al. (1980) study called attention to managers' perceptions of political behavior in organizations. The most political situation in the managers' opinion was reorganization changes, followed by personnel changes. Other environmental pressures conducive to political activity included budget allocation, dealing with outsiders, policy changes, conflicts, status or ego involvement, and traumatic change or pressure. This discussion in the literature served as the job analysis typically performed in the first steps of an in-basket design. The environmental conditions and situations described in the Madison et al. study were specifically political job elements. A 
merger situation was chosen because it could encompass many of the political elements enumerated, including traumatic change or pressure.

A merger situation offers countless possibilities for testing one's political propensities. The literature on mergers presents a common picture of the human problems associated with any merger such as resignations, positioning for higher assignments, sabotage by employees, decrease in morale, and general confusion (Boland, 1970; Chiara, 1985; Ferguson \& Doig, 1982; Marks, 1982; Shirley, 1977).

A merger of two publishing companies was selected for the Meret simulation because of the apparently general and direct nature of that business. Publishing would be fairly easy for the pilot groups to understand. It would not deter an electronics or health professional to make decisions whereas an electronics professional might be totally lost in a hospital setting and vice versa. Concurrently, to attract the interests of electronics and health professionals and other subsets of the pilot groups, the publishing companies of the simulation specialized in computers, medical and academic materials. Both publishing companies, as described in the newspaper article (Appendix C), were profitable--an attraction for the financial professionals. In summary, there was simulation material to capture everyone's interest, yet the publishing environment was broadly defined so as not to turn anyone away .

A Synops is of the Meret simulation, Instructions for the Participants, and Administration Procedures

The in-basket items were developed from merger case studies
(Chiara, 1985; Ferguson \& Doig, 1982; Marks, 1982; Shirley, 1977),


the 10 dimensions and the various situations of the Madison et al. (1980) study. The participants first are given some preliminary instructions. These instructions include background information, a Meret organization chart, and a newspaper article on the merger of Meret and Muse publishing companies, and instructions (Appendixes A, B, C). The administrator reads aloud the brief background sheet, and then the group has about 10 minutes to become familiar with the background of the organization by reading the newspaper article and organization chart. The participants in the group are assigned the identity of Chris Wallace, the Manager of Human Resources of Meret Publishing Company. Participants are given a table-tent name card with his or her new identity and title on it. These first few minutes are critical as they set the stage for the simulation.

To involve the participants as quickly and fully as possible, the next element in the in-basket is a teleconferencing-type announcement from a senior vice-president of Muse, the acquiring firm. A two minute video presentation from the executive is played twice (Appendix D). This announcement gives further directions for the simulation and refers to materials that the participant would soon receive.

To summarize the simulation thus far, the participants are Chris Wallace of Meret Publishing Company in Ramona, California. The very profitable Muse International from St. Louis has purchased Meret, the senior vice-president from St. Louis has asked three administrative managers from Meret to choose one coordinator from among themselves to reorganize the administration at Meret. The three managers also receive word from Muse that their boss has resigned because of the 
merger. Up to this point, the participants have clear instructions and the necessary background information to complete the simulation.

The participants then receive an envelope addressed to Chris Wallace (Appendix E) containing the following materials: a message from M. Waller, the director of marketing; a sealed envelope from Bryan Emerson, the Muse senior vice-president who was in the video teleconference; a letter of resignation from their boss, Charles Goodwin; a computer memo from Everett Carlson; and a sealed envelope with a note from C. Burns, the secretary (Appendixes G, H, I, J, K, N, O, P, Q). Paper, pens, message forms, and a calendar are also in the envelope. The final set of directions is placed on top of all the materials inside the envelope (Appendix F). The administrator reads these final directions to the participants. From this point on, the participants are given one hour to complete the in-basket.

Synopsis. The first item is a message from the marketing director, Waller, who is seeking advice from Wallace (Appendix G). The envelope sent by Bryan Emerson, Muse's vice-president who appeared on the video, contains a two-page outline for Wallace to complete. On this out 1 ine is a yellow post-it note stating: "Chris--You are my \# I choice for the position. Make your case well to justify my intuition! Bryan" (Appendixes $\mathrm{H}, \mathrm{I}$ ).

A letter of resignation from Wallace's boss, Charles Goodwin, is the third item and it contains valuable information for Wallace (Appendix J). Next, a computer printout memo from Everett Carlson indicates that Wa1lace was examining an automated personnel system (Appendix $\mathrm{K}$ ). Carlson is a senior editor at Muse. 
The last item in the in-basket envelope is a sealed envelope containing three, two-page performance reviews on J. D. Ulrich, Pat Ramirez, and Chris Wallace. The performance reviews provide information on Wallace's two peers with whom Wallace is in competition for the coordinator's position. They also gave Wallace a picture of his or her strengths (Appendixes $\mathrm{N}, 0, \mathrm{P}, \mathrm{Q}$ ). After the examinees read these materials, about 15 minutes into the in-basket hour, a tape of two telephone messages is played after the following verbal instructions are read by the administrator: "You notice your answering machine is blinking; you play your messages through twice."

The two messages are brief. One is from Bruce Farley, present1y the supervisor of general administration under Ramirez, and it mentions a rumor about J. D. Ulrich taking Goodwin's place. The other message is from Pat Ramirez, Muse's manager of the legal department. A female voice mentions the new position and implies that Wallace owes favors to Ramirez (See transcriptions, Appendixes L, M). Consequent1y, Wa1lace is in direct competition with Ramirez and U1rich, and as typical within mergers, rumors are spreading already.

With 10 minutes remaining of the hour, participants are given notice of the time so they can finish the exercise; most completed within the hour.

Administration. All of the items, directions, and other materials were pretested by six high-level managers for clarity and content validity and then the instrument was administered to the first pilot group on January 21, 1986. After the first pilot group completed its work, a 
few minor changes were made to the items and the administration. These changes were as follows:

1. The direction, "Use the information at hand", was added to the final instructions because several participants complained of not having enough information to make their decisions. That is a frequent complaint in simulations.

2. The statement, "In-basket items as of late Friday afternoon, March 14, 1986", was added to the front of the large in-basket envelope (Appendix E). A few of the participants thought that this entire package was from Emerson when in fact it was not.

3. Everett Carlson's name was added to the organization chart in the senior editor's block. Although he was defined as a senior editor in the computer area of the company, several participants were unsure of who he was or how powerful he might be. They seemed to want the security of having him on the chart. His memo reflected this change (Appendix K).

4. In the Waller message, the name Cathy was substituted for another female name. Cathy was on the organization chart and the other name was not (Appendix G).

5. In the administration outline, Emerson's name was added to the outside envelope and his rank was restated in the first sentence on the out line (Appendixes H, I). Again, a few examinees were unclear as to who Emerson was, though it was mentioned in the background information (Appendix A). 
6. Finally, because a few were unclear why Chris Wallace received the confidential performance reviews, this statement was added to the sealed envelope with Chris's name on it:

"I came upon these in clearing C. Goodwin's desk and thought you should place them in the confidential personnel files. Thank you, C. Burns"

In $a 11$, there are seven items in the actual in-basket that require a response or action. No changes were made in the administration of the simulation (Appendix S).

The Interview and the Action Report Form

After completing the in-basket, each participant in both pilot groups was interviewed and required to complete a form about the simulation. Both of these data collection procedures were included in the research experiment to enrich the understanding of political behavior and to confirm the results of the simulation. The interview explored why the respondents acted politically through these questions:

1. What did you think of the Meret situation?

2. What did you do for each item? (Go through each item, be sure you understand what the participants did, make marginal notes when necessary, probe for reasons decisions were made.)

3. How did you approach the in-basket? (Sort, sequence)

4. What was the most challenging item and why?

5. What experiences and strengths did you bring to the situation?

6. How willing were you to make a decision based on the information at hand? 
7. Do you think that you, as Chris, would have an impact on the organization? (Appendix U).

The interviews for the two pilot groups were conducted by trained assessors and monitored by the researcher. Out of 33 interviews, 26 were completed by pairs of assessors for reliability purposes. Because of a variety of logistical problems, the remaining seven interviews were conducted by individual assessors. The strongest, most senior interviewers were assigned to conduct these seven interviews and the researcher observed each one in turn. Most of the interviews lasted onehalf hour.

While interviewing the participants, the assessors recorded their notes with a red pen directly on the in-basket items (samples in Appendixes $Y, Z$ ). Other notes from the interview were recorded on the interview sheet (Appendix U). The only change on the Meret Interview Form from the first to the second pilot group was the moving of question seven to the second place because of its importance.

The Action Report Form (Appendix V) was designed to address several issues in the simulation and to serve as an open-ended evaluation on the simulation. The form required about 10 minutes to complete. No changes were made on it between the pilot groups.

$\underline{\text { Tryout }}$

The Meret in-basket was administered three times in order to meet the quota of 30 participants. The in-basket was administered to the first pilot group of 13 examinees on January 21, 1986. The second pilot group of 20 examinees entailed two administrations of the inbasket on February 24, 1986 and March 6, 1986. 
Judging and Scoring Key Development

The procedures for judging the Meret in-basket responses are integra1 to the scoring key development. The objective of running pilot groups throughout in-basket construction is to gather sufficient responses from the participants to form a behaviorally anchored scoring key. After the assessors interviewed the participants in the first pilot group, the assessors immediately summarized the essence of each participant's response to the seven items. These summaries were placed on index cards and then categorized with the interview answers onto the list of 10 dimensions. Afterwards, the index cards were presorted by the researcher, item by item, on a range of effective political behavior based on the definition in chapter one. This preliminary sorting of the behaviors was examined separately by each of the three judges and adjustments were made accordingly. The judges examined over 300 behaviors and evaluated their appropriateness to the Meret situation. Each judge was also asked to rank the seven items in order of importance and to assign scoring weights to each item. The judges' assigned weights allowed for a conversion of the raw scores to an adjusted score. This adjusted score is important for it gave appropriate weights to the items which varied in difficulty.

The scoring key was used by two assessors to mark the in-baskets (Appendix W). Each assessor marked all 13 in-baskets of the first pilot group for interrater reliability purposes.

After the assessment for the second pilot group of 20 was concluded, additional behaviors were added to the scoring key, and the judges met as a group to finalize the scoring key, ranking, and weights. The 
judges reached consensus on the items in the scoring key, and then turned their attention to the rankings and weights. Based on the assumption that the rankings should be determined by how critical the items were to Chris Wallace's self interests and how important the items were for Wallace's political effectiveness now and in the future, the following ranks and weights were established.

Item numbers and description

$$
\begin{aligned}
& \text { 1. Waller Message } \\
& \text { 2. Administration Outline } \\
& \text { 3. Letter of Resignation } \\
& \text { 4. Computer Memo } \\
& \text { 5. Farley Message } \\
& \text { 6. Ramirez Message } \\
& \text { 7. Performance Reviews }
\end{aligned}
$$

Two different assessors marked the second pilot group's inbaskets, and the final score totals were calculated. Statistical tests for interrater reliability were also calculated and are discussed in chapter four.

\section{Assessor Training}

Fifteen student volunteers from local universities were trained as assessors for the Meret simulation. (See the assessor training manual in Appendix $\mathrm{AA}$ and the explanatory correspondence in Appendix $\mathrm{BB}$. ) After receiving more than three hours of instruction, including interviewing practice with video feedback, the assessors received several sheets of instructions and feedback notes from the researcher during 
their training (Appendixes CC, DD). The researcher continuously observed the assessors as they interviewed and recorded the data, and she answered questions throughout the interview and data transcribing period. The assessors became familiar with the Meret in-basket, the dimensions, and the definition of political behavior. They verified each other's notes, dimensions, and index cards on each respondent.

The in-basket scorers were trained additionally in how to use the scoring key (Appendix EE). The researcher evaluated the scorers' training after they scored the responses of the first 13 participants. Two new scorers were assigned to mark the 20 in-basket responses of the second pilot group. Changes were made in the scorers' training prior to the marking of the second pilot group's responses to increase interrater reliability. These changes included checking three scores of theirs against the researcher's scores on particular in-baskets before going on to mark all the in-baskets. This procedure allowed for discussion of differences. Emphasis was placed on the three ranges of effective political behavior and their descriptions instead of literal adherence to a particular behavior (Appendix FF). These two additional training components increased the interrater reliability scores by almost 10 points.

The assessors evaluated the entire process as the experiment continued. Several of their suggestions contributed to the thoroughness of the data collection, for example, placing the item exploration question at the beginning of the interview. 


\section{Feedback of Results to Participants}

In volunteering for this research project, the participants were assured of receiving detailed, individualized feedback on their responses to the Meret simulation. They received a letter summarizing the purpose of the research, their score, comments by the researcher, and the dimension sheets (Appendix GG). The dimension sheets included the assessors' synthesis of the individual's responses with specific behavioral examples (Appendix $\mathrm{HH}$ ). The participants also received a sample page from the answer key to illustrate how the scoring was derived (Appendix II). Finally, the researcher invited all participants to an open discussion session on the results of the entire simulation. This session, attended by six participants, lasted $1 \frac{1}{2}$ hours and followed the outline in Appendix $\mathrm{JJ}$.

\section{Pilot Groups and Panel of Judges}

Political behavior is prevalent in every type of organization, therefore a wide variety of organizations is represented in the pilot groups. Responding to a letter received (Appendix KK) from the researcher, 20 professional contacts asked two or three participants of management level from their organizations to participate in the research project. In a packet of materials for the future participants, the research described a decision-making study. The materials also included a confidentiality statement, a consent form, a return envelope, and dates for the assessment (Appendixes LL, MM).

For the first assessment date, participants returned 17 consent forms. Then, acknowledgement letters (Appendix NN), maps and phone calls reminded each person of the designated assessment time and a new 
location. In the first pilot group, 13 attended and completed the exercise. Addressing confidentiality concerns, each participant received a number for all identification, and the assessors called everyone Chris or the number assigned to the person.

To reach the targeted 30 participants, the second pilot group required 17 participants. Out of the 20 new participants registered for the February 24, 1986 session, 9 did not attend, and 2 managers arrived for the simulation as last minute substitutes, which resulted in a total of 13 individuals. Still short 4 people for the goal of 30 , a third session of 7 participants completed the effort.

In summary, because of participant absences for the second pilot group, the in-basket was administered to another group to complete the target number of 30 . Before this make-up group of 7 could be combined with the second pilot group of 13, further statistical analysis of the groups was required. A student $\underline{t}$-Test for independent samples was ca1culated at the .05 alpha level for the scores of both groups. This level would ensure that the null hypothesis of $=2$ for the two groups would not be falsely accepted. The $p \quad .71$ calculated verified the hypotheses that the groups were similar, that no statistical difference between the sample groups existed, and that the groups could be combined. Consequent $1 y$, the group of 13 and the group of 7 were combined and called the second pilot group.

The pilot group participants held such titles as director of finance, deputy city director, administrator, director of special projects, quality control manager, and program engineer. There were five participants from the health field, five from sales and marketing, five 
from finance, four from the active military, six from manufacturing, and eight from the public sector. There were 12 female and 21 male participants.

The judges represented the sample groups in various ways. One judge was a college dean, highly active in the politics of education. The second was a senior executive in a large aerospace firm. The third was the president of a successful consulting firm whose clients included all the subsets of the sample group: manufacturing, health, finance, sales, and the public sector. The judges were selected because of their position, experience, and familiarity with organizational politics; they were not personal or professional associates. They each received an hour's orientation from the researcher on the Meret simulation and research guidelines (Appendix 00). They met with the researcher individually to review the scoring key for the first time after the initial pilot group, and all three met with the researcher to reach a final consensus on the key and the item rankings when the second pilot group had completed its in-baskets. 
CHAPTER FOUR

Results of the Experiment

Introduction

The results of the in-basket instrument development and validation lie chiefly in the scoring key, the scores themselves, and the political dimension analysis materials. Within this information lies the verification of the instrument's three major hypotheses: (1) various political behaviors can be presented by the in-basket respondents; (2) these behaviors will range from ineffective to effective solutions to organizational situations; and (3) the political behaviors expressed will vary with the type of problem presented. These hypotheses are discussed in this chapter. The Meret Interview Form and Action Report data are summarized and compared with the in-basket results for data triangulation. Although not triangulation in the strictest sense, where three different measures of identical content are used, this comparison of three kinds of data about one event supports data accuracy and content validity. Finally, this chapter includes some discussion on the reliability issues of assessor training, panel and rater judgments, and test administration.

Hypothes is 1: Various Political Behaviors Can Be Presented by the In-Basket Respondents

The in-basket item responses and interview answers for each participant were synthesized onto the dimension sheets (Appendix X), immediately after the simulation and interviews so that all the participants' behaviors and reflections could be captured accurately. Hypothesis 1 
was upheld because of the strong evidence of varying political behaviors as recorded on the dimension sheets (Appendix $\mathrm{HH}$ ). A content analysis of the participants' dimension sheets presented a range for each political behavior depending on the particular dimension examined. For example, from examining Neutralizing Opposition the following five categories of behavior emerged:

\begin{tabular}{|c|c|c|c|c|c|c|}
\hline $\begin{array}{l}\text { ignored } \\
\text { compet }- \\
\text { tion } \\
\text { altogether } \\
\text { i }\end{array}$ & b & $\begin{array}{l}\text { avoided c } \\
\text { competi- } \\
\text { tion, but } \\
\text { acknowledged } \\
\text { it }\end{array}$ & $\begin{array}{l}\text { used infor- } \\
\text { mation about } \\
\text { the competi- } \\
\text { tion, rivalry }\end{array}$ & $\mathrm{d}$ & $\begin{array}{l}\text { demoted } \\
\text { rivals }\end{array}$ & $\begin{array}{l}\text { e wanted to } \\
\text { fire or } \\
\text { fired } \\
\text { someone }\end{array}$ \\
\hline
\end{tabular}

A11 10 political dimensions of behavior demonstrated by the respondents afforded similar ranges of behaviors. The most used tactics were Use of Information as a political tool, Coalition Building, and Sense of Organization. Moderately displayed behaviors included Use of Resources, Neutralizing Opposition, Self-interest/Power and Exchanging Favors, and Bargaining/Compromising. The behavior used least was outside Activity. Each dimension, its particular range, and the number of responses are listed in Appendix PP in the order just described. From these ranges one can see that within a particular dimension there are levels of intensity as a participant exercises the behavior. In fact, one may argue that the nondemonstration of a particular tactic may be deliberately political. If that were true, the nonbehavior would probably show up in some other form, such as withholding information.

Hypothesis 2: The Behaviors Will Range from Ineffective to Effective Solutions to Organizational Situations

The assessors summarized each individual's response to the seven in-basket items onto $3 \times 5$ index cards immediately after the interview 
(Appendix $\mathrm{CC}$ ). These explicit behavioral responses of the participants eventually comprised the scoring key. The researcher sorted approximately 40 index cards for each item along a range of effective political behavior and then the judges approved or adjusted the researcher's sorting. In some cases, the judges believed a particular behavior was quite sophisticated, and they moved it into the high range. In other cases, the judges agreed that a particular behavior was unwise, so they moved it to a low or moderate place on the continuum. This sorting and judging occurred after each pilot group and produced the final scoring key (Appendix W).

As shown in Appendix $W$, the respondents demonstrated a wide range of behaviors. Usually, the low or ineffective behaviors consisted of inactivity, avoidance of competition, or indecisiveness. The moderate range contained behaviors that affected some solution to the problem, clarified communications, or recognized political behaviors in others. The high level of effectiveness presented clear, decisive examples of political behavior and acceptable solutions to the items according to the pane1 of judges.

Insert Table 1 about here

In addition to the rich examples of political behavior in the high range of the scoring key, the final effectiveness scores for the 33 participants demonstrate this hypothesis (Table 1). The adjusted scores range from 21 to 89 out of a possible 20 to 100 range. The 33 scores discriminate over 15 levels of low effectiveness, 17 levels of 
Table 1

Scores of 33 Respondents on Effectiveness Range from Low to High

\begin{tabular}{|c|c|c|}
\hline $\begin{array}{l}\text { Low } \\
(20-46)\end{array}$ & $\begin{array}{l}\text { Moderate } \\
(47-73)\end{array}$ & $\begin{array}{c}\text { High } \\
(74-100)\end{array}$ \\
\hline 21 & 47 & 89 \\
\hline 27 & 47.5 & \\
\hline 28 & 49 & \\
\hline 33 & 50 & \\
\hline 33.5 & 51 & \\
\hline 34 & 53 & \\
\hline 34.5 & 53.5 & \\
\hline 35 & 54 & \\
\hline 35.5 & 55 & \\
\hline 37 & 56 & \\
\hline 37.5 & 58 & \\
\hline 38 & 59 & \\
\hline 42 & 61 & \\
\hline 43 & 63 & \\
\hline \multirow[t]{3}{*}{45} & 64 & \\
\hline & 65 & \\
\hline & 69 & \\
\hline 15 total & 17 tota 1 & l total \\
\hline
\end{tabular}

Note. Minimum Score $=20$, Maximum $=100$, Median $=47$. 
moderate, and 1 of high effectiveness based on the weights assigned to each item by the judges. The scoring key provides many examples of highly effective behaviors for the in-basket but, because the items were weighted, only one participant emerged with a high total score.

Insert Table 2 about here

Table 2 illustrates several frequency statistics. The first column lists the adjusted scores for each of the 33 participants. This score is based on the raw scores for each item, and it is calculated so that a perfect score equals 100 points. Column one shows the adjusted scores from the lowest to the highest.

The second column shows the actual count each score received. As the column illustrates, each participant received a different score, except for the score of 37 (calculated as a mode of 36.8), which was obtained twice.

The last three columns show the percentages of relative, adjusted and cumulative frequencies for each score. The columns Relative and Adjusted Frequency are identical because of the single score frequencies and small sample size. The Cumulative Frequency column displays percentages and is useful for further analysis of the scores. The mean of the 33 scores is 47.44 and $50 \%$ of the participants scored 47.40 or less, the median score.

One score, 89 , is 20 points higher than the next best score (69) and as such is an outlier. "An outlier is a research subject whose scores differ remarkably from the general pattern established by the 
Table 2

Frequency and Distribution of 33 Cases

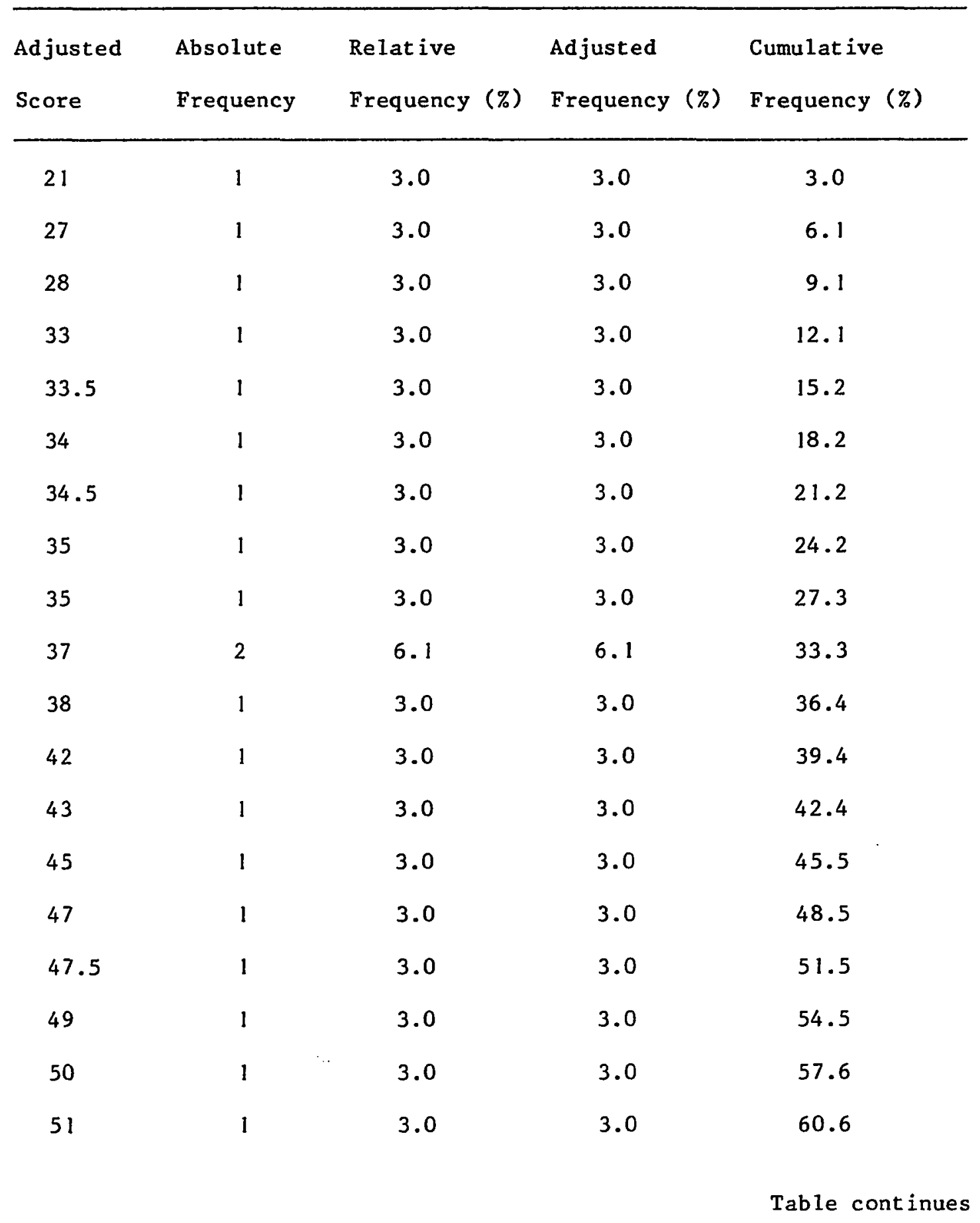


Table 2

Frequency and Distribution of 33 Cases (Continued)

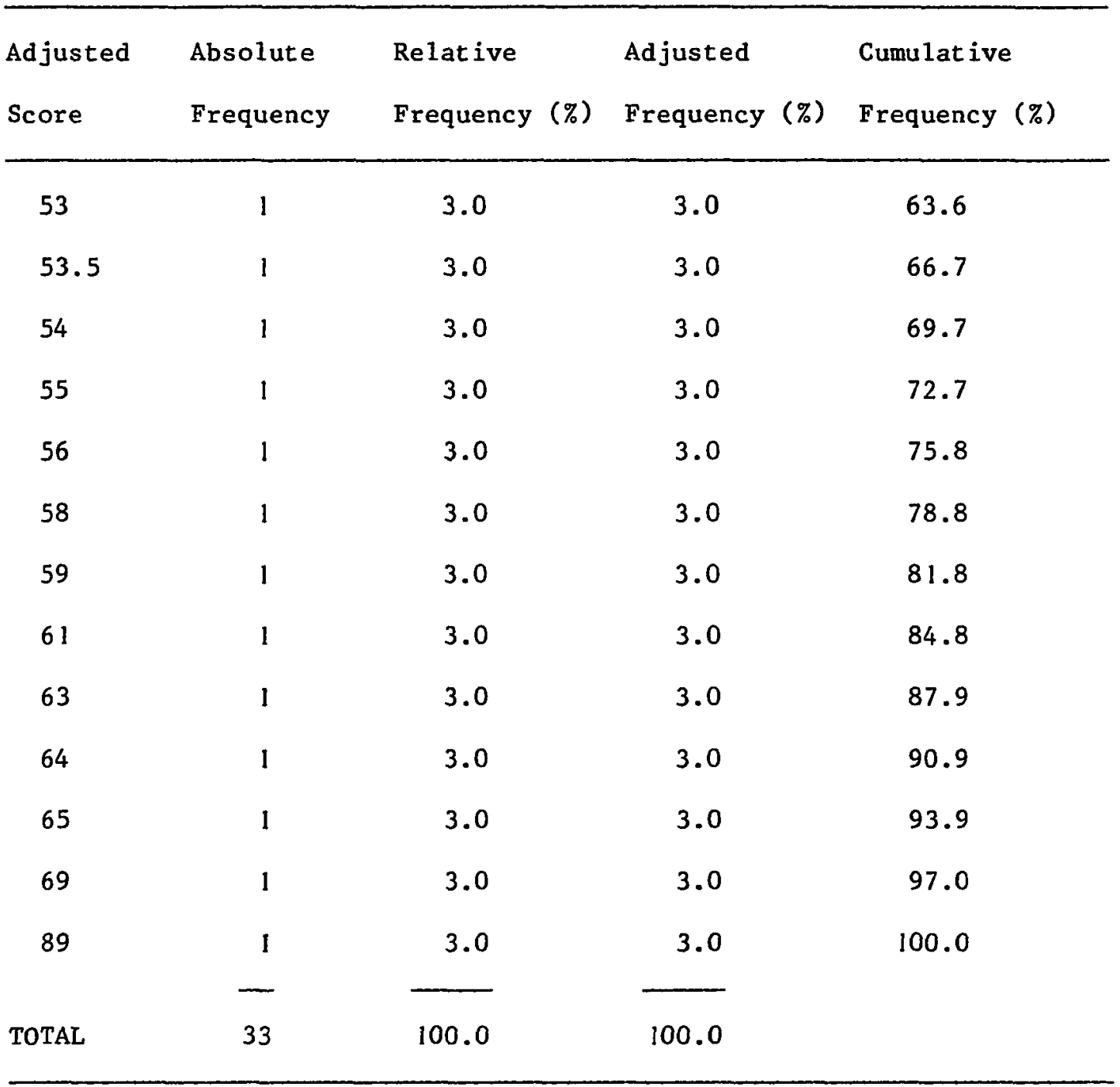

Note. Mean $=47.44$, Median $=47.40$, Mode $=36.8$. 
other subjects in the sample," wrote Borg and Gall (1983, p. 391). In this research, the outlier was included in all the data analysis. Examination of this subject's materials and interview notes actually demonstrated that the in-basket could challenge someone sufficiently. This individual stated his political frame of analysis quite clearly in the interview: "I wanted to know more about internal politics, personalities, sensitive areas, and the politics of the situation." The strongly demonstrated political skills of this individual are examined in chapter five.

In summary, hypothesis 2 is supported by the varieties of political behavior listed in the scoring key (Appendix $W$ ) and in the final adjusted scores of the participants. These scores chiefly extend from the low range to the moderate range of effectiveness, but the instrument picked up one high scoring participant. Out of a possible 33 scores, the instrument discriminated over 30 different scores of effectiveness in political behavior.

\section{Hypothesis 3: The Political Behaviors Expressed Will Vary}

\section{with the Type of Problem Presented}

Hypothesis 3 was examined using the matrix in Appendix QQ. Here the intent was to examine the participants' responses to each item to see if a particular political behavior was consistently demonstrated in that instance. For the majority of the items, any one or more of the dimensions could have been demonstrated.

The 1 ist of considerations for each item that are enumerated at the top of each page in the scoring key (Appendix $x$ ) presents the type of problem offered to the participants. For example, the Waller 
Message is a policy formulation request from a senior person in Muse. In contrast, the Farley Message is a rumor from someone of a lower position in the organization. The Administration outline is a planning-type problem and the Letter of Resignation, a personnel and organizational change issue. The Computer Memo reflects the problem of new technology. The Ramirez Message is a relationship problem. Lastly, the Performance Reviews could be viewed as an ethical dilemma regarding use of confidential information.

To test the third hypothesis, each participant's response to each item was examined one item at a time to see if a response pattern emerged among the pilot groups for that one item or problem. In the Waller Message (Appendix G), for example, an alliance with Waller was sought by 11 respondents as illustrated in Figure 2. They viewed Waller as a resource or an opportunity. Other strong patterns were evident and are summarized next.

\section{Insert Figure 2 about here}

The Administration Outline (Appendix I) evoked various behaviors because of its complexity. The Outline was first introduced by Bryan Emerson in his video instructions, and it required utilization of all the information contained in the in-basket materials. On Emerson's request, Chris Wallace was to submit a reorganization plan that also called for Wallace's self-nomination. Four political dimensions were exhibited above all others: Self-interest/Power, Gaining Support, Using Resources; and Sense of Organization. The other six dimensions 


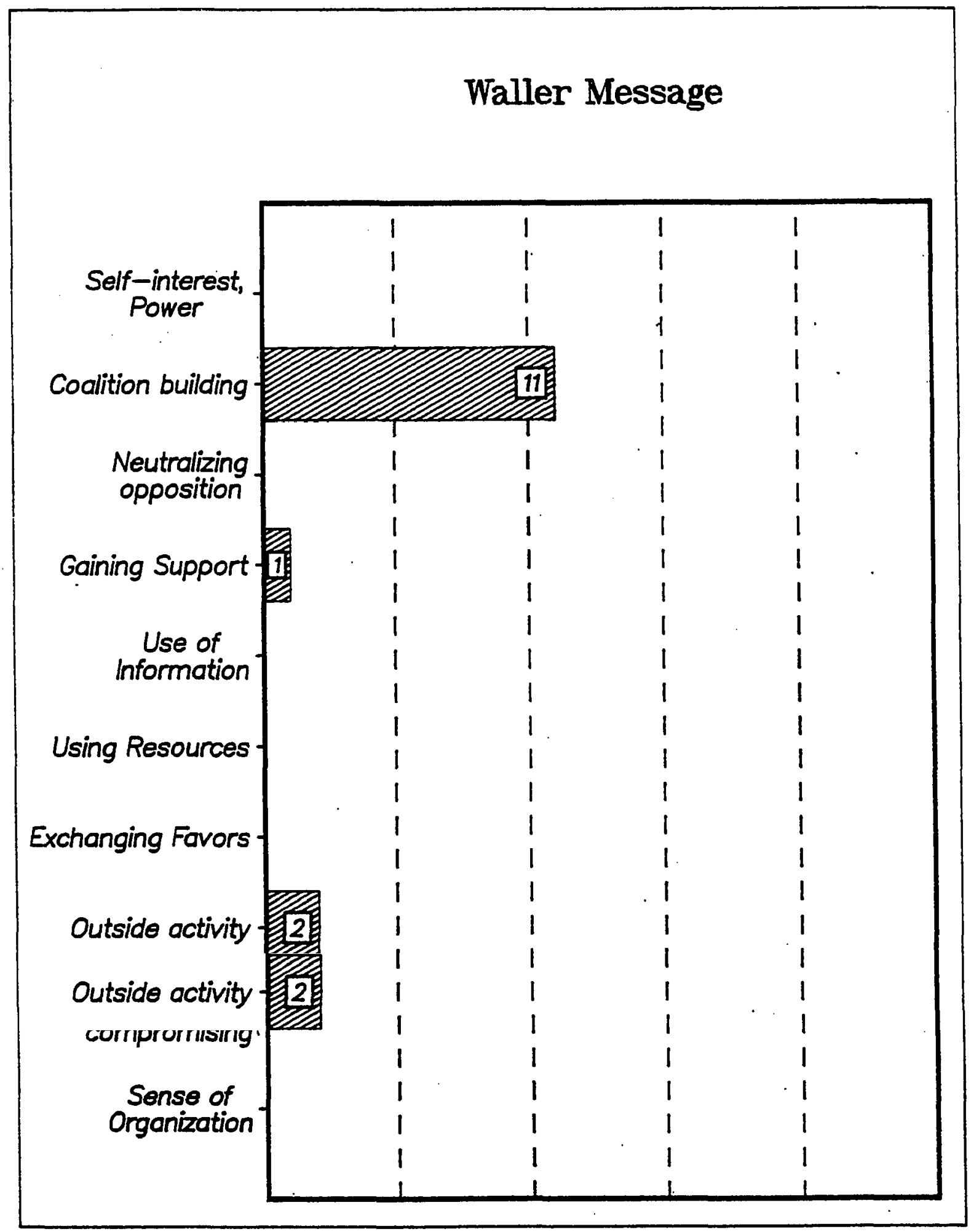

Figure 2. Haller Message: Political Behaviors Exhibited 
were displayed to a lesser degree. In all, 106 political behaviors were demonstrated by the respondents, including repeated behaviors.

Insert Figure 3 about here

The Letter of Resignation (Appendix J) appeared to most participants as a source of valuable information which they did or did not utilize. One half of the participants relied heavily on the information in the letter to plan the Administration outline. On one hand, several participants aligned the Meret financial department with the parent company, Muse, as suggested in Goodwin's letter. On the other hand, information about the infusion of capital and building monies from Muse was overlooked by everyone. This information could have fueled the Use of Resources dimension. Three participants actively sought support from Goodwin, the man who resigned at Meret.

Insert Figure 4 about here

A moderate level of Coalition Building was the principal response to the Computer Memo (Appendix $K$ ) as shown in Figure 5. Nine participants set up a meeting with Carlson to examine the computer program and to work out its implementation.

Insert Figure 5 about here

No dominant pattern emerged from the Farley Message (Appendix L). One half of the group ignored the message or briefly acknowledged it. 


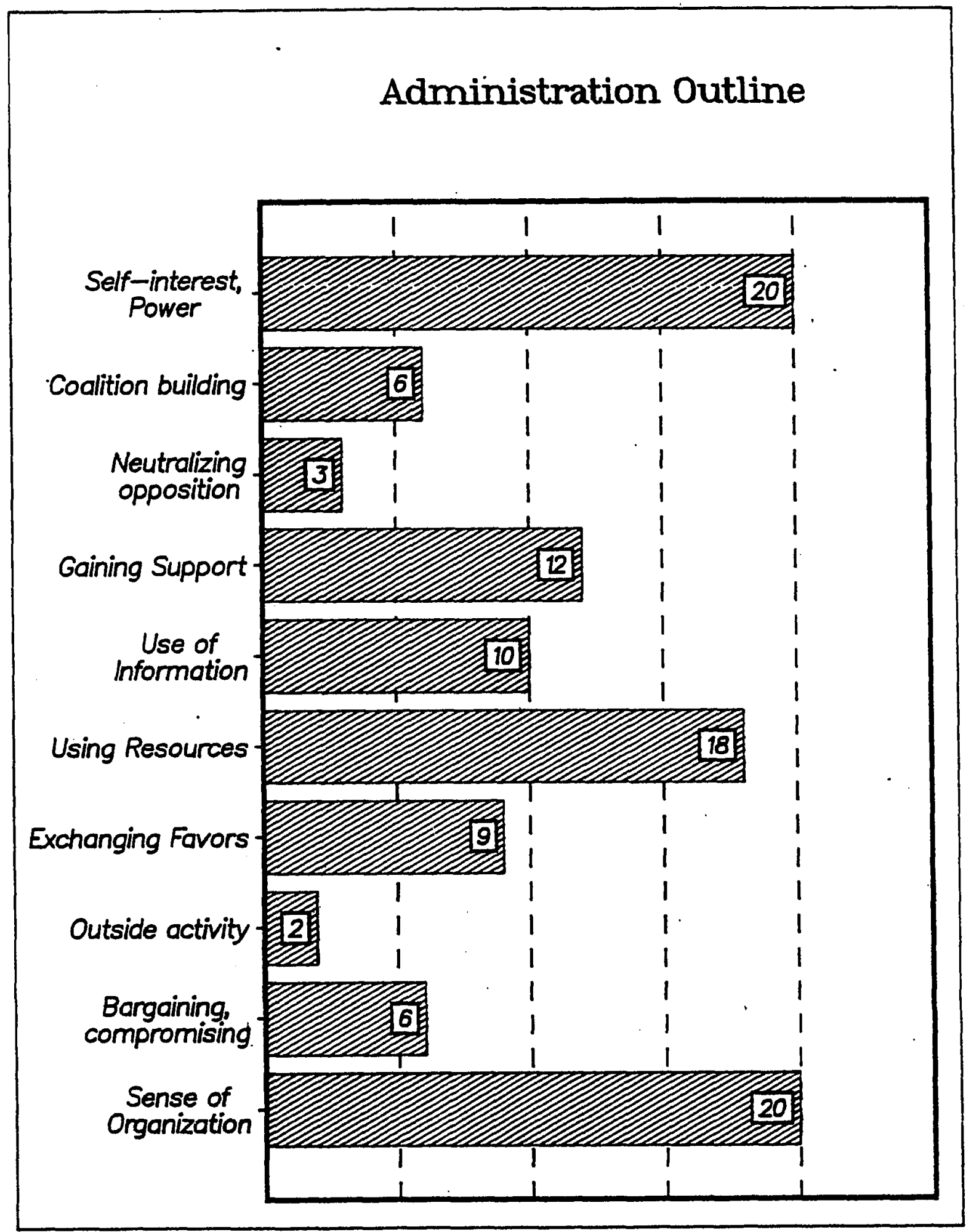

Figure 3. Adainistration Outline: Political Behaviors Exhibited 


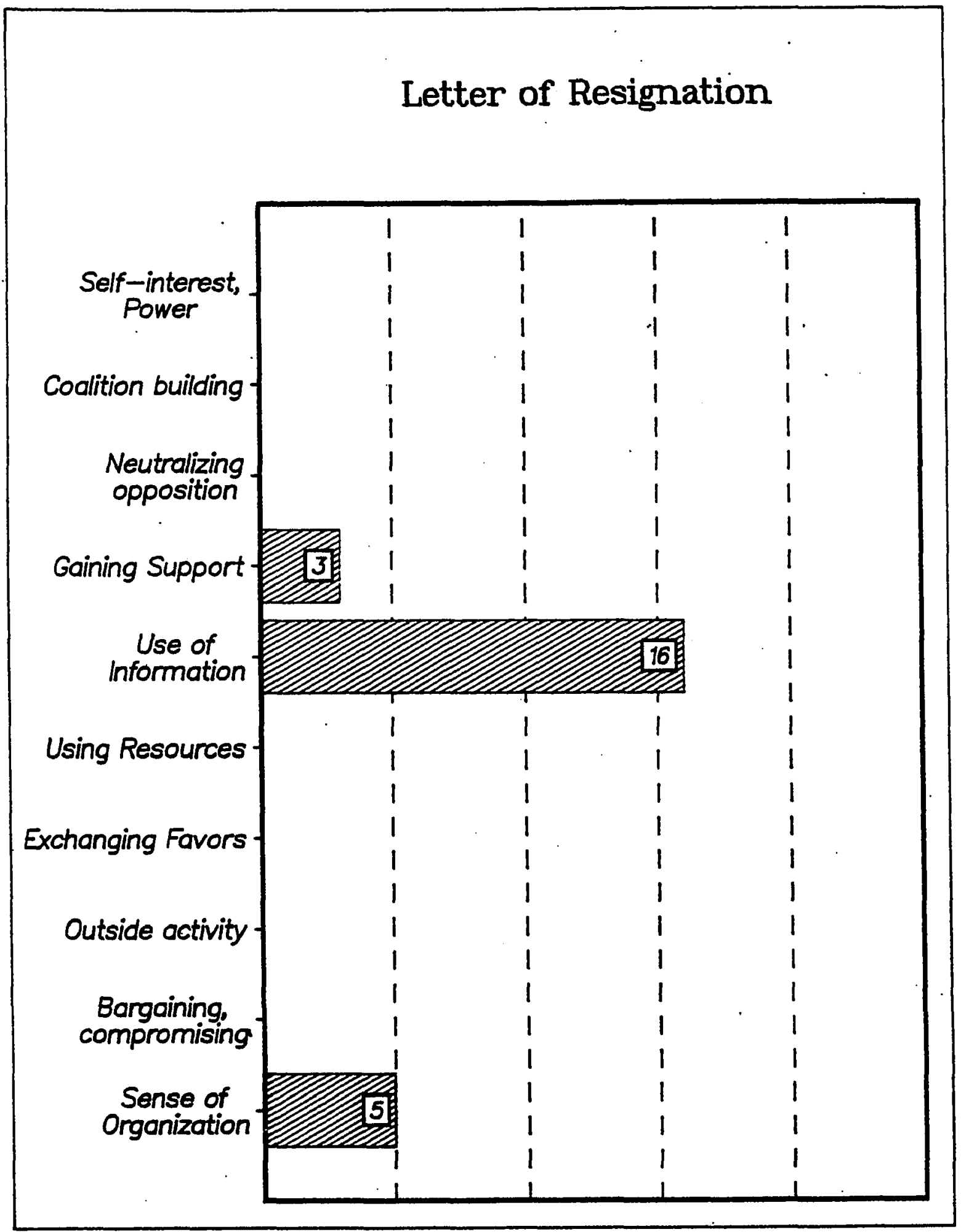

Figure 4. Letter of Resignation: Political Behaviors Bxhibited 


\section{Computer Memo}

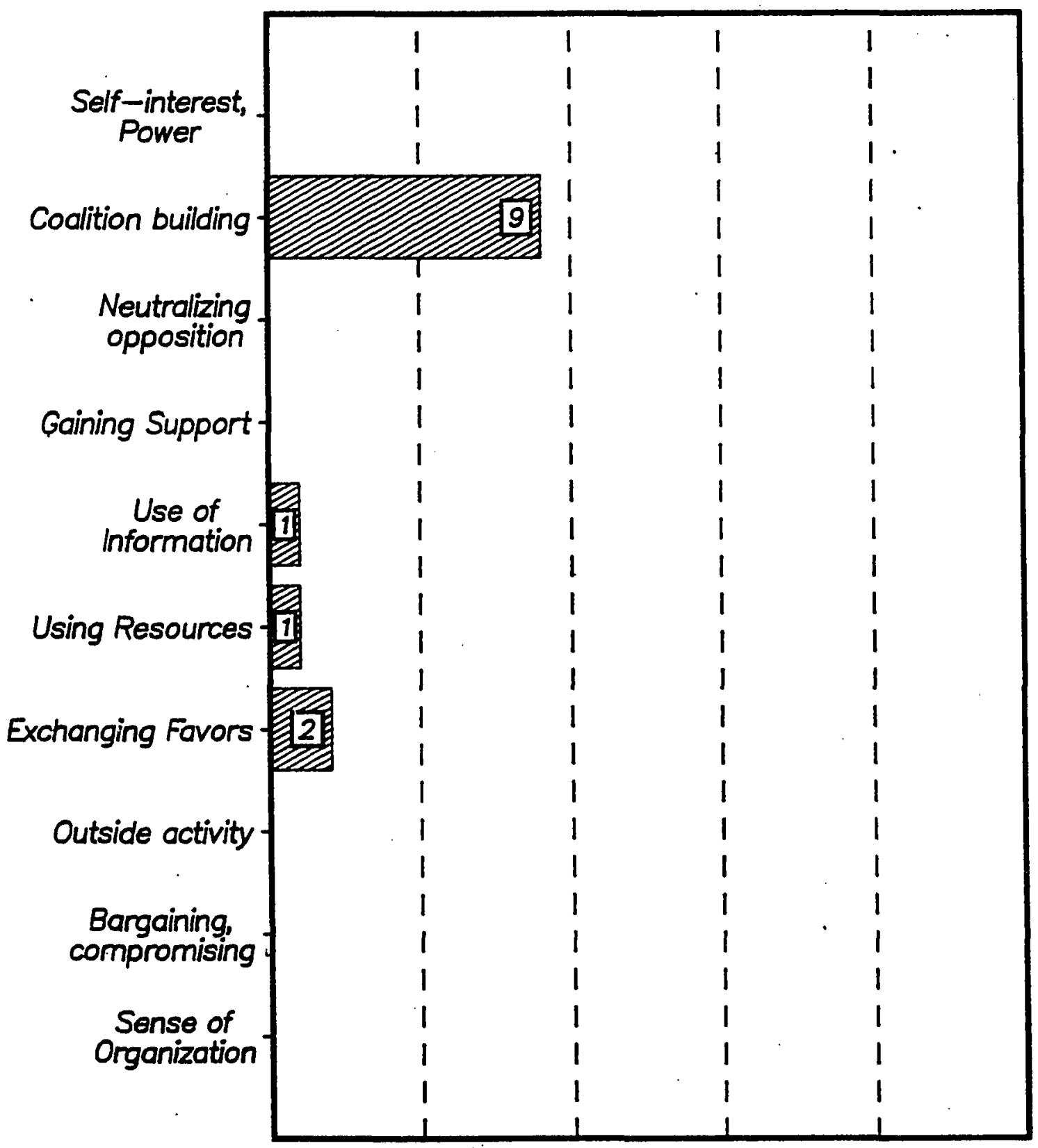

Figure 5. Computer Memo: Political Behaviors Exhibited 
A few demonstrated either annoyance with Farley or very direct political behavior such as promotion of Farley, direct confrontation, or recognition of him as a good source of information.

Insert Figure 6 about here

The Ramirez Message (Appendix M) gave the participants the opportunity to deal with competition and political behavior on the part of someone else. Here a moderate Coalition Building pattern emerged but chiefly as an effort to avoid competition and smooth the relationship.

Insert Figure 7 about here

The majority of participants used the information in the Performance Reviews (Appendixes 0, P, Q) to strengthen their position as Chris Wallace in the company. This information was used by 24 respondents to make decisions and to take action against Ramirez. In summary, the data in Figures 2 through 8 illustrate the patterns of political behavior as demonstrated by the participants and support the third hypothesis.

Insert Figure 8 about here

A summary of the exhibited behaviors illustrated in Figures 9 and 10 also supports hypothesis three.

Insert Figures 9 and 10 about here

Reproduced with permission of the copyright owner. Further reproduction prohibited without permission. 


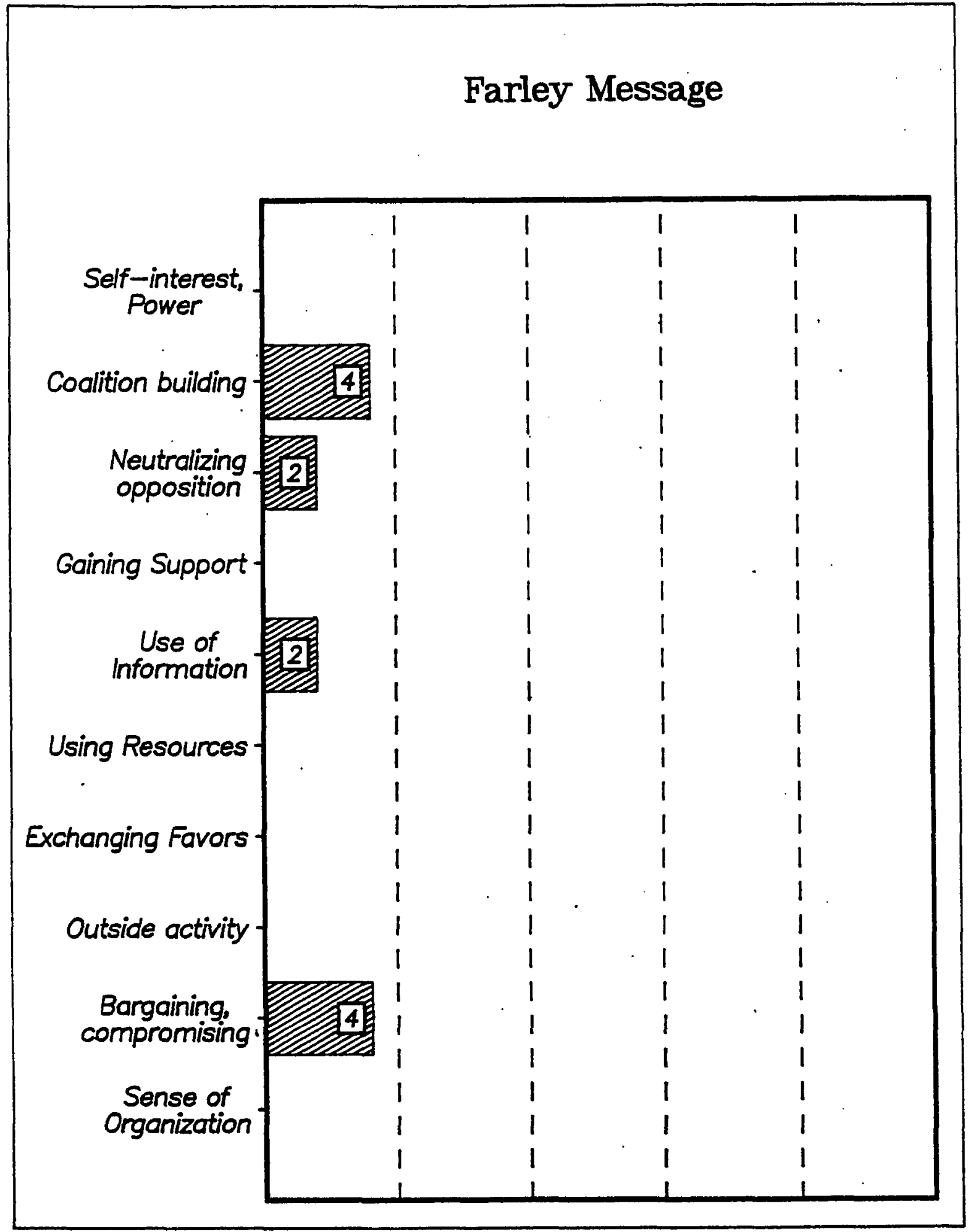

Figure 6. Farley Message: Political Behaviors Exhibited 


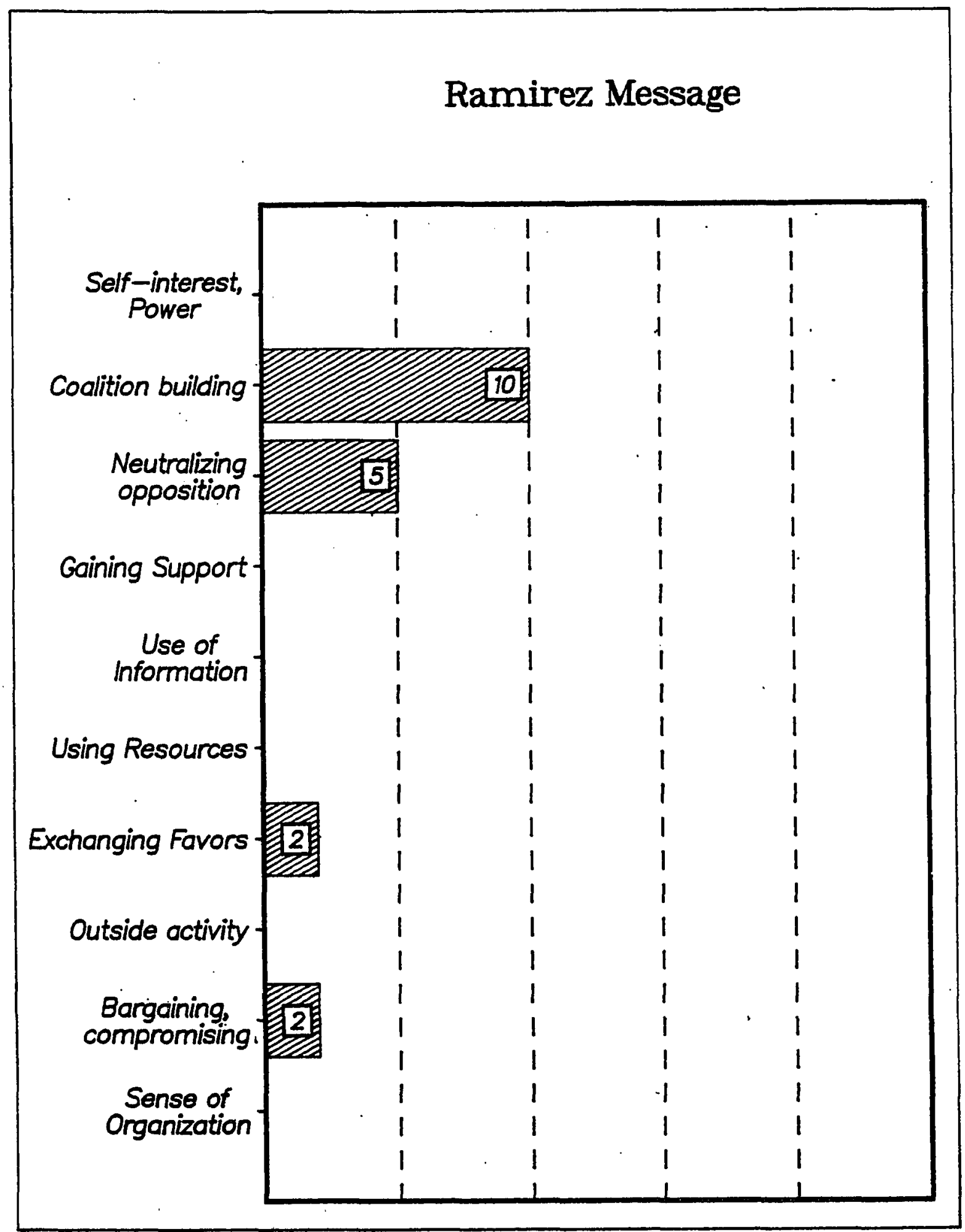

Figure 7. Ramirez Message: Political Behaviors Bxhibited 


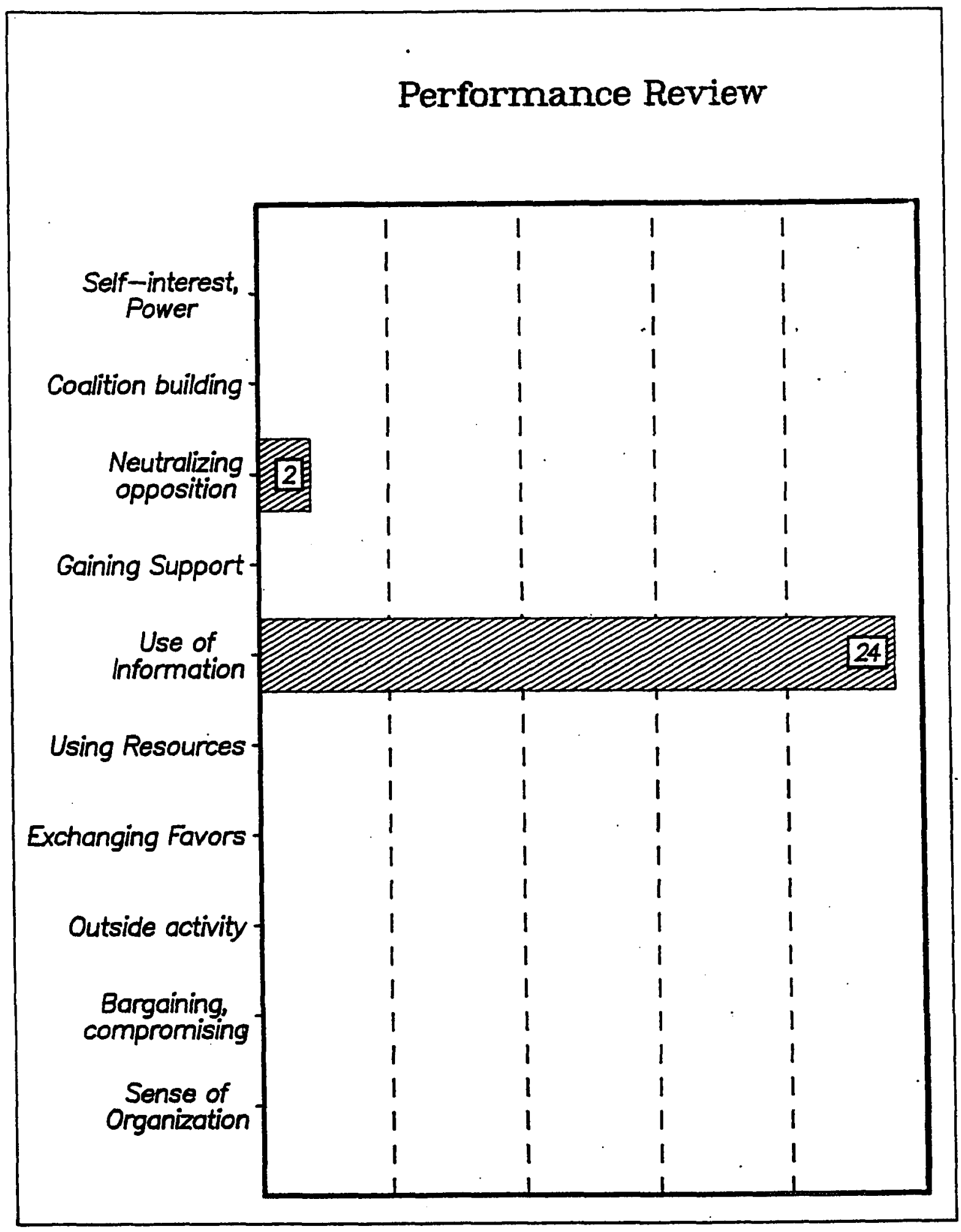

Figure 8. Performance Reviews: Political Behaviors Exhibited 


\section{Frequency of Behaviors over all Items}

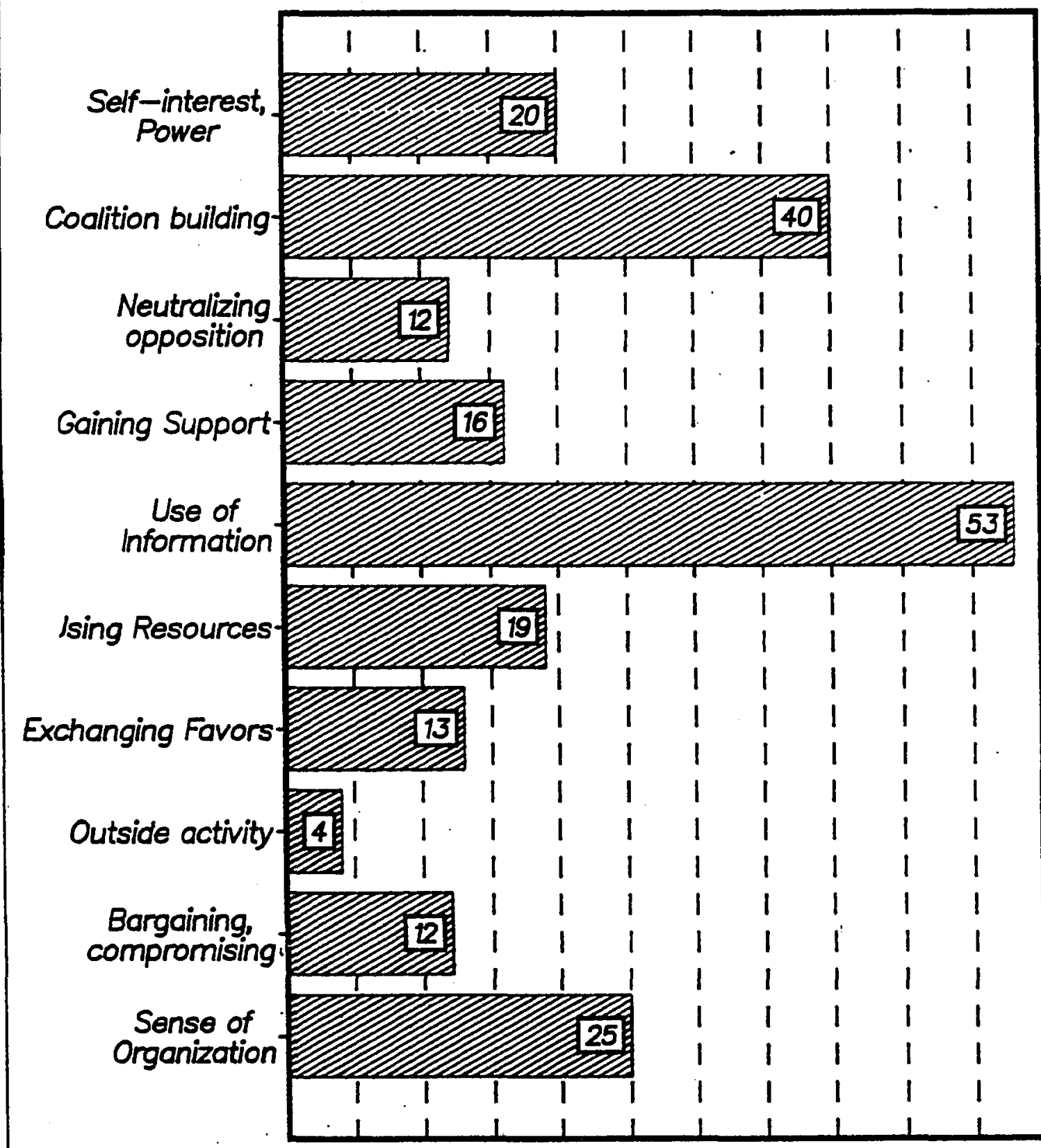

Figure 9. Frequency of Behaviors Over 111 Items 


\section{Totals of Political Activities for Items}

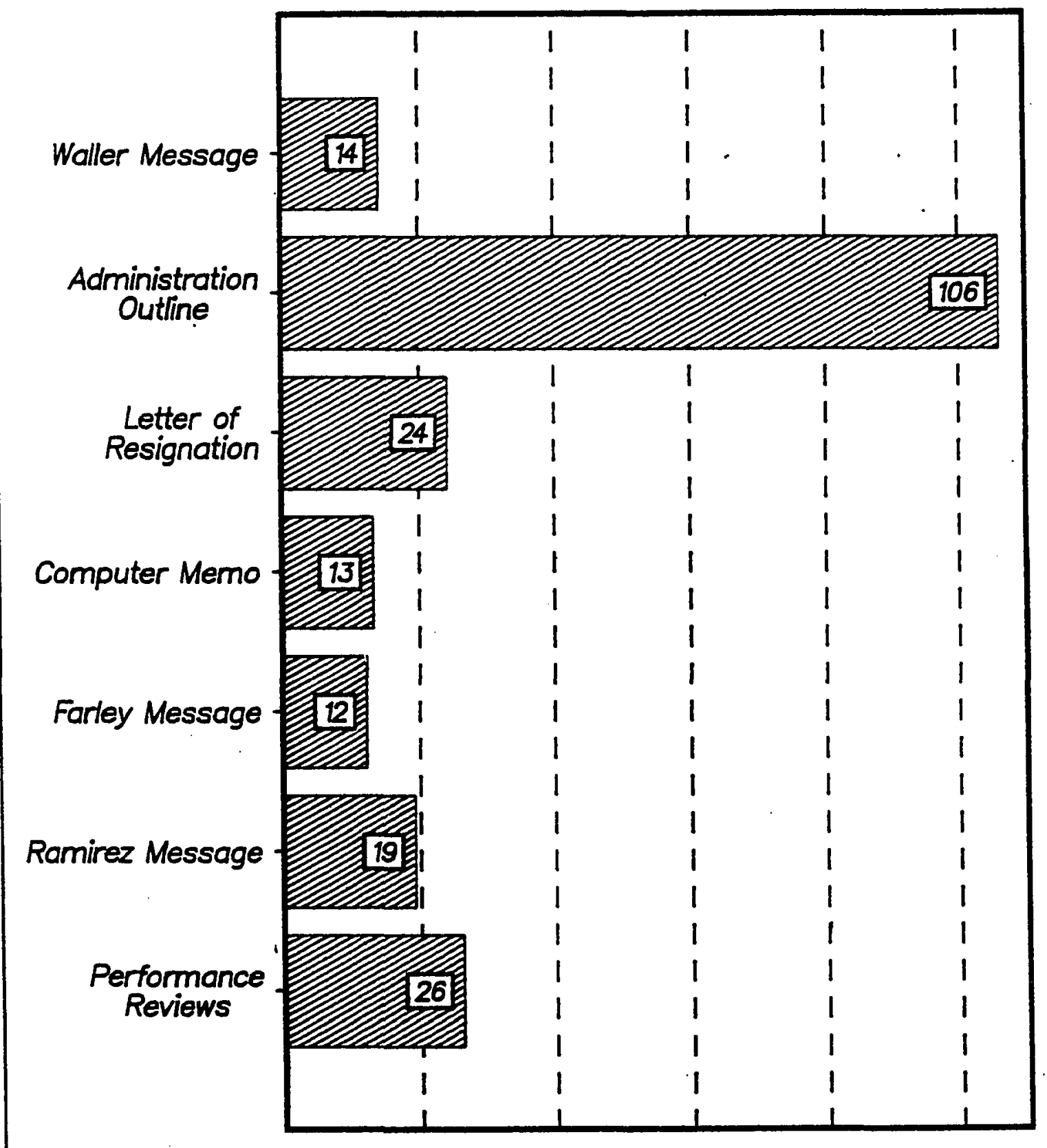

Figure 10. Totals of Political Activities for Items 
Figure 9 represents the totality of political behaviors exhibited across all items. Use of Information was the highest with 53 examples followed by Coalition Building with 40 . Sense of Organization was exhibited 25 times, and the Self-Interest/Power dimension was used 20 times. The lowest behavior was Outside Activity which, in the Meret situation, would have been registered by a specific contact with Muse. In comparison with Appendix PP, which shows ranges of each dimension based on individual summaries, Figure 9 represents a count of actual examples. Such a comparison indicates that two dimensions were exhibited more than once by a participant--Use of Information and Coalition Building. Lastly, Figures 9 and 10 illustrate that the Administration outline evoked not only the most political behaviors of all the in-basket items but also every kind of political behavior in question. Figure 10 shows the tallies of political behaviors exhibited for each item. The Administration outline evoked 106 political behaviors; the Performance Reviews and Letter of Resignation evoked 26 and 24 responses, respectively. This order of activity directly correlates with the participants ranking of criticalness of items which is discussed next in the interview summaries.

The data in Figures 2 through 10 clearly illustrate that there is some order to the tactics exhibited by the respondents and support the third hypothesis. For the Waller Message, Computer Memo and Ramirez Message, Coalition Building is the dominant choice because stakeholders are recognized. Use of Information is appropriate to the Letter of Resignation and Performance Review problems. Lastly, it is not surprising that the major item, the Administration Outline, evoked all 10 
dimensions of political behavior because of its complexity and importance.

\section{Interview Summaries}

The half hour interviews which followed after the simulation centered chiefly on the items of the in-basket. The assessors went through each in-basket item and asked each respondent why they did what they did. About 10 minutes were spent on the remaining questions in Appendix $U$, while the participants' responses were simultaneously transcribed onto the Meret Interview Form by the assessors. Usually one assessor took notes while the other presented the questions. These forms were examined question by question to see what patterns emerged. A summary of these answers follows.

What Did You Think of the Meret Situation?

Answers to this question varied. Several saw the situation as full of opportunity and typical of mergers. Seven participants wanted more information and five found it stressful. A few discussed their concern for more organizational structure. How Did You Approach the In-Basket? (Sort, sequence)

Most participants first sorted the items and then quickly dispensed with the easy ones so that time could be devoted to the out line requested by Emerson.

What Was the Most Challenging Item and Why?

Most participants stated that the Administration Outline was the most challenging, in particular the restructuring of the staff. Reasons why the Administration Outline was most challenging varied from 
one's having to use all the information at hand to its having an impact on Chris Wallace's career.

What Experiences and Strengths Did You Bring to the Situation?

Again, various responses were presented by the 33 respondents. Five minor themes emerged: my ability to work with and communicate with others; changes in my own businesses; my ability to look at the overall situation; my political experience and my exposure to immediate needs. Four respondents said that they had never had a reorganization experience.

How Willing Were You to Make a Decision Based on the Information at Hand?

More than one half of the respondents thought it was easy to make decisions, especially when Emerson called for certain decisions. A few respondents were hesitant or found the decision-making difficult. Do You Think You, as Chris, Would Have an Impact on the Organization?

There was almost unanimous agreement that Chris would have an impact on Meret for two reasons: first, the participants as Chris saw themselves as strong communicators who knew the organization as a whole and, second Chris was a resource person of high visibility.

The Action Report Form

The Action Report Form (Appendix W) gave the participants an opportunity to respond independently of the interviewers upon completion of the in-basket. About 10 minutes were required to complete the form. 
What Three Words Would You Use to Describe the Situation at Meret?

Three themes emerged from the words used to describe the Meret situation in this open-ended question. Out of 99 possible words from the 33 respondents, one-third of the words were negative, such as unsettling, uneasy, uncertain, tense, anxious, dangerous, or confusing. Another third of the words fell into categories like challenge, opportunity, and future growth. The remaining third of the adjectives used by the participants described the situation with words such as change, growth, adjustment and transition. These last two categories of words were used by those who scored significantly higher on the simulation. Most of those who scored above the median of 47 used the more positive words like challenge and growth. A few blamed Meret for its poor organization and only twice was the adjective political used.

Which Three Items Requiring Attention from Chris Wallace are the Most Critical in This Situation?

Question two required a ranking of the criticalness of the items. Emerson's Administration Out line was almost unanimously ranked as the most critical. Other high priorities were the Performance Reviews, the Letter of Resignation, and the Waller message. Table 3 shows the rankings of the items by the participants. Items 7 and 3 were extremely close in ranking, almost tied for second place. Item 1 was next so it is included in the Table.

Insert Table 3 about here 
Table 3

Participants' Ranks for the In-Basket Items

\begin{tabular}{ll}
\hline \multicolumn{1}{c}{ In-basket items } & Rank $^{\mathrm{a}}$ \\
\hline 1. Waller Message & $4^{\mathrm{b}}$ \\
2. Administration Out line & 1 \\
3. Letter of Resignation & 3 \\
4. Computer Memo & \\
5. Farley Message & \\
6. Ramirez Message & \\
7. Performance Reviews & 2 \\
\hline
\end{tabular}

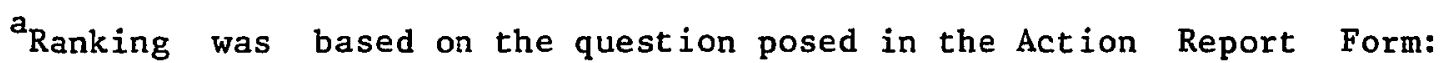
"Which three items requiring attention from Chris Wallace are the most

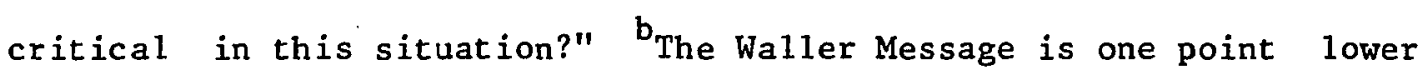
in the composite rankings, so it is included. 
After the first pilot group, when the judges familiarized themselves with the items and the scoring key, they assigned ranks to the seven in-basket items as shown in Table 4 . The judges ranked the items independently. As Table 4 illustrates, all three judges ranked the Administration Outline as the most critical item. This first effort towards a consensus clearly shows disagreement among the judges on the ranks of the next six items. It was not until the judges discussed the items that they reached a consensus.

Insert Table 4 about here

In addition to initial rankings, the judges weighted each item so that the most important items would receive a greater number of points. Although this ranking and weighting was a preliminary one as shown in Tables 4 and 5 , it prepared the judges for the consensus discussion which was held after the second pilot group.

Insert Table 5 about here

The judges met after the second pilot group to discuss the scoring key and to rank and weight the items. They exchanged opinions and formulated the statement on criticalness which they then used to rank the items: "Which items are most critical to Chris Wallace's selfinterest and how important are the items for Wallace's political effectiveness now and in the future?" This question diverged from the question asked the participants: "Which three items requiring attention from Chris Wallace are the most critical in this situation?" The 
Table 4

Judges' Ranks for the In-Basket Items after the First Pilot Group

\begin{tabular}{lccc}
\hline & Rank for & Rank for & Rank for \\
Jn-basket items & Judge 1 & Judge \#2 & Judge \# 3 \\
\hline 1. Waller Message & 4 & 3 & 3 \\
2. Administration Out line & 1 & 1 & 1 \\
3. Letter of Resignation & 6 & 2 & 4 \\
4. $\quad$ Computer Memo & 2 & 4 & 5 \\
5. Farley Message & 5 & 5 & 7 \\
6. $\quad$ Ramirez Message & 3 & 6 & 6 \\
7. $\quad$ Performance Reviews & 7 & 7 & 2 \\
\hline
\end{tabular}

${ }^{a}$ Ranking was based in the criticality of the item. 
Table 5

Judges' Weights for the In-Basket Items after the First Pilot Group

\begin{tabular}{|c|c|c|c|c|}
\hline & In-basket items & $\begin{array}{l}\text { Weight }{ }^{a} \text { of } \\
\text { Judge \# } 1\end{array}$ & $\begin{array}{l}\text { Weight of } \\
\text { Judge \#2 }\end{array}$ & $\begin{array}{l}\text { Weight of } \\
\text { Judge \#3 }\end{array}$ \\
\hline 1. & Waller Message & 15 & 15 & 15 \\
\hline 2. & Administration Outline & 24 & 40 & 30 \\
\hline 3. & Letter of Resignation & 8 & 20 & 10 \\
\hline 4. & Computer Memo & 20 & 10 & 10 \\
\hline 5. & Farley Message & 10 & 5 & 5 \\
\hline 6. & Ramirez Message & 18 & 5 & 10 \\
\hline \multirow[t]{2}{*}{7.} & Performance Reviews & 5 & 5 & 20 \\
\hline & & $=\overline{100}$ & $=\overline{100}$ & $=100$ \\
\hline
\end{tabular}

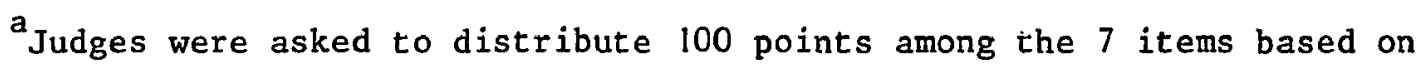
their rankings and the criticalness of the items. 
differences in these two questions may explain the discrepancy between the participants rankings and the judges, as delineated in Table 6 .

Insert Table 6 about here

The judges did not address the criticalness of the Performance Reviews for the immediate situation as the participants did. Rather, as they discussed the situation, they included a future consideration in their question. In fact, the question upon which they based their rankings was their own. They did not refer to the question posed to the participants.

For many participants, and this is the second reason for the discrepancy, the information in the Performance Reviews was very helpful. In contrast, the judges evaluated the process of reviews and believed that performance reviews are generally irrelevant to one's political effectiveness. In summary, the judges looked at the Performance Reviews as routines and the respondents relied heavily on the content of the reviews. Even the judge who originally placed the Reviews in the second place (Table 4; Judge \#3) referred to the importance of the Performance Review in military settings, rather than the importance of the information in the Meret reviews.

Despite this discrepancy, little scoring impact resulted. Very few of the participants scored high on the Performance Reviews and therefore, they were not shorted potential points in the adjusted scores. 
Table 6

Judges' Consensus of Ranks and Weights for the In-Basket Items and

Ranks of the Pilot Groups

\begin{tabular}{llccc}
\hline Item \# & Item & $\begin{array}{c}\text { Judges' } \\
\text { Rank }^{\mathrm{a}}\end{array}$ & $\begin{array}{c}\text { Judges' } \\
\text { Weights }\end{array}$ & $\begin{array}{r}\text { Pilot Groups' } \\
\text { Rank }^{\mathrm{b}, \mathrm{c}}\end{array}$ \\
\hline 2 & Administration Out1ine & 1 & 40 & 1 \\
3 & Letter of Resignation & 2 & 15 & 3 \\
1 & Waller Message & 3 & 14 & 4 \\
4 & Computer Memo & 4 & 12 & \\
5 & Farley Message & 5 & 8 & 2 \\
7 & Performance Reviews & 6 & 6 & \\
6 & Ramirez Message & 7 & 5 & \\
\hline
\end{tabular}

${ }^{a}$ Ranking was based on the question: "Which items are most critical to Chris Wallace's self-interest and how important are the items for Wallace's political effectiveness now and in the future?" ${ }^{b_{N}}=33$. ${ }^{c}$ Composite scores for question number two on the Action Report Form: "Which three items requiring attention from Chris Wallace are the most critical in this situation?" 
Which Decision or Action of Yours as Chris Wallace was the Most Outstanding? In Other Words, About Which Decision Are You Most Confident?

Question three sought information on the quality of the participants' decisions and their levels of confidence in decision-making. The majority believed that their response to the Administration Outline was their best decision, and they recommended themselves for the position.

About Which Decision Are You the Least Confident? Why?

The least confident decisions were either directly related to lack of information in the restructuring process or to relationship issues with Farley and Ramirez.

Did Your Professional Background/Experiences Help You in Any Way with the Meret Situation?

Twenty-two participants referred to previous experiences that had helped them in the Meret situation, such as mergers, restructuring, and handling uncomfortable situations. Open Comments in the Meret Simulation Exercise

The final question provided an open comment section on the simulation. Responses ranged widely with no theme emerging. A few wanted more time and more information. Others described the in-basket as fun, interesting or challenging. One said that it seemed loaded with Machiavellian intrigue.

The scoring key, dimension sheets, Meret Interview Form data and Action Report Form complement one another. In some questions, such as questions one and five on the Interview and the Action Report Forms 
(Appendixes U, V), the participants gave very similar answers. All the data confirmed the importance of the Administration Outline. These data triangulations will be discussed further in chapter five.

\section{Reliability}

Assessor training is one of the most important aspects of assessment centers and in-basket simulations. The thoroughness of the training ultimately contributes to the scoring key development, to the scoring of the in-baskets, the quality of the feedback provided the participant, and to the significance level of the reliability statistics. These factors interrelate and substantiate the initial reliability estimates for the Meret in-basket.

The assessors received 3 hours of training as outlined in the manual (Appendix $A A$ ) and further training before and after the first pilot group. The most important aspects of this training emphasized the dimensions, the items of the in-basket themselves, and the importance of interview skills. The assessors actually practiced on interviewing each other and received constant feedback from the researcher and the other assessors. Using a video camera was very effective for this practice time because of the quality of feedback it affords. The teams of interviewers were paired up carefully by the researcher to balance their ages and experience.

The first sample group was actually the major practice run for the assessors. Assessors were given additional notes, sample in-basket items, and suggestions before the simulation (Appendix RR). During the first pilot test of the instrument, the researcher observed the assessors continuously and commented afterwards on their particular 
strengths. The assessors were enthusiastic about the interviews they were intrigued by the differences among the participants. The researcher checked each assessor's written index cards, dimension sheets, and other materials for accuracy and adherence to the dimensions. After the first sample group, examples of good index card summaries and dimension sheets were sent to the assessors with an accompanying letter of encouragement (Appendix CC). The assessors needed only minor interview adjustments. Their questions to the researcher were centered chiefly on the dimensions.

The two assessors from this group who volunteered to mark the 13 in-baskets of the first sample group received additional training (Appendix EE). They were given an explanation of the scoring key, its use, and the ranges of effective political behavior. A scoring sheet was provided for each participant (Appendix SS). Both raters worked slowly at first, becoming familiar with the key but in the end, each finished in 3 hours averaging 15 minutes on each in-basket.

The panel of judges approved the first draft of the scoring key (Appendix W) which the scorers used to mark the first pilot group's results. Not until the judges reached a consensus on all the item ranks and weights was a scoring conversion calculated. The weighting task presented the judges with a different task. For numerical simplicity, a total weight of 100 was assigned by the researcher for all seven items. The judges reached a consensus on the distribution of the 100 points so that a scoring conversion could be tabulated. Table 5 presents the scoring conversion equation. The maximum raw score for each item is five (see Appendix $\mathrm{W}$ to understand how the scores are assigned 
to specific behaviors) and the adjustment factor was calculated by dividing five into the weight assigned by the judges, giving the adjustment factor. The adjusted scores are calculated by multiplying the raw score by the adjustment factor.

Insert Table 7 about here

Once the raw scores of the first pilot group were converted using the judges' formula, the interrater reliability for the first pilot group was computed using the Pearson correlation for each item and then averaging the seven scores. Table 8 displays the item-by-item correlation for each rater and the level of significance for each item. Three weak items emerged from this analysis: the Administration Out line, the Farley message, and the Ramirez message. Consequently, these three items were carefully analyzed and appropriate adjustments were made in assessor training and in the scoring key before the second pilot group was evaluated.

Insert Table 8 about here

Following are the item scoring problems and the changes for the second pilot group. 
Table 7

Scoring Conversion from the Raw Score to the Adjusted Score

\begin{tabular}{llccc}
\hline & Item & Maximum & Adjustment & Adjusted \\
Item \# & Description & Raw Score $^{a}$ & Factor $^{b}$ & Score $^{c}$ \\
\hline 2 & Administration Outline & 5 & 8 & 40 \\
3 & Letter of Resignation & 5 & 3 & 15 \\
1 & Waller Message & 5 & 2.8 & 14 \\
4 & Computer Message & 5 & 2.4 & 12 \\
5 & Farley Message & 5 & 1.6 & 8 \\
7 & Performance Reviews & 5 & 1.2 & 6 \\
6 & Ramirez Message & 5 & 1 & 5 \\
\hline
\end{tabular}

Note. The adjusted score total equals 100 points, the highest score a person can obtain for effective political behavior in the in-basket.

Maximum Raw Score is the highest score any participant can obtain on the range of political behavior as described in the Scoring Key

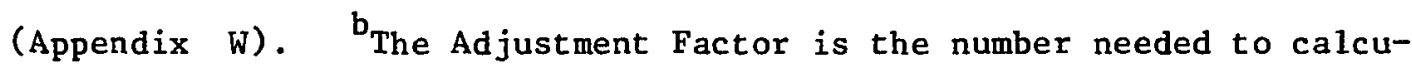
late the weight assigned by the judges for each item. ${ }^{c_{T h}}$ The Adjusted Score is the highest possible score that a participant can obtain derived from the Raw Score times the Adjustment Factor. 
Table 8

Interrater Reliability Scores of First Pilot Group,

Means, Standard Deviations, Pearson " $r$ " Coefficients Between Two

Scorers' Independent Ratings of the Seven In-Basket Items (Raw Scores)

\begin{tabular}{|c|c|c|c|c|c|c|}
\hline \multicolumn{2}{|c|}{ In-basket items } & \multirow{2}{*}{$\frac{\text { Mean } x^{a}}{2.7692}$} & \multirow{2}{*}{$\frac{\text { Mean } \mathrm{Y}^{\mathrm{b}}}{2.0769}$} & \multirow{2}{*}{$\frac{S D x^{a}}{1.3009}$} & \multirow{2}{*}{$\frac{S D Y^{b}}{.9541}$} & \multirow{2}{*}{ Pearson " $\mathrm{r}$ " } \\
\hline 1. & Waller Message & & & & & \\
\hline 2. & Administration & & & & & \\
\hline & Out line & 3.6154 & 2.6923 & 1.0439 & 1.1821 & .5714 \\
\hline \multirow[t]{2}{*}{3.} & Letter of & & & & & \\
\hline & Resignation & 2.2308 & 2.0769 & 1.5359 & 1.4979 & $.8972^{* *}$ \\
\hline 4 . & Computer Memo & 2.3846 & 2.4615 & 1.5021 & 1.5064 & $.7989 * *$ \\
\hline 5. & Farley Message & 2.0769 & 2.4615 & 1.0377 & 1.1266 & .3948 \\
\hline 6. & Ramirez Message & 2.7692 & 2.0769 & 1.6408 & 1.4979 & $.6860 *$ \\
\hline \multirow[t]{2}{*}{7.} & Performance & & & & & \\
\hline & Reviews & 2.6154 & 2.3846 & 1.6093 & 1.4456 & $.8570 * *$ \\
\hline
\end{tabular}

Note. $\mathrm{n}=13$, Mean $=.71$

$a=$ Rater A. $\mathrm{b}=$ Rater $\mathrm{B}$

** Significant at .001 level. * Significant at .005 level 
Scoring problems in first sample group

a. A few participants' responses to the Farley and Ramirez messages were not recorded anywhere on paper because they were taped audio messages; therefore, raters assumed these items were ignored and gave 1's to the participants. line elicited a wide variety of behaviors. In some instances, raters centered on only one or two behaiors on the scoring key and failed to see the item as a cumulative whole.
Changes made to scoring key and rater training

The raters used the index card item summaries for these items. (See Appendix TT for the revised Meret Interview Form.)

$$
\begin{aligned}
& \text { A NOTE was added to the } \\
& \text { scoring key: "This item is } \\
& \text { critical. For a } 5 \text { score, } \\
& \text { several behaviors in the High } \\
& \text { Column must be demonstrated, } \\
& \text { as well as behaviors in the } \\
& \text { Moderate column. Also, if a } \\
& \text { participant fires Pat Ramirez } \\
& \text { immediately, although that } \\
& \text { might seem to be a power } \\
& \text { stance to reduce an adver- } \\
& \text { sary, the judges felt that } \\
& \text { this act would be politi- } \\
& \text { cally unwise in the Meret } \\
& \text { situation." }
\end{aligned}
$$


c. The raters had no clear c. The researcher marked 3 inmodel of an accurate baskets and withheld these score against which to these scores. When the measure their proficiency raters marked these 3 inas a rater. baskets, their scores were checked against the researcher's and the differences were discussed so that the researcher could correct any faulty decision making (Appendix UU).

d. Raters sometimes looked d. Raters were reminded to refer more for literal behavto the descriptions (ranges ioral examples rather the of effective political behavthree ranges of effecior) for their ranking decitiveness. sions.

e. One participant seemed e. In such an instance, this set difficult to assess and of scores would be evaluated the raters varied on all by the administrator of the of his items. Either the sinulation.

the assessors were weak in this particular instance or the individual presented ambiguous behaviors. 
When the second pilot group completed their in-baskets and the judges finalized the scoring key (amplified with a variety of new behavioral examples), an additional note was added to the scoring key page for the Administration Outline: "If a participant fires Pat Ramirez immediately, which might seem to be a power stance to reduce an adversary, the judges felt that this would be politically unwise in the Meret situation."

These changes to the scoring key and the revised training of the two new volunteer raters increased the interrater reliability coefficient for the second pilot group by seven points, from a .71 to a .78 Pearson correlation. Table 9 displays the coefficient for each item and the level of significance at .001 for each item in the in-basket. Further additions and improvements to the scoring and assessor training will be recommended in the final chapter.

Insert Table 9 about here

Test administration is an important reliability consideration because of the need to stabilize the instrument over repeated administrations. The directions to administer the test were identical for both sample groups and no changes had to be made in them (Appendix S).

This chapter reported the results of the in-basket study through the various products of the research. Content and construct validity were established throughout the entire process of the instrument design and testing, but both became strikingly clear as the three hypotheses were verified. Initial reliability figures were tabulated and are 
Table 9

Interrater Reliabilty Scores of Second Pilot Group

Means, Standard Deviations, Pearson " $r$ " Coefficients Between Two

Scorers' Independent Ratings of the Seven In-Basket Items (Raw Scores)

\begin{tabular}{|c|c|c|c|c|c|c|}
\hline \multicolumn{2}{|c|}{ In-basket items } & \multirow{2}{*}{$\frac{\text { Mean } \mathrm{x}^{\mathrm{a}}}{2.15}$} & \multirow{2}{*}{$\frac{\text { Mean } \mathrm{Y}^{\mathrm{b}}}{1.75}$} & \multirow{2}{*}{$\frac{\operatorname{SD} \mathrm{x}^{\mathrm{a}}}{1.3089}$} & \multirow{2}{*}{$\frac{S D Y^{b}}{1.1642}$} & \multirow{2}{*}{$\frac{\text { Pearson " } r \text { " }}{.8204 *}$} \\
\hline 1. & Waller Message & & & & & \\
\hline 2. & Administration & & & & & \\
\hline & Out line & 2.95 & 2.45 & 1.3563 & 1.0501 & $.7927 *$ \\
\hline \multirow[t]{2}{*}{3.} & Letter of & & & & & \\
\hline & Resignation & 1.55 & 1.55 & .8870 & .7592 & $.8558 *$ \\
\hline 4 . & Computer Memo & 1.80 & 1.85 & 1.3611 & 1.2680 & $.9270 *$ \\
\hline 5 . & Farley Message & 2.00 & 1.80 & 1.2978 & 1.1050 & $.6606 *$ \\
\hline 6. & Ramirez Message & 2.25 & 1.95 & 1.2927 & 1.0501 & $.7076 *$ \\
\hline \multirow[t]{2}{*}{7.} & Performance & & & & & \\
\hline & Reviews & 2.10 & 1.85 & 1.2524 & .9333 & $.6889 *$ \\
\hline
\end{tabular}

Note. $\underline{\mathrm{n}}=20$, Mean $=.78$

$\mathrm{a}=\operatorname{Rater} \mathrm{C} . \quad \mathrm{b}=$ Rater $\mathrm{D}$

* Significant at .001 for all scores. 
shown in Tables 8 and 9. These results are discussed in the concluding chapter. 


\section{CHAPTER FIVE}

\section{Understanding Individual Political Behavior in Organizations}

\section{Introduction}

The purpose of this research is to design and to validate an instrument in the in-basket format that measures and explores an individual's political behavior. The Meret in-basket experiment accomplishes that purpose as it offers fresh insights into the political actor. These insights also amplify the theoretical base about organizational political behavior. This final chapter evaluates the instrument itself and offers a framework of political behavior built upon a synthesis of the literature and detailed by the body of evidence from the experimental study. Concluding remarks address the significance of this research, particularly in relation to leadership.

\section{Instrument Evaluation}

Two questions can be posed to any test developer: "Is the test any good as a measure of the characteristics it is expected to assess?" and "Should the test be used for the proposed purpose?" For the Meret in-basket, the answer was yes to both these questions. A Measure of an Individual's Political Behavior

The in-basket scores represent a wide range of effective political behavior among 33 individuals. The three hypotheses of the instrument tested specific characteristics of political behavior and were strongly verified: Various political behaviors were presented by the in-basket respondents; the behaviors ranged from ineffective to effective solutions to the Meret situation; and the political behaviors expressed 
varied with the type of problem presented. Figures 2 through 10 indicate that more than 200 behaviors were measured by the Meret in-basket. The ciata from these figures triangulate with that synthesized from the Action Report Form and the interview. For example, the Administration Out line registered more than 100 political behaviors as shown in Figure 10. That item was ranked the most critical by both pilot groups and the judges, and it was described as the most challenging by the pilot groups. The next two most critical items for the pilot groups were the Performance Reviews which elicited 26 behaviors, and the Letter of Resignation which elicited 24 behaviors (Figure 10).

Hypothesis 2 presupposes that the most effective solution to the Meret situation is a political one. This presupposition can be made because of the major elements of the Meret merger: change, ambiguity, reorganization and competition. These elements are the classic environmental conditions for political behavior. Therefore, although the scoring key captured all the behaviors demonstrated by the participants, only the most effective and truly political behaviors earned a raw score of 5 . The moderately effective behaviors on the scoring key are chiefly administrative responses to the situation, although hints of political behavior are exhibited in the moderate range.

The judges faced the issue of true effectiveness for all the behavioral responses demonstrated by the participants. For them, the most effective solutions to the Meret situation were political ones. Yet, if an unwise political move was made by a participant, the judges placed that behavioral example on the moderate or low range. The most significant example of ineffective political behavior was the firing of 
Pat Ramirez by several participants. The judges felt strongly that this was politically unwise in the Meret situation.

In summary, construct validity was built carefully upon a precise definition of political behavior that included the elements of influence, self-interests, competition, and discretionary behavior. These elements of what makes a behavior political instead of social can readily be seen in the behavioral examples on the high range of the scoring key (Appendix W). For example, a few participants sought direct alliance with Coventry Meret, the president. Some prepared for levels of power even higher than Goodwin's, the targeted position. Several focused on exchange of favors with the players in the situation. All of these examples and other highly rated behaviors were influencing, discretionary, self-seeking, and competing with other persons in the simulation. They were also the most effective solutions to the simulation. One participant said:

I selected myself to head the Administration Department. Ramirez needs an infusion of job motivation before consideration for promotion. She is otherwise not sufficiently experienced/capable of the full task.

Ulrich needs more time to develop people and delegation skills. He has good managerial ability, but as a people manager, my talent brings out and makes use of the other two managers' strengths to full department advantage (Participant in first pilot group).

Power considerations: A sense of personal power appeared to be an extremely integral factor for one's effectiveness in the Meret 
situation. Although the entire simulation was designed to support and to substantiate Chris Wallace's power base, nearly one-half of the participants were reluctant to utilize this power and, consequently, were ineffective in the in-basket situation. Their non-powerful attitudes were expressed vividly: "It's not my job to do this"; "I plan to wait for an okay--for direction"; "I cannot go outside the chain of command"; "Chris Wallace's position is not an important one"; and "I think J. D. is better for the job." In contrast, some participants depended on their position power using an authoritative manner rather than an influencing one. The most effective participants relished power and actually sought more power. They contacted both presidents of Muse and Meret and looked for higher positions in the future--even the presidency of Meret. They were proactive.

Power considerations permeate political activity. The Meret inbasket successfully measured the presence of one's power stance through the participant's actions, the interview, and the Action Report Form. For example, the individual scoring 89 on the simulation presented a picture of power in action. This individual proposed himself for a new vice-president's position and suggested his new position include contro1 of operations as well as administration. He expressed a desire for the greater power base of the new vice-president's position and a need for the extra responsibility. He planned to call Coventry Meret, the former Meret president, to set up a meeting with him. He wrote, "Set up meeting about Muse transfer policy. Use opportunity to lobby for Goodwin's position for myself." In the interview, he said that he wanted to put in a few good words for himself. Dealing with the letter 
of resignation, this individual wrote: "Call Pat and J. D. to organize a retirement dinner for Charles. Set up meeting with Charles to inform him of retirement benefits and how he can maximize his exit from Meret." He stated in the interview that he wanted to know why Goodwin was leaving. These examples also indicate the importance of the stakeholder dimension.

Without a sense of one's own power, it appeared difficult to the individuals scoring low in the simulation to sense the power of the stakeholders at Meret. Chain-of-command type thinking, with its emphasis on position power, did not include a deeper level of power analysis such as awareness of the level of Marlyn Waller or the recognition of Everett Car1son as senior editor. Carlson directed the vital editing function for the publishing firm and, as such, would have the clout of a doctor, engineer or senior loan officer in their respective organizations. In summary, there was a direct link between low personal power levels and the inability to observe or acknowledge power in others.

Limitations. Validity as a process is almost never accomplished through one study or by one researcher (Benson \& Clark, 1982). Reliability also improves with repeated applications. Typically, in-baskets become more standardized with each application because the scoring key is improved and scorers gain proficiency. For an experiment with a new instrument, the Meret in-basket is on solid ground, yet five limitations are recognized.

The in-basket itself, as a situational test, can elicit lifelike behavior (Frederiksen, Jensen \& Beaton, 1982). This can be done only in proportion to the participant's willingness to enter into the 
situation, to really act as though he or she were Chris Wallace in the Meret exercise. A first limitation is that simulations always fall short of real life, and participants always request more time and more information. Several participants reserved judgment and delayed action because of this limitation. Nevertheless, simulations are the strongest means for measures of personality save for real-life observation and certainly more valuable than the usual self-report methods (Frederiksen, et al., 1972).

A related and second limitation concerns the important prehistory for any actor in a simulation. 1though a few examples of Chris Wallace's stock exchange were offered and a surface picture of the network of relationships was assumed by the participants, the four years of Wallace's time at Meret would be much richer and certainly more complex.

Frost defined two levels of power. One level was the surface activity such as that represented in the Meret simulation. The other lay deep within the very structure of the organization. He wrote:

It is a more subtle phenomenon, its origins and impact being embedded in the symbols and systems that evolve out of contests and struggles among organizational actors. Such contests are, in many cases, preserved and renewed through the perpetuation of earlier power relations, hidden beneath the surface of current organizational functioning. (in press, p. 3)

This deeper level of power and its resulting activity becomes invisible and taken for granted with the passage of time and, according to Frost, this level of power is the basis for the surface level decision making 
and political activity. Similarly, as Bacharach and Lawler (1981) claimed, power must be studied in terms of a network of relationships. This simulation only scratches the surface of power and relationships.

A third limitation challenges the important role of the panel of judges and their expertise. The judges were selected to represent the varieties of organizations in the pilot groups and levels more senior than the middle managers in the groups. By virtue of their collective job experience and present executive level positions, the pane1 of judges had a clear picture of the political environment at Meret. The additional training they received (Appendix EE) on the definition of political behavior and the 10 various behaviors to be examined contributed greatly to the impact of their decisions and final consensus. However, because it is difficult to determine a level of political astuteness, this limitation is important to acknowledge.

One judge represented the public sector, working as a dean in the community college system with years of labor negotiation experience, she had a keen sense of the gatekeepers in the Meret situation. For example, she pointed out the power resources that Bruce Farley had because of his control over information in Meret as supervisor of data processing.

The second judge was an executive in a large, complex aerospace firm who contributed to the perspective of the technical participants. At the same time, he offered his knowledge of the changes and the political ambitions of middle managers.

The last judge had military experience and was at the time of the simulation a reserve commander. Most importantly, as president of his 
own consulting firm, he had direct experience with many of the organizations in the pilot group. His initial bias on the importance of the performance reviews was tempered by the other judges who believed that these reviews were only moderately critical. Significantly, the two pilot groups also ranked the performance reviews as second to the Administration outline. Table 3 illustrates the first pilot group's agreement with this judge (number 3 in the Table). However, judge number 3 was willing to defer to the other judges on this item because he believed that his military experience exaggerated the importance of performance reviews per se. Nonetheless, the sample group relied heavily on the three reviews as a major source of information regarding Chris Wallace's competition.

Together, the three judges brought their various experiences and reflections on political behavior to the development of the scoring key, the considerations for each item, and the ranks and weights of each item (Appendix W; Tables 3 and 4). They based their ranking on the items after formulating this statement: "Which items are most critical to Chris Wallace's self-interest and how important are the items for Wallace's political effectiveness now and in the future?" The judge's familiarity with all the dimensions of political behavior and their grounding in the assumptions of the research added to the strength of the experiment.

The fourth limitation questions the sample group and, consequent$1 y$, the generalizability of the findings. The sample group was formed through organizational contacts (Appendix KK). In a few instances, contacts sent their middle managers so doubt could be cast upon some 
participants' willingness to cooperate, even though a voluntary consent form was signed by each participant (Appendix MM). Other than the directions given in the letter, the researcher had little control over how the contacts invited the participants in the pilot group. As in most social experiments, one deals with the experimentally accessible population and makes generalizations from that group.

The uniqueness of the in-basket as a projective test overrides this type of limitation. The subjects could not guess the variety of scoring categories for the in-basket exercise. The subjects were told that the simulation would examine their decision making skills. As Frederiksen et a1. wrote: "The fact that the subjects do not know the scoring categories makes it impossible for them to bias responses deliberately to get high scores on certain performance categories. The examinee presumably guesses only that he should do well, accomplish a lot and show good judgment" (1972, p. 65). This was true for the entire pilot group. No one guessed the precise focus of the Meret inbasket .

The fifth and final limitation follows the discussion of the previous one. It is important to address the fact that the simulation created or evoked exactly what was to be measured. Thrown into a high1y political arena, would an apolitical participant be forced to act politically and then attain a successful score? Though none of the participants identified the simulation as a political exercise, and though in-basket participants tend to respond as they would in real life, this limitation is a real one. Since few participants scored high, apparently no one was forced to act politically. In the future, 
a study might compare results between two groups, one of which would be told that the exercise was a political one.

Another aspect of this limitation calls attention to calculated versus accidental political behavior. Some participants in the Meret simulation scored moderately well, yet these participants may have done so accidentally. This would be true of some participants who exercise political tactics without a vocabulary or framework to explain them.

Most of the limitations accentuate the complexities of political behavior and challenge the very purpose of the research. It may be that political behavior lies beyond the schema of analysis. The actual tactics of political behavior, or units of analysis as Bacharach and Lawler (1981) defined such actions, may be the tip of the iceberg and therefore, underlying motives and assumptions must be also explored for a thorough understanding of an individual's political effectiveness. The Purpose of the Test: Research and Development

"Should the test be used for the proposed purpose?" is the second question posed by a test developer. The proposed purpose of this instrument is the exploration of an individual's political behavior for two reasons: (1) as a new research tool to facilitate quantitative and qualitative research; and (2) as a developmental activity for the examinees.

New research tool. In comparing the few studies that have been conducted of political behavior, one can see that as Porter et a1. (1981) observed, the study of political behavior is in its infancy. Each of these studies is exploratory in nature. As outlined in Figure 
11, few studies used instrumentation and when it was used, the instrument only relied on self-reported answers.

Insert Figure 11 about here

Several of the research samples were drawn from faculties and part-time MBA students enrolled in evening classes, reflecting a variety of levels within their organization. Only one study went directly to three specific levels of management (Allen et al., 1979). The study of Kipnis et al. (1980) addressed types of influence such as coalitions and exchange. But since the definition of political behavior claims discretionary and nonroutine activities, many of the tactics of influence reported by Kipnis et al. fall outside the realm of political behavior and are more administrative as differentiated by Frost and Hayes (1979). In other words, not all influencing behaviors are political.

This research endeavored to build on the exploratory nature of these studies by utilizing their broad hypotheses to strengthen the content validity of the instrument. Indeed, although this research was also exploratory, the instrument itself will provide a solid tool for future research. A simulation evokes real-life behavior and, therefore, presents more accurate data than self-report questionnaires. The two pilot groups represented a clearly defined population, that of middle managers. Following the recommendation of Gandz and Murray (1981), a modest phenomenological approach to the study of political behavior was made in the post in-basket interviews which are reported in chapter four. 


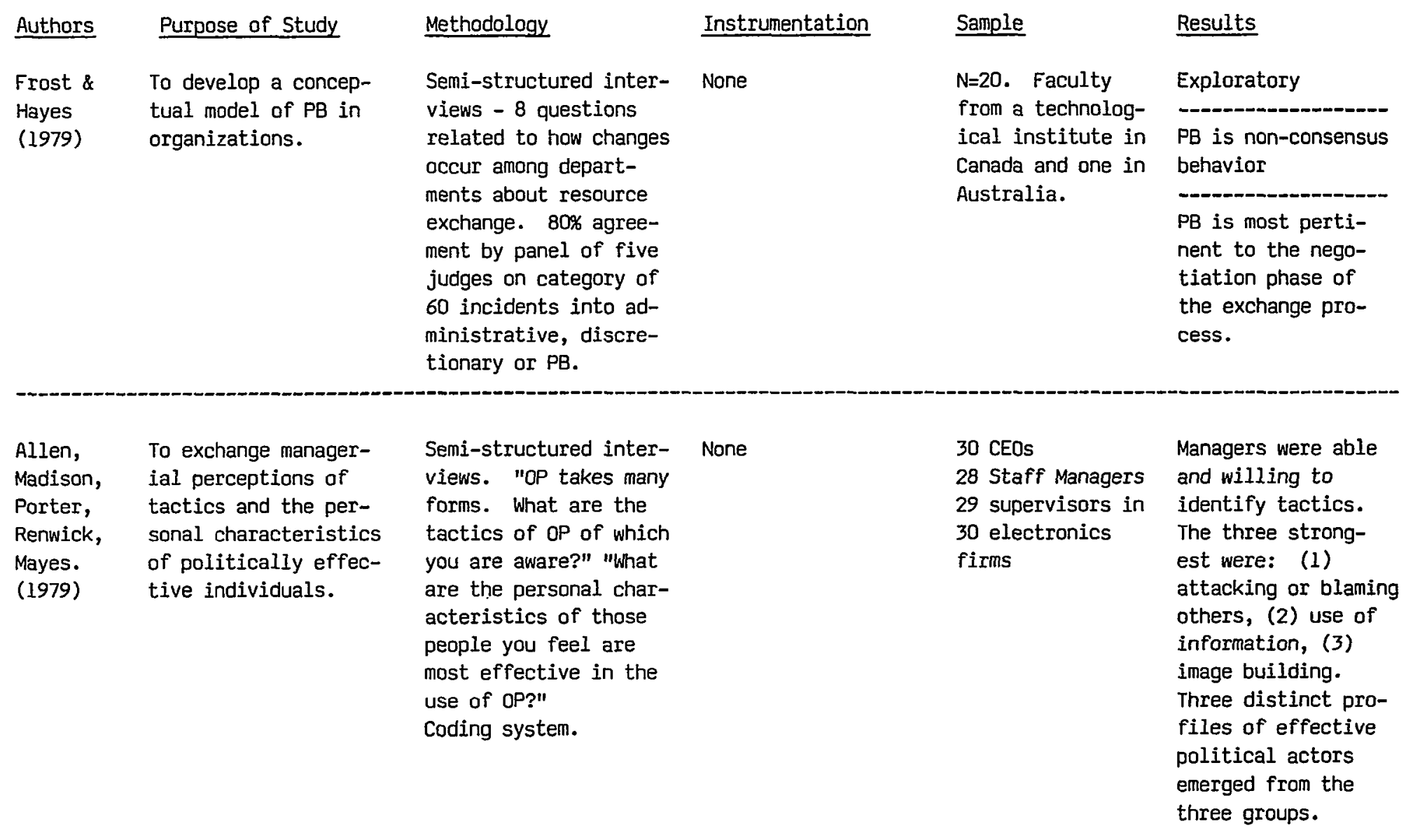

Figure 11. Comparison of Studies of Political Behavior (PB) in Organizations (0) 1979-80 


\begin{tabular}{|c|c|c|c|c|c|}
\hline Authors & Purpose of Study & Methodology & Instrumentation & Sample & Results \\
\hline $\begin{array}{l}\text { Madison, } \\
\text { Allen, } \\
\text { Porter, } \\
\text { Renwick, } \\
\text { Mayes. } \\
\text { (1980) }\end{array}$ & $\begin{array}{l}\text { To explore perception } \\
\text { of practicing mana- } \\
\text { gers regarding the } \\
\text { overall incidence and } \\
\text { characteristics of } \\
\mathrm{PB} \text {, conditions and } \\
\text { impacts of PB. To } \\
\text { determine whether } \\
\text { managers perceive a } \\
\text { direct relationship } \\
\text { between power and } \\
\text { politics. }\end{array}$ & $\begin{array}{l}\text { Structured interview. } \\
\text { Coding schemes. }\end{array}$ & None & $\begin{array}{l}\text { Same as Allen, et } \\
\text { al. study. }\end{array}$ & $\begin{array}{l}\text { Managers shared } \\
\text { clearly defined } \\
\text { perceptions of } O P \text {. } \\
60 \% \text { indicated } P B \\
\text { is frequent, } 74 \% \\
\text { stated individual } \\
\text { interests were } \\
\text { represented. 90\% } \\
\text { agreed PB occurs at } \\
\text { middle and upper } \\
\text { levels, staff over } \\
\text { line, and in mar- } \\
\text { keting areas more } \\
\text { than others. Reor- } \\
\text { ganization occurs. }\end{array}$ \\
\hline
\end{tabular}

\section{Gandz \& To test six broad}

Murray hypotheses about PB,

(1980) such as: Talk about politics and politicians would be common in most 0.
Descriptive statistics Mailed, self-administered questionnaire
$N=428$. North

American and

Canadian MBA students.
Support for the six hypotheses. Recommendation to study PB phenomenologically.

Figure 11. (Continued) 


$\begin{array}{lll}\text { Authors } & \text { Purpose of Study } & \text { Methodology } \\ \text { Kipnes, } & \text { To examine the tactics } & \text { Content analysis of } \\ \text { Schmidt, } & \text { of influence used by } & \text { written descriptions } \\ \text { Wilkinson } & \text { people at work when } & \text { about how they } \\ \text { (1980) } & \text { attempting to change } & \text { succeeded in getting } \\ \text { Part A } & \text { the behavior of the } & \text { someone to do some- } \\ & \text { superiors, co-workers } & \text { thing they wanted. }\end{array}$
and subordinates.

\section{Instrumentation}

Structural questionnaire to determine demographics and job situation issues.
Sample

$N=165$. Graduate business students in evening classes.
Results

The choice of influence tactics is associated with what the respondents are trying to get from the target person, the amount of resistence shown, and the power of the target person. dimensions of influence uncovered in Part A.
Questionnaire compiled of 58 items, 5 point scale of frequency that a tactic of influence was used with bosses, coworkers and subordinates.
Eight dimensions of influence: asser-

$\mathrm{N}=754$. Employed respondents of graduate business students in evening classes. ; ingratiation; rationality, sanctions; exchange, upward appeal; blocking; coalitions.

Figure 11. (Continued) 
For research purposes, the procedures have been standardized (Appendix $\mathrm{T}$ ) and simplified. Compared to more traditional in-baskets, the Meret instrument is quite brief and easy to score. In little more than an hour, a substantial amount of written data can be collected. The interview time allows for exploration of the individual's perspective. These further recommendations would improve the administration procedures and assessor training:

1. The revised Meret Interview Form (Appendix TT) includes a sufficient space to record responses from the telephone messages and Performance Reviews. It eliminates the question about how the person approached the in-basket. The answers to that question were superfluous.

2. Assessor training could be improved by the design and use of an assessor performance measure; the requirement to complete the Meret in-basket as part of assessor training; the use of written critiques of the assessors' reports; the viewing of a mock interview; and the expansion of the assessor training manual to include sample assessor work, as explained in Appendix CC.

3. Scorers' training would be improved significantly by completing the suggestions in number 2 above.

4. A standardized feedback form for individuals would conserve time.

5. Appendix PP could be adapted to synthesize materials about the dimensions.

Utilizing the instrument for future research is limited only by the creativity of the research plan. For example, the instrument could 
be administered by demographics of age, sex, occupation and so forth for comparison. It could be administered to senior managers to see if the scores of such individuals would be higher. Results from various departments within an organization could be contrasted.

Variables could be correlated as well. For example, groups might be told that the Meret situation is political. The sex roles of the Meret key players could be reversed. Concurrent and predictive validity studies might be possible. Most importantly, the future studies should increase the validity and reliability of the instrument.

Cobb (1986) spoke of political skills as either diagnostic or tactical. The diagnostic skill was based on two factors: an individual's ability to gain access to information and to process that information by knowing its political possibilities and ramifications. Diagnostic skills were clearly demonstrated by the high-scoring participants. Tactical skills, as Cobb delineates them, are similar to the 10 behavioral dimensions of the Meret in-basket. He emphasized the importance in flexibility regarding tactics. As Figure 9 depicts, several tactics were underutilized in the Meret situation, perhaps because of overreliance on certain tactics or inflexibilities. Tactics, as the bottom line of political diagnosis, can be examined now. The significance of the Meret in-basket will be its value as a research tool to facilitate both quantitative and qualitative results.

A developmental activity. Political tactics and political models for decision making and leadership are not part of a typical management development curriculum. Very few, if any, of the sample group had a political model to guide them during the Meret simulation. Several 
possessed a political vocabulary without a model. Phrases and words such as: heir apparent, lobby for position, ally, network, owed me, and hidden agendas were frequently used. The taboo related to power and to politics was evidenced in such phrases as: back stabber, Machiavellian intrigue, and bad politics. It seemed apparent that most participants went on instinct and that they found the ambiguity and open structure difficult. The Meret scenario was not predictable or orderly and, without a framework upon which to study such a scenario, half of the participants fared poorly. Thus, the value of the instrument as a development activity seems obvious. By administering the Meret inbasket and by assessing the level of a group of middle managers' political effectiveness, an excellent training needs analysis would result.

That the results of the simulation provided a needs analysis was true for the pilot groups. From the participant's responses, strong developmental areas surfaced. First and foremost, the participants needed a framework for understanding the Meret situation. The participants had misconceptions about the power motive, competition, conflict, and exchange of favors. Individual developmental areas that surfaced included authoritarian styles, weak communication with the employees, and meeting too frequently. The in-basket could be used for individual developmental work as well as for group diagnosis and training. After the data was collected from the 33 participants, everyone received a broad overview of the results, individual performance sumnaries (Appendixes $G G$ and $V V)$, and an invitation to attend an optional debriefing session (Appendix JJ). 
At the debriefing session for the participants (Appendix JJ), the researcher summarized the main patterns of behavior demonstrated by the pilot groups. Several restraining points of reference and negative themes prevailed which hindered effective behavior. For example, a few participants were completely unwilling to trade or compromise, or they were unwilling to rely on others for anything, even support, thereby shutting out potential allies. Some held too many meetings, others refused to acknowledge employees lower than Wallace in the organizational chart, and several were overly suspicious and mistrustful of everyone at Meret.

Another major pattern that the less effective participants demonstrated was avoidance of conflict, particularly with Pat Ramirez. "Keep everyone happy" was the theme for these people. Several admitted to avoiding conflict at all costs and these individuals planned to be objective, to smooth things over, and to discuss strengths rather than to deal with weaknesses. In this day of participative management, only a few shared information with their employees or attended to some form of communication. And finally, the debriefing session with the participants highlighted the importance of a macro view of Meret. Such a view, in addition to power considerations, seemed to be the keys to success for the high scoring participants. The macro view of Meret was more than knowing the history of the organization; it was a sense of the power centers and gatekeepers like Carlson, Waller, Goodwin, and Farley. The successful participants saw themselves as stakeholders and the importance of the editorial function in the company was recognized. 
The less effective participants remained in the administrative function and never looked beyond that.

The in-basket is a projective test. As such, participants are traditionally responsive to the results of their work, and in the Meret research, this feedback was exciting to them. They wanted to compare their results with those who had high scores. Several participants called and thanked the researcher for the personalized feedback. In a letter, one participant wrote, "Politics are interesting. We don't tend to learn anything about them in management training" (Appendix WW). That the instrument is a valuable development activity is clear. As the Meret in-basket has been evaluated and affirmative answers presented to the test developers' questions, the value of a political model becomes more practical. In the next section, such a model is developed. It is a realistic model because of the research effort and results.

A Framework for Understanding Political Behavior in Organizations Porter et al.'s ( 1981 ) exploratory model of political behavior, "Episodic Upward Political Influence Model," is quite complex and impractical. The researcher greatly adapted and simplified the Porter et al. model to focus on the political actor and to incorporate the lessons of the Meret sample group.

Insert Figure 12 about here

The framework centers on the political actor whose nature and role have been overlooked (Frost, in press) and the antecedents to his or 


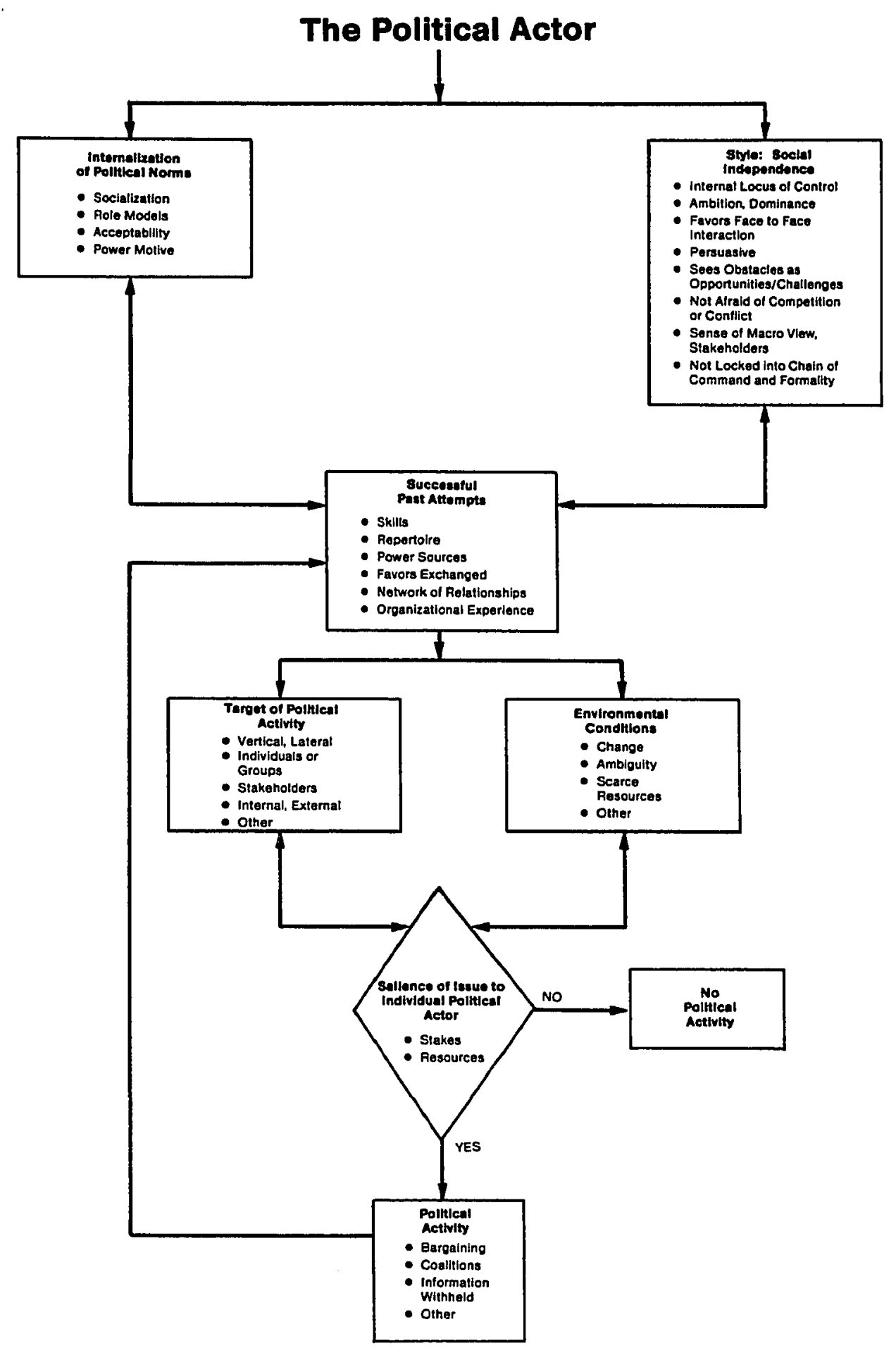

Figure 12. Framework for Understanding Political Behavior In Organizations 
her political activity. Of the top two boxes, one represents the internalization of political norms and the other represents the actor's style: social independence. It is clear from the Meret responses that the power motive was a critical effectiveness factor. The acceptability of power and self-interest type behaviors was expressed in the interviews. Further research conducted using the Meret in-basket could investigate the actor's role models and past socialization with regard to power and politics. That political norms must be internalized is important.

The social independence style is a picture clearly painted by the Meret sample group. Ambition and dominance, which are not aggression as Frost (in press) points out, are linked to one's internal locus of control and power motive. Christie and Geis (1970) supported the presence of face to face interaction and persuasiveness in their studies. The most effective Meret participants seemed to have an opportunistic outlook--they used many more positive words to describe the Meret scenario. These effective participants recognized competition and conflict, had a sense of the stakeholders, and were not crippled by a chain-of-command mentality. This style, painted by previous researchers and the Meret actors, is certainly a vigorous one, but it is only a precondition for political activity.

The third box represents successful past attempts and the "battlefield" learning that one participant referenced. This important antecedent to political activity includes the obligations or stock exchange concept of Burns (1961), the network idea of Bacharach and Lawler (1981), and the historical position or power sources considerations of 
Frost (in press). The Meret sample group confirmed the importance of organizational experience in the arenas of political activity.

With these three preconditions for political activity in readiness, the model now highlights the environmental causes and the targets of political activity. A person who challenges another's power may be a cause of political activity and a target at the same time. This was true when Bryan Emerson opened the bid for power in the Meret situation because he was also one of the targets of political behavior. Farrell and Peterson's (1982) typology defined the targets of organizational politics as vertical, lateral, internal, and external ones. Stakeholders can be any of these four types, as well as individuals or groups. In the Meret in-basket, the targets were principally internal, vertical and lateral individuals rather than external targets. The environmental conditions that are often concurrent with the target choice is discussed below.

The decision point in this model is represented by the diamond figure, the salience of the issue to the individual political actor. Unless the potential actor has stock in the issue or unless one's personal resource is threatened, he or she will not behave in a political manner. Political behavior is calculated, not usually accidental (Cobb, 1986). However quick and second-natured it might be, a decision takes place. The result is some form of political behavior such as the 10 dimensions displayed by the research participants.

It is true, as Frost (in press) stated that the real selfinterests of actors are occasionally hidden or disguised as nonselfinterested, nonpolitical activity. Such behavior still stems from a 
political decision point, and the behavior could be termed covert political behavior.

This exploratory model may represent a moment or years. It could be applied to group analysis as well, with adaptations as necessary. In combination with the Meret instrument, it could be a valuable discussion point for management development purposes.

Environment a1 Conditions

The conditions which foster political activity can be examined further and in harmony with the preceeding conceptual framework. The environmental conditions of political behavior are illustrated in Figure 13 and are contrasted to administrative behaviors. As shown in the Meret scenario, the conditions that evoked political behavior are varied and intertwined. Open or non-zero sum issues, shown on the left side of the diagram, are present and available for the political actor. Informal, indirect, and discretionary behaviors are often prevalent and surround the actor, for example, the two telephone messages of the Meret scenario. The stakes are most likely high, especially when political behavior is at an extreme--coup d'etat, sabotage, and mutiny (Zald \& Berger, 1978).

Insert Figure 13 about here

Change, ambiguity, and uncertainty are conditions that immediately signal the likelihood for political action as in the merger at Meret. Compounding the merger at Meret, the protagonist, Chris Wallace, was placed in competition with his or her peers immediately. Finally, when 


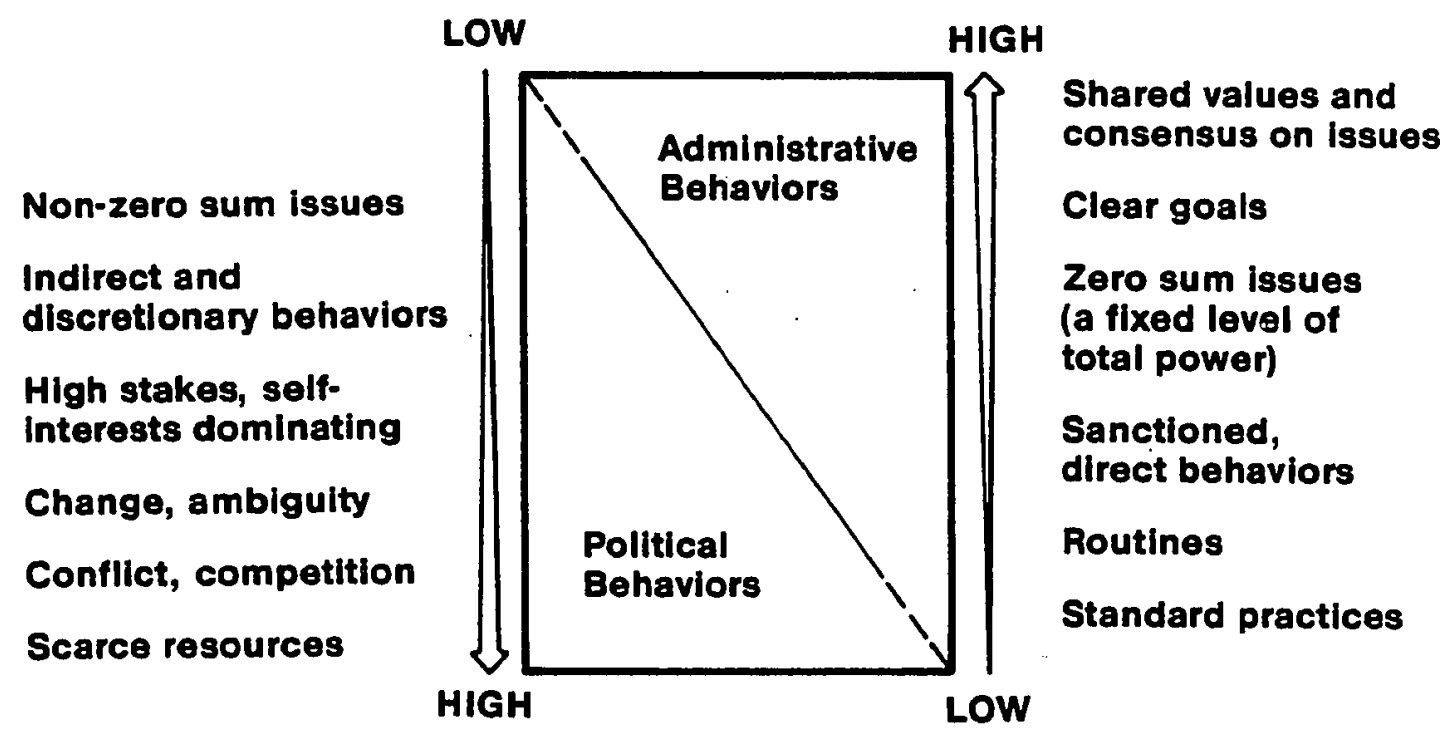

Figure 13. Environmental Conditions 
resources of time, money, symbols or personnel are scarce or even shifting, the political arena is complete. All of these conditions were prevalent in the Meret situation, yet as the figure depicts, the broken line at the top and bottom of the box indicates that a to the portion of administrative behaviors usually continues simultaneously with the political behavior.

The right side of the figure illustrates the conditions that suppress political behavior. The stronger the goals, values and other elements represented on the right side of the figure, the less likely political behavior will be expressed by individuals or groups. The broken line at the bottom depicts the overflow of political behaviors and the fact that political behaviors cannot be completely separated from administrative ones. For example, minor alliances and favors exchanged could be part of a dominant administrative arena.

This figure characterizes the importance of understanding the political environment, part of the significance of the research project which will be summarized next.

\section{Significance of the Research}

\section{Leadership Studies}

As the most studied and least understood phenomena in organization behavior, leadership theories and models beg even more for an understanding of political activity. Such activity could be called the least studied and most acknowledged phenomena in organizations. In his extensive work on leadership, Burns (1978) continually referred to the importance of the leader understanding and utilizing power. He wrote: 
The leader is dealing with persons--potential followers--who have their own power bases, however small, and their own hierarchies of motives.

In this process both behavioral and structural variables are converted into two sets: (1) the motive bases--hierarchies of want, need, aspiration, etc.--that can be mobilized by competing leaders and (2) the actual power that can be mastered through these motive bases--power that rests in economic, social, and other resources centered in institutions, technology, coalitions, constitutions, rules, traditions, ballots, money, information, intelligence, genius, skills. The leader eternally must deal with the double and interrelated question: What can these persons do for (or against) me in a pursuit of collective goals and what will these persons do for (or against) me? Hence, leaders must assess collective motivation--the hierarchies of motivations in both leaders anc followers--as studiously as they analyze the power bases of potential followers and rival leaders. (1978, p. 435)

Burns' recommendation that leaders assess collective motivation and analyze power bases brings us back full circle to the underlying purposes of this research. Political diagnosis, models, and tactics are underresearched (Cobb, 1986) and for leaders earnest in their vision and needing assistance, the shelf is bare. The results of the instrument and its potential for future research and leadership training is promising.

Figure 13, for example, demonstrates the need for a leader to recognize that the absence of shared values, consensus, and clear goals 
forces $\mathrm{him}$ or her to enter the political arena. As these elements gain significance, the leader moves into the administrative realm, although some leaders turn that responsibility over to others. Actually, the normal environment of leadership is the political arena because, as Burns stated, "Political leadership is tested by the extent of real and intended change achieved by leaders' interactions with followers through the use of their power bases" (1978, p. 434). A practical application of the Meret simulation for leadership development was the attention needed by Chris Wallace to a common purpose--few, if any, participants articulated such a purpose.

Observations of the Researcher

Everyone involved in the research had his or her political story to tell--the assessors, contacts, participants, judges, and media assistants. Every organization appears to be political: produce sections of supermarkets, academic departments of universities, and ballet schools. The in-basket participants were not queried explicitly on political behavior, but in future research and developmental situations, the interview might include direct questions on political behavior.

Clearly, without a framework or perspective upon which to examine political activity, the taboo related to the topic abounds. Often used pejoratively, the word political is overused and misunderstood. In attempts to explain or grasp everything that the rational approach dissatisfies, the term political has become a convenience, almost a black hole of unexplained events. This is unfortunate because the lessons to 
be learned from the political aspects of our human behavior are valuable.

The researcher observed other themes in conducting the experiment. The in-basket is an instrument of great potential. It allowed for unlimited creativity on the part of the examinees who planned retirement dinners, created new vice-president positions, and promoted various characters at Meret. The instrument completely involved the examinees. One said, "I really felt like Chris Wallace for a few moments."

Everyone brought his or her personal interpretive scheme to the situation, or more than one. Some participants ruled out the possibility of power on the part of a human resources manager (Chris Wallace) though numerous facts painted the picture of a strong and nontraditional human resources manager. Formality and chain-of-command was a mind set for several examinees though facts established Meret as very informal such as: the Waller visit to Wallace's office and the tone of Goodwin's letter. These schemes or mind sets were the organizational histories of participants which directly affected their ability to adapt to political activity as summarized in the social independence area of Figure 12.

A final observation on the part of the researcher is about the experiment's value for the student assessors. Most of the assessors had little organizational experience, other than traditional part-time jobs like teaching assistantships, yet they quickly recognized the nuances of political activity in their own lives. They became keen observers and interviewers, amazed at the variety of responses and the differences among the managers. Severa1 applied some of the principles they 
learned to their own political arenas, such as thesis committees. One assessor expressed her comments in a personal letter (Appendix $\mathrm{XX}$ ). Meaning and Importance of the Study

The instrument development and validation process raises numerous questions about organizational political behavior that need further attention. Is it possible, for example, to be effective in a highly political environment without utilizing any political tactics? Will purely administrative activities, formal routines, and standard operating procedures be effective in a merger situation such as the Meret one? The participants' responses in the Meret in-basket and the opinion of the judges strongly indicate that this is not the case.

What about the prevalent negative connotations of the word politics? This dilemma is a critical one. In the Madison et al. (1981) study, the majority of the participants labeled attacking or blaming others as the most frequent political behavior that they had observed or experienced in their organization when in fact, these behaviors may have been just plain rudeness and lack of professionalism. However, the managers in the study observed these behaviors and attributed the word political to them. The Meret in-basket revealed this type of judgment on the part of the participants as they attributed negative motives and behaviors to the players in the scenario. The problem is that many self-directed behaviors, communication difficulties or interpersonal conflicts are tossed into the black hole of nonrational events and labeled politics. This dilemma requires patient and methodical reeducation of organizational actors so that the positive aspects of political behavior--especially within the context of leadership--are 
acknowledged and practiced. Likewise, the value of competition and conflict in the political arena deserves study. The reality that winlose outcomes exist and that such outcomes are very negative at times is part of this dilemma. Again, re-education is important. The dimensions of political behavior, the framework, scoring key, and environmental model of the research are all useful educational tools that can assist individuals in clarifying political behavior.

Furthermore, the definition of political behavior that is utilized throughout the research effort (Porter et al., 1981) demands the purposefulness of leadership so that the promotion of self-interests type political behavior for purely personal reasons is recognized as just that. In fact, as political behavior is explored further, the macro, meso, and micro levels of activity as well as the Machiavellian (powerwielding) versus the leader behavior can be more carefully delineated as depicted in Figure 14.

Insert Figure 14 about here

This figure illustrates the three levels of analysis important to recognize--the macro, meso, and micro levels. It also represents the existence of political behavior in the context of leadership and a common purpose. That varies from the power-wielding type of political behavior. However, the figure does represent the reality of powerwielding co-existing in some leader activity. Such a delineation of political behavior can assist in the resolution of the misconception 


\section{Political Activity}

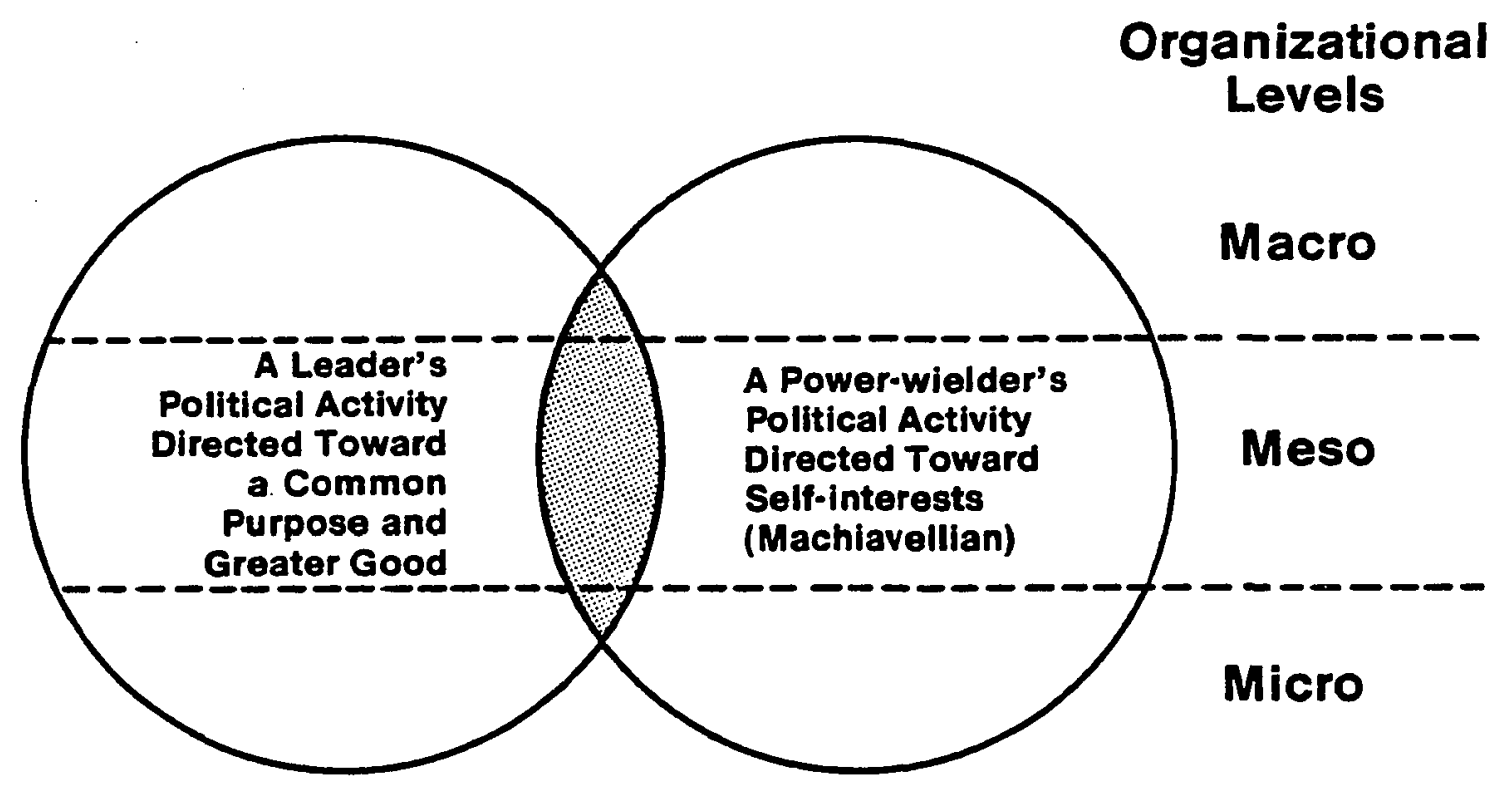

FIGURE 14. Leader, Power-wielder, and Levels of Political Activity 
that political behavior is entirely self-centered and in discussions on the complexities of political behavior.

Another question posed by the Meret research is that of organizational norms regarding political activity. Many of the managers in the pilot groups relied heavily on their own organizational experience and a particular frame of reference. Research supports the prevalence of political activity in some departments such as marketing, sales, the Board of Directors, and personnel, so individuals from these types of departments may have been more familiar with organizational political behavior (Madison et a1., 1980). The stimulus of the Meret in-basket would enable individuals and departments to discuss organizational norms and in turn, individual ones.

These questions, the limitations of the research, the future research possibilities, and the products of the instrument development substantiate the enormous task of understanding political behavior and based on the results of this research, the effort to understand political behavior should move forward.

The instrument, as a new measure, has unlimited research applications in both the qualitative and quantitative realms. Future researchers should experiment with variables as previously suggested in the new research tool section of this chapter. Interviews could be expanded to include phenomenological insights of the political actor. As a developmental activity, the simulation could add a vital perspective on management behavior issues and it could be a responsible discussion point on the nonrational elements of organizations. The simulation might serve as a heuristic device for the understanding of macro levels 
of political analysis and for the understanding of ethical issues in organizations. The features of the Framework for Understanding Political Behavior in Organizations (Figure 12) can be tested and expanded. The salience point in the framework can be examined, particularly in connection with purpose--the reason for leadership. As Borg and Gall commented, "The progress of any science is closely linked to the deve1opment of new and better measures of the phenomena that are its concern" (1983, p. 301). 
References

Ackerman, L. (1982). Guide to managing the politics of change. McLean, VA: Linda S. Ackerman.

Allen, R., Madison, D., Porter, L., Renwick, P., \& Mayes, B. (1980). . Organizational politics: Tactics and characteristics of its actors. California Management Review, 22, 77-83.

Allison, G. (1971). Essence of decision. Boston, MA: Little, Brown and Company.

American Psychological Association (1974). Standards for Educational \& Psychological Tests. Highland Park, NJ: Grysham Press.

American Psychological Association, American Educational Research Association, and National Council on Measurement in Education (1978). Standards and ethical considerations for assessment center operations. Washington, DC: American Psychological Association.

Bacharach, S., \& Lawler, E. (1981). Bargaining: Power, tactics, and outcomes. San Francisco: Jossey-Bass.

- Bader, G. (1982). A dialectical theory of organizations. Unpublished manuscript, University of San Diego, School of Education, San Diego, CA.

Bader, G. (1984). Political behavior in organizations: A conceptual and practical dialogue. In G. Calvert (Ed.), Proceedings of the 1984 Organization Development Network Conference, 181-188.

Bateman, T. (1980). Organization change and the politics of success. Group and Organization Studies, $5(2), 198-209$.

Bennis, W. (1969). Organization development: Its nature, origins and prospects. Reading, MA: Addison-Wesley. 
Benson, J., \& Clark, F. (1982). A guide for instrument development and validation. American Journal of Occupational Therapy, 36, 789-800.

Benson, T. K. (1983). Paradigm and praxis in organizational analysis. Research in Organizational Behavior, 5, 33-56.

Blau, P. (1964). Exchange and power in social 1ife. New York: John Wiley \& Sons.

Boland, J. (1970). Merger planning: How much weight do personnel factors carry? Personne1, 47(2), 8-13.

Borg, W., \& Gall, M. (1983). Educational Research. New York: Longman.

Bourgeois, R., \& Slivinski, L. (1974). The inter-rater reliability of the consolidated fund in-basket. Studies in Personnel Psychology, $\underline{6}(1), 47-52$.

Bray, D. W., Campbell, R., \& Grant, D. (1974). Formative years in business: A long-term AT\&T study of managerial lives. New York: John Wiley \& Sons.

Burns, J. M. (1978). Leadership. New York: Harper \& Row.

Burns, T. (1961). Micropolitics, mechanisms of institutional change. Administrative Science Quarter $1 \mathrm{y}, 6$, 257-281.

Buros, 0. K. (1978). The Eighth Mental Measurements Yearbook. Highland Park, NJ: Gryphan Press.

Burre11, G., \& Morgan, G. (1979). Sociological paradigms and organizational analysis. London: Heinemann. 
Cavanagh, G., Moberg, D., \& Velasquez, M. (1983). The ethics of organizational politics. In R. Allen \& L. Porter (Eds.), Organizational influence processes (pp. 423-439). Glenview, IL: Scott, Foresman.

Chiara, L. (Ed.). (1985). Mergers and acquisitions [Special issue]. Personne1 Administrator, $30(11)$.

Christie, R., \& Geis, F. (1970). Studies in Machiavellianism. New York: Academic Press.

Chun, K. T., Cobb, S., \& French, J. (1974). Measures for psychological assessment: A guide to 3,000 original scores and their applications. Ann Arbor, MI: University of Michigan, Institute for Social Research .

Cobb, A. (1986). Political diagnosis: Applications in organizational development. Academy of Management Review, 11(3), 482-496.

Cohen, M., \& March, J. (1974). Leadership in ambiguity. New York: McGraw-Hill.

Cohen, S., \& Sands, L. (1978). The effects of order of exercise presentation on assessment center performance: One standardization concern. Personne1 Psychology, 31, 35-46.

Crooks, L. (1968). Issues in the development and validation of inbasket exercises for specific objectives (RM-68-23). Princeton, NJ: Educationa1 Testing Service.

Culbert, S., \& McDonough, J. (1980). The invisible war. New York: John Wiley \& Sons.

Dexter, L. A. (1976). Organizational and political climate: A preliminary discussion. Political Methodology, 3 , 141-158. 
Durbrin, A. (1978). Winning at office politics. New York: Ballantine Books .

Dyson, K. (1976). Institutional government: a new perspective in organization theory. Journal of Management Studies, 13(2), 131-151.

Erez, M., \& Rim, Y. (1982). The relationships between goals, influence tactics, and personal and organizational variables. Human Relations, $35,871-878$.

Etzioni, A. (1970). Power as a societal force. In M. 01sen (Ed.), Power in societies (pp. 18-27). London: Macmillan.

Farrell, D., \& Peterson, J. (1982). Patterns of political behavior in organizations. Academy of Management Review, 7, 403-412.

Ferguson, C., Doig, R. (1982). When interests collide: Corporate growth versus human needs. Chief Executive, 18(1), 18-19.

Fitzpatrick, A. R. (1983). The meaning of content validity. Applied psychological measurement, $7,1,3-13$.

Fletcher, C. (1982). Assessment Centres. In D. Mackenzie Davey \& M. Harris (Eds.), Judging people: A guide to orthodox and unorthodox methods of assessment (pp. 42-54). Maidenhead, Berkshire, England: McGraw-Hill.

Frederiksen, N. (1962). Factors in in-basket performance. Psychological Monographs, $\underline{76}(22), 1-25$

Frederiksen, N. (1966). Validation of a simulation technique. Organizational Behavior and Human Performance, 1, 87-109.

Frederiksen, N., Jenson, 0., \& Beaton, A. (1972). Prediction of organizational behavior. New York: Pergaman Press, Inc. 
Frederiksen, N., Saunders, D., \& Ward, B. (1957). The in-basket test. Psychological Monographs, $71(9), 1-25$.

Frost, P. (1980). Toward a radical framework for practicing organization science. Academy of Management Review, $\underline{5}, 501-535$.

Frost, P. (in press). Power, politics and influence. In L. W. Porter, L. L. Putnam, K. H. Roberts, \& E. M. Jablin (Eds.), The handbook of organizational communication. Beverly Hills, CA: Sage.

Frost, P., \& Hayes, D. (1979). An exploration of two cultures of a model of political behavior in organizations. In G. England, A. Negandhi, \& B. Wilpert (Eds.), Organizational functioning in a cross-cultural perspective (pp. 251-272). Kent, OH: Kent State University Press.

Gamson, W. (1968). Power and discontent. Homewood, IL: The Dorsey Press.

Gandz, J., \& Murray, W. (1980). The experience of workplace politics. In R. Allen \& L. Porter (Eds.), Organizational influence processes (pp. 440-454). Glenview, IL: Scott, Foresman.

Gibson, G. (1961). A new dimension for "in-basket" training. Personne1, 38(4), 76-79.

Gil1, R. (1979). The in-tray (in-basket) exercise as a measure of management potential. Journal of Occupational Psychology, 52, 185-197. Gill, R. (1982). A trainability concept for management potential and an empirical study of its relationship with intelligence for two managerial skil1s. Journal of Occupational Psychology, 55, 139-147. 
Greenhalgh, L., Neslin, S., \& Gelkey, R. (1985). The effects of negotiator preferences, situational power, and negotiator personality on outcomes of business negotiations. Academy of Management Journal, $\underline{28}(1), 9-33$.

Griffiths, B. (1979). In-basket scoring keys: Rationale and procedure. Unpublished Manuscript. San Diego, CA: Organization Systems, Inc.

Guba, E., \& Lincoln, Y. (1981). Effective evaluation. San Francisco, CA: Jossey-Bass.

Hawley, A. (1970). Power as an attribute of social systems. In M. 01sen (Ed.), Power in societies (pp. 10-11). London: Macmillan.

Hickman, C., \& Silva, M. (1984). Creating excellence. New York: Signet Books.

Hickson, D., Hinings, C., Lee, C., Schneck, R., \& Pennings, J. (1981). A strategic contingencies' theory of interorganizational power. In R. Allen \& L. Porter (Eds.), Organizational influence processes (pp. 33-51). Glenview, IL: Scott, Foresman.

Instrumentation Network (1984). Directory of human resource development instrumentation. Minnetonka, MN: Douglas Peters and Associates.

Jaffee, C. (1972). Supervisory selection program for disadvantaged or minority employees. Training and Development Journa1, 26(1), 22.

Jaffee, C., \& Burroughs, W. (1970). Problems in insurance company management. Reading, MA: Addison-Wesley.

Kanter, R. (1977). Men and women of the corporation. New York: Basie Books . 
Kanter, R., \& Brinkerhoff, D. (1981). Organizational performance: Recent developments in measurement. Annual Review of Sociology, 1 , $321-349$.

Kei1, E. C. (1981). Assessment centers: A guide for human resource management. Reading, MA: Addison-Wesley.

Kennedy, M. (1980). Office politics, seizing power, wielding clout. Chicago, IL: Follett Publishing Company.

Kesselman, G., Lopez, F. M., \& Lopez, F. E. (1982). The development and validation of a self-report scored in-basket test in an assessment center method. Public Personnel Management Journal, $\underline{3}$, 228238 .

Kim, K., \& Organ, D. (1982). Determinants of leader-subordinate exchange relationships. Group and Organization Studies, $\underline{7}(1), 77-89$.

Kipnis, D. (1981). The use of power. In R. Allen \& L. Porter (Eds.), Organizational influence processes (pp. 17-32). Glenview, IL: Scott, Foresman.

Kipnis, D., Schmidt, S., \& Wilkinson, I. (1981). Interorganizational influence tactics: Explorations in getting one's way. In R. Allen, \& L. Porter (Eds.), Organizational influence processes (pp. 105123). Glenview, IL: Scott, Foresman.

Lawler, E., Nadler, D., \& Cammann, C. (1980). Organizational assessment: Perspectives on the measurement of organizational behavior and quality of work 1ife. New York: John Wiley \& Sons.

Lindblom, C. (1968). The policy-making process. Englewood Cliffs, NJ: Prentice-Hall. 
Lips, H. (1981). Women, men, \& the psychology of power. Englewood Cliffs, NJ: Prentice-Hall.

Lopez, F. (1966). Evaluating executive decision making: The in-basket technique (Research Study 75). New York: American Management Association.

Luthans, F. (1977). Organizational behavior. New York: McGraw-Hil1. Mackinnon, D. (1975). An overview of assessment centers. Greensboro, NC: Center for Creative Leadership. Technical Report \#1. Madison, D., Allen, R. W., Porter, L. W., Renwick, P. A., \& Mayes, B. T. (1980). Organizational politics: An exploration of managers' perceptions. Human Relations, $33(2), 79-100$.

Manz, C., \& Gioia, D. (1983). The interrelationship of power and contro1. Human Relations, 30(5), 459-476.

March, J. G. (1962). The business firm as a political coalition. Journal of Politics, 24, 662-678.

Margulies, N., \& Raia, A. (1984). The politics of organization deve1opment. Training and Development Journal, 38(8), 20-23.

Marks, M. (1982). Merging human resources: A review of current research. Mergers and Acquisitions, 17(2), 38-44.

Mayes, G., \& Allen, R. (1977). Toward a definition of organizational politics. Academy of Management Review, 2, 672-677.

McClelland, D. (1982). The development of social maturity. New York: Irvington Publishers.

McClelland, D. (1984). The two faces of power. In D. Kolb, I. Rubin, \& J. McIntyre (Eds.), Organizational psychology (pp. 59-72). Englewood Cliffs, NJ: Prentice-Hall. 
Mehrens, W., \& Lehmann, I. (1973). Measurement and Evaluation in Education and Psychology. New York: Holt.

Meyer, H. (1960). The in-basket technique conference proceedings. Princeton, NJ: Educational Testing Service.

Meyer, H. (1970). The validity of the in-basket test as a measure of managerial performance. Personnel Psychology, 23, 297-307.

Meyers, M. W., \& Associates (1978). Environment and organizations: Theoretical and empirical perspectives. San Francisco, CA: JosseyBass .

Miller, D. (1964). Handbook of research design and social measurement. New York: Mikay Company.

Morgan, G. (1980). Paradigms, metaphors, and puzzle solving in organization theory. Administrative Science Quarter1y, 25, 605-622.

Morrison, A., McCa11, M., \& DeVries, D. (1978). Feedback to managers: A comprehensive review of twenty-four instruments. Greensboro, NC: Center for Creative Leadership. Technical Report \# 8.

Moses, J., \& Boehm, V. (1975). Relationship of assessment center performance to management progress of women. Journal of Applied Psychology, 60, 527-529.

Murray, J. (1978, Winter). Toward a contingency model of strategic decision. International Studies of Management and Organization, pp. $7-34$

Nadler, D. (1980). Role of models in organizational assessment. In E. Lawler, D. Nadler, and C. Cammann (Eds.), Organizational assessment (pp. 119-131). New York: John Wiley \& Sons. 
Narayanan, V., \& Fahey, L. (1982). The micro-politics of strategy formulation. Academy of Management Review, $\underline{7}, 25-34$.

Newman, B. (1985, December 23). U. S. Book exports lag as publishers leave business to the British. The Wall Street Journal, 1, 12. 01sen, M. (Ed.). (1970). Power in societies. London: Macmillan.

Peters, T. J. (1983). Leadership: Sad facts and silver linings. In E. Collins (Ed.), Executive success (pp. 202-213). New York: John Wiley \& Sons .

Peters, T., \& Waterman, R. (1982). In search of excellence. New York: Harper \& Row.

Pettigrew, A. (1975). Towards a political theory of organizational intervention. Human Relations, 28, 191-208.

Pfeffer, J. (1978). The micro-politics of organizations. In M. Meyers and Associates (Eds.), Environment and organizations: Theoretical and empirical perspectives. San Francisco, CA: Jossey-Bass.

Pfeffer, J. (1981). Power in organizations. Marchfield, MA: Pitman.

Pfeffer, J., \& Moore, W. (1980). Power in university budgeting: A replication and extension. Administrative Sciences quarterly, 25, $637-652$.

Porter, L., Allen, R., \& Angle, H. (1981). The politics of upward influence in organizations. Research in Organizational Behavior, 3 , $109-149$.

Porter, L., Allen, R., \& Angle, H. (1983). The politics of upward influence in organizations. Organizational Influence Processes (pp. 408-422). Glenview, IL: Scott, Foresman. 
Roberts, N., \& King, P. (1985, August). The stakeholder audit: A key political tool in the change process. Paper presented at the Academy of Management meetings, San Diego, CA.

Robino, D., \& DeMeuse, K. (1985). Corporate mergers and acquisitions: Their impact on HRM. Personnel Administrator, 30(11), 33-37.

Robins, S. (1983). The effects of sex and physical appearance on assessment center ratings. Unpublished master's thesis, San Diego State University, San Diego, CA.

Robinson, J., Athanasion, R., \& Head, K. (1968). Measures of occupational attitudes and occupational characteristics. Appendix A to J. Robinson, et al., Measures of Political Attitudes. Ann Arbor, MI: University of Michigan, Institute for Social Research.

Robinson, J., Rusk, J., \& Head, K. (1968). Measures of political attitudes. Ann Arbor, MI: University of Michigan, Institute for Social Research .

Robinson, J., \& Shaver, P. (1969). Measures of social psychological attitudes. Appendix B to J. Robinson et al., Measures of Political Attitudes. Ann Arbor, MI: University of Michigan, Institute for Social Research.

Rosen, B., \& Jerdee, T. (1974). Influence of sex-role stereotypes on personnel decisions. Journal of Applied Psychology, 59(1), 9-14. Salancek, G., \& Pfeffer, J. (1981). Who gets power--and how they hold on to it: A strategic-contingency model of power. In R. Allen \& L. Porter (Eds.), Organizational influence processes (pp. 52-71). Glenview, IL: Scott, Foresman. 
Schein, V. (1977). Political strategies for implementing organizational change. Group and Organizational Studies, $\underline{3}(1), 42-48$.

Schmitt, N., \&Hill, T. (1977). Sex and race compositions of assessment center groups as a determinant of peer and assessor ratings. Journal of Applied Psychology, 62, 261-264.

Scholl, R. (1981). An analysis of macro-models of organizations: The goal and political models. Administration and Society, 13(3), 271298 .

Schweiger, D., \& Ivancevich, J. (1985). Human resources: The forgotten factor in mergers and acquisitions. Personnel Administrator, 30( 11$), 47-61$.

Shapira, Z., \& Dunbar, R. (1980). Testing Mintzberg's managerial roles classification using an in-basket simulation. Journal of Applied Psychology, 65(1), 87-95.

Shirley, R. (1977). The human side of merger planning. Long Range Planning, 10(1), 35-39.

Stevenson, W., Pearce, J., \& Porter, L. (1985). The concept of "coalition" in organization theory and research. Academy of Management Review, $10(2), 256-268$.

Stogdi11, R. M. (1974). The handbook of leadership. New York: Free Press.

Strausbaugh, D., \& Wagman, B. (1977). An assessment center examination to select administrative interns. Public Personnel Management, $\underline{6}(4), 263-268$.

Tannenbaum, A. (1966). Social psychology of the work organization. Belmont, CA: Brooks/Cole. 
Terborg, R., \& Ilgen, D. (1975). A theoretical approach to sex discrimination in traditionally masculine occupations. Organizational Behavior and Human Performance, 13, 352-376.

Thompson, K., \& Luthans, F. (1981). A behaviorial interpretation of power. In R. Allen \& L. Porter (Eds.), Organizational influence processes (pp. 72-86). Glenview, IL: Scott, Foresman.

Thornton, G., \& Byham, W. (1982). Assessment centers and managerial performance. New York: Academic Press.

Tichy, N. (1983). Managing strategic change: Technical political and cultural dynamics. New York: John Wiley \& Sons.

Truskie, S. (1981). Guidelines for conducting in-house management development. Personnel Administrator, 26(7), 25-27.

Turner, T. (1973). A different way to assess management. Canadian Business, $\underline{6}(8), 54-56$.

Tushman, M. L. (1977). A political approach to organizations. Academy of Management Review, 2 2 , 206-2 16 .

Uleman, J. (1972). The need for influence: Development and validation of a measure, and comparison with the need for power. Genetic Psychology Monographs, 85, 157-214.

Ulschak, F. (1983). Human resource development. Reston, VA: Reston Publishing Company.

Veroff, J. (1957). Development and validation of a projective measure of power motivation. In J. Atkinson (Ed.), Motivation fantasy, action, and society (pp. 105-116). Princeton, NJ: Van Nostrand.

Waddell, G. (1982). Simulation: Balancing the pros and cons. Training and Development Journal, 36(1), 80-83. 
Weick, K. E. (1976). Educational organizations as loosely-coupled systems. Administrative Science Quarterly, 21, 1-11.

Winter, D. (1973). The power motive. New York: Free Press.

Wollowick, H., \& McNamara, W. (1969). Relationship of the components of an assessment center to management success. Journal of Applied Psychology, 53, 348-352.

Yuk1, G. (1981). Leadership in organizations. Englewood Cliffs, NJ: Prentice-Hal1.

Zald, M. N., \& Berger, M. A. (1978). Social movements in organizations: Coup d'etat, insurgency and mass movements. American Journal of Sociology, 83(4), 823-861.

Zaleznik, A. (1970). Power and politics in organizational life. Harvard Business Review, 48, 47-60.

Zanze, A. (1985, August). Applied models for political diagnosing in organizations. Paper presented at the Academy of Management meetings, San Diego, CA. 


\section{Appendix A}

\section{Background In formation}

You are Chris Wallace, the manager of the human resources department at Meret Publishing Company. Meret has recently been acquired by a large publishing firm, Muse International, and although things have proceeded as usual, you have just been called to view a tape sent by Muse's vice president, Bryan Emerson. You had met Emerson a week ago when he was out from St. Louis for his first visit to Meret. Emerson runs everything but the editing functions for Muse. Your fellow managers, J. D. U1rich and Pat Ramirez, are also there to view the tape.

Other related information is attached:

1. Meret organization chart

2. Newspaper clipping about merger of Meret and Muse

Look these things over before the tape is shown

[Additional instructions will be provided after viewing the message from Emerson.] 


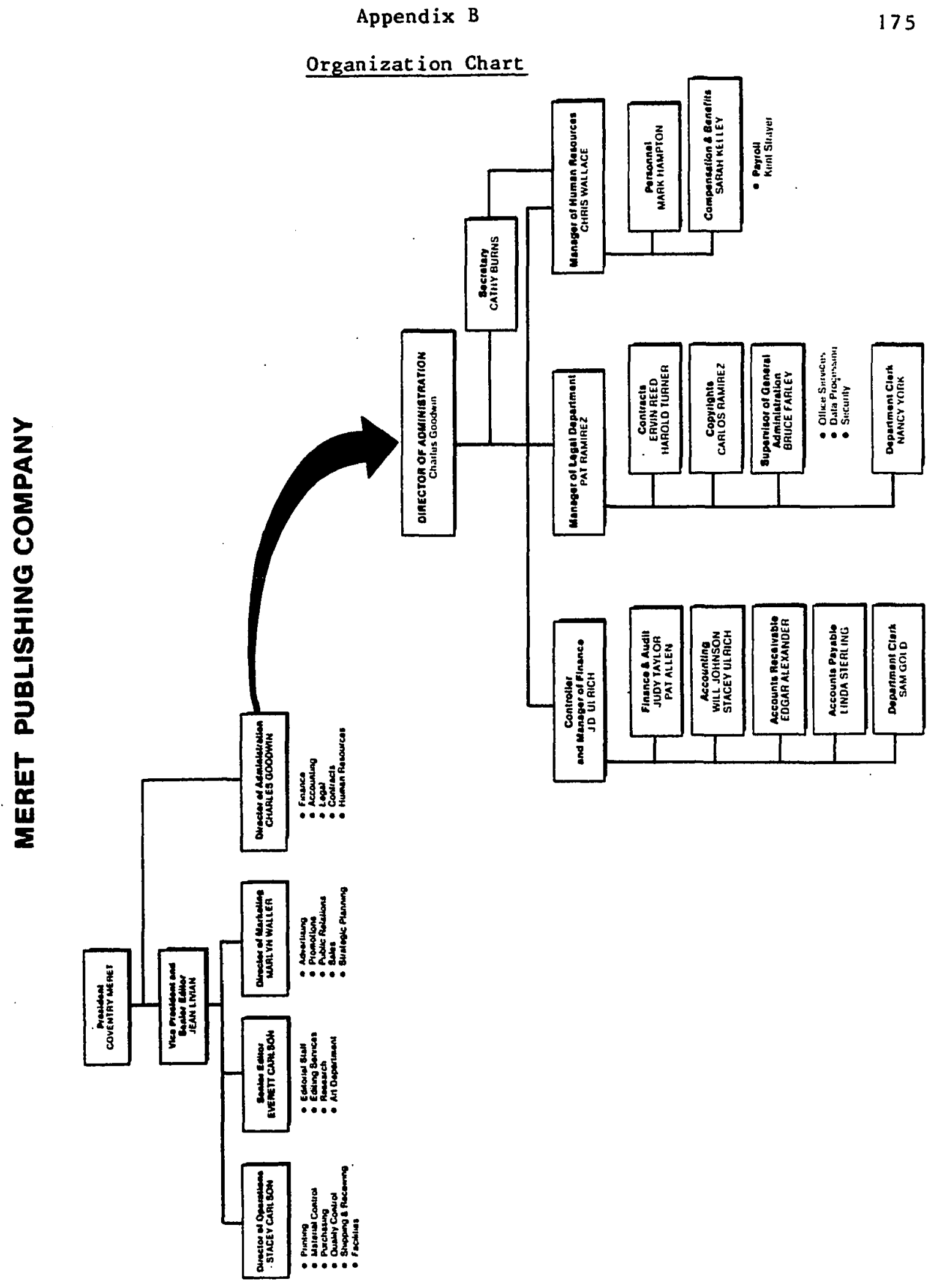




\section{Muse}

International to Acquire Meret Firm

By J.D. Johnson

Staff Writer

ST. LOUIS, MISSOURI Continuing its restructuring, Muse International, on Monday announced an agreement in principle to acquire Meret Publishing Company of Ramona, CA, a specialty book press with revenues last year of about $\$ 4$ million.

St. Louis-based Muse, which reported 1985 profits at $\$ 100$ million is famous internationally for such fiction titles as Castle Red Victoria. Two Friends. Ocean Affair and The Peace Trilogy. but reaps most revenues from its educational. business and technical works. With most of the world's top computer programmers located in California. Muse sees Meret as a gatekeeper to that technical market. Muse also recognizes Meret's expertise in children's books. "It's hard to imagine being 'bullish' in children's books but sales are up 15 to 20 percent over last year," said Muse's president, Sturges Crane.

Meret House is an up-by-thebootstraps organization that has managed to flourish in the field of books for computer science, medical and science professionals. The company originates and publishes anthology-style manuscripts that represent the leading edge of research in such areas as artificial intelligence, pediatrics and ecology. Their books are distributed internationally through wholesalers for students, professionals and doctors in private practice.
The children's section caters to these same professionals who are interested in getting their children the right books "We want to foster a love of books" says Marlyn Waller. marketing director. "The culture as a whole and especially the video/TV generation is moving away from reading- Children's books such as Sky Pictures Lancelot and Mammals are beautifully illustrated. textured. and touchable. Waller claims success is due to their annual anendance at the Bologna Book Fair. the world's most prestigious assembly of publishers of children's books. There they buy the American rights to foreign titles and meet an international group of writers and artists. With such strengths. Meret should prove to be an investment plum for Muse.

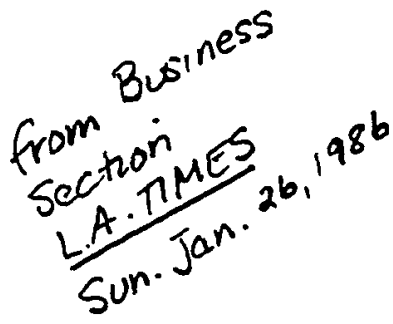




\section{Appendix D}

\section{Video (Teleconference) Script of Bryan Emerson .}

Good morning, Chris, J. D, and Pat.

Good to have an opportunity to meet you and to talk with each of you about Meret. By now you know that merger means changes and there's one special problem I need to talk to you about. Your boss has just advised me that he wishes to take early retirement -- effective immediately. Since one of the goals I've established is to reduce the number of managerial levels, I'd like to restructure the administrative functions at Meret. I want one of you coordinating everything Charlie was responsible for and reporting to me. Now here's the special problem with which I need your help.

How can this be done and who among you should do the coordination? I want each of you individually to out line how you would go about the task. I'd like it just as soon as possible and I'd like it as if you were actually doing the coordination. Maybe I could hear from you by Tuesday.

I'11 make my decisions based on your recommendations and have had some materials sent to you. I look forward to your input. Bye for now. 
Appendix E

Large Envelope that Contained $F, G, H, I, J, K, N, O, P, Q$

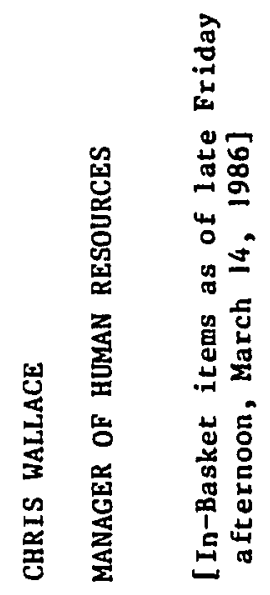

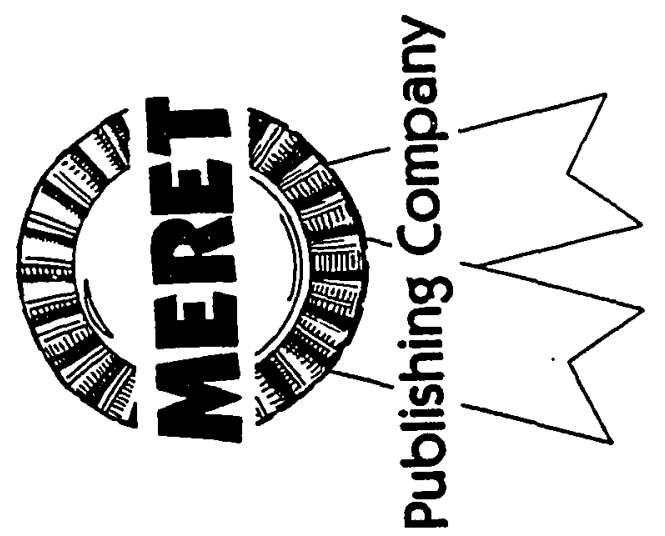

ic: 


\title{
Appendix F \\ Final Instructions
}

\section{Time and Place:}

After viewing the video of Emerson, you were involved in a conference most of the day. It is now late afternoon, Friday, March 14, and everyone has left for the weekend. At your office, you intend to clear your desk and to respond to Emerson's request so that you can express mail it out Saturday morning. You cannot reach anyone by phone and you cannot plan to work Monday on this.

Your role and task:

As Chris Wallace, you are to respond to the items that are in your in-basket in writing. For example, if you want to meet with someone, write out why you would meet and what you would say/ask. If you call a meeting, briefly outline the agenda and rationale. You may write or make notes to yourself directly on the in-basket items, or you may use the enclosed blank sheets of memo paper and clip your response to the appropriate item.

You have one hour to complete the in-basket. Then, all materials can be replaced in the envelope and returned to your moderator. Finally, you will be asked to complete a short form about the in-basket and to answer questions in an interview setting.

Remember: Be yourself in this role. Do what you would actually do as Chris Wallace. Make the decisions and plan accordingly. Use the information at hand.

\author{
You are Chris Wallace \\ It is late Friday, March 14 th \\ You have to respond to Emerson's request.
}


Appendix G

Waller Message

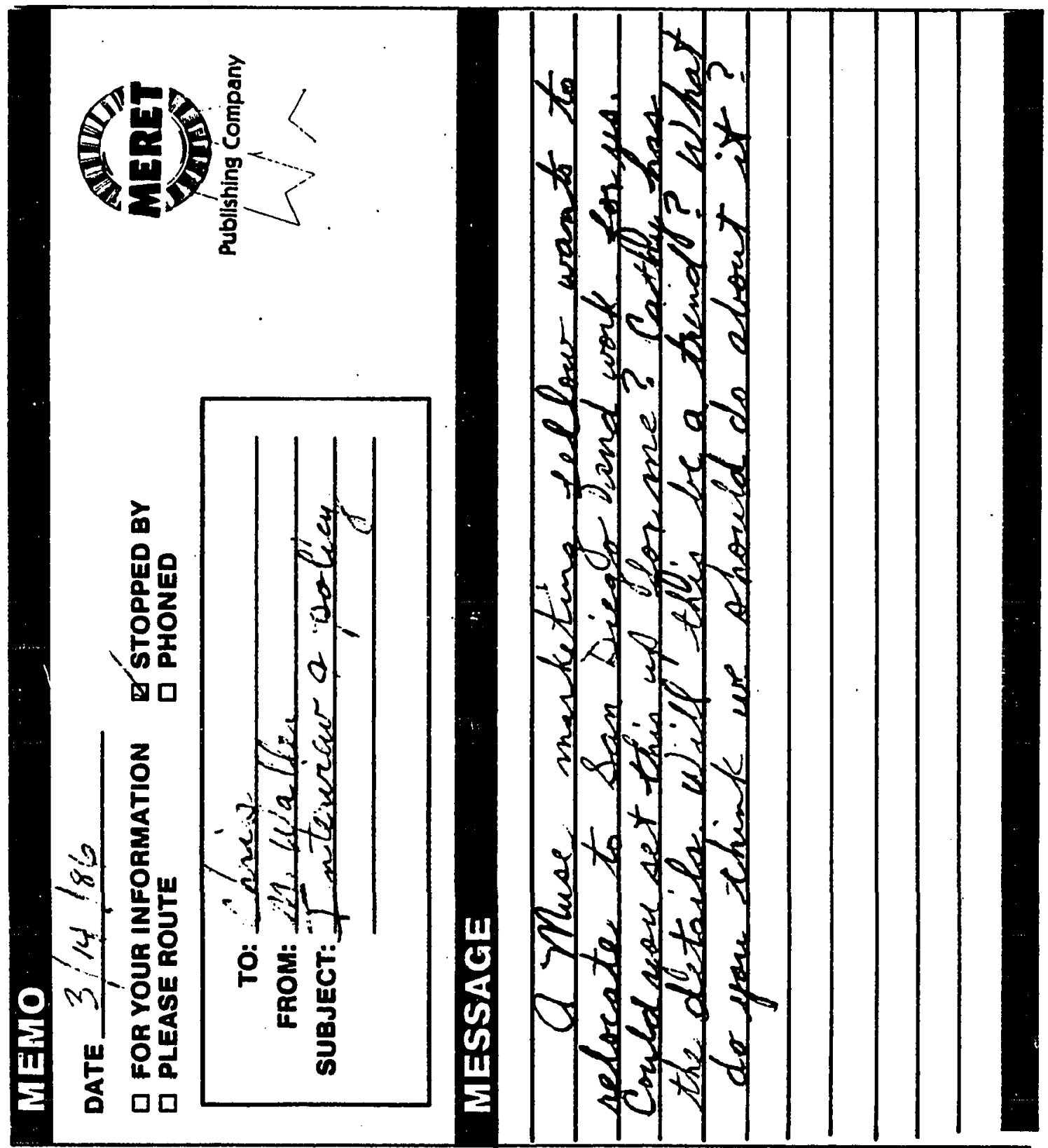


Appendix I

Administration Out 1 ine

Muse International

P.O. Box 4321

St Louis, MO 63121-4321

MERET ADINISTRATION OUTLINE

Objective: To restructure administrative functions at Meret; to select one coordinator/manager to report to V. P. of Administration in St. Louis, Bryan Emerson

1. What vould you do formally to restructure the idministrative functions at Meret?

2. What would you do informally to restructure the administrative functions at Meret?
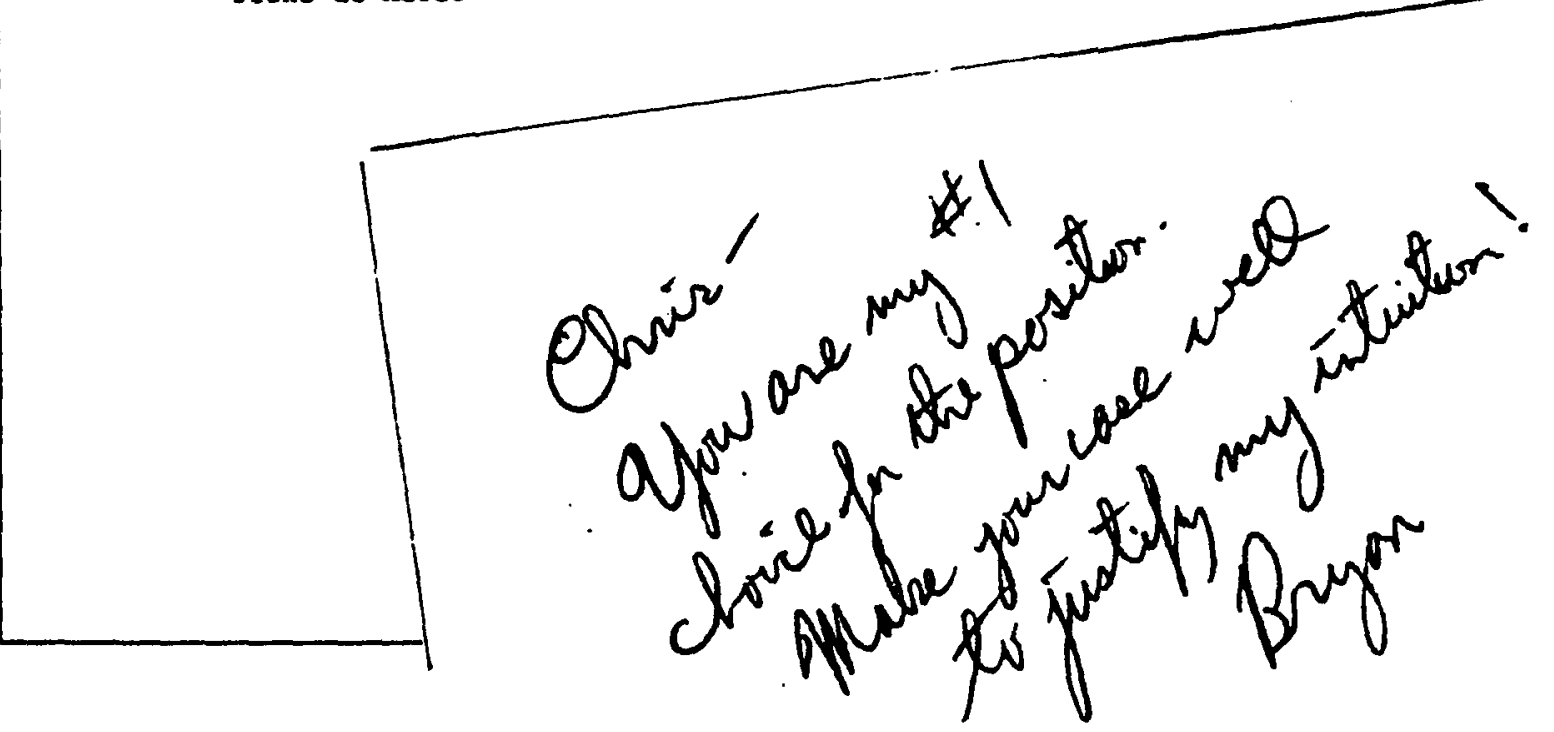

Reproduced with permission of the copyright owner. Further reproduction prohibited without permission. 
Appendix I (Continued)

3. How would you proceed?

4. Who would you choose to report to me and why? 


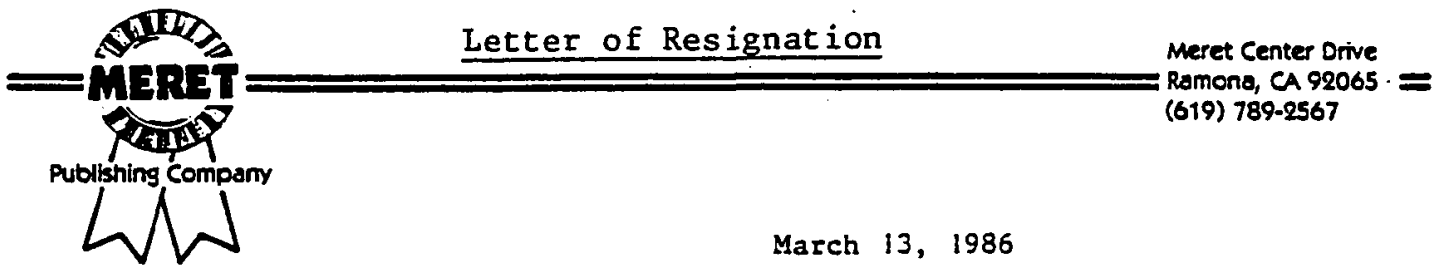

Dear Pat, J.D. and Chris,

Since we have been working together for so many years ic is difficult, and certainly not preferable, to maintain illusions in our close collegial relationship. Your support, dedication and hard work has been one of the assets of my long tenure at Meret. Since it soon will be announced officially, I want you to know that I have decided to cake advantage of the early recirement option offered as a result of the recent merger. As you can imagine, this has not been an easy decision. My concern for this company, the family armosphere and our love of books and ideas makes moving on particularly difficult.

Muse International is a very large and successful publishing firm and $I$ am cercain they will treat our people and accounts with dignity. However, at this stage of my $1 \mathrm{ife}$, I do not wish to become part of a large bureaucratic structure. Since I am not ready to be let out to pasture, I will be examining several alternatives in the book industry.

I am confident that you and your colleagues will offer your professional expertise and support to whomever Bryan Emerson appoints to replacé me.

There are a few issues which have been decided in joint sessions with Muse:

1. We (Meret) will increase our editing staff in the computer and children's books sections. The total employee count will reach 425 by April 1986.

2. Our President, Mr. Coventry Meret, will report to Harlan Thomas, Sr. V. P. Muse. Mr. Meret will no longer report directly to the board members and 250 stockholders.

3. Meret will receive a substancial infusion of capical and building investment from Muse in order to be-able to serve as the distribution point for the new joint operations.

4. Effective immediately, all Meret accounting procedures will be shifted to conform to Muse International financial systems.

Once again, thank you for your loyalty and hard work over chese many years. I will miss you and trust you to give my successor the same fine support.

Sincerely,

Charles Goodwin

Director of Administzat ion

CGed 


\section{Computer Memo}

MERET PUBLISHING

MEMORANDUM

Mareh 13, 1986

To: Chris Wallace, Manager of Human Kesources

From: Everett Carlson, Senior Editor

Re: Comshare evaluation

Some of my editors in the computer area know this group and heartily approve of their work. A few even want to attend the training course! I'm pleased you asked for our input. You have our full support. In fact, your efforts on our behalf are truly appreciated. You are bringing our acministrative side into the 1980's! Now, let's talk about electronic mail and networking to St. Louis... 


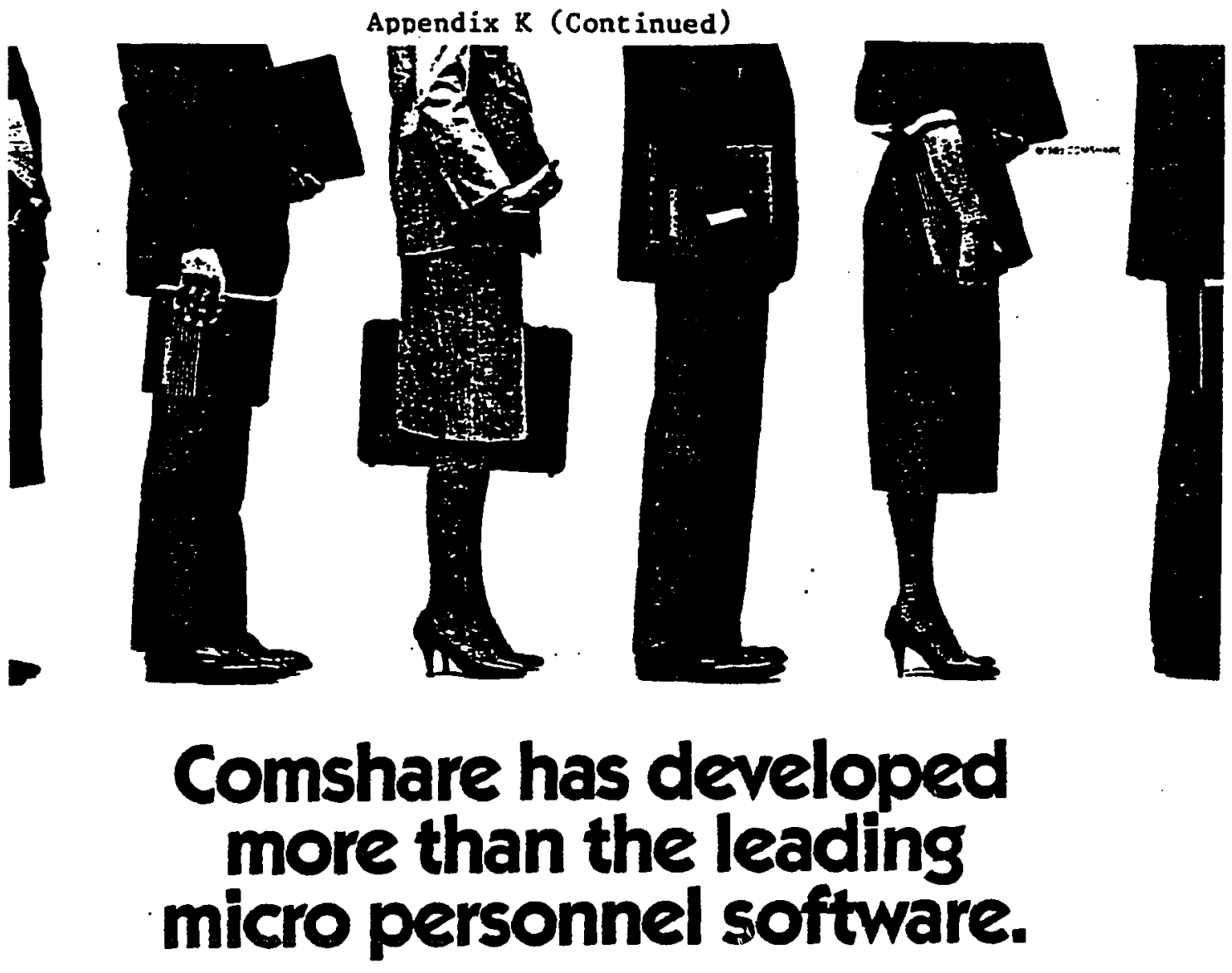

\section{We've also developed a following.}

When Comshare introduced Profiles/PC, we had great expectations for it, of course. But the response has been overwhelming. Today Profiles/PC is in departments than any other software product of its kind. How did we do it?

We listened to your needs and designed Profiles' PC specifically for the personnel professional. It runs on the IBM XT or IBM AT. And it's menu driven, which tells you it's easy to use. Whether you're creating a new report or updating employee information, you're guided each step of the way; without learning a computer language.

Decision making becomes convenient because all your information is in your department.

Salary, benefits, education, skills and demographics are just five of the 16 modules you get, mak. ing Profiles/ PC as powerful as a mainframe at one-tenth the cost.

We also addressed the universal need for support. Our pre-installation workbook and our three-day training course will leave you self-sufficient in all aspects of the system.

There's also easy to understand documentation, a Comshare hotline, and a professional services team. In short. we provide a complete range of services for every possible need.

To see what Profiles $P C$ has done for others like you, call Chris Kelly at Comshare wollfree: 1-800-922-7979 (in Michigan call: 313-994-4800). And do what a lot of personnel departments are doing.

Following the leader.

Dapeonnel gortwara ano anavices

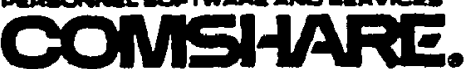




\section{Appendix L \\ Farley Message (transcription)}

$\mathrm{Hi}, \mathrm{Chr}$ is. This is Bruce Farley.

I heard via the grapevine that the administrative departments will be consolidated under J. D. Is this true? What a crazy idea.

Everybody knows J. D. is rigid and certainly not a communicator. When can we meet and discuss? 


\section{Appendix M}

\section{Ramirez Message (transcription)}

Chris, this is Pat Ramirez. How are you doing? I wanted to talk with you about Emerson's request from us. I'd like your support in backing me for the manager's position. For two reasons: my legal background and seniority. Besides, you owe me a few! Give me a call. Thanks . 


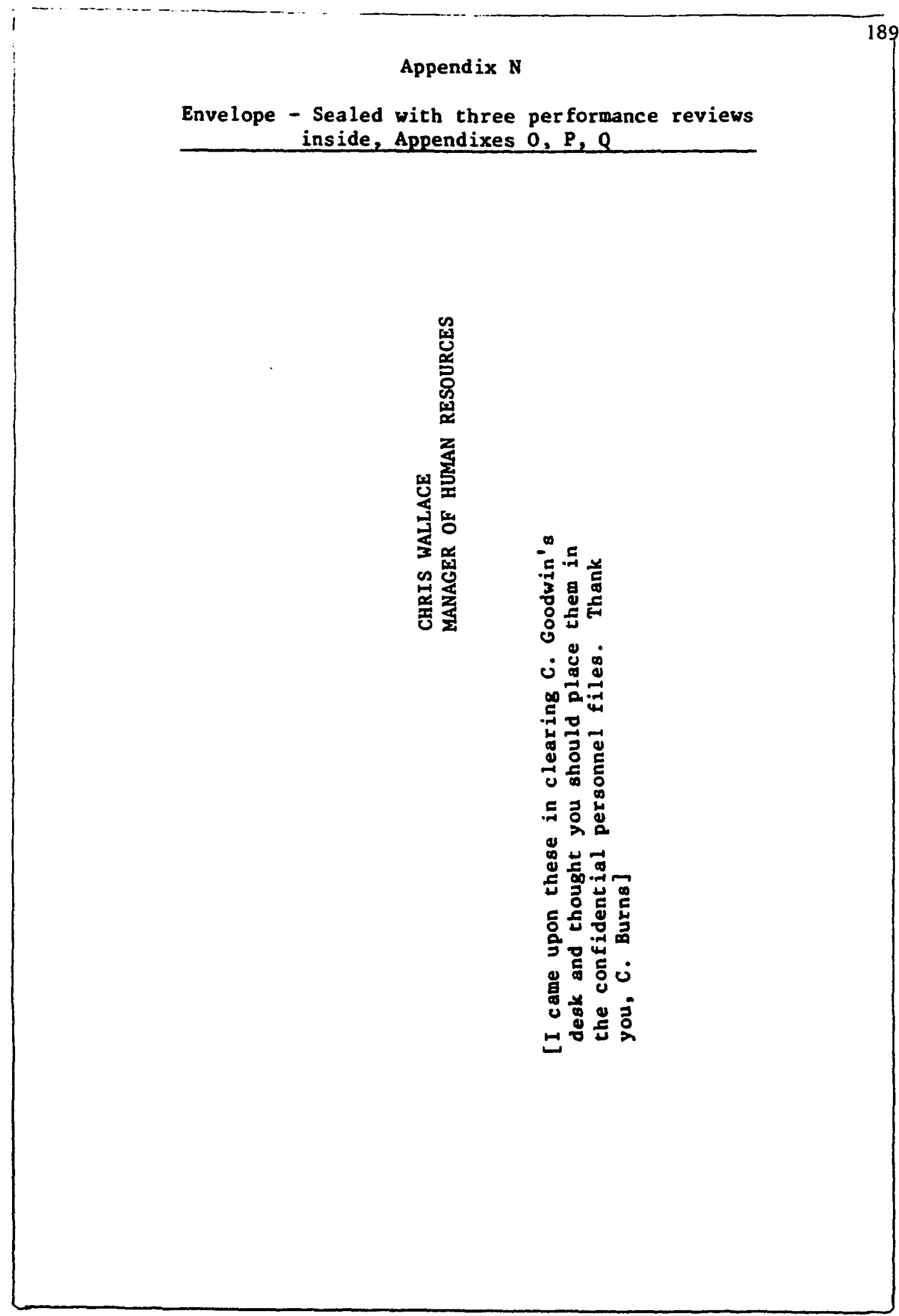

Reproduced with permission of the copyright owner. Further reproduction prohibited without permission. 
Appendix 0

\section{Performance Review}

\section{COMPANY PRIVATE INFORMATION}

\begin{tabular}{|c|c|c|c|c|c|}
\hline \multicolumn{3}{|c|}{$\begin{array}{l}\text { Ulrich, J.D. } \\
\text { Employee Name (Leat, Firat and Initian }\end{array}$} & $\begin{array}{l}273 \\
\text { Empl. No. }\end{array}$ & $\begin{array}{l}\text { Controller and Wanager } \\
\text { of Finance } \\
\text { Position Titse }\end{array}$ & $\begin{array}{l}1-11-80 \\
\text { Date of Hire }\end{array}$ \\
\hline $\begin{array}{l}1-11-80 \\
\text { Date Aacigned } \\
\text { This Postition }\end{array}$ & $\begin{array}{c}1-13-86 \\
\text { Date of Review }\end{array}$ & $\begin{array}{l}\text { Charle } \\
\text { Rowlewer: }\end{array}$ & & $\begin{array}{l}\text { Length of time you hove } \\
\text { eupervieed thle employes }\end{array}$ & ye \\
\hline
\end{tabular}

\section{WORK EXPERIENCE RECORD}

(Compere the esslenments undertiken by the employes during thile review period with those of the previous review period. Deseribe all now, different and/or expanded work expertences reflecting profeselonal growth.)

Financial analysis of merger work; stock analysis; attended valuable Accounting Association meeting on foreign currency exchange and international finances.

\section{PERFORMANCE REVIEW}

Use this section to recond the exeential polntio of the performance review. Base evaluations on obeervable pentormance dinethy related to the job.

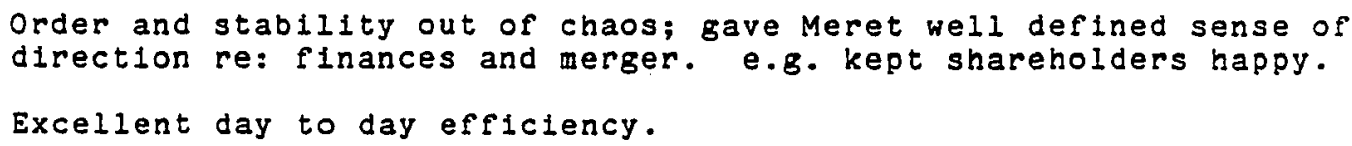




\section{Appendix 0 (Cont inued)}

\section{MANAOEMENT RESPONSIEILTTES}

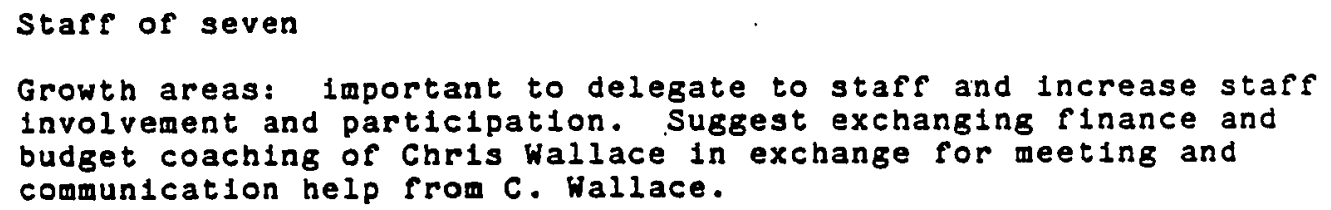

\section{EAPLOVER AEMAAKS}

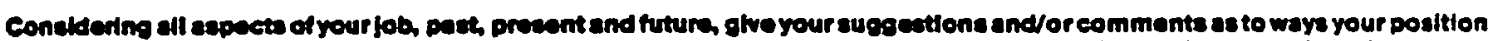

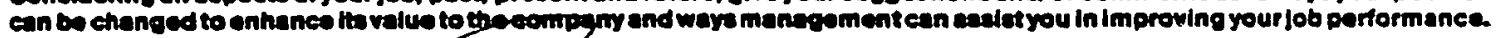

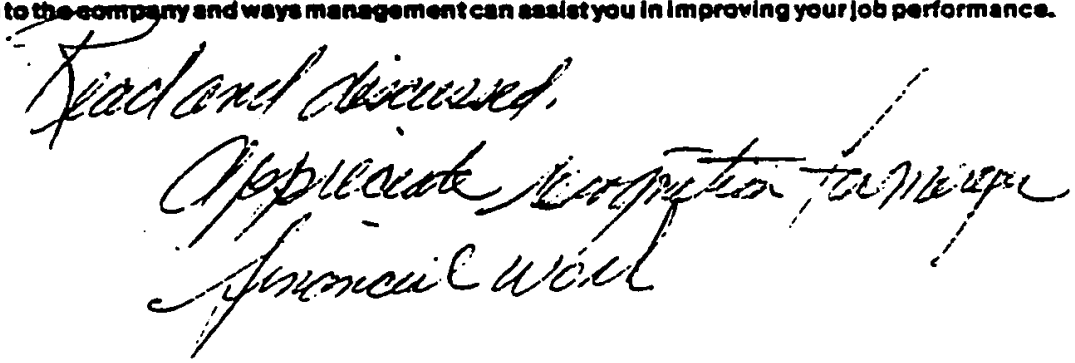

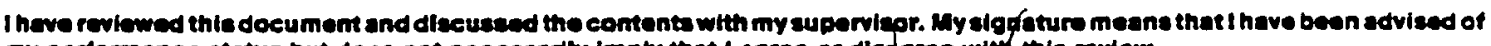

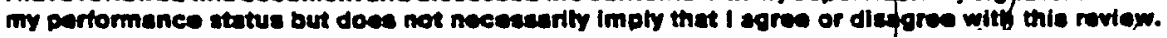

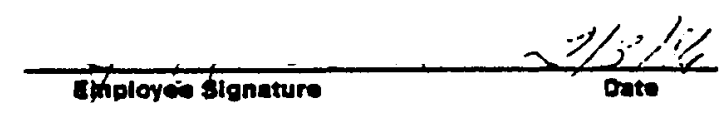

Supervieors slonature

Dete

Aeviewers signature

Oete 
Appendix P

\title{
Performance Review
}

\author{
COMPANY PRIVATE INFORMATION
}

\begin{tabular}{|c|c|c|c|c|c|}
\hline \multicolumn{3}{|c|}{$\begin{array}{l}\text { Ramirez, Pat } \\
\text { Employee Name (Laet, First and Inltuel) }\end{array}$} & $\begin{array}{l}230 \\
\text { Empl. No. }\end{array}$ & $\begin{array}{l}\text { Manager of Legal } \\
\text { Department } \\
\text { Posttion Title }\end{array}$ & $\begin{array}{l}3-17-75 \\
\text { Date of Hire }\end{array}$ \\
\hline $\begin{array}{l}1-11-80 \\
\text { Dote Aesigned } \\
\text { This Position }\end{array}$ & $\begin{array}{c}1-13-86 \\
\text { Date of Roviem }\end{array}$ & $\begin{array}{l}\text { Charle } \\
\text { Roviower: }\end{array}$ & & $\begin{array}{l}\text { Longth of time you have } \\
\text { elupervileed this employee }\end{array}$ & 10 years \\
\hline
\end{tabular}

WOAK EXPERIENCE RECORO

(Compare the ecelgnments undertaken by the employee during thle revlew period with these of the prevlous reviow period. Describs all now, different and/or expanded work experlences roflecting profosalonal growth.)

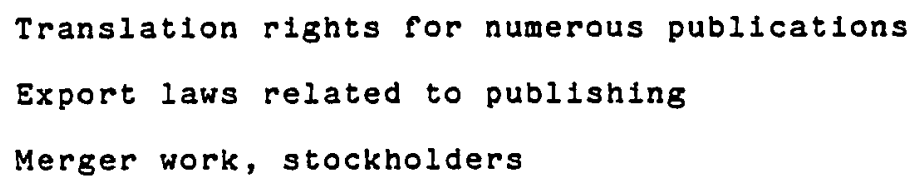

Performance ReVIEW

Use this section to record the easential points of the performance review. Base evaluations on obsorvable performance directly related to the job.

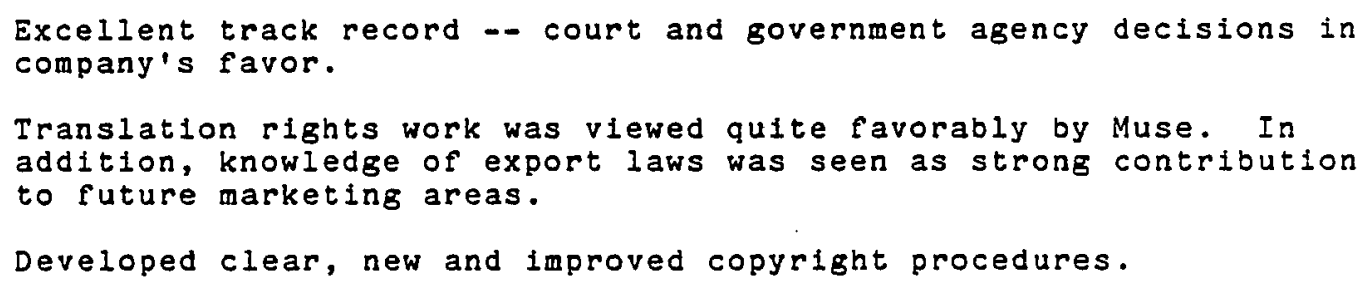


Appendix P (Continued)

\section{manacezanent nesponsialumes}

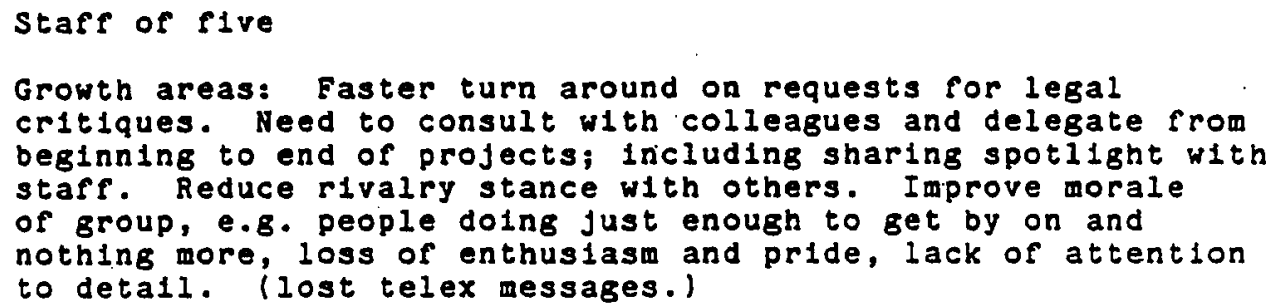

\section{EMPLOVER ALMARKS}

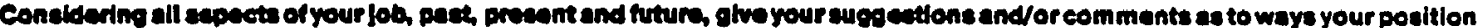
ean bo changed to enhance tis value to the company and weys mansogmentean seciletyou in improving your job portormence.

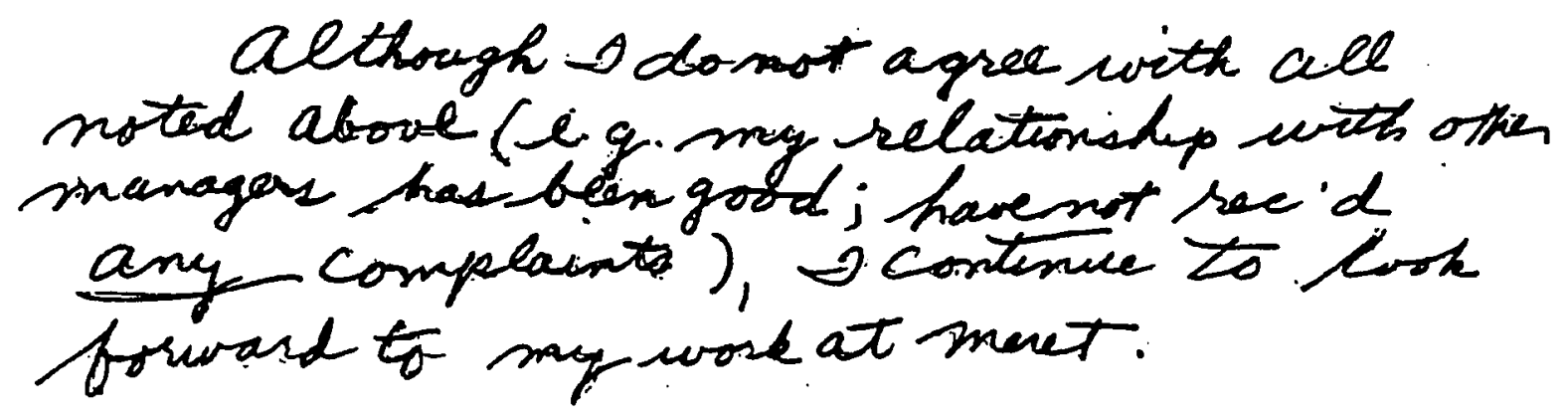

I heve reviowed thile document and discuased the contente with my supervicor. My stonature means that I heve been advised of my portomance status but does not necesearily imply that 1 soree or disagree with this ruviow.

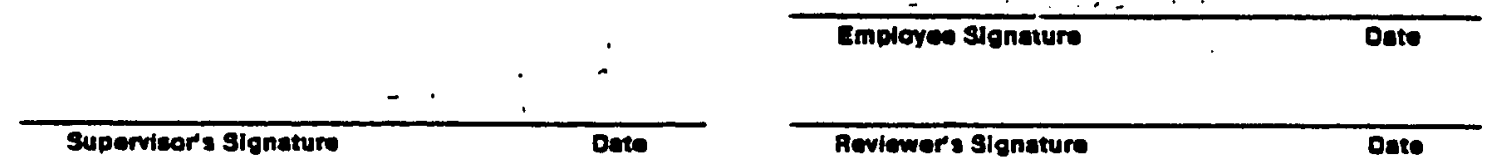




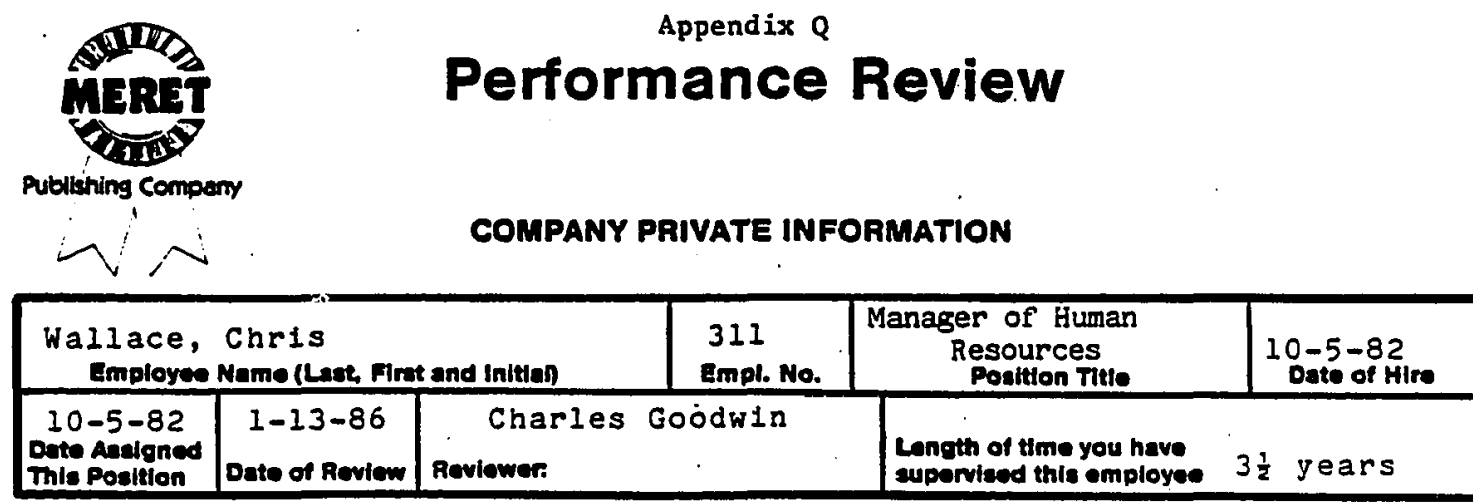

WOAK EXPERIENCE RECORD

(Compere the asaignments undertaken by the employee during this review period with those of the previous review period. Describe all now, different and/or expended work experiences roflecting profeaslonal growth.)

New problems of merger, including stockholder and employee relations. Growth of company and streamlining administration. New salary and health plan.

PERFORMANCE REVIEW

Uea this section to record the escential points of the pertormance review. Batee evaluations on observable performance dincetty ralated to the job.

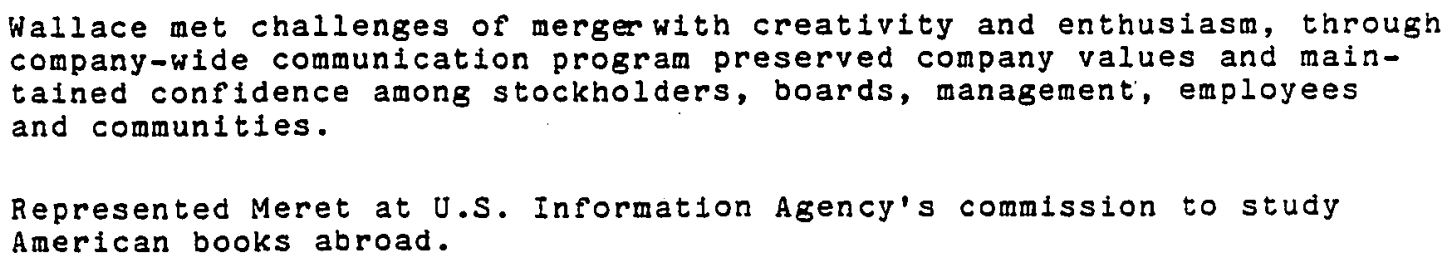




\section{Appendix Q (Continued)}

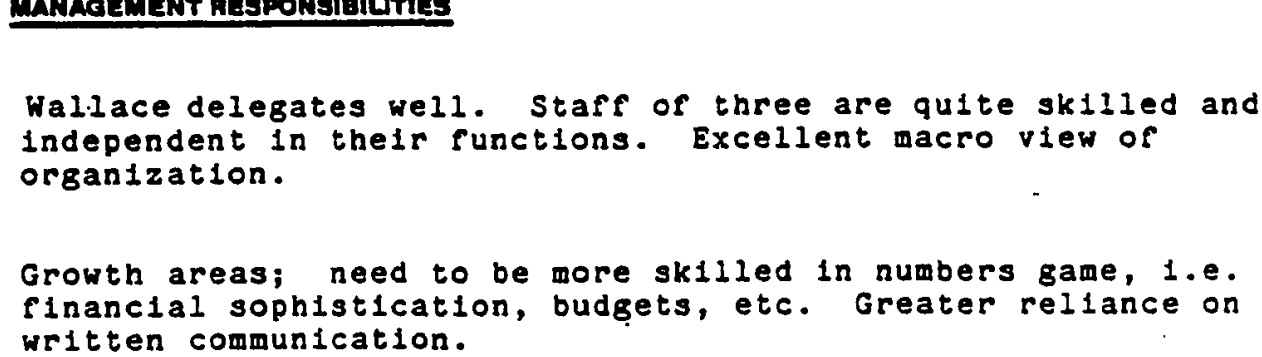

Wallace delegates well. Staff of three are quite sk1lled and independent in their functions. Excellent macro view of organization.

Growth areas; need to be more skilled in numbers game, $1 . e$. financial sophistication, budgets, etc. Greater reliance on written communication.

\section{EMPLOVER REMARKS}

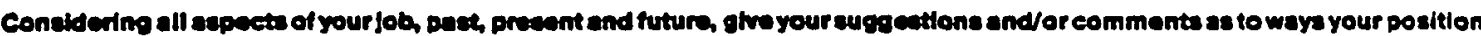
ean be changed to enhance the valuo to the company and way manacement ean aedel you in improving your job portormance.

I have read and reviewed this. It is a very fair summary of the past year. I appreciate management support and look forward to new opportunities and challenges of what the merger will bring, e.g.

-co-ordination of payroll and benefits

-influx of 50 employees

- computerized personnel system

Inove rovlowed thls document and dlecuesed the contents witth my supervisor. My signature means that i have been advised of

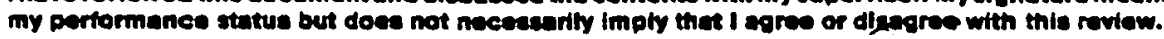

\begin{tabular}{|c|c|}
\hline Employes Slgneture & Date \\
\hline
\end{tabular}




\section{Appendix R \\ Materials for Meret In-Basket}

$(10-15$ minutes $)$

1. Background In formation

2. Meret organization chart

3. Newspaper clipping about merger

$\ldots-\ldots \ldots-\ldots-\ldots-\ldots-\ldots-\ldots$

( 5 minutes)

4. Video - Bryan Emerson's announcement

- $-\ldots \ldots \ldots \ldots-\ldots \ldots$

( 1 hour)

Items as they appear in the In-Basket

5. Instructions

6. Blank memo paper, calendar, name tent, clips, etc.

7. Message from Marketing Director, Marlyn Waller

8. Three performance reviews by Goodwin on J.D., Pat and Chris. A note requesting that they be filed is attached.

9. Envelope from Emerson with Administration Outline and note from Emerson.

10. Goodwin's letter of resignation.

11. Computer software ad and memo from Senior Computer Editor, Everett Carlson

12. Taped message from Bruce Farley

13. Taped message from Pat Ramirez

- - - - - - - - - - - - - - - - - - - - -

(30 minutes)

14. Interview

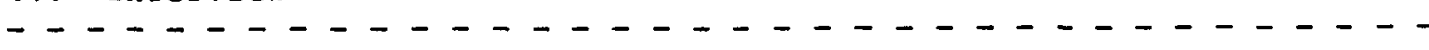

(15 minutes)

15. Action Report Form 
Appendix S

Administration Directions for First Pilot Groups

1. This is an individual exercise or simulation. You may take a break for personal reasons any time, but please do not discuss the in-basket with each other until you leave.

2. After the in-basket, you will be interviewed by two trained student assessors from local universities. You will be given a short form to complete.

3. Please do not discuss the in-basket with anyorie else in your organization who might be scheduled to take the exercise in February.

4. Please use the numbers assigned to you. Only I will have access to these codes.

5. I will forward an individual analys is of your work to you alone in a few weeks. I will schedule a discussion session on the exercise after the February date. Your attendance at this is optional.

6. Once we begin, no questions will be answered. Use the information you have at hand to make your decisions.

7. (Distribution of introductory materials. Reading of directions. Five minutes later, show video through twice. The five minutes gives the participants time to read the newspaper article and organization chart.)

8. (Distribute in-baskets. Reading of directions. Participants have one hour to complete exercise from this point.)

9. Fifteen minutes later: play the audio tape with these directions: 
Appendix S (Continued)

You notice your answering machine is blinking. You play your messages through twice.

10. Announce ten minutes to go at the appropriate time. 


\section{Appendix T \\ Administration Directions for the Meret In-Basket \\ Outline}

1. Overview of Meret In-Basket and its Purpose

2. Items (Appendixes $A-Q$ )

3. Scoring Key (Appendix W)

4. Administrative Directions

5. Meret Interview Form (Appendix TT)

6. Sample Dimension Sheet (Appendix HH)

7. Sample Assessor Notes on Items (Appendixes $Y, Z$ )

8. Action Report Form (Appendix V)

9. Assessor Training Manual (Appendix AA)

10. Scorers' Training Outline and Materials (Appendix FF)

11. Sample Comments for Participants (Appendix VV)

12. Materials Checklist 
Appendix $\mathrm{T}$ (Continued)

1. Overview of the Meret In-Basket and Its Purpose

The Meret In-Basket was designed for middle management level

participants to test their level of political awareness and ability to respond effectively in a political situation. To set the stage, there are several introductory materials providing a sense of the company: an organization chart and a newspaper article about the merger of two fictitious publishing companies -- Meret and Muse. Along with these items, the participant receives a name card to place in front of their work area and a short set of instructions. They are given the identity of Chris Wallace, the manager of human resources at Meret Publishing Company. The newspaper article gives insights into the vitality of the company -- it is an investment plum for Muse International. .

Then the participants are asked to watch a short video from a Muse vice-president, Bryan Emerson. Emerson directs Chris Wallace and his or her two peers, J. D. Ulrich and Pat Ramirez, to come up with a plan to restructure the administrative function at Meret.

The participants now receive the actual in-basket items which supposedly collected during the same day while wallace was at a conference. There are a few items and two envelopes in the in-basket. From this point on, the participants have an hour to complete the exercise.

The items in the in-basket all interrelate and the participants must use their organizational chart frequently to follow the characters' positions at Meret. Two messages are from people senior in Meret to Chris Wallace. One envelope contains the written request 
Appendix $T$ (Continued)

Emerson explained to them and the other envelope, a set of performance reviews. By the time the participants have read over these things, two telephone messages are heard via a tape player. These last two items add relationship issues to the scenario.

This is not a traditional in-basket seeking to test one's planning, time management or writing skills. The Meret in-basket represents a political environment and the successful completion of the exercise depends on the participants' repertoires of political behaviors. But even more importantly, its successful completion calls for a political framework of analysis. 


\section{Appendix T (Cont inued)}

4. Administrative Directions (to be read by the administrator)

[Standarized verbal directions and procedures to be used after the participants are settled and ready to begin.]

1. This is an exercise, also known as a simulation.

2. You will work alone and you may take a break at any time, but please do not discuss the exercise with each other until the end of the entire process.

3. No questions will be answered once you begin. Use the information you have at hand to make your decisions.

4. [Discuss arrangements for interviews and the action report form.]

5. Please use the numbers assigned to you.

6. [Distribution of introductory materials. Read Background Information Sheet aloud.]

7. [Start timing a five minute segment. Participants use this time to read the introductory materials.]

8. [Five minutes later, show the video of Bryan Emerson through twice, after saying these words: "You have been called to view this tape sent by Muse's vice-president, Bryan Emerson. You run the tape twice."]

9. [Distribute the in-baskets. Read the Final Directions Sheet aloud. Participants have one hour from this point to complete the exercise.]

10. You have until -- one hour to complete the exercise.

11. [Fifteen minutes into the hour, play the audio tape after saying these words: "You notice your answering machine is blinking. You 


\begin{abstract}
Appendix $T$ (Cont inued)
play your messages through twice."]
\end{abstract}

12. [Announce ten minutes remaining at the end of the hour. Collect materials at the end as people finish and direct the first participants finished to their assigned interviews. Some participants may need an extra five minutes -- that is acceptable, but do not give more time than that.] 
Appendix T (Continued)

12. MATERIALS CHECKLIST

1. Table tents: Chris Wallace, Manager of Human Resources, Meret Publishing Company

2. Pens, paper clips, extra paper

3. In-baskets

4. Video tape and recorder/monitor

5. Audio tape and audio playback machine

6. Background information, organization chart and newspaper article

7. Red pens for assessors

8. Dimension sheets for assessors

9. Administrative Directions

10. Scoring key and scoring sheets

11. Feedback materials for participants

12. Action Report Forms

13. Meret Interview Form 
Appendix $U$

Meret Interview Form

1. What did you think of the Meret situation?

2. Go through each item, be sure you understand what the participant did, make marginal notes when necessary, probe for reasons decisions were made.

3. How did you approach the In-Basket? (Sort, sequence)

4. What was the most challenging item and why? 
Appendix U (Continued)

5. What experiences and strengths did you bring to the situation?

6. How willing were you to make a decision based on the information at hand?

7. Do you think you, as Chris, would have an impact on the organization? 


\section{Appendix V}

\section{Action Report Form}

Now that you have completed the In-Basket, please answer the following questions:

1. What three words would you use to describe the situation at Meret?

2. Which three items requiring attention from Chris Wallace are the most critical in this situation (Please write a \#l 1 by the most critical, a \# 2 by the next most critical, etc.):

1. Message from the Marketing Director, Marlyn Waller

2. Three performance reviews on J.D., Pat and Chris

3. Emerson's Administration Outline

4. Goodwin's letter of resignation

5. Computer editor's memo about the personnel software system

6. Answering machine message from Bruce Farley

7. Answering machine message from Pat Ramirez

3. Which decision or action of yours as Chris Wallace was the most outstanding? In other words, about which decision are you most confident? Why? 
Appendix V (Continued)

4. About which decision are you the least confident? Why?

5. Did your professional background/experiences help you in any way with the Meret situation?

6. Open comments on the Meret simulation exercise. 


\section{Appendix \\ Scoring Reg.}

1 Waller Message -- Request in person for assistance with an interview and policy decision on transfer of personnel from Muse.

\section{Considerations}

- Waller is director of marketing for Meret

- Waller stopped by C.W.'s office in person

- Waller is quored in newspaper article

- Waller asks for policy suggestions on Muse transfers

- Waller asks for help in setting up an interview

\section{Rating Scale and Indicators of Political Behavior}

Low

1

2

Fails to influence or take action to influence others. Relies heavily on formal organizational structures. Avoids competition and conflict. Fails to see or use proven resources of one's self or others. Does not promote self-interests or solve issue at hand.

- Defers to muse's policy and delays response

- Returns meno to Waller, deferring policy decisions

- Sees memo as unimportant

- Needs further information

- Sees request for transfer only as a single request

- Waits; anticipating a layoff

- Avoids influencing new policy; "it isn't up to C.W."

- Does not want to look as though he was "plrating"; wants to protect self
Moderate

3

Takes action to solve immediate issue demonstrating influence and desire for power. Exhibits some political awareness and some range of political behaviors. Makes moderate, often negative, political assumptions. Relates itens to each other. Proactive. More prescribed than discretionary actions.

- Arranges interview details through Mark or Cathy; delegates recruitment function appropriately

- Plans to meet waller or Emerson to discuss policy on transfers

- Sees transfer of people from St. Louis as a good way of infusing new ideas and fresh approaches

- Contacts applicant directly; sees him as an alliance

- Reassures waller; opens door for relocations both ways; ccoperation

- (Some contact with waller is minimm response here.)
4

High 5

Goes beyond moderate levels of behavior and actions. Exhibits high level of polftical awareness and ability to take appropriate action. Promotes one's self or group's interest. Influences. Does not avoid conflict or competition with others. Displays ambition and desire for power. Attributes strong political motives to others.

- Contacts Waller and Meret president to establish transfer policy; seeks alliance with Meret president

- would talk with counterpart at Muse regarding details for influencing purposes

- Meets with waller for lunch to discuss impact of merger and to explore hidden agenda; seeks alliance 
Appendix W (Continued)

\#2 Administrative Out line - This came in a sealed envelope from Emerson. It is a two-page item containing four questions: 1. What would you do formally to restructure the administrative function at Meret? 2. What would you do. informally? 3. How would you proceed? 4. Who would you choose to report to me and why?

\section{Considerations}

- These are the materials promised by Emerson in the video presentation

- Emerson's video presentation gives the rationale for this outline

- Emerson requires an immediate response

- Emerson is a senior V.P. at Muse who is responsible. for everything but the editing function

- Emerson attaches a post-it note to the outline claiming that C.W. is his number one choice for the position

- This is the most critical item in the in-basket

(NOTE: This item is critical. For a 5 score, several behaviors in the High column must be demonstrated, as well as behaviors in the Moderate column. Also, if a participant fires Pat Ramirez immediately, although that might seem to be a power stance to reduce an adversary, the judges felt this act would be politically unwise in the Meret situation.) 


\section{Appendix W (Cont inued)}

Rating Scale and Indicators of Political Behavior

Low

1

Fails to influence or take action to influence others. Relies heavily on formal organizational structures. Avoids competition and conflict. Fails to see or use power resources of one's self or others. Does not promote self-interests or solve issue at hand.

- Hedges; presents outline as a draft only, more details to come

- Advocates little structural change

- States that only Meret should report to Emerson

- Avoids competition over position with J.D., Pat.

- Avoids confrontation with others

- Recommends someone else to be coordinator; resits the challenge of the new position

- Sees note from Emerson as confldence builder; no action

2
Maderate 3

Takes action to solve immediate Issue demonstrating influence and desire for power. Exhibits some political awareness and sone range of political behaviors. Makes moderate, often negative, political assumptions. Relates items to each other. Proactive. More prescribed than discretionary actions.

- Implements computer network based on Carlson's memo

- Aligns policy and procedures with Muse; moves finance under Muse V.P.

- Plans to ineet directly with Emerson

- Suggests regrading, retaining and integration of certain positions in administration

- Meets with Meret adninistrative heads and Farley to plan

- Vents feelings and discusses roles with everyone to bulld teamwork

- Eliminates managerial roles from Goodwin's staff

- Feels that informal reporting causes internal problems

- Gives direction to J.D., Pat based on reviews

- Assumes role as coordinator; moderate pewer displayed

- Believes post-it note means "He's in a position to make it happen for me"

- Suggests Pat may be an undesirable employee coes beyond moderate levels of behaviors and actions. Exhibits high level of political awareness and ability to take appropriate action: Promotes one's self or group's interest. Influences. Does not avoid conflict or competition with others. Displays ambition and desire for power. Attributes strong political motives to others.

- Notes that all three may have received note from Emerson, suspicious

- Questions if Carlson or athers "fit politically"

- Sees need for macro view of Muse/Meret by all personnel

- Generates a memo from Emerson explaining changes; assumes full power

- Assumes higher level than Coodwin's original position; widens responsibilities of $\mathrm{C} . \mathrm{W}$.

- Gives added responsibilities to J.D. and Pat; gives equal staff numbers to them

- Meets with J.D. and Pat to discuss restructuring and teamwork; form alliance with $P$ at and legal department

- Highlights own strengths and others' weaknesses; trade off tasks to J.D. for C.W. support

- Needs to know who supports what decision; "get them into my camp"; manipulate levels as you rise

- Conceal fact that C.'N. has inside $P R$ on J.D. and P.R.

- Plans to work closely with Coventry to keep track of operational needs 


\section{Appendix W (Cont inued)}

\#3 Letter of Resignation -- This is a full letter from Goodwin that expresses $h$ is reasons for retiring early and $h$ is confidence in the three managers. Goodwin includes several important strategic planning facts in the letter.

\section{Considerations}

Goodwin expresses confidence in each of the three managers

Goodwin indicates Meret's culture: family atmosphere and love of books

Goodwin sees Muse as a large bureaucratic structure

Goodwin announces staff increase to 425

Goodwin announces Coventry Meret's new reporting relationship to Sr.

V.P. at Muse

Meret will receive capital and building monies

Meret's financial system will conform to Muse's

Rating Scale and Indicators of Political Behavior

$$
\text { Low }
$$$$
1
$$

2

Fails to influence or take action to influence others. Relles heavily on formal organizational structures. Avoids competition and conflict. Fails to see or use power resources of one's self or others. Does not promote self-interests or solve issue at hand.

- Does not respond to letter

- Responds positively to information but takes no action; received overall feel for situation

- Sees need for more information before fully developing plans

- Focuses on one item of information only

- Holds information until organizational structure is complete
Moderate

3

Takes action to solve immediate issue demonstrating influence and desire for power. Exhibits some political awareness and some range of political behaviors. Makes moderate, often negative, political assumptions. Relates items to each other. Proactive. More prescribed than discretionary actions.

- Issues memo to staff because of effect Goodwin's announcement will have on them

- Uses information in letter for other itens, especially outline for Emerson

- Writes letter of appreciation to Goodwin; takes action on items

- Delegates payrol and recruitment tasks to staff

- Thinks C.W. may be Goodwin's heir apparent

- Saw clues as to how to move up the "ladder"

- Saw need to use the same information as other managers had
High

Goes beyond moderate levels of behavior and actions. Exhibits high level of political awareness and ability to take appropriate action. Pronotes one's self or group's interest. Influences. Does not avoid conflict or competition with others. Displays ambition and desire for power. Attributes strong political motives to others.

- Arranged retirement lunch or dinner and exit interview for Goodwin; family culture reinforced; future networking insured

- Explores reasons for retirement; expresses concern that Goodwin is avoiding corporate battles by retiring

- Shares strategic planning information with Evans and Carlson

- Sees political maneuvering and ego involvement 


\section{Appendix W (Continued)}

\#4 Computer Senior Editor's Memo -- This memo supports Wallace's interest in a personnel software system. It also praises Wallace for the administrative improvements that have been made.

\section{Considerations}

- Carlson is a senior editor at Meret

Wallace solicited opinions from Carlson on the software system

Carlson shows strong support for what C.W. has done at Meret

Carlson shows interest in alliance about teleconferencing and networking to St. Louis

Article on computer software relates to C.W.'s performance review goal of computerizing personnel system

Computer publications are a chief growth area for Meret

\section{Rating Scale and Indicators of Political Behavior}

Low

1

2

Fails to influence or take action to influence others. Relies heavily on formal organizational structures. Avoids competition and conflict. Fails to see or use proven resources of one's self or others. Does not promote self-interests or solve issue at hand.

- Writes memo to Carlson about Muse's requirements; misses point entirely

- Defers to J.D. for review; unsure of who Carlson is

- Focuses on educational worth of Comshare course

- Wants more information; sets aside; no response

- Expresses concern about work/ information from someone in another department
Moderate

3

Takes action to solve imnediate issue demonstrating influence and desire for power. Exhibits some political awareness and some range of political behaviors. Makes moderate, often negative, political assumptions. Relates items to each other. Proactive. More prescribed than discretionary actions.

- Further action and research on Comshare; desire to match with Muse's system

- Ask Carlson for names of people to be trained

- Wants Farley to see materials

- Solicits information on electronic mail

- Assumes Carlson to be "kissing up"

- Thinks C.W. has "something going" with this manager; feels his information could be an asset
High

4.5

Goes beyond moderate levels of behaviors and actions. Exhibits high level of political awareness and ability to take appropriate action. Promotes one's self or group's interest. Influences. Does not avoid conflict or competition with athers. Displays ambition and desire for power. Attributes strong political motives to others.

- Arranges luneh with Carlson to "check him out"

- Invites representatives from Muse to discuss automated systen

- Uses information in outline for Emerson

- Saw memo as information for favor exchanges from this department

- Sees Carlson as important figure in future organization changes; builds coalition with him and editorial group

- Arranges meeting with Carlson and others to discuss electronic mail and networking/datalinking

- C.N. sees self as anead of J.O. and Pat because of the contact with Carlson and his position 
Appendix W (Continued)

\#5 Telephone message from Bruce Farley -- This is a brief message requesting a conversation with C.W. about J.D. taking Goodwin's place

\section{Considerations}

- Farley is a member of Pat's staff

- Farley is confiding his concern about rumor with C.W.

- Rumor indicates Emerson's request has been spoken about by either J.D. or Pat

- J.D. is seen as rigid, not a communicator

- Farley, as data processing supervisor, controls information flow in Meret

Rating Scale and Indicators of Folitical Behavior

Low

1

2 irate

3

Takes action to solve immediate issue demonstrating influence and desire for power. Exhibits some political awareness and some range of political behaviors. Makes moderate, often negative, political assumptions. Relates items to each other. Proactive. More prescribed thap discretionary actions.

- Views Farley's message as support for self (C.W.)

- Ignores because Farley is outside chain of command or at a lower rank

- Plans to get back to him; acknowledges message

- Takes no action

- Puts Farley off until all changes are in effect

- Ignores information regarding J.O.; does not relate to performance review
- Plans to call Farley so that Farley can vent concerns; C.W. to assess situation

- Plans to comment on Farley's concerns; plans to "set Farley straight"; gives facts as they are

- Feels message was "bad politics" -- wants to know more about what is going on politically

- Keeps neutral with B.F. So as not to fuel any more rumors; withholds information from him

- Reassures B.F. that he will be with P.R., not J.D.
4 High :

Goes beyond moderate levels of behavior and actions. Exhibits high level of political awareness and ability to take appropriate action. Promotes one's self or group's interest. Influences. Does not avoid conflict or competition with others. Displays ambition and desire for power. Attributes strong political motives to others.

- Seeks to gain information on J.D.; sees Farley as source of information on problems

- Uses information to reinforce negatives about J.D., Pat

- Requests advice from Farley despite fact he is at a lower level

- Relates Farley's role to Comshare and electronic mail; sees him as a gatekeeper

- Assumes political motives to Farley, e.g., he wants P.R. promoted so B.F. would move up; or B.F. is sabotaging J.D. for P.R.

- =elt that P.R. had talked to B.F. to put idea of rumor in B.F.'s mind to feel out the tninking process that was taking place 
Appendix $\mathrm{W}$ (Cont inued)

\#6 Telephone Message from Pat Ramirez -- This call requests support from C.W. in Pat's role to coordinate the administrative functions at Meret. Pat implies favors owed to her.

\section{Considerations}

- Pat is manager of the legal department, an attorney

- Pat implies favors owed to hei by C.W.

- Pat wants backing for the positicn

- Pat presents her caze on seniorjcy and legal background

- Performance review on Pai indicates her rivalry stance with others

\section{Rating Scale and Indicators of Political Behavior}

Low

1

Fails to influence or take action to influence others. Relles heavily on formal organizational structures. Avoids competition and conflict. Fails to see or use power resources of one's self or others. Does not promote self-interests or solve issue at hand.

\footnotetext{
- No response

- Avoids any confrontation with Pat

- Ignores favors owed statement

- Sees request for support as a weakness, "if you can't make it on your own merits and have to go begging, hat in hand..."

- Appeals to objectivity and professionalism to handle this

- Refuses to make decisions based on tradeoffs
}

Moderate
3
Takes action to solve immedi-
ate issue denonstrating influ-
ence and desire for power.
Exhibits some political aware-
ness and some range of politi-
cal behaviors. Makes moder-
ate, often negative, political
assumptions. Relates items to
each other. Proactive. More
prescribed than discretionary
actions.
- Relates message to Pat's
performance review
- Plans to meet to preserve
long-range relationship
o Sees Pat as potential obstruc-
tion; mistrusts her; refuses
support; she may quit
O Feels message is controver-
sial and seeks to explore
Pat's ideas
- Seeks to explore "favors
owed" comment; resents it
- Meet with P.R.; focus on
positive to avoid fight
- Feels owing P.R. favor is
something to consider
depending on relationship
of mentor or peer
a
4
High
a

Goes beyond moderate levels of behaviors and actions. Exhibits high level of political awareness and ability to take appropriate action. Promotes one's self or group's interest. Influences. Does not avoid conflict or cempetition with others. Displays ambition and desire for power. Attributes strong political motives to others.

- Invites Pat to lunch to discuss their bids for position; willing to compete

- Offers Pat compromise on other situations that might arise; give her more responsibilities as favor

- Shares information with Pat as a peer; negotiates; convinces

- Uses message to build negative case vs. Pat ; refuses support;

- Requests give and take of support, defines positions, lays cards on table

- Sees Pat as peer and imoortant ally 
Appendix W (Continued)

\#1 Performance Reviews -- Reviews for J.D., Pat and Chris are in a sealed envelope to C.W. marked: "Confidential for the files from C. Goodwin". Each review indicates excellent contributions by the three managers.

\section{Considerations}

C.W. is the reviewer's signature

Reviews are dated $2 / 3 / 86$ before the merger article

Each manager has growth areas to address

Pat Ramirez

10 years service; staff of five

Excellent track record in courts, translation rights and export areas

Several critical growth areas to attend to

Denies problem areas

- J. D. Ulrich

5 years service; staff of seven

Excellent merger work

Excellent efficiency with day to day

Needs interpersonal help from $C . W$.

$\circ$

C. Wallace

$3 \frac{1}{2}$ years service; staff of three

St reamlined administration

Macro perspective

knows all stakeholder groups, both within and without Meret

Needs budget help

Poor typist 
Appendix W (Continued)

Rating Scale and Indicators of Political Behavior

Low

1

Fails to influence or take action to influence others. Relies heavily on formal organizational structures. Avoids competition and conflict. Fails to see or use power resources of one's self or others. Does not promote self-interests or solve issue at hand.

- Refuses to use any of this information, either positive or negative, or both

- Moderate use only as background information to strengthen C.W.'s stand
Moderate

3

Takes action to solve immediate issue denonstrating influence and desire for power. Exhibits some political awareness and some rante of political behaviors. Makes moderate, often negative, political assumptions. Relates items to each other. Proactive. More prescribed than discretionary actions.

- Expresses suspicion about receiving reviews; were they a "hidden agenda" from Emerson, i.e., use to make a stronger case for C.W.'s new position

- Takes time to assess strengths and weaknesses of each; strengthens C.W.'s position

- Would forward C.w.'s review to Emerson, withhold others
High 5

Goes beyond moderate levels of behavior and actions. Exhibits high level of political awareness and ability to take appropriate action. Promotes one's self or group's interest. Influences. Ooes not avoid conflict or competition with others. Displays ambition and desire for power. Attributes strong political motives to others.

- Conceals that C.W. has information, but uses it to cover self and for own purposes

- Sees information as helpful to a political awareness

- Attempts to confront Pat about managerial style expecting Pat might quit

- Uses all information to sell self; focus on weakness of J.D., Pat 


\section{Appendix X}

\section{Dimensions}

1. Self-interest, Power: ambition and desire for influence, wanting power ( $n$ power), the power motive, independence, dominance and superiority .

2. Coalition Building: alliances and coalition building with other individuals and units, developing and maintaining a power base. (Independent of the formal structure, coalitions are explicitly created by their members for a specific purpose. Coalitions must act as a group, e.g., jointly signing a memorandum.)

3. Neutralizing Opposition: neutralizing or destroying stakeholders, e.g., firing, ignoring, reprisals, blocking, attacking or blaming others. (Scapegoating and blaming are usually reactive. Proactive attacking is more personal and is usually geared toward reducing competition with a rival.)

4. Gaining Support: gaining support from higher levels, aligning with powerful others, clearing the investment with the immediate boss, ingratiating oneself with one in authority, praising, establishing good rapport and touching bases.

5. Use of Information: using information as a political tool, e.g., withholding, distorting, using information to overwhelm others, outright lying or falsifying in some instances, using selective disclosures or innuendo, whistleblowing and overwhelming the target with data to obscure a piece of information. 


\section{Appendix X (Continued)}

6. Using Resources: using material and physical resources, accessing information, securing personnel assignments, equipment or space as political tools. Also, collecting data, garnering real or symbolic resources to support one's position.

7. Exchanging Favors: exchanging favors, horse trading, developing quid pro quo deals, making payoffs in exchange for support, and performing services or favors to create obligations.

8. Outside Activity: talking with a counterpart from another organization or engaging in outside professional activity.

9. Bargaining, Compromising: bargaining, negotiating, compromising, usually with regard to issues and policies.

10. Sense of Organization: stakeholder sense/analysis, understanding organizational dynamics and the macroview, and knowing the gatekeepers and power centers. 
Sample Assessor Notes on Item

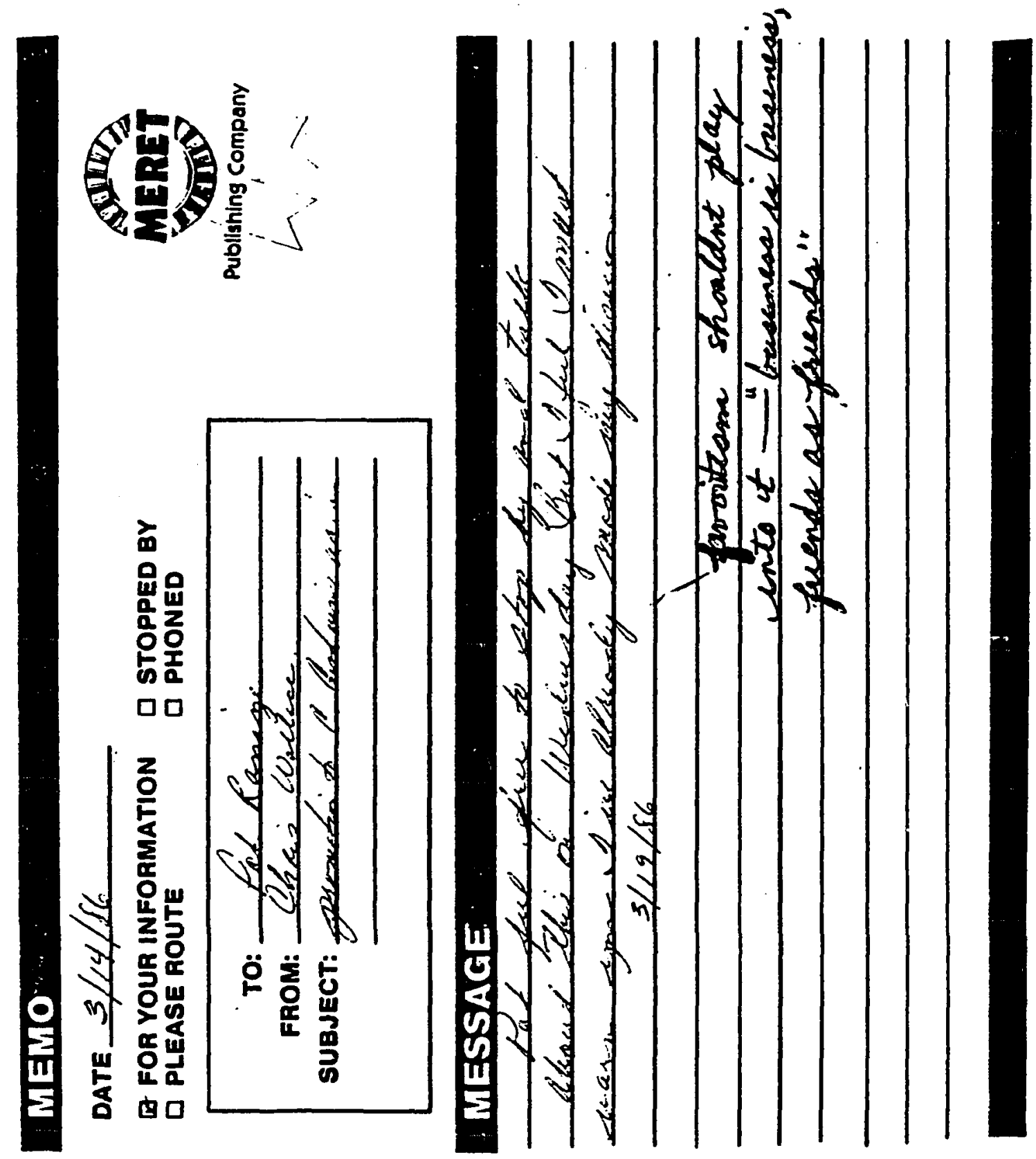



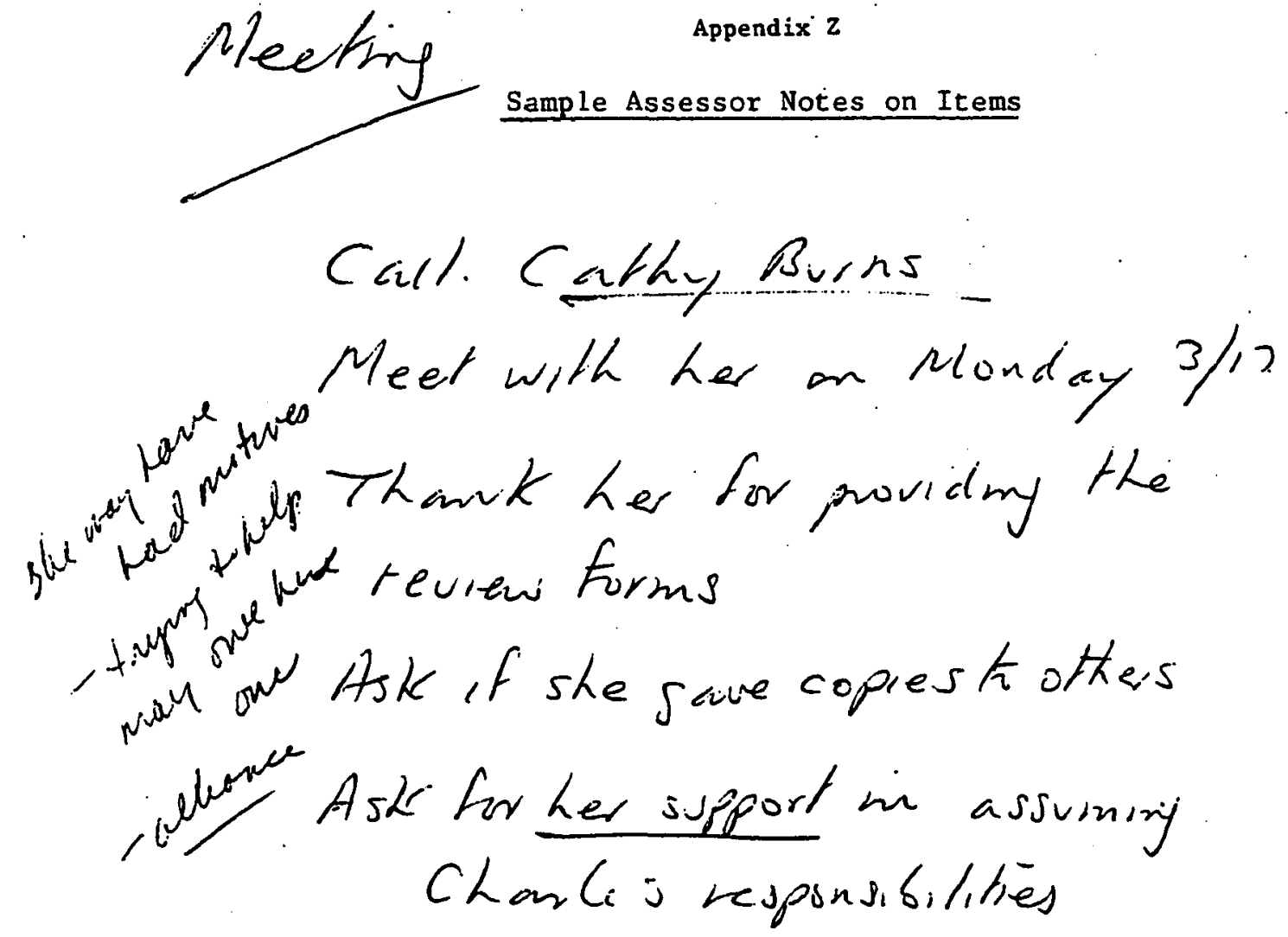
Appendix AA

Assessor Training Manual

DOCTORAL RESEARCH PROJECT

GLORIA E. BADER

Assessor Training Manual

January 1986

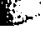

Reproduced with permission of the copyright owner. Further reproduction prohibited without permission. 


\section{Appendix AA (Continued) \\ Training Session for Student Assessors}

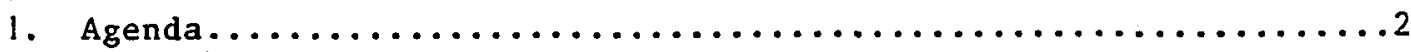

2. List of student assessors..........................

3. Times, dates, place of interviews, maps, parking tickets.......4

4. Research information

a. Abstract and design summary....................

b. Assessor roles and APA Guidelines...............10-11

c. Confidentiality..............................

d. Ethical Statement...........................

e. Interrater reliability checks................. 14

5. Definition of political behavior .................

6. Dimensions of political behavior.................. 16-17

7. Interview techniques and guidelines................ 18-19

8. Semi-structured interview form - Meret Interview Guide......20-21

9. Action Report Form..............................22-23

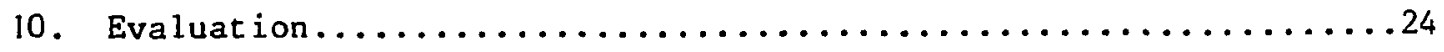

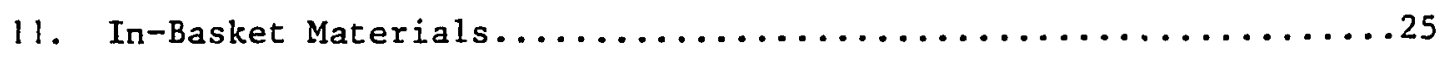


Appendix AA (Continued)

Training Session for Student Assessors

1. Agenda.

2. List of student assessors

3. Times, dates, place of interviews, maps, parking tickets

4. Research information

a. Abstract and design summary

b. Assessor roles and APA Guidelines

c. Confidentiality

d. Ethical Statement

e. Interrater reliability checks

5. Definition of political behavior

6. Dimensions of political behavior

7. Interview technique and guidelines

8. Semi-structured interview form - Meret Interview Guide

9. Interview summary sheet

10. Action Report Form

11. Evaluation 
Appendix AA (Continued)

MERET SIMULATIONS

I. Tuesday, January 21, 1986

9:30 a.m. - 1:00 p.m.

University of San Diego, Manchester Center

Room 206A

Lunch will be provided.

Maps and parking tickets are attached

II. Monday, February 24, 1986

5:00-8:00 p.m.

Main Conference Room - Enter off Main Lobby

Supper will be provided 
Appendix AA (Cont inued)

ABSTRACT

As educational leaders, it is important to recognize and understand the levels and complexities of political behavior. We must learn to value political activity. Consequently, the objective of this research is to design an instrument, in the in-basket simulation format, which measures the amount, type and occasion of an individual's political behavior. Furthermore, the post in-basket interview will examine individuals' underlying reasons for acting or not acting in a political manner. The instrument will test the theories about politics in organizations .

The in-basket's construct is threefold: a composite definition of political behavior; a typology of political behavior; and the body of social exchange theory which includes power considerations. The researcher will collect critical incidents related to political behavior and draw upon case studies to design the in-basket. Two pilot groups will participate in the in-basket and generate responses to establish a scoring key. Expert judges experienced in organizational politics will then organize a behaviorally anchored scoring key. Instructions, the interview format and administration procedures will be standardized. In short, every effort will be made to produce a valid and reliable instrument for measuring and interpreting political behavior. 


\author{
Appendix AA (Continued) \\ Understanding Individual Political \\ Behaviors in Organizations: \\ Instrument Development and Validation \\ Statement of the Issue
}

Organizational politics impacts decision making, leadership, implementation, change and individual effectiveness. Although generally acknowledged as a reality of organizational life, political behavior is little understood and certainly a highly sensitive topic (Porter Allen \& Angle, 1981). Scholarly literature decries the paucity of empirical research in organizational politics (Farrell \& Peterson, 1983; Frost \& Hayes, 1979; Madison, Allen, Porter, Renwick \& Mayes, 1980; Porter et al., 1981).

A strong theoretical and empirical base is required from the nontraditional approaches to organizations. Alternate paradig:s, like the political one, can explain and assist organizations in ways the dominant rational approach cannot. The rational model emphasizes logic, order and goaldirected behavior that is predictable. Since its explication by Weber, Taylor and Fayol, this approach to organizational life has been so pervasive. that other models need the sling and courage of a David to defeat the Goliath. But actually, defeat is not the purpose; complimentarity is. For several reasons, it is important that educational leaders recognize and understand the levels and complexities of political behavior. For example, in today's global society, the cross-cultural nature of political behavior must be recognized (Dexter, 1976; Frost \& Hayes, 1979). Also, new leadership theories demand political skills of leaders (Burns, 1978; Hickman

$$
-6-
$$


Appendix AA (Continued)

\& Silva, 1984; Lindblom, 1980), and holistic views of policymaking and implementation give significant weight to political behavior (Allison, 1971). Tushman offered, "As organizations become more complex internally and as the change rate of technical and economic environments increases, the internal dynamics of organizations must be understood. The importance of a political perspective is then accentuated" (1977, p. 214). The requirement for political savvy is stronger than ever before.

The objective of this research is to design an instrument that will explore political behaviors. This instrument will be developed, validated, tested and examined for reliability. It will contribute to the very scarce, if not empty, pool of organizational political behavior assessments and it will facilitate quantitative and qualitative research.

An unstructured situational test in the in-basket format wili be to simulate a dilemma that may or may not evoke political behavior from the participants. Its purpose is to quantify, describe and understand individuals' political behavior in organizations. As a simulation, it will predict a person's ability to participate in political activity because, as Frederiksen stated, the in-basket "provides an opportunity for the examinee to display spontaneously certain response tendencies which comprise a part of his 'personality'" (1966, p. 107). The in-basket format serves all the requirements of this research.

The in-basket will comprise 10-12 items: memos, letters, taped telephone conversations, financial statements, involves, drafts of policies, and a short videotaped meeting. These items will be designed and integrated

$$
-7-
$$


Appendix AA (Continued)

based on critical incidents of upper management and the literature on power and politics. From the response of two pilot groups of 15 people each who will take the in-basket, expert judges will develop a scoring key of behavioral anchors. The judges will also identify the considerations important to each in-basket item and weight the items according to priority and organizational impact.

In addition, a multiple-choice form to be used as a post-test will be constructed. Known as the action report form (Kesselman, Lopez \& Lopez, 1982), this instrument and a semistructured interview will allow triangulation of all data collected (Guba \& Lincoln, 1981).

Construct validity of the in-basket will derive from three theoretical bases: a clear definition of political behavior as summarized by Porter et al. (1981), an excellent typology of political behaviors recently formed by Farrel1 \& Peterson (1982), and the body of social exchange theory which includes power considerations. Content validity will be founded upon careful construction of incidents, materials and the scoring key. Predictive and concurrent validity can only be achieved through time and simultaneous testing, respectively, and are inherent limitations of instrument development at its origins. Reliability will be checked through numerous procedures such as interrater correlation and standardized assessor training.

A few years ago, Porter et al. (1981) remarked that the study of organizational politics was in its infancy. Of the several factors that comprise the activity of organizational politics, the belief system, motives, and personal characteristics of the political actor are indeed critical. The 
Appendix AA (Continued)

questions arise: Who is the political actor? Who has the propensity to engage in political behavior? When?. Why? Are some factors more important than others? Not only are the answers to these questions underpinnings to research on political behavior in organizations, but also, the answers may serve as a hueristic device aiding the understanding of political leadership and the political education of organizational members. The post in-basket interviews of the participants will yield rich qualitative data addressing these questions.

The entire process of the development and validation of the in-basket will be rich in support of the theory of political behavior in organizations. The key individuals who will be asked to solicit participants will have their own understanding of political behaviors. The assessors will improve their understanding of the issue through the training, the interviewing, and the scoring of materials. The subjects themselves will upgrade their level of political awareness and, in turn, expand their repertoiries of political tactics. All of these secondary outcomes of instrument development will be reported in the findings of the research.

The research effort should contribute to the development of future leaders, to the future of research about political activity in organizations, to the history and study of the in-basket as an instrument of great potential and adaptability, and to individual political assessment on many levels. 


\section{Appendix AA (Continued)}

ROLE OF STUDENT ASSESSORS

Student assessors assist in interviewing the In-Basket participants, writing a summary of the interview, recording behavioral responses, marking the Action Report Forms and, in some cases, marking the In-Baskets.

It is important for the student assessors to be objective, neutral, and highly confidential with the data. 


\section{Appendix AA (Continued) \\ APA PERFORMANCE STANDARDS FOR ASSESSORS}

a. The ability to recognize, observe, and report the behaviors measured in the center.

b. The ability to classify behaviors into the appropriate behavior or skill.

Some measurement is needed indicating that the individual being trained has the capability of functioning as an assessor. The actual measurement of assessor performance may vary and could include data in terms of (1) rating performance, (2) critiques of assessor reports, (3) observation as an evaluator, etc. It is important that assessor performance is evaluated to ensure that individuals are sufficiently trained to function as assessors, prior to their actual duties, and that such performance is periodically monitored to insure that skills learned in training are applied.

Each organization should prepare to demonstrate that its assessors can meet minimal performance standards. This may require the development of additional training or another action for assessors not meeting these performance standards. 
Appendix AA (Continued).

CONFIDENTIALITY

Numbers will be assigned to each In-Basket participant for all

data collection purposes. Only the research leader will have access to the names/number key. Student assessors are required to sign an ethical statement about confidentiality. 


\section{Appendix AA (Continued)}

\section{ETHICAL STATEMENT}

(for Assessors)

I agree to the professional standards outlined by APA Guidelines for this research project and I promise to maintain confidentiality regarding the data collection and interviews that I conduct.

(Signed)

(Date)

$-13-$

Reproduced with permission of the copyright owner. Further reproduction prohibited without permission. 
Appendix AA (Continued)

INTERRATER RELIABILITY CHECKS

Two assessors will be assigned to interview one participant. For reliability purposes, both assessors must agree on the interview content. Both assessors will sign the interview summary sheet.

Two assessors will mark 15 In-Baskets separately and a statistical test to ascertain correlation of scores will be conducted. 
Appendix AA (Continued)

DEFINITION OF ORGANIZATIONAL POLITICAL BEHAVIOR

1. Social influence attempts which can be obligations and resource exchange;

2. That are discretionary (i.e., that are outside the behavioral zones prescribed or prohibited by the formal organization);

3. That are intended (designed) to promote or protect the selfinterests of individuals or groups (units); and

4. That threaten the self-interests of others (individuals, units). 


\section{Appendix AA (Continued)}

\section{DIMENSIONS}

1. Advocating own self-interest or interest of one's group/department and at the same time achieving organizational goals. Ambition and desire for influence and power ( $n$ power), wanting power.

2. Coalitions, building alliances with other individuals and units, developing and maintaining a power base.

3. Neutralizing or destroying stakeholders, e.g., firing, ignoring, reprisals.

4. Gaining support from higher levels, aligning with powerful others. clearing the investment with the immediate boss.

5. Withhoiding information.

$-16-$ 
Appendix AA (Continued)

6. Using material and physical resources, access to information, securing personnel, equipment or space.

7. Exchanging favors, horse trading, payoffs in exchange of support.

8. Talk with counterpart from another organization; outside professional activity.

9. Bargaining, negotiating, compromising.

10. Stakeholder sense/analysis/ knowledge of organization.

$$
-17-
$$


Appendix AA (Continued)

\section{INTERVIEW TECHNIQUES AND GUIDELINES}

There are many kinds of interviews, such as: job, information gathering, biographical. The interviews for the In-Basket partiçipants fall more.into the information gathering category. The purpose of this interview is to offer the participant the opportunity to more fully explain decisions and to establish the degree of the participants' understanding of the characters and the problems in the exercise (Griffiths, 1979).

The interview for this research will combine an Action Report Form and a semistructured interview. The richness of these interviews will attest to the motives of the political (or nonpolitical) actor. Ethical dilemmas will surface and reasoning processes will emerge. The valuable quantitative results of the Action Report Form, plus the colorful reflections of the more open interview, will complement each other.

Be sure to follow these guidelines:

1. Introduce yourself. Relax the participant by saying something like: "Well, now Chris Wallace can talk to us about how his/her day went!" or "This is a short interview to let you tell us what you thought about Meret, Chris, and why you did what you did. It will only take a half hour."

2. Explain the role of two assessors. "In order for us to be objective about this interview, the two of us must agree and keep each other on target!"

$-18-$ 
Appendix AA (Continued)

3. Follow the interview format. Take notes.

4. Use probe questions, such as: "Tell me more about how you came to that decision," "What was that like?" "How," and "Why that choice?"

5. Repeat or summarize certain statements, "You had many worries about Pat..."

6. Watch for non-verbal clues and probe. "You seem to be excited about the chance to be the top person."

7. Maintain eye contact. Encourage openness via a nod or short interjection.

8. Avoid agreeing or disagreeing with decisions. Maintain neutrality, yet encourage opinions.

9. End the interview with a note of thanks. Remind the participants to complete the Action Report Form before they leave, if they have not already done so.

10. Remind the participants that they alone will receive the summary of their results. 
Appendix AA (Continued)

MERET INTERVIEW GUIDE

1. What did you think of the Meret situation?

2. How did you approach the In-Basket? (Sort, sequence)

3. What was the most challenging item and why?

4. What experiences and strengths did you bring to the situation?

$-2 \mathrm{C}-$ 
Appendix AA (Continued)

5. How willing were you to make a decision based on the information at hand?

6. Do you think you, as Chris, would have an impact on the organization?

7. Go through each item, be sure you understand what the participant did, make marginal notes when necessary, probe for reasons decisions were made. 


\section{Appendix AA (Continued) \\ MERET IN-BASKET ACTION REPORT FORM}

Now that you have completed the In-Basket, please answer the following questions:

1. What three words would you use to describe the situation at Meret?

2. Which three items requiring attention from Chris Wallace are the most critical in this situation ( $P$ lease write a \# 1 by the most critical, a 2 by the next most critical, etc.):

1. Message from the Marketing Director, Marlyn Waller

2. Three performance reviews on J.D., Pat and Chris

3. Emerson's Administration Out line

4. Goodwin's letter of resignation

5. Computer editor's memo about the personnel software system

6. Answering machine message from Bruce Farley

7. Answering machine message from Pat Ramirez

3. Which decision or action of yours as Chris Wallace was the most outstanding? In other words, about which decision are you the most confident? Why? 
Appendix AA (Continued)

4. About which decision are you the least confident? Why?

5. Did your professional background/experiences help you in any way with the Meret situation?

6. Open comments on the Meret simulation exercise. 
Appendix AA (Continued)

Evaluation

Background Information

Dimensions

Meret In-Basket

Materials

Interview Practice/Techniques

January 21 and February 24

Interviews

Forms

Format

$-24-$

Reproduced with permission of the copyright owner. Further reproduction prohibited without permission. 


\section{Appendix AA (Continued) \\ MATERIALS FOR MERET IN-BASKET}

(10-15 minutes)

1. Background In formation

2. Meret organization chart

3. Newspaper clipping about merger

$----\ldots-\ldots-\ldots-\ldots-\ldots-\ldots-\cdots$

( 5 minutes)

4. Video - Bryan Emerson's announcement

- - - - - - - - - - - - - - - - - - - - - - - - -

(1 hour)

Items as they appear in the In-Basket

5. Instructions

6. Blank memo paper, calendar, name tent, clips, etc.

7. Message from Marketing Director, Marlyn Waller

8. Three performance reviews by Goodwin on J.D., Pat and Chris. A note requesting that they be filed is attached.

9. Envelope from Emerson with Administration Outline and note from Emerson .

10. Goodwin's letter of resignation.

11. Computer software ad and memo from Senior Computer Editor, Everett Carison.

12. Taped message from Bruce Farley

13. Taped message from Pat Ramirez

- - - - - - - - - - - - - - - - - - - - - - - -

( 30 minutes)

14. Interview

- - - - - - - - - - - - - - - - - - - - -

( 15 minutes)

15. Action Report Form

$$
-25-
$$




\section{Appendix BB \\ Assessor Correspondence: Explanation of Research}

December 11,1985

Dear

You recently expressed interest in my doctoral research project by volunteering your time and energy for a number of hours. Before you fully commit yourself to this endeavor, I thought you would like some details. For example, this is what I would need you to do:

1. Attend one of two training sessions at : Monday, January 13, $1986 \quad 4: 00-7: 30$ p.m.

or

Wednesday, January 15, 1986 12:30-4:00 p.m.

(The agenda of this training session is attached.)

2. Conduct interviews of managers and perform various data collection tasks on two dates:

$$
\begin{array}{ll}
\text { Tuesday, January } 21,1986 & 9: 30 \text { a.m. }- \text { 1:00 p.m. } \\
\text { Monday, February } 24,1986 & 5: 00-8: 00 \text { p.m. } \\
\text { (Both sessions at } & \text { Corporation.) }
\end{array}
$$

3. (Only four students will be needed for this task). Mark 15 InBaskets over a week's time with the use of a scoring key.

February 6-13, 1986 or March 3-10, 1986

(This task can be done at or elsewhere.)

4. Participate in evaluation of tasks and materials of items \#1 through \#3.

By now, you are asking yourself the purpose of this project, what is in it for you, and why should you get involved. I will address each concern and then ask you to call and let me know your decision about participation. 
Appendix BB (Continued)

The purpose of my doctoral research project stems from the interest I have in developing leaders. Throughout my coursework at the University of San Diego, I have devoted specific attention to the political theories and skills essential to leadership. Because of the dearth of models, applications and experimental research on the topic, I decided to develop an instrument that could be used for future research, as well as for individual training in political skills. I chose the In-Basket instrument because of its projective capabilities and high face validity.

The design, development, testing and validation of an instrument is a complex dissertation topic in and of itself. Your assistance in the project is part of the internal validity process.

What is in it for you and why get involved are important concerns. I'II proceed from the bottom to the top of Maslow's hierarchy of needs to answer these questions.

1. You will be served lunch or supper at the training and data collection events.

2. You will have a safe, comfortable environment for the project and free parking.

3. You will meet and work with ten to twelve students from several universities who are interested in leadership, psychology and political behavior. You will meet and interview middle managers from numerous organizations in San Diego.

4. You will gain experience, a solid resume item, a letter of recommendation, academic credit (if applicable to your study program), and specific assessor skills. Your performance as an assessor will be evaluated.

5. Self-actualization is impossible to promise, but your enjoyment of the project and the sense of achievement you will have upon its completion could lead in that direction.

I would appreciate a call from you as soon as possible so that I can proceed with the organization of the research project. , extension

). In the meantime, best of luck to you as you end the quarter or semester. I look forward to hearing from you.

Sincerely,

Gloria E. Bader

GEB1st 
Appendix BB (Continued)

Agenda of Training

(Int roductions)

1. Out line research methodology and student assessor roles.

2. Preview In-Basket simulation and behavioral dimensions under study.

3. Review interview techniques; conduct In-Basket interview using a semistructured format; video practice.

4. Examine data collection techniques and materials, such as:

Action Report Form

Interview Summary

Inter-rater reliability checks

Recording of responses for panel of judges

5. Evaluate assessor training manual and procedures.

6. Demonstrate scoring of In-Baskets.

7. Evaluate assessor training.

Schedule

Monday, January 13, 1986

$$
\text { 4:00 - 7:00 p.m. at }
$$

$\underline{\mathrm{OR}}$

Wednesday, January 15, 1986

$12: 30-4: 00$ p.m. at

Please indicate which session you will attend. 


\begin{abstract}
Appendix CC
Assessor Correspondence and Materials (after first pilot group)
\end{abstract}

February 3, 1986

Dear

You did a fine job interviewing and collecting data for the Meret in-basket. The overall results are fascinating. All varieties of political behavior were displayed.

I've enclosed some Xerox samples of especially good materials you produced: interview summaries, index cards and dimension sheets. Please look them over before the 24th. I will make minor adjustments in the in-basket, e.g., add Carlson to the organization chart and make a clear note on the performance reviews. Also, several of you suggested going through the items at the beginning of the interview rather than the end. I will revise the interview sheet appropriately.

Another topic: if you are interested in being part of 0.D. Network and would not mind helping with registration at events, please call at . The first event is an all day'seminar on February 27 th at the Atlantis. I will send you the announcement as soon as it is printed.

The last in-basket session is here at

on Monday, February 24th. You can come to the main lobby at and the security guard will show you into the conference room. You need to be here by 5:30 at the latest. I would suggest that you come earlier to avoid traffic delays and to give yourself time to collect your thoughts. I expect the interviews to start at 5:30 p.m. We will have $18-20$ people this time, so some of you may do three interviews. It will be important to keep to a half hour for the interviews to keep things moving. Lastly, I will have refreshments and supper set up for you.

Again, I was pleased and impressed with your work as assessors. It will be easy to recommend each of you. Good luck with your classes.

$$
\text { Sincere1y, }
$$

Gloria E. Bader

GEBlst 
Appendix CC (Continued)

Welcome!

Here are materials for review and use this morning.

1. 3 Performance Reviews of the In-Basket. (These items were not complete during your training.)

2. Interview Questions - several copies

3. Red pen for marginal notes on items

4. Dimension sheets for data transcribing

5. $3 \times 5$ cards for item recording

6. Revised Assessor Iist

7. Evaluation sheet for Assessors

A. After your interviews, take the raw data from the In-Basket and the interview and "translate" that onto the dimension sheets.

B. Take the essence of each In-Basket item and transcribe that onto a $3 \times 5$ card.

C. Confer with your interview partner on all notes, $3 \times 5$ cards, dimension sheets, etc. Both interviewers must agree on the recording and analysis of all materials.

D. Be sure to keep each person's materials together in the original envelope.

When this is complete, we will discuss and evaluate the entire process thus far.

1,000 Thanks for an outstanding job! 
252

Appendix CC (Continued)

Meres Interview Form

1. What did you think of the Meres situation?

Pesmallengoyed it wast reef dectoperment, we how J row as a my e.

profesumally - paw courelateris worth everyday work

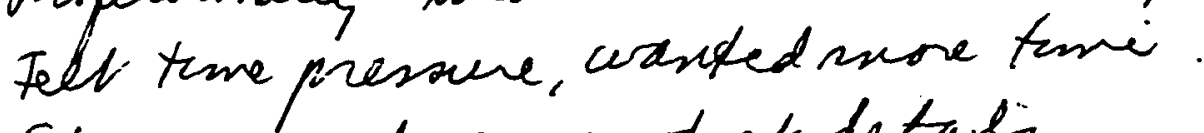

Chusuas not ven good at details.

2. Go through each item, be sure you understand what the participant did, make marginal notes when necessary, probe for reasons decisions were made.

3. How did you approach the In-Basket? (Sort, sequence) Look though every there feat Preoutze what a enjeortint ard colet not is deflower terns fen is.

4. What was the most challenging item and why?

Reorganization chert - What would charge.

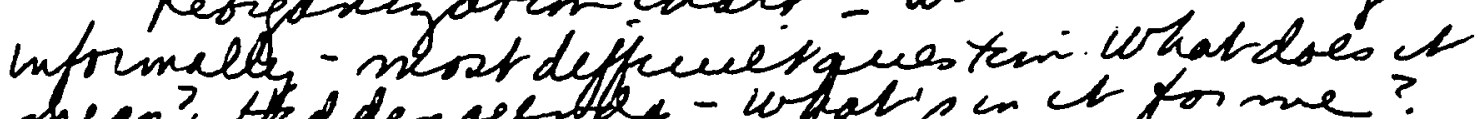
sheen? Hidden ogebthe - what is en ct for me?

Reproduced with permission of the copyright owner. Further reproduction prohibited without permission. 
253

Appendix CC (Continued)

5. What experiences and strengths did you bring to the situation?

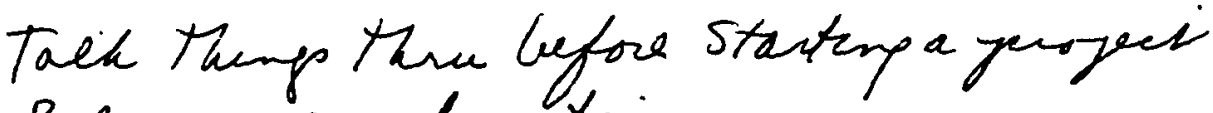
Role as a coorderato.

6. How willing were you to make a decision based on the information at hand?

meant surest le uris deciseon Hidden agenda.

Bod of co. careen in a hypothetical situation Real lefe-tend tow rids seef-inteiest You alcurag have to make decencies on inadequate data.

7. Do you think you, as Chris, would have an impact on the organization?

Broadens overview - Best qualified

Downgrade finance + legal

pood moodier

Reproduced with permission of the copyright owner. Further reproduction prohibited without permission. 


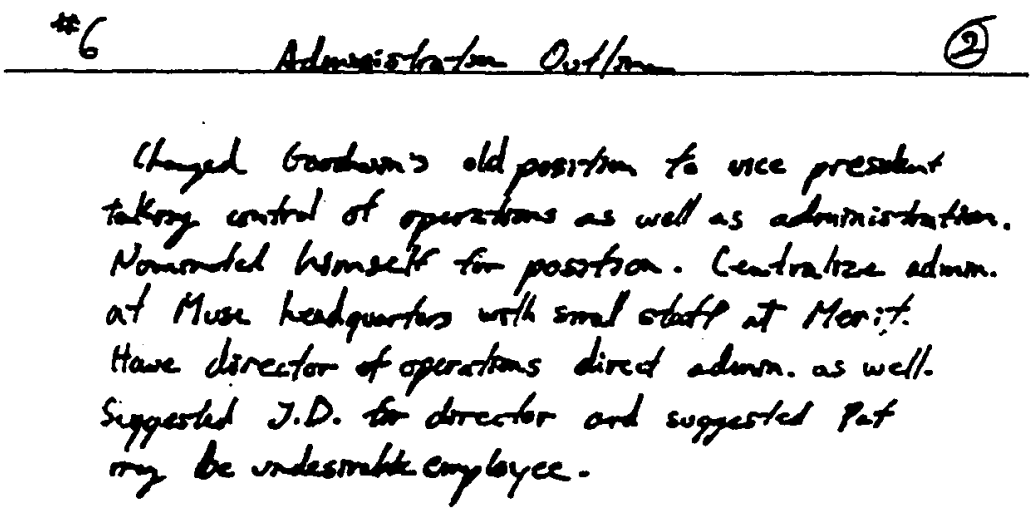

ADMIN. OUTUNe $\# 1$

WAS UNCOMFORTABLE WITH USING INTO. FROM PERTORMANICE APPRAISALS, BUT FELT CHRIS WOULD MAEE A BETER sHowING IF HE EHMVED AWAREARES OF $M D$. I PAT'S WEAKMTESSES MDD LISTED THGM SPECRECALUL gaw IT IMPORTONT THAT THE PERSONOTEL IN THE-DEPARONENTS UNDER HIM CAS NEW ADMINISTRATOR) UNDERSTOCD THE OVERALL COATS OF THE ORCANUZATLN, THE MACRDVIEN.

RESPONSE TO COST CUIIINGNEEOS - COMPUTERS F GREATER AUTOOMIION

\footnotetext{
13 (acis) $\# 2$

(2) direct access of Meret depts w/ Muse counter' parts; allowing for informal (bypassing) chain. - Concerned with chaed of conernand-STCKy POLIncauy "BE going through C. Meret who may have subsurted oun plan.

(3) mitg $w / B F+$ Meret admin heads - clarifygoals develip goals, determine procedure/mterface between 3 mgrs - alignment - roles procedures, policies. Investigate methods
} 
幽e

- reeveluate her ferformande review

- diswes with her such issues ad: What are her goals? Are youready for it. Pat?

- wald not sqy anything neqative about - ker-"inet that ksina of person"

- wauld say pasitive info. about her if asked - wald not gffer any info. spontaneausly.
(winhtd the info.)

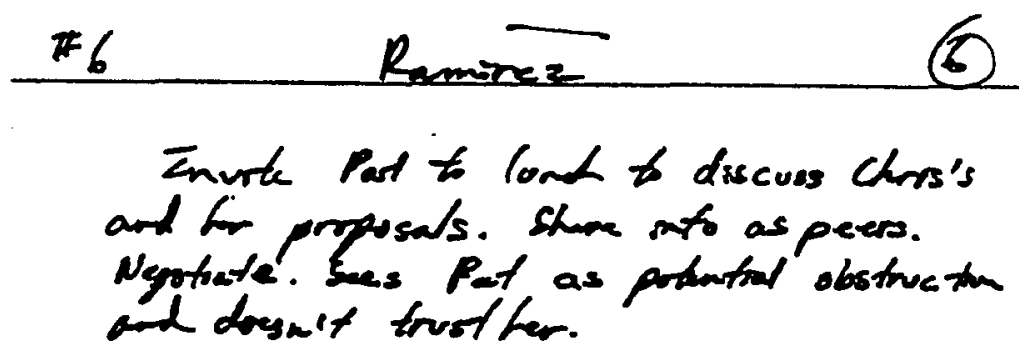

$x-0$

$+2$

7) Performance Revieus

- used info. to see who would he most suitable determened he was wost gualified

- didn't want to use ingto to "knack" others 
Appendix CC (Cont inued)

DIMENSIONS

1. Advocating own self-interest or interest of one's group/department and at the same time achieving organizational goals. Ambition and desire for influence and power ( $n$ power), wanting power.

DEFINITELY WANTED THE POSITION AS NEW DIRECTOR OF ADAINIETMATION (WHETHER PAT WAS "BETIER FOR HOR NOT")

EMPNASIZED PARTICIPATIVE manAGemeAT, A SKILL WAACH CHRIS WAS PERCEIVED TO HAVE - NOT AN EMPHABIS ON PAUER OR COATROL.

SAW CHRIS AS HANING FEWER "SHORTFALLS" OR WRAKNESSES THAN PAT OR J.D.

2. Coalitions, building alliances with other individuals and units, developing and maintaining a power base.

OID NOT SEE EARLEY'S mEMO AS AN OPPORTUNTTY TO BULD CHRIS'S POURE BASE, THOUGTT IT "ONT OF PLACE."

NO RESPONBSE TO WAUER AT ALL.

DID SEE COMSAARE memo AS A CHANCE TO EXCHANBE pAVORSBUILD SOMETHIF WGETHER.

3. Neutralizing or destroying stakeholders, e.g., firing, ignoring, repri-

sals. WILLING TO WORK WITH PAT, BUT NOT HELP. HER.

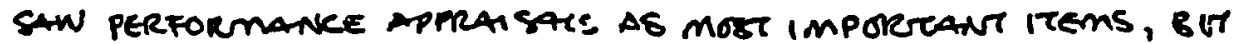
FELT UNCOMFORTABLE WTH HAVING INSIDE INFORMAFIONON

PEERS -KEPT SAYING, BUT I WOURDN'T ORDINARILY Hare TAHS INTORnarion. TENDED TO DEVHeVE PAT MORE THAN S.D.

CLEAR ABOUT THE WEAKNESSES OT THE COMPETITION \$े USED $T$

BUT WAS UNCOMFORTARE W. IT.

DID NOT ADVOCATE CIIUNG PERSONNEL - INETEAD, PROPOSED AUTOMATION Gaining support from higher levels, aligning with powerful others. TO INCRISASE Clearing the investment with the immediate boss.

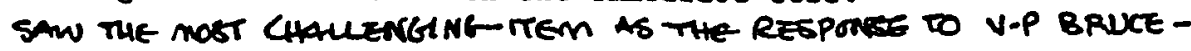

PLACES PRIORTYY ON $\pi$.

TOOK GOODWIN OUT TO WNEH TO THANK HM 'ं CET MORE

INFO. ABOUT HOW MERET WOULD BE AFFECTED

DID MOT UNDERETAND EMERSONIS POSIIION, TELT CONFUERD ABOUTHS

ACTUAL FUNGTION (MISEEO THISIMPORTANT DETALL IN THE INSTRUCTIONS)

5. Withholding information.

WANTED to DESSIMINATE INFO, GVV GLOBAL PICTURE

To AU, THE MACRO-VIEN

FELT HE WASNT GIVEN ENOWGH INTO.

$$
-16-
$$




\section{Appendix DD \\ Assessor Correspondence: Appreciation}

March 26, 1986

Dear

Thank you very much for your participation in my doctoral research project. You were a key factor in its success. You received three hours of assessor training and practiced interviewing as well. You then assisted with interviews of middle managers. Your synthesis of the data was excellent. The managers were pleased and impressed with the thoroughness of your interviews.

I would like to invite you to an open discussion of the Meret in-basket on April 8 at 3:30 p.m. The managers who participated in the session have been invited as well. The purpose of the meeting is to give the managers the opportunity to respond to the feedback they received. The session is optional, but I expect eight to ten individuals. You might be interested in hearing their comments. Plus, you may enjoy learning the results of the project and the preliminary conclusions. The session will be here at Corporation -- the I plan to end by 5:00 p.m.

Attached is a possible resume item you may want to use in the future. In the meantime, best of luck in your studies and your career preparations.

Sincerely,

Gloria E. Bader

GEB1st

At tachment 
Appendix DD (Continued)

Resume Item:

Research Assistant

Participated in a doctoral research project on political behavior in organizations. Trained as an assessor. Interviewed middle managers and evaluated written data. Synthesized all data into ten dimensions of political behavior. Evaluated project. Marked in-basket responses of sample group using a scoring key and a range of effective political behaviors. 
Appendix EE

Scorers' Training Out line and Materials

1. Review the definition of political behavior from Training Manual (Appendix AA, p. 15).

2. Review the dimensions of political behavior (Appendix $\mathrm{X}$ ).

3. Study the ranges of effective political behavior (Appendix $W$ ).

4. Become familiar with the scoring key (Appendix W).

5. Use a scoring sheet for each participant (Appendix SS). 
Appendix FF

Scorers' Training Out line and Materials (Revised)

[In addition to items $1-5$ in Appendix CC, these points were added to the scorers' training.]

6. Use the index card item summaries for items 5 and 6 in the inbasket .

7. Refer to the NOTE in the scoring key for the Administration Out line (Appendix $\mathrm{W}$, page 2).

8. Do a preliminary marking of in-baskets $\# 18,22$ and 5 and then compare your scorers with the researcher's scores (Appendix UU).

9. Refer back to the descriptions (ranges of effective political behavior) for your ranking decisions.

10. Keep in mind the role of the administrator of the simulation (the researcher) to resolve unusually difficult scoring problems. 
Appendix GG

Feedback Letter to Participants

March 26, 1986

Dear

I cannot thank you enough for your participation in my doctoral research project. Your time, energy and hard work resulted in a very successful study. As I share the results generally and specifically with you, I hope you will view your involvement in the project as well worth the effort. The feedback I promised you is ready and presented in this order:

1. Purpose and underlying theories of the research project

2. Methodology

3. Scoring results

4. Dimensions

5. Comments on your overall results in the Meret situation

6. Recommendations on your use of this feedback

7. Invitation to attend a follow-up session on April 8, 1986.

Purfose and underlying theories of the research project

It is important to recognize and understand the levels and complexities of political behavior and we must learn to value political activity. Consequently, the objective of this research was to design an instrument in the in-basket simulation format, which measures the amount, type and occasion of an individual's political behavior. The post in-basket interview examined your underlying reasons for acting or not acting in a political manner. The instrument tested the theories about politics in organizations.

There is very little research about political behavior in organizations and few models or tools exist to assist us in this area. The theories are untested hypotheses -- even speculations. They include the concepts of who the political "actor" is, when he or she acts politically, the types of political behavior, the conditions that evoke political behavior and the effectiveness of the behavior. These theories were built into the research design. It is my hope that the instrument will serve as a valid and reli$a b l e$ research tool that can be used in the fucure, not only to collect data about individual political behavior but also to offer rraining and understanding of the political model to participants. 
Appendix GG (Continued)

\section{Methodology}

The in-basket was first used as a selection and testing instrument over 30 years ago by the Educational Testing Service (ETS) in cooperation with AT\&T. Today, it is still incorporated into assessment centers as a principal exercise to determine a managerial candidate's skill in planning, organizing, controlling and delegating.

I followed the guidelines established by the ETS to develop the Meret in-basket and based the situation on case studies of mergers and the power struggles that are typical in uncertainty. My goal was to provide a situation that would evoke political behavior, decisions and actions.

As a simulation, the in-basket is a predictor of one's behavior. If you tend to think and act politically, you would respond similarly in the Meret situation and conversely, if you do not view organizational change and activity with in a political framework, you would use other models to make your decisions, such as: rules and regulations, chain of command, finance or cooperation.

Since political behavior is considered more critical as one rises in an organization, I concentrated on the middle manager level for the sample group. You were managers, directors, associate deans, chief administrators or comparable military ranks. All types of public and private organizations were represented: government, military, education, aerospace, finance, health, retail and manufacturing. There were 33 participants in the total sample group.

Other methodological considerations include: the interviews, the action report form, the use of several readers and scorers, testing for internal item and interrater reliability.

\section{Scoring Results}

From your two hundred responses to the Meret situation, a scoring key was built on a range of effective political behavior. A sample page from the scoring key is included in these materials. A panel of expert judges who were higher organizationally than the sample group and experienced in organizational politics reached a consensus on the scoring key and weighted and ranked the items on their criticality. Finally, two independent scorers marked each in-basket and their scores were averaged and adjusted to a 100 point scale.

The ranges of effectiveness were built on this definition of political behavior.

Political behavior in organizations is: 


\section{Appendix GG (Continued)}

1. Social influence attempts which can be obligations and resource exchange;

2. That are discretionary (i.e., that are outside the behavioral zones prescribed or prohibited by the formal organization);

3. That are intended (designed) to promote or protect the selfinterests of individuals or groups (units); and

4. That threaten the self-interests of others (individuals, units).

Generally, if you scored low in effectiveness, you tended to ignore, hold or wait for information in the Meret situation. More critically, you avoided any competition or conflict which was seen as ineffective in this situation. In fact, political effectiveness seems to thrive on vigorous and health conflict.

If you scored moderate on effectiveness, you assumed some power, faced opposition and made good organizational decisions. The high score indicated political awareness and a wide range of political behaviors. Here is a description of low, moderate and high.

\section{Rating Scale and Indicators of Political Behavior}

Low Scores $20-46$

1

2

Fails to influence or take action to influence others. Relies heavily on formal organizational structures. Avoids competition and conflict. Fails to see or use proven resources of one's self or others. Does not promote self-interests or solve issue at hand.

Moderate Scores $47-73$

$$
3
$$

Takes action to solve immediate issue demonstrating influence and desire for power. Exhibits some political awareness and a limited range of political behaviors. Makes moderate, often negative, political assumptions. Relates items to each other. Proactive. More prescribed than discretionary actions.

High Scores $74-100$

Goes beyond moderate levels of behavior and actions. Exhibits high level of political awareness and ability to take appropriate action. Promotes one's self or group's interest. Influences. Does not avoid conflict or competition with others. Displays ambition and desire for power. Attributes strong political motives to others.

Your score is - This number is based on a 100 point scale based on the importance of the item and the range of effectiveness you received 


\section{Appendix GG (Continued)}

by the scorers. The sample group had a range of 21 to 89 , with approximately one third in each range.

\section{Dimensions}

Based on the literature, there are varieties or types of political behavior sometimes termed dimensions or competencies. In the first sample group, I looked for eleven types of political behavior throughout the simulation and the interview. Since there was no evidence of use of deceit in either sample group, I combined this dimension into the - use of information one. In the list of dimensions, the item numbers refer to the seven in-basket problems.

Key to item numbers

$$
\begin{aligned}
& \text { 1. Waller Message } \\
& \text { 2. Administration Outline } \\
& \text { 3. Letter of Resignation } \\
& \text { 4. Computer Memo } \\
& \text { 5. Farley Message } \\
& \text { 6. Ramirez Message } \\
& \text { 7. Performance Reviews }
\end{aligned}
$$

\section{Weights assigned by judges} to total 100 points

Here are the ten dimensions:

14 points

40 points

15 points

12 points

8 points

5 points

6 points

1. Ambition and desire for influence and power ( $n$ power). Power motive. Independence, dominance and superiority. The Administration out line best indicates this dimension. Items: 1 , $2,3,4,5,6,7$.

The effective manager usually wants influence and power ( $n$ power). He or she chooses positions of influence and actively seeks them out.

2. Coalitions, building alliances with other individuals or units, developing and maintaining a power base. Independent of the formal structure, coalitions are explicitly created by their members for a specific purpose. Coalitions must act as a group, e.g., jointly signing a memorandum. Waller's and Carlson's contacting Chris Wallace provide opportunity to exercise this dimension, as does the Farley message. Items: $1,2,3,4,5,6,7$. 
Appendix GG (Continued)

3. Neutralizing or destroying stakeholders, e.g., firing, ignoring, reprisals, blocking, attacking or blaming others. Scapegoating and blaming are usually reactive. Proactive attacking is more personal and is usually geared toward reducing competition with a rival. The telephone message from Pat Ramirez and her performance review could demonstrate this dimension more than any other items. The judges, though, strongly agreed that to immediately fire Ramirez would be a mistake. Items: $2,5,6,7$.

On occasion, the effective manager must take a strong stand with others who directly or indirectly oppose his or her self-interests/group interests. (Other approaches such as bargaining or coalition building are or have been ineffective. Some tactics within this dimension may be illegitimate or unethical, e.g., threats or reprisals.)

4. Gaining support from higher levels, aligning with powerful others. Clearing the investment with the immediate boss. Ingratiation. Praising and establishing good rapport. Touching bases. The Outline and Goodwin's letter of resigna$t$ ion offer examples of this dimension. Items: $1,2,3,4$, 7 .

5. Use of information as a political tool. Withholding, distorting or using information to overwhelm another. In rare instances, outright lying or falsification is a tactic. Withholding information when it might be detrimental to selfinterest; selective disclosure, innuendo. Sometimes overwhelming the target with data to obscure a piece of information. Whistleblowing. The performance reviews and telephone messages, more than the other items, present this dimension. Items: $1,2,3,4,5,6,7$.

6. Using material and physical resources, access to information, securing personnel, equipment or space. Collecting data to use as a political tool. Garnering real or symbolic resources. The letter of resignation offers the opportunity to expand resources. Items: $1,2,3,4,5,7$.

7. Exchanging favors, horse trading, payoffs in exchange for support. Performing services or favors to create obligations. Pat's message indicates this behavior. Items: 1,3 , $4,5,6,7$.

8. Talking with a counterpart from another organization; outside professional activity. Any contact with Muse features this dimension. Items: $1,2,3,4$. 
Appendix GG (Continued)

9. Bargaining, negotiating, compromising. Usually in regard to issues and policies. Win/win. Farley's message, Pat's. message and the performance reviews would elicit this dimension. Items: $1,2,5,6,7$.

10. Stakeholder sense/analysis; knowledge of organization. Macro view. Knowledge of gatekeepers and power centers. All the items call for this dimension. Items: $1,2,3,4,5,6,7$.

As you can see, most of the items in the Meret simulation could evoke all of the dimensions. The interviewers, the scorers and I synthesized all the data from your materials and interview and transcribed them into the various dimensions. Here in the attached sheets you can see how wide a range of political behavior you did or did not demonstrate. You can see the strength level of each dimension or your over-reliance on a few.

Comments on your overall results

Recommendations on your use of this feedback

You may or may not wish to utilize this feedback. Political behavior may even seem to be offensive to you. But the fact of its reality in organizational decision-making cannot be overlooked. The fact of its intensity in ambiguous situations is important to realize. I would suggest that you study the dimensions and see them as necessary strategies in any situation that threatens your self-interest or your department's. Look at your strengths. Examine the dimensions that you did or did not exhibit and compare them with your past experiences. Finally, remember that this feedback information is yours alone. No one else will receive it. 
Appendix GG (Continued)

Invitation to attend a follow-up session on April 8, 1986

Finally, however lengthy this feedback summary might be, you still may have questions or comments. You are welcome to attend an open discussion on the entire research project on Tuesday, April 8, 1986 here at - The session will be open to all participants and the interviewers. We will discuss the Meret situation, the general results and the conclusions of the research project. Of course, no individual references will be made. This session is entirely optional. If you cannot attend, but still have a question or two for me, please do not hesitate to call me after April 8th at $-$ , extension

$\begin{array}{ll}\text { Date: } & \text { Tuesday, April 8, } 1986 \\ \text { Time: } & 3: 30 \text { p.m. }-5: 00 \text { p.m } \\ \text { Place: } & \text { Training Room 10-C o }\end{array}$

(corner of ask for Gloria Bader at the security desk)

I hope this feedback has been helpful and interesting to you, that in the end it assists you as you do your job and as you grow in your responsibilities. All the best in your professional endeavors.

$$
\text { Sincerely, }
$$

Gloria E. Bader

Senior Management Training Specialist and

Doctoral Candidate, University of San Diego

GEBIst

Attachments :

Sample Scoring Key

Dimension Results 
Sample Dimension Sheet (with Assessor's Comments)

DIMENSIONS

1. Advocating own self-interest or interest of one's group/department and at the same time achieving organizational goals. Ambition and desire for influence and power ( $n$ power), wanting power.

DSINITELY WANTED THE POSITION AB NEW DIRECTOR OF ADAIINISTIVATION CWHETHER PAT WAS "BETER FOR TT OR NOT"S

EMPNASIZED PARTICIPATIVE MANDESMEAT, A SKILL WAKCH CHRS WAS PERCEIVED TO WAVE - NOT AN EM PHABIS ON POUTER OR COATROL.

GAW CHRIS AS HANING FEURE "SHORTFALLS" OR WRAKNESSES itHAN PAT de J.D.

2. Coalitions, building alliances with other individuals aqd units, developing and maintaining a power base. OID NoT SEE EARLEV'S MEMO AS AN OPPORTONITY TO BUIL CHRIS'S POURE BASE, THOUGTT $I T$ "ONT OF PLACE."

NO RESPONBE TO WAUER AT AL.

DID SEE COMSAARE MEMO AS A CHANCE TO EXCHANGE PANORS BUILD SorreTHING WGETHER.

3. Neutralizing or destroying stakeholders, e.g., firing, ignoring, reprisals. WILLING TO WORK WITH PAT, BUT NOT HELP. HER.

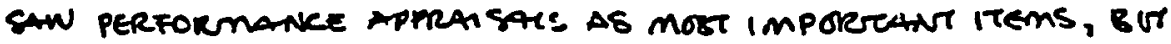
FET UNCOMFORTABLE WTH HAVING INSIDE INFORMATION ON PEERS -KEPT SAYING, BUT I WOURDN'T ORDINARIL HAVE THS INFORnation. TENDED TO DEVUEE PAT MORE THAN J.D. CLEAR ABOUT THE WEAKNESSES OT THE COMPETITION $\$$ USED IT,

BUT UAS UNCOMFORTARE W. IT.

DID NOT ADYOCATE CIIUNG PERSONNEL - INSTEAD, PROPOSED AUTOMAMON Gaining suppore fxom higher levels, aligniag with powerful others. TO INCREASE. Clearing the investment with the iumediate boss. SAW THE MOST CHALESKGING TEM AS THE RESPONRS TO V.P BRUCEPLACES PRIDARTY ON $\pi$.

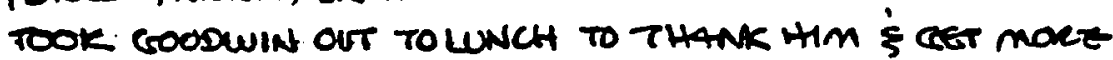
INFO. ABOUT HOW MERET WOULD SE AFFECTED

DID NOT UNDERETAND EMERSON'S POSITION, TELT CONFUSED ABOUTHS ACTUP,L FUNCTION (MISEEO IMPORTANT DETAL IN THE INSTRUCTIONS) 5. Withholding information.

WANTED TO DESSIMINATE INEO, GVE GLOBAL PICURE

TO AL, THE MACRO-VIEN

FELT HE WASNT GIVEN ENSOKG INFO. 
6. Using material and physical resources, access to information, securing personnel, equipment or space.

FOUND PERFORMANCE MPRAISALS CONTUSINL ; SAW ND OPPORTUNITY

IN WAUER'S MESSAGE (T BUILD MKTG FUNCTION IN S.D.)

SAW IT APIRORRATE TO SEEK NORE INFO FROM HIS RETIRING BOSS,

BUT NOT FOOM OIIER PEERS OR \&UBORDINATES(IN THE DEPARTMENTS

OF PAT \$ J.D AS WELL AS COMPUTER DIV. \& MARKETING-).

7. Exchanging favors, horse trading, payoffs in exchange for support.

DID NOT SEE WALER'S OVERTURE AS IMPORTANT -FURGOT

Aeour IT.

carison (ComsHare) conNECTION

ALSO A WAY TOCUT COSTS WO CUING PEOPLE

WANES PAT TO HELP HM IF HEHELPED HER.

8. Talk with counterpart from another organization; outside professional activity.

9. Bargaining, negotiating, compromising.

FOUND TARLEY'S MESSACE OUT OF PLACE - CROSEIKG DEPARTMRNTA LUNES NO COMPROMISES OR BARGAINS CONSIDED - ANTI-POLITICAL RESPONTE

" COmPRT

DID EXPRESS DESIRE TO HANDLE POTENTIALLY DISRUPTVE STTUATION CORRECTLY, TO MALE $T$ LESS VOLATILE "HANDLE IT CAREFURLY"

10. Use of deceit, clandestine actions.

uAs willing to USE iNFo. From PEesormanie APpratsals.

11. Stakeholder sense/analysis; knowledge of organization

FELT NEEDED MORE INTORMATION ; CONCERNED MBOUT THE POTENTIAULY

DISRUPTIVE SITUATION CAUSED BY COMPETITION OF THE 3 DEP'T HEADS

FOR THE ADMINSTRARVE POSITION.

EXPRESSED NEED TO KNW IHILOSOPHY OF THE COMPANY AND

WAS UNEASY THAT BRUCE'S POSITION WAS NOT CLEARLL DELINEATEPA VPOF MUSE, GUT IN WHAT CAPACITY? V-P OF A PARTICURAR FUNCTION? 
Appendix II

Sample Scoring Key: Waller Message

\#1 Wailer Message -- Request in person for assistance with an interview and policy decision on transfer of personnel from Muse.

\section{Considerations}

- Waller is director of marketing for Meret

- Waller stopped by C.W.'s office in person

- Waller is quoted in newspaper article

- Waller asks for policy suggestions on Muse transfers

- Waller asks for help in setting up an interview 
Appendix II (Continued)

Rating Scale and Indicators of Political Behavior

Low
Fails to influence or
take action to influence
others. Relies heavily
on formal organizational
structures. Avoids com-
petition and conflict.
Fails to see or use
proven resources of one's
self or others. Does not
promote self-interests or
solve issue at hand.

- Defers to Muse's policy and delays response

- Returns meno to Waller, deferring policy decisions

- Sees memo as unimportant

- Nees further information

- Sees request for transfer only as a single request

- Waits; anticipating layoff

- Avoids influencing new policy; "it isn't up to C.W."

- Does not want to look as though he was "pirating"; wants to protect self
Moderate

3

Takes action to solve immediate issue demonstrating influence and desire for power. Exhibits some political awareness and some range of political behaviors. Makes moderate, often negative political assumptions. Relates items to each other. Proactive. More prescribed than discretionary actions.

- Arranges interview details through Mark or Cathy; delegates recruitment function appropriately

- Plans to meet Waller or Emerson to discuss policy transfers

- Sees transfer of people from St. Louis as a good way of infusing new ideas and fresh approaches

- Contacts applicant directly; sees him as an alliance

- Reassures Waller; opens door for relocations both ways; cooperation

- (Some contact with Waller is minimum response here.)
High

4 5

Goes beyond moderate levels of behavior and actions. Exhibits high level of political awarenss and ability to take appropriate action. Promotes's one's self or group's interest. Influences. Does not avoid conflict or competition with others. Displays ambition and desire for power. Attributes strong political motives to others.

- Contacts Waller and Meret president to establish transfer policy; seeks alliance with Meret president

- Would talk with counterpart at Muse regarding details for influencing purposes

- Meets with Waller for lunch to discuss impact of merger and to explore hidden agenda; seeks alliance 
Appendix JJ

Outline of the Open Discussion Session for all Simulation Participants April 8, $1986 \quad 3: 00-5: 30$ p.m.

[Welcome and expression of appreciation for your cooperation in the research]

1. Ways to look at Meret: goals, finances, chain of command, rules and regulations or politics.

2. Purpose of the simulation

3. Definition of organizational politics

4. Overview of Meret simulation, item by item

5. What you responded (samples of the most political behaviors from the scoring key)

6. Scoring key developing; range of scores

7. General trends that prevented individuals from being more ef fective

8. What to do with all this 
Appendix KK

Letter to Contacts

December 10, 1985

Dear

As you know, I am conducting my dissertation research through the University of San Diego and would like to call upon you for assistance. I would appreciate your securing two or three mid-level managers or administrators from your organization to participate in one training session that I will conduct in late January and again in February 1986. I cannot ask you to be in the training session because of your familiarity with my research interests summarized in the attached abstract; hence my request for other individuals from your organization. It is important that these individuals be experienced managers and not firstlevel supervisors or administrators.

The training session will be comprised of a managerial simulation in an In-Basket format on decision-making, followed by an interview and the completion of a short form. Approximately three hours will be required for these activities. A few weeks after the session, each individual

will receive written feedback on their participation in the simulation and a summary of the results of the research. A short group session to further interpret the simulation and the optimum responses required for it will be scheduled, but attendance at this is completely optional. To insure confidentiality, letters will be assigned to each participant and used in my writing of the results.

Two sessions to choose from are scheduled: Tuesday morning, January 21,1986 , and Monday evening, February 24, 1986. The details are included in the attached letter which you may give to participants.

I suppose the best selling points for you and your organization supporting this project are free management training for the individuals and the specific high quality feedback that will be presented to them. If possible, I would like to have firm commitments from the participants prior to the holidays. It is only necessary that they return the attached form to me in the envelope provided. Do not hesitate to call if you have any questions. Please be assured of my appreciation.

Sincerely,

GEBIst

Gloria E. Bader

Enclosures 
Appendix KK (Continued)

Letter to Contacts

April 3, 1986

Dear

Thank you very much for sending me members of your organization to participate in my dissertation research. 'I have just sent them their individual scores, feedback and a summary of the project. They have also been invited to a follow-up session on April 8 from 3:30 to 5:00 p.m. here at . The session is entirely optional and it will be an open discussion of the simulation and its general results. You are most welcome to attend as well.

For your background information on the entire issue, I have enclosed the summary letter about the project that I sent to the participants. I am still examining the data in order to draw general conclusions. I will send you a final summary when that is completed. Again, I am most appreciative of your assistance.

Sincerely,

Gloria E. Bader

GEBlst

At tachment 
Appendix LL

Letter to Participants: Explanation of Research

December 11,1985

Dear Professional,

I have asked

to solicit your participation in a special research project. I am a doctoral student at the University of San Diego and my dissertation requires that I conduct a comprehensive research project. The purpose of the research is to design an instrument that will shed light on how and why decisions are made by managers and administrators under certain circumstances. Your participation in an individual assessment exercise that $I$ have organized is the crux of the research project. Here is exactly what you can expect:

1. Participation in $1 \frac{1}{2}$ hour assessment exercise. This exercise is comprised of letters, messages and tasks in a typical inbasket tray. Although the exercise will be administered to 15 people, you work as an individual.

2. You will be interviewed after the assessment task for $30-40$ minutes. This interview will focus on $1 \mathrm{y}$ on the $1 \frac{1}{2}$ hour assessment exercise and how and why you made certain decisions.

3. You will be asked to complete a short form about the exercise ( 15 minutes).

A few weeks later, you will receive an individually prepared report of how you did in the assessment exercise and a summary of the research project. To insure confidentiality, letters will be used instead of names in this summary. Lastly, a group session will be scheduled for further feedback and analysis, but attendance at this is optional. If you have any questions regarding the research or procedures, please ask them of me before you send in your confirmation. I can be reached at , extension

Two dates are scheduled for two different groups of 15 participants. You can sign up for either session as they are identical.

$$
\text { Tuesday, January } 21,1986 \quad 8: 30-11: 30 \mathrm{a} \cdot \mathrm{m} \text {. }
$$

OR

Monday, February 24, $1986 \quad 4: 00-7: 00$ p.m. 
Appendix LL (Continued)

Each session will be held at

(corner of

)

in the Main Conference Room (10-1). Ask for me at the front desk and I will bring you to the Conference Room. Parking is available.

I would appreciate a confirmation of your participation in this project before the holidays. Please read and sign the attached form regarding confidentiality, research ethics, and check the session you can attend. This can be mailed to me in the envelope provided. I look forward to meeting you and working with you in January or February.

Sincerely,

Gloria E. Bader

GEBlst

Enclosures 
Appendix MM

\section{Consent Form}

I have read the purpose and procedures of this research project and understand that my participation in it is entirely voluntary and that I can withdraw at any time. I understand that my name will never be used in research writings; that my answers will be held in strict confidence; and that all identifying information will be disguised or deleted.

I, the undersigned, understand the above explanations and, on that basis, I give consent to my voluntary participation in this research.

Signature

Date

San Diego, CA

Signature of Researcher

Date

Signature of Witness

Date

Name (please print)

Address (where you want

to receive information)

Phone

Occupation

(Please return this form in the envelope provided. Directions and final confirmation will be sent to you.) 
Appendix NN

Acknowledgement

January 10, 1986

Dear Professional:

Thank you for volunteering to be part of my doctoral research project on Tuesday, January 2 lst. I received your consent form and now that the date is drawing near, you will want specific directions.

Originally, I planned to have the session here at, but I have chosen a more central location -- Manchester Conference Center at The University of San Diego. A map is attached. We will begin promptly at 8:30 a.m. in Room 206A on the second floor of Manchester. Juice and croissants will be available for you at 8:00 a.m. You are welcome to come early.

As you recall from my original letter, this is an individual assessment. Only you will receive the results of your work in the assessment exercise. I look forward to meeting you on Tuesday, January 2 Ist at Manchester.

$$
\text { Sincerely, }
$$

Gloria E. Bader

GEB1st

Enc losure 
Appendix NN (Continued)

February 4, 1986

\section{Dear Professional:}

Thank you for volunteering to be part of my doctoral research project on Monday, February 24, 1986. I received your consent form and now that the date is drawing near, you will want specific directions.

The program will be here at (see enclosed map). We will begin promptly at 4:00 p.m. in the main conference room adjacent to the corporate lobby. Refreshments will be available for you at $3: 30$. You are welcome to come early. We should be finished between $6: 30$ and $7: 00$ p.m.

As you recall from my original letter, this is an individual assessment. Only you will receive the results of your work in the assessment exercise. I look forward to meeting you on Monday, February $24 \mathrm{th}$.

\section{Sincerely,}

Gloria E. Bader

GEBIst

Enc losure 
Appendix NN (Continued)

February 28, 1986

Dear

Thank you for participating in my research project on January 21st. Your individualized feedback is nearing completion and will be sent to you shortly. I had some delay because of the second sample group on February 24th; several no-shows affected my sample size and, consequent $1 y$, I am running a third group on March 6 th.

I do have a date for the open discussion session - Tuesday, April 8 from 3:30-5:00 p.m. here at You may want to make a note of it. This is an option session simply to discuss the simulation. In the meantime, best of luck in your professional endeavors.

Sincerely,

Gloria E. Bader

GEBIst 
Appendix 00

Training Agenda for Panel of Judges and Correspondence

( 2 hours)

1. Abstract and research design (Appendix AA, p. 5-9)

2. Definition of political behavior (Appendix AA, p. 15)

3. Dimensions (Appendix $X$ )

4. Sample scoring sheet and matrix (Appendixes SS and QQ)

5. In-Basket items (Appendixes $A-Q$ )

6. Role of panel of judges 
Appendix 00 (Continued)

Role of Panel of Judges

The role of the panel of judges is to build a scoring key for the in-basket and to rank and weight the seven items. In addition, important considerations for the in-basket scores can be added to the scoring key. A consensus is to be reached on each task. 
Appendix 00 (Continued)

December. 17, 1985

7250 Mesa College Drive

San Diego, California 92111

5230 Carroll Canyon Road, Suite 212

San Diego, California 92121

P. 0. Box 85227

San Diego, California 92138

Dear

I am most grateful to each of you for agreeing to be the panel of experts for my dissertation research project. An abstract of the project is attached. You can be sure that I will make the most efficient use of your time.

In essence, your task as judges is to agree on the effectiveness of the participants' responses to the In-Basket. You will sort the responses on a range of effectiveness and rate the most appropriate political behavior.

To prepare for this, I need to walk you through the In-Basket, outline the project and define political behavior. In short, you will need a brief orientation. I can do this with you individually, at your convenience. It should take no longer than $\frac{1}{2}$ hour. The best time for this is January 13 to January 20. If you like, I could come to your office, in order to save you time.

The actual scoring of responses will need to take place sometime January 22 through February 3. It would probably work most quickly with all three judges present. You could sort, discuss and come to agreement on the responses. This should take no longer than three hours. The second sample group will need judging also, but since a base scoring key will have been established, this task should go smoothly and efficiently. The week of February 24 is scheduled for this second judging, at your convenience. 


\title{
Appendix 00 (Continued)
}

I am sure you have questions and suggestions for me. Please give me a call and we can discuss dates and any other thoughts you have about the research project. I will be at until December 20, again December 30 and 31; January 2 and 3; and January 6 on. My best wishes for a very Merry Christmas and a Happy New Year.

\section{Sincerely,}

\author{
Gloria E. Bader
}

GEBIst

Enclosure 
Appendix 00 (Continued)

April 3, 1986 .

7250 Mesa College Drive

San Diego, California 92111

5230 Carroll Canyon Road, Suite 212

San Diego, California 92121

P. 0. Box 85227

San Diego, California 92138

Dear

Thank you very much for participating in my doctoral research project as an expert judge. The effort was well worth it! The scores ranged from 21-89 out of a possible range of 20 to 100. There were more scores in the low and moderate range than in the high range. The inter-rater reliability correlations reached .79 and .71 for internal reliability. But more importantly, significant patterns of behavior were noted that will delight behavioral psychologists. For example, if one avoided competition, relied on chain of command, held too many meetings, ignored the macro view, they scored low on effective political behavior.

You are welcome to attend an open discussion of the Meret inbasket on April 8 from 3:30-5:00 p.m. here at . The session is an optional one for all 33 managers in the sample group and the student assessors. I will summarize the results and go through the items with plenty of time for questions and discussion. I have already sent an individual feedback letter to each participant so I see this session as one to tie loose ends for anyone interested.

The next goal for me is the completion of Chapters 3,4 and 5 so that I can catch up with who will be defending his work April 4, 1986. Congratulations, All the best to each of you, both personally and professionally.

Sincerely,

GEBIst

Gloria E. Bader 
Appendix PP

Variety and Ranges of Political Behavior Presented by the

Repondents in Order of Degree

Number of responses $(r)$

1. Use of information as a political tool. Withholding, distorting or using information to overwhelm another.

$\begin{array}{ccccc}1 & 2 & 3 & 4 & 5 \\ \text { None } & & \text { Withholding } & \begin{array}{l}\text { Discrete } \\ \text { Use; } \\ \text { Selective } \\ \text { Disclosure }\end{array} & \text { Distortion } \\ \mathbf{r}=7 & \mathrm{r}=0 & \mathrm{r}=10 & \mathrm{r}=16 & \mathrm{r}=0\end{array}$

2. Coalitions, building alliances with other individuals and units, developing and maintaining a power base.

1

No Minimal

Alliances

$\mathbf{r}=5 \quad \mathbf{r}=1$
3

Build Smooth Relationships

$r=12$
4

Act ively

Seeks

Alliance

$r=16$
5

Coalition $r=0$

3. Stakeholder sense/analysis: Knowledge of organization. Macro view. Knowledge of gatekeepers and power centers. Frequency range: number of responses $(r)$.

$\begin{array}{ccccc}1 & 2 & 3 & 4 & 5 \\ \text { None } & \begin{array}{l}\text { Little } \\ \text { Knowledge }\end{array} & \begin{array}{l}\text { Average } \\ \text { Knowledge }\end{array} & \begin{array}{l}\text { Need } \\ \text { to Know } \\ \text { More }\end{array} & \begin{array}{l}\text { Macro } \\ \text { View }\end{array} \\ \mathbf{r}=3 & \mathbf{r}=2 & \mathbf{r}=10 & \mathbf{r}=4 & \mathbf{r}=15\end{array}$




\section{Appendix PP (Continued)}

4. Using material and physical resources, access to information, securing personnel, equipment or space. Collecting data to use as a political tool. Garnering real or symbolic resources.

$\begin{array}{ccccc}1 & 2 & 3 & 4 & 5 \\ \text { No use } & \begin{array}{l}\text { Access to } \\ \text { Information }\end{array} & \begin{array}{l}\text { Garnering } \\ \text { as } \\ \text { Information } \\ \text { Comes }\end{array} & \begin{array}{l}\text { Active } \\ \text { Collection } \\ \text { of } \\ \text { Information }\end{array} & \begin{array}{l}\text { Actual } \\ \text { Use }\end{array} \\ r=9 & r=2 & r=3 & r=7 & r=12\end{array}$

5. Ambition and desire for influence and power ( $n$ power), wanting power. Power motive. Independence, dominance and superiority.
1
2
3
4
5

$\begin{array}{lllll}\text { No power Not Strongly } & \begin{array}{l}\text { Wanted } \\ \text { Position } \\ \text { Power }\end{array} & \begin{array}{l}\text { Wanted } \\ \text { Strongly }\end{array} & \text { Sought More Power } \\ r=10 & r=4 & r=9 & r=10 & r=2\end{array}$

6. Gaining support from higher levels, aligning with powerful others. Clearing the investment with the immediate boss. Ingratiation. Praising and establishing good rapport. Touching bases.

$\begin{array}{ccccc}1 & 2 & 3 & 4 & 5 \\ \text { None } & \begin{array}{l}\text { Brief } \\ \text { Mention }\end{array} & \begin{array}{c}\text { Some } \\ \text { Communication }\end{array} & \begin{array}{l}\text { Communication } \\ \text { with Intent }\end{array} & \begin{array}{l}\text { Seeks Highest } \\ \text { Levels for } \\ \text { Support }\end{array} \\ \mathbf{r}=10 & \mathrm{r}=2 & \mathrm{r}=5 & \mathrm{r}=10 & \mathrm{r}=6\end{array}$


Appendix PP (Continued)

7. Exchanging favors, horse trading, payoffs in exchange for support. Performing services or favors to create obligations.

$\begin{array}{ccccc}1 & 2 & 3 & 4 & 5 \\ \text { None } & \begin{array}{l}\text { Distaste } \\ \text { of Favor } \\ \text { Exchanges }\end{array} & \begin{array}{l}\text { Exchanged } \\ \text { Favors }\end{array} & \begin{array}{l}\text { Actively } \\ \text { Exchanged } \\ \text { Favors or } \\ \text { Support }\end{array} & \begin{array}{l}\text { Performed } \\ \text { to Create } \\ \text { Obligations }\end{array} \\ \mathbf{r = 1 6} & \mathbf{r}=4 & \mathbf{r}=3 & \mathrm{r}=8 & \mathbf{r}=2\end{array}$

8. Neutralizing or destroying stakeholders.

1

$\begin{array}{ll}\text { Ignored } & \text { Acknowledged } \\ \text { Competition } & \text { But Avoided } \\ & \text { the } \\ & \text { Competition }\end{array}$

$r=7$
2

3

Used

In formation

About

Competitors,

Rivals
4

Demoted

Rivals

$r=9$

$r=4$

$r=7$

9. Bargaining, negotiating, compromising.

1

None

$r=12$

$r=3$

3

Doesn't Give Seeks to Anything Up Convince

$r=7$
4

Some Bargaining

$r=10$

\section{5}

Wanted to Fire or Fired

10. Talking with a counterpart from another organization; outside professional activity.

$$
1
$$

None

$r=29$

$$
2
$$

(




\section{Appendix QQ}

Matrix of Types of Problem and Political Behaviors"Exhibited

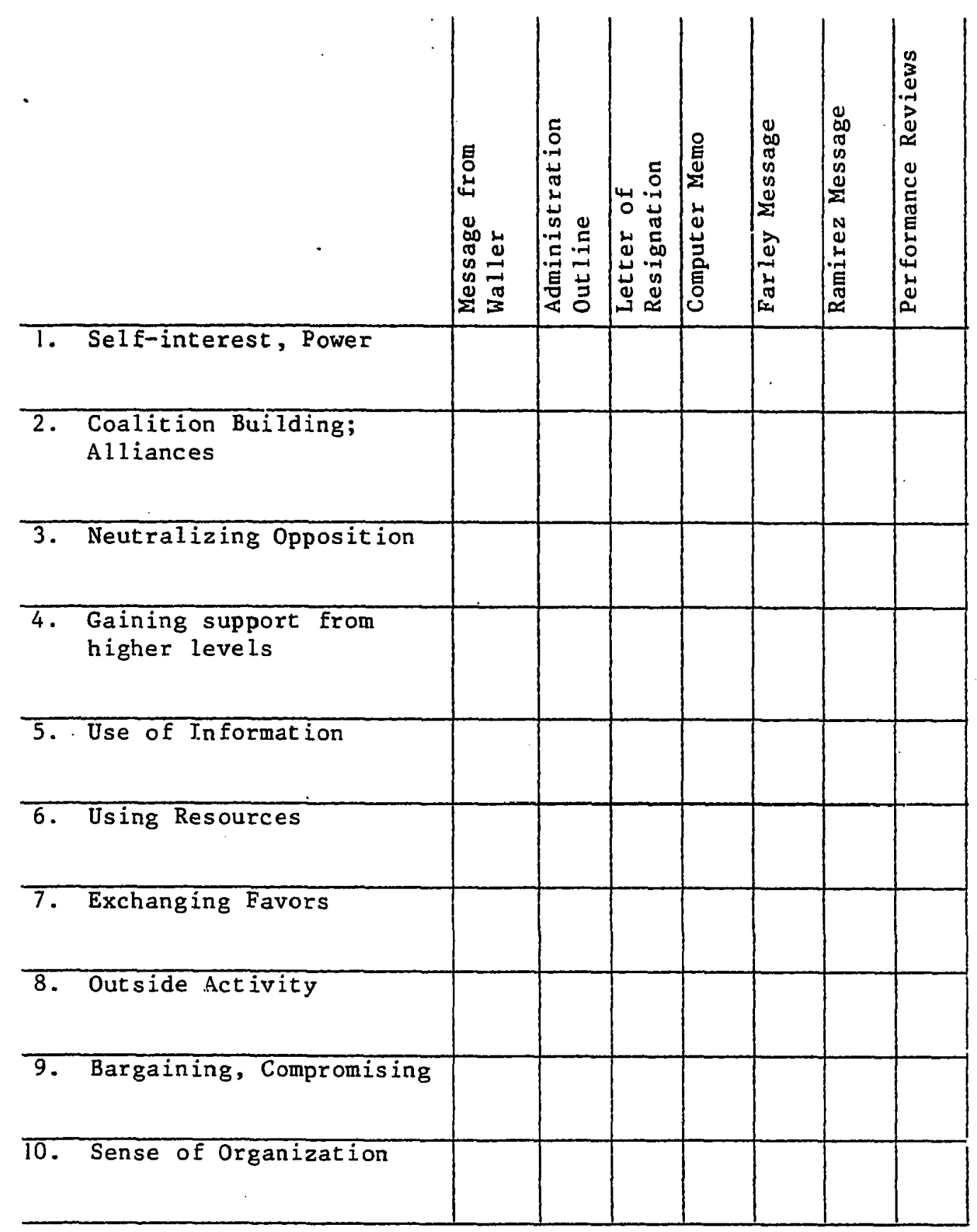


Appendix RR

Addenda to Assessor Training

February 24, 1986

We Icome!

A few reminders:

1. Please preview the sample in-basket to note changes that are highlighted in yellow.

2. Note that the item question is moved to 非 spot (interview).

3. Index card format:

\#7 ITEM $\$ 17$ Subject

4. Dimensions have been reduced to 10. "Use of deceit" is merged with "information".

5. Don't forget to evaluate everything (see form attached).

6. I'd like to have a general discussion this evening before we finish -- your reactions to the interviews, etc.

7. Pizza will be brought in for an elegant supper circa 7 p.m.

8. Please keep me informed of your address changes.

9. I need 2 volunteers to mark the in-baskets (2nd sample group).

10. When all this is done, I will send you letters of recommendation and a sample resume item to reflect your work on this project. Needless to say, your efforts are greatly appreciated. 


\section{Appendix SS}

\section{Scoring Sheet for Each Participant}

Rater \#

1. Message from Waller

2. Administrat ive Out line

3. Letter of Resignation

4. Comshare Memo

5. Farley Message

6. Ramirez Message

7. Performance Reviews

Participant \#

\section{Participant}

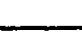

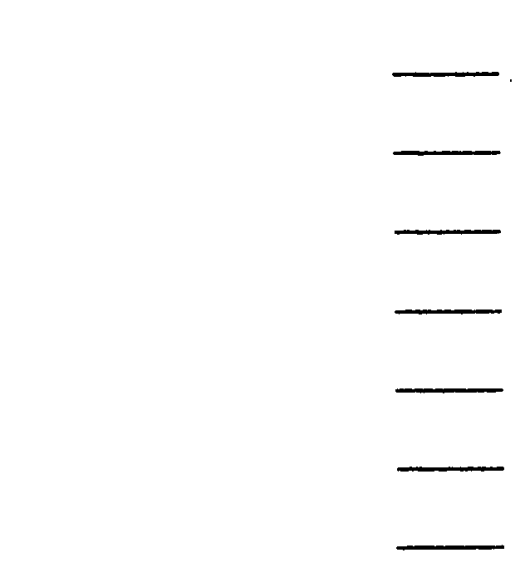

Reproduced with permission of the copyright owner. Further reproduction prohibited without permission. 


\section{Appendix TT}

Meret Interview Form (revised)

1. What did you think of the Meret situation?

2. [Go through each item, be sure you understand what the participant did, make marginal notes when necessary, probe for reasons decisions were made.]

Items \# 1-4 - Write marginal notes on each item.

Item 1 5 - Explain here

Item \#6 - Explain here

Item $\# 7$ - Explain here

$$
\text { . }
$$

Reproduced with permission of the copyright owner. Further reproduction prohibited without permission. 
Appendix TT (Continued)

3. What was the most challenging item and why?

4. What experiences and strengths did you bring to the situation?

5. How willing were you to make a decision based on the information at hand?

6. Do you think you, as Chris, would have an impact on the organization? 
Appendix UU

Scoring Practice for In-Basket Raters

Participant \#18 Participant \#22 Participant \#5

ITEM

1 - Waller Message

2 - Administration Out line

3 - Letter of Resignation

4 - Computer Memo

5 - Farley Message

6 - Performance

Reviews

7 - Ramirez Message
Scores

1

2

1

1

1

1

2
Scores

1

1

3

3

3

3

3

5

3

3

3

3

1

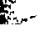

Reproduced with permission of the copyright owner. Further reproduction prohibited without permission. 


\section{Appendix VV}

\section{Sample Comments for Participants}

(This individual's comment section is taken from his

Feedback Letter for Participants, Appendix KK.)

Your score is in the moderate range of effectiveness -- with in the top fourth of the total sample group of 33 .

You were especially strong in your confidence and bid for power. For example, you wanted to enlarge your responsibilities at Meret. On the other hand, your wanting to fire Ramirez was seen as unwise by the panel of judges. Neutralizing the opposition (dimension three) is a strong political tactic, but at this point in the Meret situation it would be premature to fire Ramirez.

You demonstrated a strong organizational viewpoint or macro sense (dimension ten) when you recognized Waller and Carlson's importance to the company and when you restructured functions to align with Muse. You contacted Muse officials and informed Meret's president of your decisions. In contrast, you neglected to plan or act in any way to communicate with your employees in the old and new structure. Such communication is critical in a merger and would complete your macro view skill.

There is no doubt that you have a good sense of the political environment. To increase your effectiveness, I would refer you to the dimensions that you did not exhibit -- alliance building and exchanging favors -- to see if this matches with your everyday working skills. You did well. Good luck to you and thank you for participating. 
Appendix WW

Letter from Student Assessor

April 30, 1986

Dear Gloria,

Thank you for the opportunity to assist you with the Meret inbasket project. As an assessor for the in-basket instrument, I assisted in interviewing middle managers from various organizations, wrote a summary of the interviews, classified the behavioral responses into dimensions of political behavior, and marked the action report forms. In doing so, I gained experience in interviewing and learned to recognize the complexities and levels of political behavior.

Prior to helping you with your research, I had not realized the impact organizational politics has on decision-making, leadership, and organizational $1 \mathrm{ife}$. I see now that particular attention should be paid to political theories and the enhancement of political skills which are so much a part of leadership. The in-basket you have created is not only unique, but successfully assesses and displays managerial skills in terms of political behavior. I sincerely believe this particular instrument is a valuable one for those managers who are smart enough to take advantage of it.

Once again, thank you for such a wonderful opportunity!

Sincerely,

Human Resources Associate 
Appendix $\mathrm{xx}$

Letter from Participant in the Pilot Group

April 14, 1986

Gloria Bader

Cubic Corporation

9333 Balboa Ave.

P.O. Box 85587

San Diego, CA 92138-5587

Dear Gloria,

I'm writing to let you know that I appreciate the detailed feedback I received on the assessment exercise. I wasn't really sure how I would do since the directions were gketciny, so I was pleased to find that I was at least making some of the right political decisions.

Politics are interesting. We don't tend to learn anytining about them in management training. My experience tells me politics are taught asd practiced on the "battlefieid".

What a nice two-way situation you developed for your frojest.

lou are able to continue earnirg credits and I was abie to get assessment information which I found interesting and helpful. Thank pou very much.

Sincerely,

Assistant Vice-President

Training Manager

$30 / 10$

Reproduced with permission of the copyright owner. Further reproduction prohibited without permission. 